\title{
EFEITOS DA CAL HIDRATADA E DO ÁCIDO POLIFOSFÓRICO NAS PROPRIEDADES MECÂNICAS E SUSCETIBILIDADE À UMIDADE DE MISTURAS ASFÁLTICAS DENSAS
}

Dissertação apresentada à Escola de Engenharia de São Carlos da Universidade de São Paulo, como parte integrante dos requisitos para obtenção do título de Mestre em Ciências, Programa de Pós-graduação em Engenharia de Transportes.

Área de concentração: Infraestrutura de Transportes Orientador: Prof. D. Glauco Túlio Pessa Fabbri

São Carlos, SP 
AUTORIZO A REPRODUÇÃO E DIVULGAÇÃO TOTAL OU PARCIAL DESTE TRABALHO, POR QUALQUER MEIO CONVENCIONAL OU ELETRÔNICO, PARA FINS DE ESTUDO E PESQUISA, DESDE QUE CITADA A FONTE.

Ficha catalográfica preparada pela Seção de Tratamento da Informação do Serviço de Biblioteca - EESC/USP

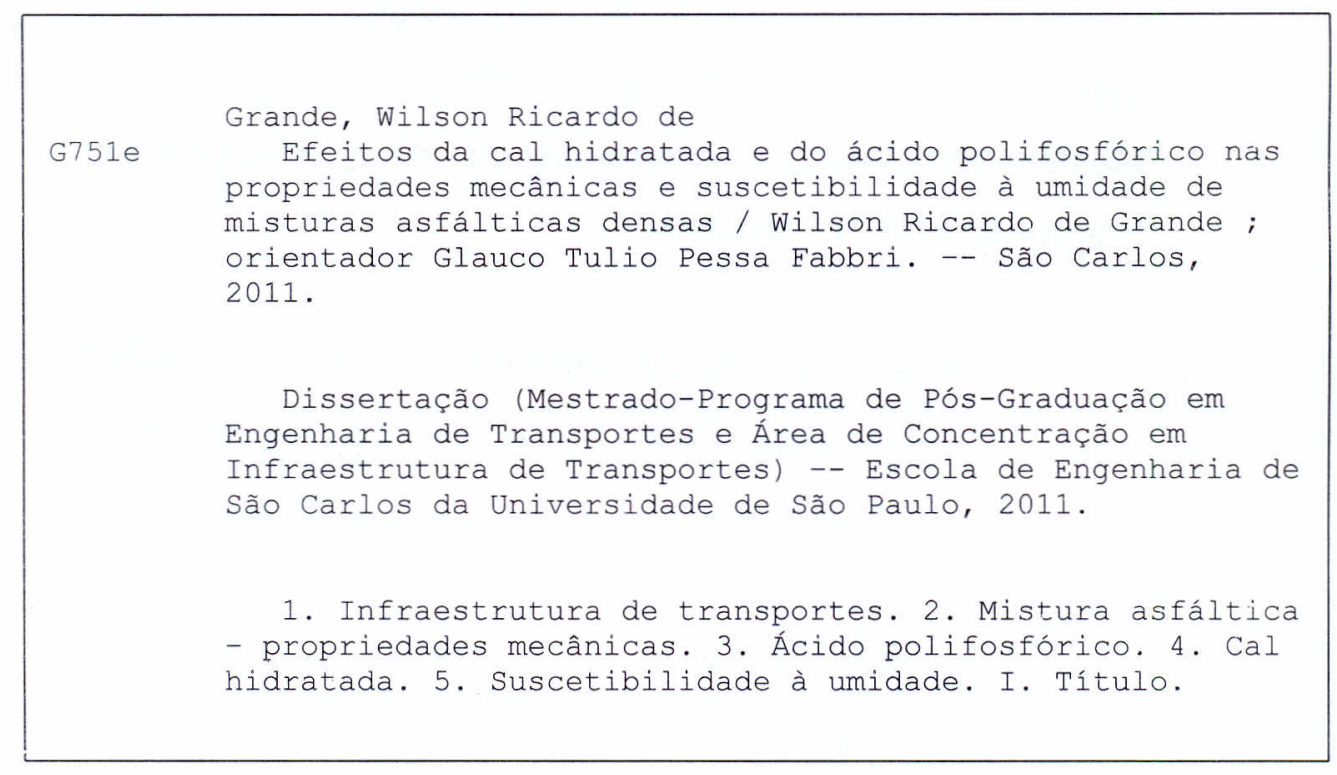


FOLHA DE JULGAMENTO

Candidato(a): Engenheiro WILSON RICARDO DE GRANDE.

Dissertação defendida e julgada em 06/06/2011 perante a Comissão Julgadora:
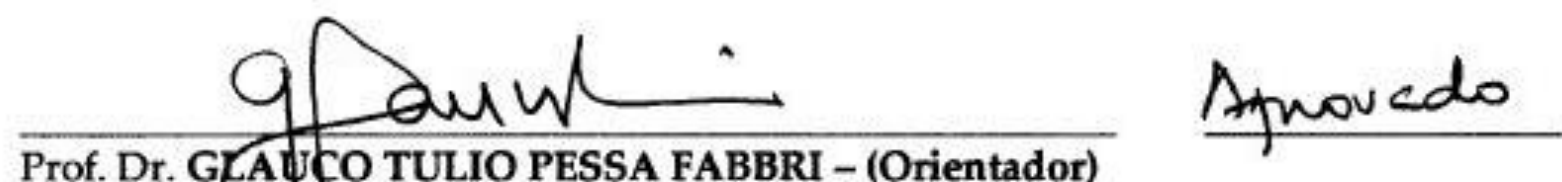

(Escola de Enger haria de São Carlos/USP)
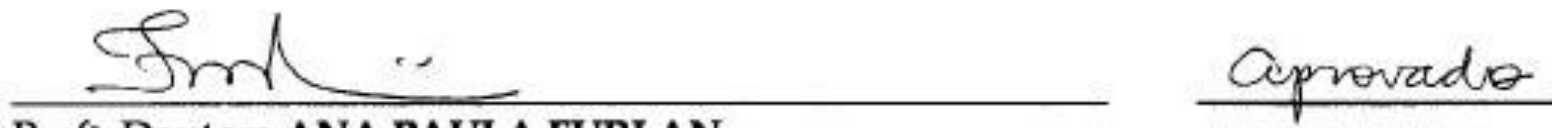

Prof. Doutora ANA PAULA FURLAN

(Escola de Engenharia de São Carlos/USP)
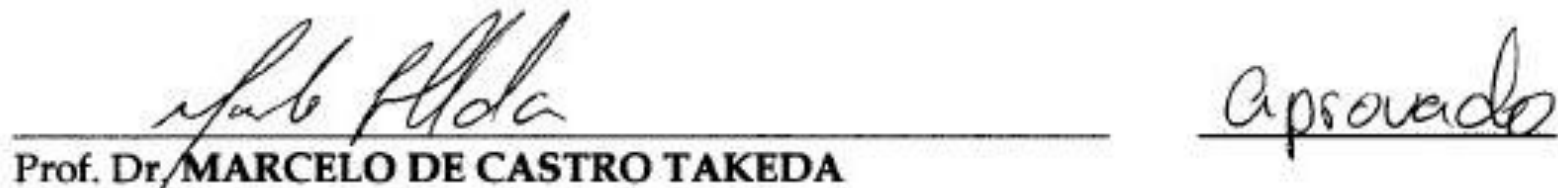

(Universidade Federal de São Carlos/UFSCar)

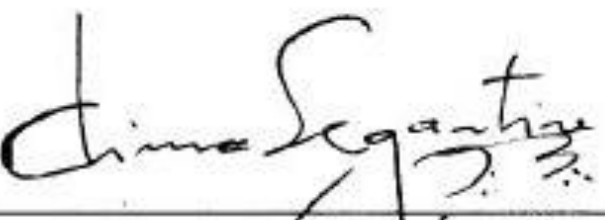

Prof. Associado PAULO CÉSAR LIMA SEGANTINE

Coordenador do Programa de Pós-Graduação em Engenharia de Transportes e Presidente da

Comissão de Pós-Graduação 
Dedico esse trabalho à minha família, José, Bernadete e Eduardo; e a minha noiva Pamela. 
"Enquanto houver vontade de lutar haverá esperança de vencer." (Santo Agostinho) 


\section{AGRADECIMENTOS}

A Deus, pela sabedoria, harmonismo e força em todos os momentos.

Aos meus pais, pelo apoio, carinho e amor incondicional em todas as etapas da minha vida. Ao meu irmão, Robson Eduardo De Grande pelo apoio e conselhos durante toda a minha vida.

À minha noiva, Pamela Rosa Tancredi, pela paciência inabalável e pelo apoio incondicional nos momentos mais difíceis, pelo companheirismo e incetivo sempre.

Ao Prof. Glauco Túlio Pessa Fabbri pelo seu apoio, dedicação, compreensão, e principalmente paciência durante a orientação.

Ao Prof. José Leomar Fernadez Júnior pela amizade, apoio e conselhos.

Ao Prof. Adalberto Leandro Faxina pelos ensinamentos, amizade e apoio.

Aos técnicos de laboratório, Paulo Toyama, Antônio Carlos Gigante e João Pereira pela disponibilidade, dedicação, auxílio, companheirismo e ajuda durante toda pesqusa.

Aos professores do Departamento de Transportes da EESC - USP, pelas oportunidades, pela amizade, consideração e apoio constantes.

Aos funcionários do Departamento de Transportes da EESC - USP, pelo auxílio, carinho e solicitude nos trâmites administrativos dessa pesquisa.

Aos amigos do Departamento de Transportes da EESC - USP pelos momentos felizes, apoio e incentivo para cumprimento de mais esta etapa.

Aos amigos de infância, que contribuíram de maneira primordial para estabilidade psicológica, amizade, apoio incondicional em todo e qualquer momento da minha vida.

À CAPES, pela concessão da bolsa de mestrado.

À Pedreira São Gerônimo, pelo fornecimento do agregado para realização desta pesquisa.

À REVAP - Petrobrás, pelo fornecimento do CAP 50/70.

À Inopphos, pelo fornecimento do ácido polifosfórico (E200). 


\section{RESUMO}

Grande, W. R. Efeitos da cal hidratada e do ácido polifosfórico nas propriedades mecânicas e suscetibilidade à umidade de misturas asfálticas densas. 2011. 149p. Dissertação (Mestrado) - Escola de Engenharia de São Carlos, Universidade de São Paulo, São Carlos 2011.

Esta pesquisa teve por objetivo analisar os efeitos da cal hidratada e do ácido polifosfórico nas propriedades mecânicas e suscetibilidade à umidade de misturas asfálticas densas. O ligante utilizado foi o CAP 50/70, chamado de controle, modificado com 0,6 e $1,2 \%$ de PPA, e como aditivo a cal hidratada em concentrações de 1,5 e 3,0\%, perfazendo nove combinações de misturas asfálticas. Foram moldados 108 corpos-de-prova, divididos em 4 e $7 \%$ de volume de vazios, sendo que os corpos-de-prova de $7 \%$ foram divididos em condicionados e não condicionados. Os ensaios realizados para análise das propriedades mecânicas foram o Módulo de Resiliência e a Resistência à Tração Indireta. Os resultados mostram que o aumento da concentração de ácido polifosfórico melhora a rigidez e a flexibilidade, e melhora a suscebilidade ao dano por umidade, assim como aumenta a resistência à tração; para a cal hidratada, com o aumento da sua concentração, ocorreu aumento da rigidez e da flexibilidade de maneira mais discreta, se comparado ao ácido polifosfórico, e proporciona a diminuição da resistência à tração: o teor que apresentou melhor suscetibilidade ao dano por umidade foi de $1,5 \%$ de cal hidratada.

Palavras-chave: mistura asfáltica, ácido polifosfórico, cal hidratada, propriedades mecânicas e suscetibilidade à umidade. 


\section{ABSTRACT}

Grande, W. R. Effects of hydrated lime and polyphosforic acid in mechanical properties and moisture susceptibility in dense asphalt mixtures. 2011. 149p.

Master Thesis - Escola de Engenharia de São Carlos, Universidade de São Paulo, São Carlos 2011.

This work aims to analyze the effects of hydrated lime and polyphosphoric acid on the mechanical properties and moisture susceptibility of dense asphalt mixtures. In nine combinations of asphalt mixtures, CAP 50/70, named control and modified with 0,6 and $1,2 \%$ of PPA, was employed as binder, and hydrated lime in concentrations of 1,5 and $3,0 \%$ was used as additive. 108 test specimens have been molded and divided into 4 and $7 \%$ of volume void, considering that $7 \%$ were separated into conditioned and non-conditioned. The Resilient Modulus and the Tensile Strength were the tests conducted for the analysis of mechanical properties. The results showed that the increase in polyphosphoric acid concentration improved stiffness and flexibility and increased the susceptibility to moisture damage, as well as the tensile strength. Also in the results, with the concentration increase of the hydrated lime, there was a smaller increase of stiffness and flexibility, and it provided a decrease of tensile strength, considering that the percentage of $1,5 \%$ of hydrated lime presented the best susceptibility to moisture damage.

Key words: dense asphalt mixtures, polyphosphoric acid, hydrated lime, mechanical properties and moisture susceptibility. 


\section{SUMÁRIO}

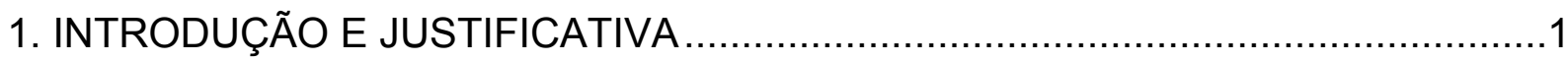

1.1. OBJETIVO

1.2. ESTRUTURAÇÃO DO TRABALHO

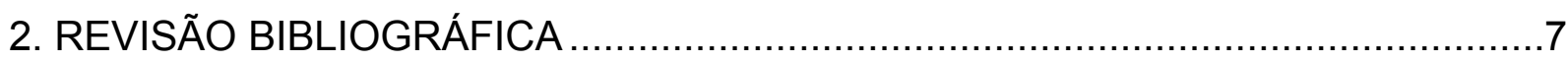

2.1 INTRODUÇÃO

2.2 PRINCIPAIS DEFEITOS DOS REVESTIMENTOS ASFÁLTICOS …..............7

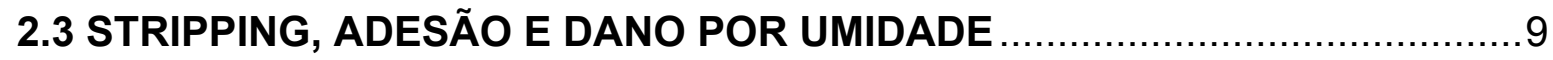

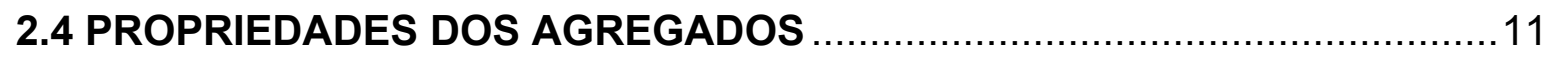

2.5 PROPRIEDADES DOS LIGANTES ASFÁLTICOS ....................................12

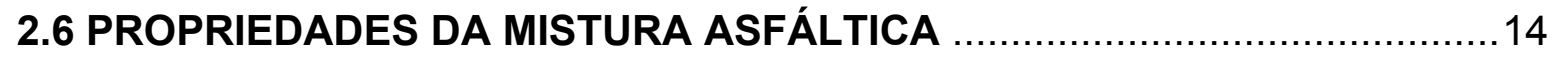

2.7 ENSAIOS DE PROPRIEDADES MECÂNICAS ….....................................18

2.7.1 Avaliação da rigidez de misturas asfálticas a partir do ensaio de módulo de

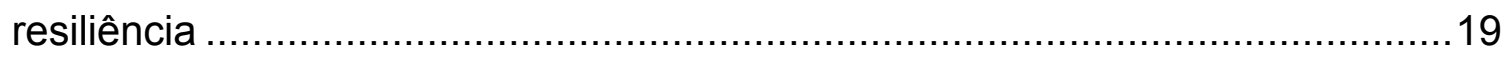

2.7.2 Avaliação da resistência à tração de misturas asfálticas .........................21

2.8 IMPORTÂNCIA DO USO DE ADITIVOS OU MODIFICADORES ..................22

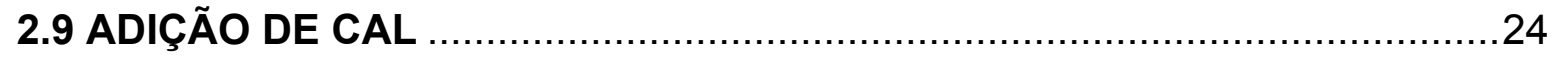

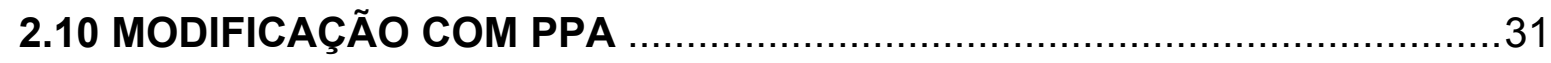

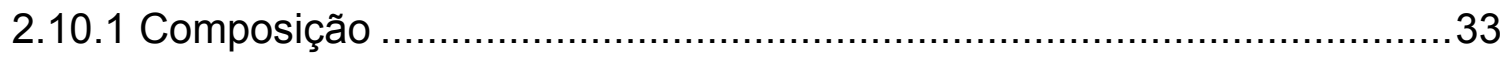

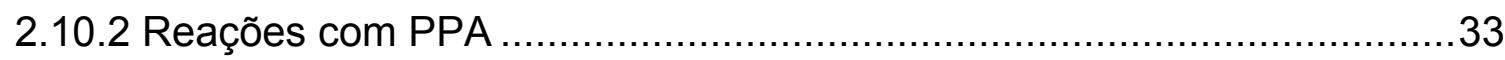

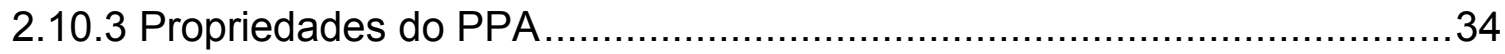

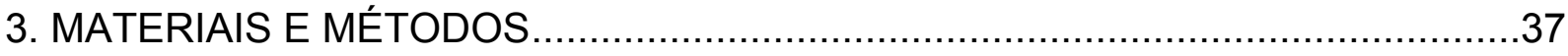

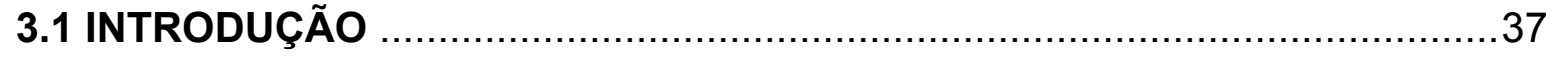




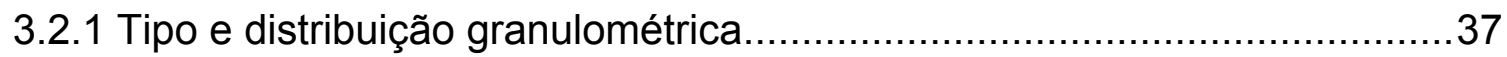

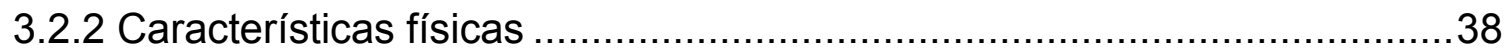

3.2.3 Procedimento de seleção, manuseio e preparação do agregado ...............38

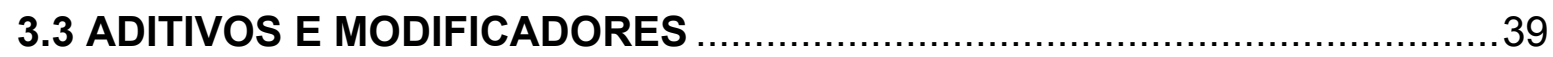

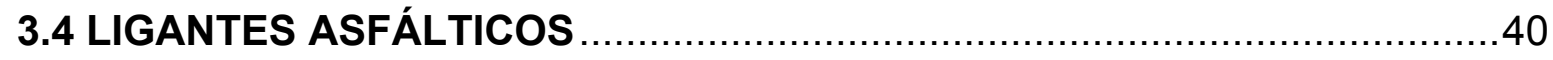

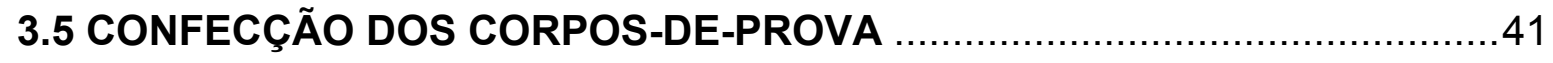

3.5.1 Temperaturas de usinagem e compactação ..........................................42

3.5.2 Determinação do teor de ligante de projeto ..........................................43

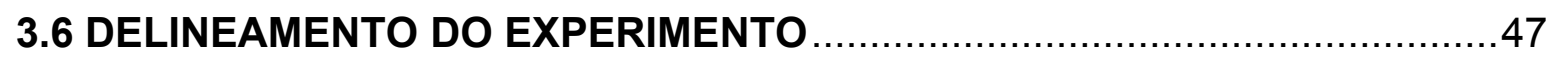

3.7 PLANEJAMENTO DO EXPERIMENTO FATORIAL ...................................47

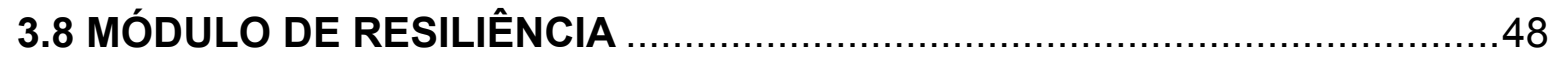

3.9 RESISTÊNCIA À TRAÇÃO POR COMPRESSÃO DIAMETRAL .................50

3.10 AVALIAÇÃO DA SUSCETIBILIDADE TÉRMICA DA MISTURA …............50

3.11 MÉTODOS DE ENSAIO PARA AVALIAÇÃO DOS DANOS POR UMIDADE .51

3.12 MÉTODO DE ANÁLISE DOS RESULTADOS …......................................

4. APRESENTAÇÃO E ANÁLISE DOS RESULTADOS.........................................53

4.1 INTRODUÇÃO

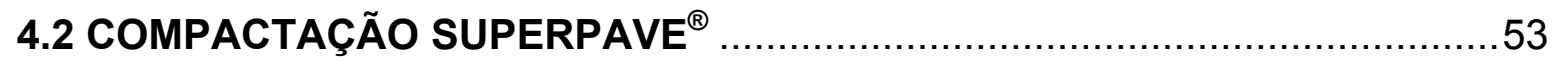

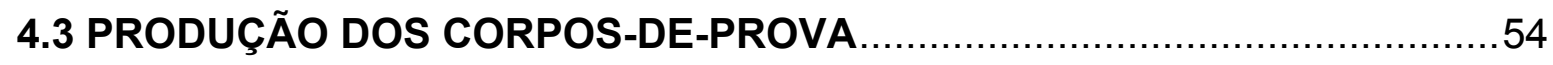

4.4 AVALIAÇÃO DAS PROPRIEDADES MECÂNICAS OBTIDAS ....................55 
4.5 APRESENTAÇÃO E DICUSSÃO DOS RESULTADOS DA RESISTÊNCIA À TRAÇÃO E DO EFEITO DO CONDICIONAMENTO PARA O MR, RR E ATRASO

4.6 VISUALIZAÇÃO DO TIPO DE DANO PELO REGISTRO FOTOGRÁFICO ...77

4.7 ANÁLISE DA SIGNIFICÂNCIA DOS FATORES .81

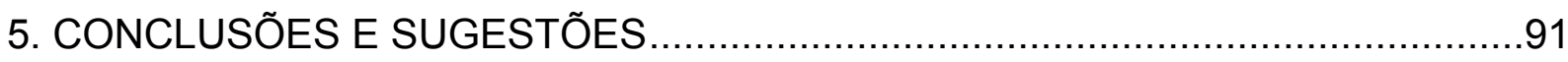

5.1 CONCLUSÕES .91

5.2 SUGESTÕES PARA TRABALHOS FUTUROS: .93

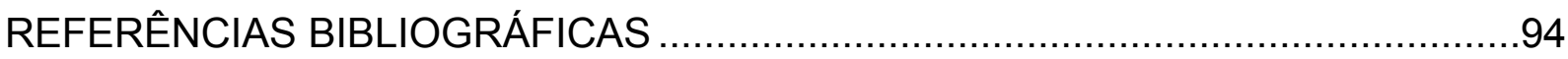

ANEXO I - MASSAS ESPECÍFICAS "REAL" APARENTE E MÁXIMA MEDIDA .....107 ANEXO II - PROPRIEDADES OBTIDAS DA MOLDAGEM ……..........................111 ANEXO III - MÓDULOS DE RESILIÊNCIA PARA AS TEMPERATURAS DE 10, 25 E $40^{\circ} \mathrm{C}$

ANEXO IV - MÓDULOS DE RESILIÊNCIA DESCARTANDO OS FORA DA MÉDIA \pm UM DESVIO PADRÃO.

ANEXO V - VALORES OBTIDOS PARA RESISTÊNCIA À TRAÇÃO. 


\section{ÍNDICE DE FIGURAS}

Figura 2.1. Curva deformação versus tempo, para um ciclo de carregamento. 21

Figura 3.1. Caracterísiticas dos ligantes utilizados na pesquisa 43

Figura 3.2. Sequência do procedimento de compactação 45

Figura 4.1. Volume de vazios versus teor de ligante para determinação do teor ideal.

Figura 4.2. (a) Relação entre módulos instantâneo e total, (b) RR em função de MR e (c) Atraso em função de $M R$, para $V_{v}=4 \%$ .58

Figura 4.3. Efeito do PPA no MR e na RR em diferentes temperaturas para $4 \%$ de $V_{v}$ $=4 \%$.

Figura 4.4. Efeito do PPA no MR e na RR em diferentes temperaturas para $V_{v}=7 \%$

Figura 4.5. Efeito da cal no MR e na RR em diferentes temperaturas para $V_{v}=4 \%$

Figura 4.6. Efeito da cal no MR e na RR em diferentes temperaturas para $\quad V_{v}=$ $7 \%$.

Figura 4.7. Efeito da interação entre PPA e a cal no MR e na RR em diferentes temperaturas para $\mathrm{V}_{\mathrm{v}}=4 \%$

Figura 4.8. Efeito da interação entre PPA e a cal no MR e na RR em diferentes temperaturas para $\mathrm{V}_{\mathrm{v}}=7 \%$

Figura 4.9. Efeito do aumento da concentração de cal e PPA no MR em diferentes temperaturas para $\mathrm{V}_{\mathrm{v}}=4 \%$

Figura 4.10. Efeito do aumento da concentração de cal no MR e PPA no MR em diferentes temperaturas para $\mathrm{V} v=7 \%$.

Figura 4.11. Efeito do aumento da concentração de cal e PPA na RR em diferentes temperaturas para $\mathrm{V}_{\mathrm{v}}=4 \%$

Figura 4.12. Efeito do aumento da concentração de cal e PPA na RR em diferentes temperaturas para $\mathrm{V}_{\mathrm{v}}=7 \%$

Figura 4.13. Efeito do condicionamento no MR e RR para diferentes concentrações de PPA 68

Figura 4.14. Efeito do condicionamento no MR e RR para diferentes concentrações de cal. 
Figura 4.15. Efeito da interação entre PPA e cal em função do condicionamento para MR e RR

Figura 4.16. Efeito da interação entre PPA e cal em função do condicionamento para MR e RR 69

Figura 4.17. Variação do Atraso em função da interação de PPA e cal ....................70

Figura 4.18. Efeito do aumento da concentração de cal na RT e no Atraso .72

Figura 4.19. Efeito do aumento da concentração de PPA no RT e no Atraso. .72

Figura 4.20. Efeito da interação entre o PPA e a cal na RT e no Atraso para diferentes $\mathrm{V}_{\mathrm{v}}$ .73

Figura 4.21. Efeito isodado e da interação entre o PPA e a cal na RR diferentes $V_{v} 74$

Figura 4.22. Efeitos do aumento da concentração de cal e PPA na RT. .75

Figura 4.23. Efeito da interação entre o PPA e a cal na RT para as misturas sem e com condicionamento .76

Figura 4.24. Relação de resistência à tração (RRT) das misturas (efeito do condicionamento) .77

Figura 4.25. Superfícies de ruptura de corpos-de-prova sem cal com CAP Puro para $4 \%$ (a) e $7 \%$ (b) de $V_{v}$ 0,6\% de PPA para $4 \%$ (c) e $7 \%$ (d) de $V_{v}$ e com $1,2 \%$ de PPA para $4 \%$ (e) e $7 \%$ (f) de $V_{v}$ 78

Figura 4.26. Superfícies de ruptura de corpos-de-prova com $1,5 \%$ de cal com CAP Puro para $4 \%$ (a) e $7 \%$ (b) de $V_{v}, 0,6 \%$ de PPA para $4 \%$ (c) e $7 \%$ (d) de $V_{v} e$ com $1,2 \%$ de PPA para $4 \%$ (e) e $7 \%$ (f) de $V_{v}$ .79

Figura 4.27. Superfícies de ruptura de corpos-de-prova com 3,0\% de cal com CAP Puro com 4\% (a) e 7\% (b) de $V_{v}, 0,6 \%$ de PPA com $4 \%$ (c) e $7 \%$ (d) de $V_{v}$ e com $1,2 \%$ de PPA com $4 \%$ (e) e $7 \%$ (f) de $V_{v}$ .80

Figura 4.28. Efeitos da interação entre fatores no MR total calculado pela NCHRP. 83

Figura 4.29. Efeitos dos fatores e suas interações entre variáveis na RR. .85

Figura 4.30. Efeitos de interação entre variáveis no Atraso Médio. 87

Figura 4.31. Efeitos de interação entre fatores na RT. .88

Figura 4.32. Efeitos de interação entre fatores no MR instantâneo. .90 


\section{ÍNDICE DE TABELAS}

Tabela 3.1: Faixa Granulométrica MIX IV B do Asphalt Institute ...........................37

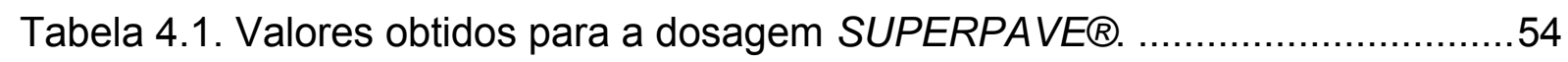

Tabela I. 1. Determinação dos valores da massa específica aparente "real"..........108

Tabela I. 2. Determinação dos valores da massa específica aparente "real"..........108

Tabela I. 3. Calculo do $\mathrm{Gmm}$ para $1,5 \%$ de cal e 0,6\% de PPA para diferentes teores

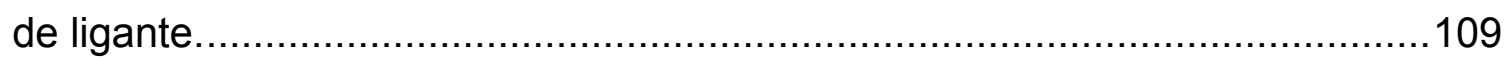

Tabela I. 4. Cálculo do Gmm para todas as combinacoes de fatores. ..................109

Tabela II. 1. Resultado das propriedades da moldagem dos corpos-de-prova. ......112

Tabela III. 1. Módulo de Resiliência para todos os fatores a $40^{\circ} \mathrm{C}$.........................116

Tabela III. 2. Módulo de Resiliência para todos os fatores a $25^{\circ} \mathrm{C} \ldots \ldots \ldots \ldots \ldots \ldots \ldots . . . . . . . . .119$

Tabela III. 3. Módulo de Resiliência para todos os fatores a $25^{\circ} \mathrm{C}$ e condicionamento.

Tabela III. 4. Módulo de Resiliência para todos os fatores a $10^{\circ} \mathrm{C} \ldots \ldots \ldots \ldots \ldots \ldots \ldots . . . . . . . . . . . .123$

Tabela IV. 1. Módulo de Resiliência para todos os fatores a $40^{\circ} \mathrm{C}$, descartando ensaios fora de um desvio padrão em relação à média. ...............................128

Tabela IV. 2. Módulo de Resiliência para todos os fatores a $25^{\circ} \mathrm{C}$, descartando ensaios fora de um desvio padrão em relação à média.

Tabela IV. 3. Módulo de Resiliência para todos os fatores a $10^{\circ} \mathrm{C}$, descartando ensaios fora de um desvio padrão em relação à média.

Tabela V. 1. Resultados para Resistência à Tração para todos os corpos-de-prova. 


\section{ÍNDICE DE ABREVIATURAS, SIGLAS E SÍMBOLOS}

AASHTO American Association os State Highway and Transportation Officials

ABNT Associação Brasileira de Normas Técnicas

SHRP Strategic Highway Research Program

FHWA Federal Highway Administration

NBR Norma Brasileira

ASTM American Society of Testing Materials

REVAP Refinaria Henrique Lage

SUPERPAVE Superior Performing Asphalt Pavements

CAP Cimento asfáltico de petróleo

TMN Tamanho máximo nominal

PPA polyphosphoric acid

C - D Congelamento - Descongelamento

CBUQ Concreto betuminoso usinado a quente

DNER Departamento Nacional de Estradas de Rodagem

EVA ethylene vinyl acetate (polímero)

LVDT linear variable differential transformer

NCHRP National Cooperative Highway Research Program

SBR styrene-butadiene-rubber (polímero)

SBS styrene-butadiene-styrene (polímero)

PG Performance grade 


\begin{tabular}{|c|c|}
\hline CP & Corpo-de-prova \\
\hline RT & Resistência à tração \\
\hline$\sigma_{\mathrm{R}}$ & Tensão de tração \\
\hline AFM & Microscopia de Forças Atômicas \\
\hline GPC & Cromatografia de permeação-gel \\
\hline h & Altura do corpo-de-prova \\
\hline d & Diâmetro do corpo-de-prova \\
\hline D & Tamanho máximo do agregado \\
\hline MR & Módulo de resiliência \\
\hline $\mathrm{MR}_{\mathrm{t}}$ & Módulo de resiliência total \\
\hline $\mathbf{M R}_{\mathrm{i}}$ & Módulo de resiliência instantâneo \\
\hline $\mathbf{N}$ & Tráfego \\
\hline $\mathbf{F}$ & Carga aplicada \\
\hline$\Delta$ & Deslocamento \\
\hline$\Delta_{\text {total }}$ & Deslocamento total \\
\hline$\Delta_{\mathrm{i}}$ & Deslocamento instantâneo \\
\hline$\mu$ & Coeficiente de poisson \\
\hline $\mathbf{R R}$ & Recuperação retardada \\
\hline$\varepsilon_{\mathbf{t}}$ & Deformação total \\
\hline$\varepsilon_{\mathbf{i}}$ & Deformação instantânea \\
\hline RRT & Relação da resistência à tração \\
\hline
\end{tabular}


CGS Compactador Giratório Superpave

$\mathbf{P}_{\mathbf{l i}} \quad$ teor de ligante inicial

TUC temperaturas de usinagem e compactação

DMM Densidade máxima teórica

$\mathbf{D}_{\text {ap }} \quad$ Densidade aparente da mistura

Gmm Densidade máxima teórica

Gsb Densidade aparente

$\mathbf{V}_{\mathbf{v}} \quad$ Volume de vazios

RBV Relação betume-vazios

VAM Vazios do agregado mineral 
A pavimentação asfáltica e os materiais nela utilizados são assuntos constantes no meio técnico e científico da engenharia civil, estimulando muitos engenheiros e pesquisadores a desenvolverem trabalhos na área. A grande variedade de materiais de pavimentação e a própria variabilidade a eles inerente, associadas às diversas condições de carregamentos e configurações dos veículos, assim como das diversas condições climáticas que, combinados, geram muitas opções quanto à escolha do melhor material para o pavimento que aperfeiçoe as condições de resistência dos materiais utilizados, com relação às solicitações em questão.

Dois dos principais defeitos que ocorrem nos pavimentos flexíveis são o trincamento por fadiga e a deformação permanente nas trilhas de roda, que são provocados pelos mecanismos de flexão alternada e compressão, respectivamente. Embora só seja visível na superfície, a deformação permanente pode ocorrer em qualquer camada do pavimento, causando depressões, corrugações longitudinais e laterais e outros movimentos (TERREL et al., 1971). As trincas por fadiga surgem na base da camada de concreto asfáltico e diretamente abaixo do ponto de aplicação da carga, e podem estar interconectadas e seladas, dependendo do nível de severidade da trinca (FHWA, 2003). Algumas combinações de solicitações podem agravar a evolução da deterioração do pavimento, como o aumento da frota comercial, da carga transportada por eixo (às vezes sobrecarga) e da pressão de inflação dos pneus, porém, os efeitos da água (dano por umidade) e da temperatura como aceleradores desses defeitos, direciona a atenção de muitos pesquisadores para o melhor entendimento do processo.

O dano por umidade causa a perda de adesão entre o asfalto e o agregado, ou em alguns casos, a perda de coesão do asfalto. As propriedades do asfalto (como viscosidade e consistência) dependem da sua origem e do processo de refinamento utilizado, assim como, o processo pelo qual o agregado é produzido, modifica a sua reação quando em contato com o asfalto e a água (D’angelo, 2003). O mesmo autor afirma ainda que uma mistura asfáltica altamente suscetível ao dano por umidade apresenta grandes variações nas propriedades adesão e coesão, na presença de pequenas variações de umidade. 
O revestimento apresenta consistências diferentes em função da temperatura a qual é exposto por se tratar de um material termoplástico, assim, asfaltos altamente suscetíveis à temperatura apresentam grandes variações de consistência, para pequenas variações de temperatura, causando tendência ao surgimento de trincas por fadiga (quando exposto a baixas temperaturas) e tendência à deformação permanente (quando exposto às altas temperaturas) das misturas asfálticas (Anderson et al., 1991).

A procura constante de novos materiais que melhorem o desempenho dos revestimentos asfálticos levou ao desenvolvimento dos asfaltos modificados com a utilização combinada de materiais que melhorem o seu desempenho. Atualmente, além dos ligantes asfálticos convencionais, há uma gama de asfaltos modificados que proporcionam opções para atender às necessidades exigidas pelas condições climáticas de onde o ligante será utilizado.

O emprego de ligantes asfálticos consistentes em misturas asfálticas proporciona maior rigidez, maior módulo de resiliência, maior resistência à deformação permanente e maior resistência à tração estática, quando comparadas a misturas de mesma faixa granulométrica e asfaltos menos consistentes (Marques, 2004; Furlan et al., 2007).

Os ligantes asfálticos podem ser modificados mediante a adição direta de materiais diversos como asfaltos naturais, polímeros (SBS - Styrene butadiene styrene, SBR - Styrene butadiene rubber e EVA - Ethylene vinyl acetate) e ácidos (por exemplo o ácido polifosfórico) com objetivo de melhorar suas propriedades reológicas e reduzir sua suscetibilidade às ações da temperatura e do tempo de aplicação de carga (Herrington et al., 1999). O ligante asfáltico pode, ainda, apresentar comportamentos diferentes e até melhorados devido à adição de produtos à mistura, como o que ocorre com a adição de certos fíleres (ex.: cal e cimento Portland).

Apesar das vantagens obtidas pela modificação direta do ligante ou indireta (a partir da adição de produtos à mistura asfáltica), ela somente é recomendada se não acarretar prejuízo às operações de usinagem, espalhamento e compactação, assim como da coesão da mistura asfáltica. 
Os asfaltos modificados por borracha moída de pneu, por exemplo, apresentam maior consistência quando comparados à do ligante original (puro), e isto resulta em melhora das propriedades reológicas do ligante asfáltico, principalmente aquelas relacionadas a parâmetros de deformação permanente (Faxina, 2006). Como conseqüência, as misturas asfálticas com asfalto-borracha, apresentam melhoras em sua flexibilidade, o que "acelera" a dissipação da energia de deformação armazenada devida à solicitação do carregamento (Bertollo et al., 2002).

Apesar das vantagens do emprego do asfalto-borracha, ainda devem ser solucionados dois problemas: a perda de trabalhabilidade da mistura devida ao aumento de viscosidade do ligante asfáltico e problemas relativos à estabilidade à estocagem do asfalto-borracha. Algumas soluções têm sido testadas a partir da adição de um óleo extensor. Já as misturas com estireno-butadieno-estireno (SBS), apesar de serem mais flexíveis, mais resistentes à deformação permanente e às trincas térmicas, menos suscetíveis à temperatura, ainda esbarram em problemas relacionados ao custo (Faxina, 2006).

Alguns estudos têm mostrado que a combinação de ácido polifosfórico com esses polímeros permite reduzir a quantidade de polímero a ser adicionado ao ligante asfáltico, o que reduz a viscosidade do ligante modificado, mas, mesmo assim, proporcionando propriedades reológicas tão adequadas quanto às do ligante asfáltico modificado apenas com o polímero (Martin e Baumgardner, 2006).

Segundo Leite et al. (2006), o uso de ácido polifosfórico possibilitou a obtenção de características superiores ao ligante betuminoso original, ou seja, de um produto de melhor suscetibilidade térmica, melhor grau de desempenho Superpave e relação "viscosidade - penetração" mais adequada, além do recobrimento dos agregados e resistência à tração da mesma ordem de grandeza daqueles obtidos com ligantes oriundos de cru naftênico (petróleo venezuelano).

Outro tipo de material que tem sido objeto de estudo em muitas pesquisas é o fíler (ou material de enchimento), que afeta as propriedades das misturas asfálticas, podendo trabalhar tanto como material inerte, preenchendo os vazios entre as partículas de agregados graúdos, quanto como material ativo, pela interação físico- 
química com o asfalto, e essa interação é regida pelas suas características geométricas, propriedades de superfície, absorção e adesão (Furlan et al., 2008).

Segundo Lutif et al. (2008) para diminuir os efeitos devido ao danos por umidade em pavimentos, muitas agências de transportes nos Estados Unidos adotam agentes como redutores de dano por umidade (antistripping agents) nas misturas asfálticas. Um dos agentes mais utilizados é a cal hidratada. De forma geral, a cal tende a contribuir para o enrijecimento dos mástiques, o que pode também reduzir sua resistência à fadiga. Particularmente, fíleres de maior superfície específica pode potencializar a perda de resistência à fadiga do ligante asfáltico, e a cal hidratada é um bom exemplo deste comportamento (Furlan et al., 2009).

A cal, em especial, tem vantagem em relação a outros fíleres (cimento Portland e o pó de pedra), que se deve à geometria das suas partículas, uma vez que, em geral, cerca de $80 \%$ delas têm diâmetros menores ou iguais a $20 \mu \mathrm{m}$ e, por isso, maiores quantidades de cal podem se concentrar no ligante asfáltico disponível/efetivo e promover mudanças nas suas características originais (Furlan et al., 2008). Algumas propriedades como rigidez, viscosidade e coesão do asfalto aumentam, por outro lado, a susceptibilidade térmica e a ductilidade diminuem, assim como quando a cal é usada em excesso torna o mástique mais frágil e quedradiço (Jimenez et al., 2008). Bianchetto (1998) afirma que a concentração de filer crítica é alcançada quando o mástique começa a enrijecer, a mistura se torna mais frágil e certas características desejadas, como flexibilidade, coesão e durabilidade são diminuídas, em outras palavras, a concentração crítica é alcançada quando (a) a tensão aplicada é absorvida pela deformação viscosa do material betuminoso e (b) a resistência friccional entre as partículas são mínimas. 


\subsection{OBJETIVO}

Este trabalho tem por objetivo estudar os efeitos da cal hidratada e/ou do ácido polifosfórico em algumas propriedades mecânicas e na suscetibilidade à umidade e a temperatura de misturas asfálticas densas.

\subsection{ESTRUTURAÇÃO DO TRABALHO}

O Capítulo 1 relata as considerações iniciais desta dissertação de mestrado, apresentando sucintamente o problema objeto de estudo, a alternativa para como solução, além do resumo de algumas propriedades das misturas asfálticas de alto desempenho.

No Capítulo 2, é apresentada uma visão geral dos principais defeitos que ocorrem nos pavimentos asfálticos em todo o mundo, assim como os fenômenos que contribuem para a redução da vida útil do pavimento; as propriedades dos agregados, ligantes asfálticos e da mistura asfáltica, com enfoque no uso de cal hidratada como aditivo, e do ácido polifosfórico como modificador, e como estas propriedades podem ser influenciadas na presença de elementos intempéricos, como a umidade e temperatura, e por fim as propriedades mecânicas das misturas asfálticas que foram analisadas.

O Capítulo 3 tem por objetivo apresentar os materiais utilizados, detalhar o planejamento do experimento, assim como técnicas e procedimentos laboratoriais adotados. No Capítulo 4 são apresentados os resultados obtidos nos ensaios, juntamente com as análises realizadas. O Capítulo 5 é reservado as conclusões da pesquisa e às sugestões para trabalhos futuros. Por fim, é apresentado o Capítulo de referências bibliográficas empregadas na dissertação. 


\section{REVISÃO BIBLIOGRÁFICA}

Este capítulo apresenta as principais características da mistura asfáltica e de seus elementos (agregado e ligante asfáltico), do uso de aditivos e modificadores, da suscetibilidade térmica e do dano por umidade de misturas asfálticas densas, e de algumas propriedades mecânicas importantes para análise dessas características.

\subsection{INTRODUÇÃO}

A função do pavimento é proporcionar economia, segurança e conforto ao usuário da via, atrelado ao nível de serviço, que fica comprometido à medida que aparecem defeitos no pavimento, reduzindo o seu desempenho e serventia.

O crescimento constante do tráfego comercial rodoviário no Brasil impõe o desafio de se manter ou aumentar a vida útil dos pavimentos, o que é feito, muitas vezes, empregando-se misturas asfálticas com melhores desempenhos.

A vida útil do pavimento asfáltico fica condicionada pelo surgimento de dois dos principais defeitos em todo mundo, que são o trincamento por fadiga e a deformação permanente. Algumas combinações podem agravar a evolução da deterioração do pavimento asfáltico, como o aumento da frota comercial, da carga transportada por eixo (às vezes sobrecarga) e da pressão de inflação dos pneus, porém, o efeito da água (dano da umidade) e temperatura como acelerador desses defeitos, direciona a atenção de muitos pesquisadores para 0 melhor entendimento desse procedimento.

\subsection{PRINCIPAIS DEFEITOS DOS REVESTIMENTOS ASFÁLTICOS}

O trincamento por fadiga é um dos defeitos mais comuns, que aparece normalmente quando o pavimento asfáltico está envelhecido e, após ser submetido às cargas cíclicas, já não oferece boa resposta às solicitações. A resistência à fadiga de uma mistura asfáltica pode ser definida como a capacidade que esta mistura apresenta de resistir aos esforços repetitivos de flexão (esforço cíclico) sem se romper; entre os esforços encontram-se as características do tráfego, do pavimento e as condições climáticas (Ildefonso, 2007). 
As trincas por fadiga não podem ser observadas em campo em etapas iniciais, já que surgem na base da camada de concreto asfáltico e diretamente abaixo do ponto de aplicação da carga, e podem estar interconectadas e seladas, dependendo do nível de severidade da trinca (FHWA, 2003). A evolução do processo de trincamento por fadiga pode ser observado quando a trinca alcança a superfície da capa asfáltica formando trincas características.

A deformação permanente é outro defeito que ocorre com frequência e se trata de um mecanismo que também pode influenciar a vida útil do pavimento (Motta e Pinto, 1994). A deformação permanente pode ocorrer por consolidação (ou densificação) e/ou por deformação cisalhante. A consolidação é a compactação que ocorre na capa e nas camadas inferiores, pelo tráfego, após a sua construção, devido ao volume de vazios da mistura asfáltica compactada ser maior que o de projeto e/ou haver deficiência do intertravamento dos agregados e, dessa forma, a ação de um tráfego canalizado faz com que haja uma densificação nas áreas das trilhas de roda, reduzindo o volume de vazios e completando, assim, a compactação (Roberts et al., 1991). O mesmo autor afirma que a baixa resistência das camadas inferiores à capa, e a perda de material de superfície com tráfego são causas desse defeito.

O combate a esses dois defeitos representa produzir misturas asfálticas com características mecânicas antagônicas. Isso se deve ao fato de que, para reduzir a suscetibilidade à fadiga, a mistura asfáltica deve apresentar alta flexibilidade, ou baixa rigidez, enquanto que para o combate à deformação permanente a mistura deve ser mais rígida, ou seja, na maioria das vezes quando se melhora de uma das características, piora-se a outra.

Algumas das causas principais que podem ocasionar ou acelerar o processo de surgimento de trincas por fadiga ou de deformação permanente são oriundos de ações intempéricas, representadas por agentes que podem agredir com maior ou menor intensidade o revestimento asfáltico, dependendo da região, como a amplitude de variação da temperatura e a presença de água.

Autores como Lutif et al. (2008) e Gouveia et al. (2004) afirmam respectivamente, que o dano por umidade e o stripping são alguns dos principais fenômenos causadores dos defeitos do revestimento asfáltico, como a trinca por fadiga e a 
deformação permanente, principalmente em regiões onde as condições climáticas são severas, com grandes variações de temperatura e umidade, onde se faz necessária a avaliação dessas condições para consideração como critério de definição do projeto de misturas asfálticas e seleção de materiais.

\subsection{STRIPPING, ADESÃO E DANO POR UMIDADE}

O stripping é um fenômeno que se caracteriza pelo deslocamento da película de ligante do agregado, a partir da parte inferior da camada de rolamento, devido aos esforços de tração resultantes do tráfego, progredindo até a superfície (Gouveia et al., 2004). Stripping é um dos principais fatores que influenciam o desempenho de misturas asfálticas. Defeitos devido à perda de adesão asfalto-agregado podem se desenvolver em estágios iniciais da vida útil do pavimento.

Para avaliação do efeito de aditivos antistripping tem sido prática o uso de ensaios relacionados ao dano por umidade. Segundo Adorjányi (2008), na prática de campo a causa do stripping frequentemente se relaciona ao uso impróprio do pó de pedra, ou da pedra britada que contêm muitos finos. Em casos mais complexos o stripping pode ter várias causas que não podem ser quantificadas com uma metodologia de ensaio somente. Assim, o uso de melhoradores da adesão é justificado pela redução do risco de desenvolver falhas prematuras e melhorar o desempenho da mistura durante a vida útil do pavimento.

O deslocamento da película de ligante asfáltico do agregado se deve ao enfraquecimento da adesão que ocorre entre o agregado e o ligante, que garante a coesão da mistura asfáltica. Esse processo ocorre pelo intertravamento mecânico do ligante na superfície do agregado e devido à textura superficial (FHWA, 2003).

Little e Jones IV (2003) afirmaram que o modelo de adesão do programa SHRP conclui que as propriedades dos agregados são mais influentes no processo de ligação do que as características dos ligantes, e que a adesão é conseguida, principalmente pelos compostos polares do CAP que se ligam aos "sítios ativos" do agregado através de forças de atração eletrostática, pontes de hidrogênio e Força de Van der Walls. Os mesmos autores afirmam ainda que os sulfóxidos e os ácidos carboxílicos são os grupos funcionais que possuem maior afinidade pelos 
agregados, mas, em contrapartida, são os mais facilmente removidos em presença de água, que os grupos dos fenóis e das bases nitrogenadas são os mais efetivos em garantir uma boa adesão, e ainda que os hidrocarbonetos aromáticos possuem menor afinidade pela superfície do agregado do que os grupos polares.

A umidade pode comprometer a vida útil do pavimento asfáltico, até mesmo em períodos iniciais, se os devidos cuidados para evitá-la ou minimizá-la não forem tomados. Segundo Lutif et al. (2008) a umidade no concreto asfáltico pode causar a perda de coesão (devido à difusão da água no cimento asfáltico de petróleo) que causa a perda de rigidez das películas de CAP, e a perda de adesão entre o CAP e os agregados, em função da água atingir a interface CAP-agregado, culminando na aceleração de defeitos, como a trinca por fadiga e a deformação permanente.

A suscetibilidade ao dano por umidade está relacionada ao volume de vazios, que quando em excesso cria lacunas que permitem a entrada da água e do ar, às vezes, até seu aprisionamento. A permeabilidade ao ar promove a aceleração do processo de endurecimento do ligante asfáltico por oxidação, e a presença de água nesses vazios causa o stripping, sob a ação dos carregamentos do tráfego, com variações de temperatura e magnitude de carga, causando nas misturas asfálticas 0 surgimento de defeitos (Huber, 1999).

Segundo Lutif et al. (2008), o desempenho dos revestimentos asfálticos está relacionado com a coesão e a adesão no sistema CAP-agregado. A perda de coesão do CAP e a perda de adesão entre os agregados e o CAP juntamente com a degradação ou fratura dos agregados foram identificados como os principais mecanismos do dano por umidade nos pavimentos asfálticos. Além dos dois mecanismos primários do dano por umidade, alguns outros fenômenos tais como deslocamento, desprendimento, e acúmulo de poro-pressão são também observados em pavimentos que tiveram dano por umidade.

As propriedades da mistura asfáltica podem ser melhoradas a partir da alteração, modificação e/ou adição de materiais que atuem em um dos elementos da mistura asfáltica, ou em ambos, com intuito de reduzir ou evitar que o desempenho seja prejudicado. Assim, o entendimento de algumas propriedades do agregado, do 
ligante asfáltico e da mistura são importantes para melhor compreensão do processo.

\subsection{PROPRIEDADES DOS AGREGADOS}

Tendo em vista a importância do agregado para a produção de misturas asfálticas de elevado desempenho, este item trata da influência das propriedades dos agregados na adesão e suscetibilidade à umidade de misturas asfálticas.

A estrutura mineral influencia a deformação permanente e o desempenho das misturas asfálticas, pois representa cerca de $95 \%$ da massa total das misturas. Os agregados minerais podem variar significativamente quanto às características que condicionam a sua adequação como material de pavimentação, tais como: mineralogia, granulometria, resistência, durabilidade, sanidade, absorção, forma, angularidade e textura superficial. Tais variações, associadas à falta de informações precisas sobre a influência dos agregados no desempenho dos pavimentos, indicam a necessidade de estudos detalhados das propriedades essenciais dos agregados, para assegurar que pavimentos de alta qualidade sejam construídos (Gouveia, 2006).

Segundo Gouveia (2006) estudos do SHRP (Strategic Highway Research Program) que foram patenteados sob a denominação Superpave (Superior Performing Asphalt Pavements) desenvolveu métodos de análise de ligantes asfálticos e de misturas asfálticas para controlar as deformações permanentes, trincas por fadiga e as trincas devido a baixas temperaturas a partir de propriedades fundamentais. As propriedades dos agregados são: granulometria, angularidade do agregado grosso e fino, resistência à abrasão, sanidade, materiais deletérios, finos plásticos e partículas planas e alongadas, volume de vazios, vazios do agregado mineral, vazios preenchidos por asfalto ou relação betume-vazios e teor de fíler (dust to asphalt ratio).

Os agregados possuem superfície heterogênea com uma grande variedade de "sítios ativos" de diferentes composições químicas e níveis de atividades. Curtis et al (1993) relataram que os "sítios ativos", presentes na superfície do agregado são muitas vezes dotados de carga elétrica, ou contém cargas parciais, que atraem e 
orientam os grupos polares do asfalto, e que são adsorvidos de uma maneira muito mais efetiva do que os compostos polares.

Cabe ressaltar que os "sítios ativos" do agregado atraem tanto compostos polares dos ligantes asfálticos quanto a água que é fortemente polar. Após a realização dos estudos, Curtis et al (1993) concluíram que os compostos polares com grupos funcionais dos tipos ácido carboxílico e sulfóxidos são os mais facilmente removidos em presença de água, os compostos com menor polaridade apresentaram resistência intermediária, enquanto que os grupos funcionais com bases nitrogenadas e fenóis se apresentaram mais resistentes à umidade, e que essa ordem foi mantida para todos os tipos de agregados testados (granitos, calcário, arenito e cascalho).

Adorjányi et al. (2008) concluíram que as misturas possuem "polaridade" por causa das diferentes características de formação dos minérios constituintes dos agregados, e que não pode ser corretamente detectada somente com ensaios mecânicos.

\subsection{PROPRIEDADES DOS LIGANTES ASFÁLTICOS}

O ligante asfáltico é o elemento que rege o comportamento da mistura asfáltica após a usinagem, já que se trata de uma estrutura termoplástica, e sofre grandes alterações de suas propriedades com variações de temperatura e de umidade. Cabe ressaltar que aproximadamente $5 \%$ da mistura asfáltica é composta de ligante asfáltico, e que grande parcela da resistência da capa asfáltica é devida à estrutura formada pela "malha" constituída pelo ligante-agregado, e não menos importante, o resultado da intensidade dessa interação caracteriza as forças de adesão e coesão, responsáveis por propriedades importantes, como a resistência à compressão e a flexibilidade do pavimento. A intensidade e o comportamento dessas forças podem qualificar o pavimento em um elemento suscetível ao dano por umidade ou temperatura, se para uma pequena variação de umidade ou temperatura, houver uma pequena variação ou manutenção das propriedades do pavimento asfáltico. Assim, o ligante asfáltico e suas variações, podem caracterizar o comportamento do pavimento diante das solicitações e ações de intempéries. 
Os ligantes asfálticos largamente utilizados na pavimentação de estradas e rodovias são materiais complexos com uma considerável variedade de compostos orgânicos. São originários do petróleo, sendo obtidos por evaporação natural de depósitos localizados na superfície da terra (asfaltos naturais), ou por destilação em unidades industriais especialmente projetadas (refinarias de petróleo) (Senço, 1997).

Os ligantes asfálticos em temperatura ambiente são um material de cor escura, semi-sólida e altamente viscoso. Composto principalmente de moléculas complexas de hidrocarbonetos, também compostos por outros átomos, como oxigênio, nitrogênio e sulfúrico, ele é classificado como material termoplástico, por que perde suas propriedades, como viscosidade, e amolece, quando aquecido, e endurece quando é resfriado (MANUAL DO ASFALTO, 1989).

Segundo Masson (2008) para melhorar o desempenho da mistura asfáltica, o ligante é modificado com elastômeros, plastômeros, termofixadores, enxofre, ou um ácido mineral, como o ácido polifosfórico (PPA), que quando combinado com um polímero, melhora de forma significativa a mistura asfáltica do que quando utilizado isoladamente.

Muitos pesquisadores que estudaram a influência do PPA nas propriedades da mistura asfáltica afirmam que o ácido proporciona um aumento da resistência à compressão, portanto melhores condições de reagir às solicitações que podem provocar deformação permanente no pavimento asfáltico.

As propriedades físicas dos ligantes asfálticos podem ser medidas a partir dos ensaios de penetração, ponto de amolecimento, suscetibilidade térmica, viscosidade e ductilidade. O carregamento pode modificar o comportamento físico e mecânico do ligante asfáltico, pois uma variação nos tempos de aplicação de carga ou na magnitude faz com que o ligante apresente características distintas, portanto, nos ensaios de caracterização dos ligantes asfálticos, se leva em consideração os valores específicos de temperatura, tempo e magnitude de aplicação de carregamentos (Pilati, 2008).

Segundo Huber (1999), o ligante asfáltico atua como uma cola, mantendo o esqueleto do agregado interconectado. O ligante asfáltico deve ser capaz de evitar que partículas sejam deslocadas pelo rolamento dos pneus. Se o ligante não pode 
manter o arranjo da estrutura mineral, as partículas de agregado se movimentarão e o esqueleto sofrerá colapso.

Lottman (1978) verificou que as características dos asfaltos como ponto de amolecimento e viscosidade cinemática obtidos a partir de testemunhos extraídos de pavimentos submetidos normalmente ao tráfego (com idades variando entre 2 e 12 anos) são diferentes que dos corpos-de-prova produzidos em laboratório. Esse efeito pode ser justificado por algum tipo de envelhecimento a longo prazo, que tornou os asfaltos mais rígidos e viscosos após determinado período de tempo. Se tratando do dano por umidade, essas características são benéficas em função de caracterizar uma maior resistência ao descolamento da película de asfalto pela água.

Agnusdei ${ }^{1}$, 1975 apud Furlan (2006), afirma que com o aumento de moléculas de asfaltenos, analogamente aumenta a viscosidade do asfalto. Esse processo evolui com a idade do pavimento asfáltico, atribuído ao envelhecimento da mistura asfáltica, que pode ser acelerada em função das condições de solicitação e agressividade das variações de umidade e temperatura.

\subsection{PROPRIEDADES DA MISTURA ASFÁLTICA}

Quando se tratam das propriedades da mistura asfáltica, o volume de vazios se destaca por, na maioria das vezes, ser o principal fator para o desencadeamento de fenômenos, principalmente o dano por umidade.

O volume de vazios em excesso na mistura asfáltica, cria lacunas que permitem a permeabilidade da água e do ar e o aumento da suscetibilidade ao dano por umidade. Grandes espaços vazios com ar causam a aceleração do processo de endurecimento e deixam a mistura mais frágil (quebradiça). A presença de água nesses vazios causa o stripping, especialmente sob a ação de carregamentos de tráfego, com variações de temperatura e magnitude de carga, causando nas

\footnotetext{
${ }^{1}$ AGNUSDEI, J. Envelhecimento do asfalto durante a mistura. Instituto de Pesquisas Rodoviárias, Publicação 586/30, p.37, Rio de Janeiro, RJ, 1975.
} 
misturas asfálticas com projetos deficientes defeitos como panelas e buracos (Huber, 1999).

O dano devido a umidade não aumenta proporcionalmente com o volume de vazios, já que a partir de um certo limite, a água e o ar percolam pela mistura asfáltica, auxiliando na diminuição do dano por umidade.

Segundo Lutif (2008), o desempenho dos pavimentos asfálticos está relacionado com a coesão e a adesão no sistema CAP-agregado. A perda de coesão do CAP e a perda de adesão entre os agregados e o CAP juntamente com a degradação ou fratura dos agregados foram identificados como os principais mecanismos do dano por umidade nos pavimentos asfálticos. Além dos dois mecanismos primários do dano por umidade, alguns outros fenômenos tais como deslocamento, desprendimento, e acúmulo de poro-pressão são também observados em pavimentos que tiveram dano por umidade.

Muitos pesquisadores estudaram o porquê do envelhecimento do ligante tornar o asfalto mais viscoso e rígido após determinado período de tempo. Do ponto de vista do dano por umidade, essas alterações são benéficas, pois se acredita aumentar a resistência ao deslocamento da película de asfalto pela água. Por outro lado, reduz a extensão da superfície de molhagem, e cria-se uma avaliação dupla dessa característica, considerando a influência no desenvolvimento das ligações adesivas como resultado da afinidade, molhagem e cobertura do agregado, e a resistência da ligação adesiva frente à ação da água (Santanna-Greco et al., 2004).

Segundo Santanna-Greco et al. (2004) o envelhecimento de misturas asfálticas durante sua vida útil ocorre em duas etapas, a primeira durante a mistura dos materiais em usina e construção do pavimento, quando ocorre uma grande perda de voláteis e oxidação da mistura asfáltica quando ainda está quente, denominado de envelhecimento de curto prazo, a segunda etapa ocorre durante a vida útil do pavimento, devido à exposição às condições climáticas, sofrendo o envelhecimento de longo prazo, quando ocorre oxidação, ação da faixa ultravioleta de radiação e a perda de componentes oleosos do asfalto ocasionado pela absorção pelo agregado poroso. 
Sosnovske et al. (1993) constataram a importância de se realizar testes de envelhecimento com a mistura asfáltica e não apenas com o ligante, pois acreditam que a suscetibilidade das misturas asfálticas ao envelhecimento depende dos tipos de asfalto e agregado utilizados, bem como da adesão entre ambos, assim, quanto maior a adesão entre o asfalto e o agregado utilizados, maior a resistência ao envelhecimento apresentada pela mistura asfáltica.

O comportamento visco-elástico do ligante rege o comportamento da mistura asfáltica, e a adição de modificadores ao asfalto, pode melhorar as propriedades de resistência e flexibilidade do pavimento, influenciando no surgimento de defeitos do pavimento, proporcionando um pavimento de alto desempenho.

Misturas asfálticas, quando expostas às condições ambientais sofrem modificações em suas propriedades, verificadas pelo enrijecimento e pelo aumento de sua fragilidade. Essas modificações, denominadas envelhecimento, tornam as misturas mais suscetíveis à desagregação e, consequentemente, aos efeitos da umidade.

Silva et al. (2004) constataram que o envelhecimento é explicado através de quatro mecanismos: oxidação, endurecimento exsudativo, endurecimento físico e perda de voláteis. A oxidação da mistura asfáltica é a causa mais importante e acontece principalmente durante a produção e a aplicação do material que constitui o revestimento asfáltico, que continua envelhecendo durante o seu uso. Além da formação de novos compostos oxigenados, os grupos polares já existentes tendem a se associar, formando micelas e aglomerados de alto peso molecular e maior viscosidade, chamados de asfaltenos. O endurecimento exsudativo é resultante da migração de componentes oleosos do ligante para o agregado mineral. $O$ endurecimento físico é um fenômeno reversível que acontece à temperatura ambiente, atribuído à reordenação de moléculas e à cristalização de parafinas saturadas do ligante asfáltico. A perda de voláteis no ligante asfáltico é baixa e de pouca importância no processo de envelhecimento em longo prazo.

Algumas mudanças nas propriedades do ligante asfáltico ao longo do tempo ocorrem por causa das reações químicas com o oxigênio, que podem ser maximizadas se a espessura da camada de asfalto que recobre o agregado for 
muito espessa, podendo representar um excesso de absorção devido ao excesso de porosidade do agregado ou uma elevada temperatura na mistura asfáltica.

A consequência direta do fenômeno da absorção é a diminuição do filme de asfalto que envolve as partículas do agregado, ou seja, diminuição da quantidade de asfalto efetivo da mistura. Essa diminuição torna a mistura mais suscetível às tensões causadas pelo tráfego e às intempéries, ocorrendo $\mathrm{o}$ endurecimento $\mathrm{e} O$ envelhecimento do asfalto prematuramente, o que leva ao surgimento de vários problemas como desgaste, desagregação, perda de adesividade, trincas, entre outros (Gouveia, 2006).

Uma maneira prática de contornar o problema da absorção é aumentar a quantidade de asfalto na mistura. Isso é eficiente quando a absorção é rápida o bastante para ser completada durante o processo de mistura. Porém, se a absorção for lenta, ocorrendo muito além do período de construção do pavimento, a necessidade de uma maior quantidade de asfalto na mistura pode não ser detectada, resultando em uma mistura, a médio e longo prazo, com pouco asfalto e, consequentemente, com problemas de deterioração precoce. Adicionalmente, se uma quantidade extra de asfalto for colocada na mistura que possui agregados com absorção lenta, a mistura terá excesso de asfalto quando compactada, ocasionando uma estabilidade inicial baixa e problemas de exsudação (Lee et al. ${ }^{2}, 1990$ apud Gouveia, 2006).

O mástique que é formado a partir da combinação do filer com o ligante asfáltico, tem efeito positivo na mistura asfáltica, como por exemplo, o aumento de viscosidade, rigidez e coesão, por outro lado, pode causar a diminuição da suscetibilidade térmica, no entanto, analogamente causa a redução da ductilidade, e em quantidade excessiva pode deixar o mástique mais frágil e quebradiço. Em alguns casos, pode exibir uma característica hidrofílica, que tende a se combinar preferencialmente com a água do que com o ligante asfáltico, pode proporcionar um processo de perda do revestimento dos agregados na presença de água, que resulta na perda de coesão e resistência (Jimenez et al., 2008).

${ }^{2}$ LEE, D.Y.; GUINN, J.A.; KANDHAL, P.S.; DUNNING, R.L. Absorption of asphalt into porous aggregates. Relatório Técnico UIR-90-009, Strategic Highway Research Program (SHRP), 1990. 
Segundo Sebaaly et al. (2007) para diminuir os efeitos devido à umidade em pavimentos, muitas agências de transportes nos Estados Unidos têm especificado o uso de agentes redutores de dano por umidade (anti-stripping agents) nas misturas asfálticas. Um dos agentes mais usados é a cal hidratada, mas são utilizados também aditivos líquidos (aminas, diaminas e polímeros), cimento Portland, cinzas e escória. Investigações laboratoriais e verificações de campo têm mostrado efeitos positivos da cal em misturas asfálticas, e que eles dependem do tipo de agregado. Segundo o mesmo autor, alguns pesquisadores do Departamento de Transportes do Texas avaliaram o impacto do tratamento com cal no desempenho de misturas no Texas com o simulador de tráfego Hamburg, e concluíram que a adição de $1 \%$ de cal hidratada reduz a deformação permanente Hamburg em 50\% para todos os tipos de PG's. Os autores concluem ainda que com base nas propriedades mecânicas de misturas com aditivos líquidos e cales em estágios condicionados e não condicionados, que as com cales são mais estáveis, menos suscetíveis à deformação permanente e ao dano por umidade, com resistência à ruptura por fadiga similar quando comparada com misturas com aditivos líquidos.

\subsection{ENSAIOS DE PROPRIEDADES MECÂNICAS}

Os ensaios de avaliação das propriedades mecânicas das misturas procuram simular as condições reais de solicitações no campo. Os ensaios mais recentes de avaliação dos danos por umidade em misturas asfálticas envolvendo propriedades mecânicas consistem da apreciação de alguma alteração no valor de uma propriedade mecânica tomada como referência. As misturas avaliadas são submetidas a algum tipo de condicionamento do tráfego e/ou ambiental e são comparadas com misturas similares não-condicionadas. Os resultados são apresentados em forma de porcentagem de perda da propriedade, sendo que as amostras sem condicionamento, normalmente, apresentam maiores valores da propriedade de referência que aquelas submetidas ao condicionamento. O tipo mais comum de condicionamento utilizado nos últimos anos consiste em saturar parcialmente o corpo-de-prova, o que, normalmente, é executado por meio da aplicação de vácuo para a indução da entrada da água no mesmo. Atingida a saturação desejada, o corpo-de-prova é submetido a algum tipo de condicionamento térmico simulador de tensões e/ou temperaturas (Furlan, 2006). 
O método de ensaio para determinação da resistência de misturas asfálticas ao dano por umidade induzida (AASHTO $T$ 283) evoluiu das pesquisas de Lottman $(1978,1983)$. Resumidamente, o método de ensaio preconiza algumas condições para preparação de corpos-de-prova, como o envelhecimento da mistura não compactada por um período de $16 \mathrm{~h} \mathrm{a} 60^{\circ} \mathrm{C}$, a compactação é executada de tal forma que resulte em volumes de vazios de $7 \pm 1 \%$ ou iguais ao do pavimento em serviço, e ainda, a saturação parcial com água desses vazios. Para a saturação parcial do corpo-de-prova compactado é utilizada uma bomba de vácuo na pressão de $660 \mathrm{~mm}$. de $\mathrm{Hg}$, que proporciona a entrada de água. Atingida a saturação desejada, que deve estar contida no intervalo entre 55 e $80 \%$, procede-se o condicionamento térmico, que é composto por um ciclo de congelamento, que se constitui de $-18^{\circ} \mathrm{C}$ por $16 \mathrm{~h}$, e um descongelamento, que consiste da imersão em água a $60^{\circ} \mathrm{C}$ por $24 \mathrm{~h}$ (Furlan, 2006).

Lottman (1978) propôs inicialmente três "níveis" de condicionamento, sendo que cada nível representava um determinado estágio do pavimento em serviço. Assim, os corpos-de-prova sem condicionamento representavam um pavimento recém construído, compactado e curado, e que ainda não sofrera nenhuma influência externa. Um segundo grupo, submetido à saturação parcial a vácuo, representava uma situação na qual o revestimento sofre a ação deletéria da presença de água. $\mathrm{E}$ um terceiro grupo, que aliava os efeitos da saturação a vácuo a ciclos de condicionamento térmico, simulava os danos causados pelo tráfego e o meio ambiente.

2.7.1 Avaliação da rigidez de misturas asfálticas a partir do ensaio de módulo de resiliência

O módulo de resiliência é um ensaio não destrutivo que permite determinar a rigidez de uma mistura asfáltica, baseado na deformação recuperável ou elástica da mistura sob a ação de cargas repetidas, onde a energia armazenada no corpo-de-prova pela parcela elástica é devolvida quando se interrompe o pulso de solicitação. $O$ ensaio de módulo de resiliência segue a norma DNER 133/94, cujo procedimento consiste da aplicação de carregamentos cíclicos de magnitudes fixas, com 1,0s de duração, sendo cada ciclo constituído por um período de carregamento de $0,1 \mathrm{~s}$ e um período 
de repouso de 0,9 s. O valor do módulo de resiliência é calculado de acordo com a norma do DNER 133/94, conforme mostra a expressão 1 :

$$
M R=\frac{F}{\Delta h}(0.9976 \mu+0.2692)
$$

Onde:

$M_{R}$ é o módulo de resiliência em MPa;

F é a carga vertical repetida aplicada diametralmente ao corpo-de-prova, em $\mathrm{N}$;

$\Delta$ é o deslocamento total (correspondente à deformação elástica ou resiliente sofrida pelo corpo-de-prova, em direção perpendicular à aplicação da carga), em mm;

h é a altura do corpo-de-prova, em mm;

$\mu$ é o coeficiente de Poisson.

Os índices multiplicativos e somatório ao coeficiente de Poisson podem variar conforme posicionamento de leitura dos LVDT's radialmente no corpo-de-prova. Foi adotado um coeficiente de Poisson de 0,35 , que é o mesmo valor utilizado em retroanálise de pavimentos. A norma da AASHTO (1994) para determinação do módulo de resiliência de misturas asfálticas (AASHTO TP31-94) menciona dois tipos de módulo de resiliência, o módulo de resiliência total $\left(M_{R}\right.$ total) e o módulo de resiliência instantâneo $\left(M_{R}\right.$ inst., calculado a partir da diferença do $M_{R}$ total do referido ciclo e a deformação na base do trecho de descarregamento da curva de deformação), como se pode verificar na Figura 2.1. 


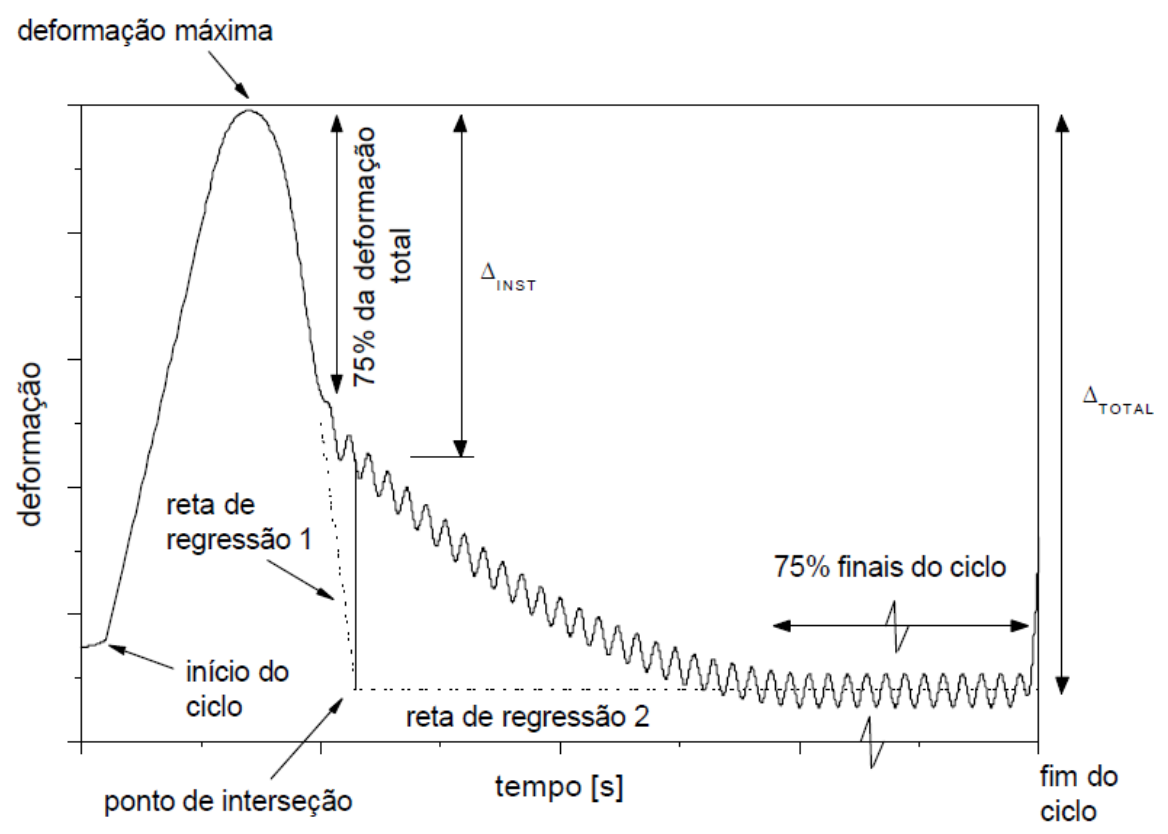

Figura 2.1. Curva deformação versus tempo, para um ciclo de carregamento.

Fonte: AASHTO (1994)

O módulo de resiliência total é calculado a partir da deformação resiliente total $\left(\Delta_{\text {total }}\right)$, que inclui tanto a deformação que é recuperada instantaneamente como a deformação recuperada durante a fase do ciclo em que o corpo de prova permanece sem carregamento ou em descanso.

A magnitude da carga aplicada foi definida a partir da resistência à tração do corpo de prova semelhante ao do ensaio, realizado previamente. A carga vertical é calibrada de maneira que permita a melhor precisão possível do equipamento, portanto, o mínimo de deformação possível para que possa ser captado pelo LVDT com qualidade de leitura, porém limitado pela deformação que não prejudique a resposta elástica e cause fadiga ao corpo-de-prova, prejudicando o resultado dos ensaios (limitado aproximadamente por 0,0025 a 0,0030 milímetros).

\subsubsection{Avaliação da resistência à tração de misturas asfálticas}

O ensaio de resistência à tração por compressão diametral permite a determinação da resistência à tração de corpos de prova cilíndricos de misturas asfálticas, seu procedimento consiste da aplicação progressiva de dada carga até a ruptura, por separação das duas metades do corpo de prova, num plano diametral vertical. $O$ 
ensaio foi realizado de acordo com DNER $138 / 94$ na temperatura de $25^{\circ} \mathrm{C}$, e o valor numérico da propriedade foi determinada a partir da expressão:

$$
\sigma_{R}=\frac{2 F}{\pi d h}
$$

Onde:
$\sigma_{R}$ é a resistência à tração, em MPa;
F é a carga de ruptura, em N;
d é o diâmetro médio do corpo-de-prova, em mm;
h é a altura média do corpo-de-prova, em $\mathrm{mm}$.

\subsection{IMPORTÂNCIA DO USO DE ADITIVOS OU MODIFICADORES}

O estudo e o desenvolvimento de misturas asfálticas densas que possuam melhor desempenho, principalmente com relação a durabilidade e manutenção de propriedades como a resistência do pavimento asfáltico quando submetido a carregamentos de tráfego a altas temperaturas, ou a da flexibilidade quando submetido a baixas temperaturas, motivam a procura de materiais que possam ser usados como aditivos e modificadores.

Atualmente, além dos ligantes asfálticos convencionais, há uma gama de asfaltos modificados, propiciando a seleção de um material mais ajustado às solicitações e variações climáticas. Os ligantes asfálticos podem ser modificados mediante a adição direta de materiais diversos como asfaltos naturais, polímeros naturais e artificiais com objetivo de melhorar suas propriedades reológicas e reduzir sua suscetibilidade às ações da temperatura e ao tempo de aplicação de carga.

Apesar das vantagens obtidas pela modificação direta do ligante (modificadores) ou a partir da adição de produtos à mistura asfáltica (aditivos), ela somente se recomenda se não acarretar prejuízo das operações de usinagem, espalhamento e compactação, assim como da coesão da mistura asfáltica, já que esse tipo de asfalto normalmente apresenta maior rigidez, módulo de resiliência, resistência à deformação permanente e resistência à tração estática, quando comparadas a misturas de mesma faixa granulométrica e asfaltos menos consistentes (Little, 2001). 
O grande desafio de grande parte dos pesquisadores da atualidade é promover o desenvolvimento de materiais ambientalmente corretos, ou o mais próximo disso possível, que promovam os melhoramentos desejáveis ao pavimento asfáltico, de maneira a atender as condições de contorno de projeto, promovendo o desenvolvimento sustentável, que pode ser exemplificado encontrando finalidade para um rejeito industrial, ou com a redução do gasto com energia e da quantidade de materiais utilizados, ou a redução da emissão de gases que poluam o ambiente durante a usinagem da mistura asfáltica, com o menor custo possível.

Os asfaltos modificados por borracha de pneu moída, por exemplo, apresentam ganho de consistência quando comparados a do ligante original (puro), e isto resulta em melhora das propriedades reológicas do ligante asfáltico, principalmente aquelas relacionadas a parâmetros de deformação permanente, e estudos indicam que com o envelhecimento do asfalto ocorre um ganho da resistência à fadiga (Faxina, 2006). Como conseqüência, as misturas com asfalto-borracha apresentam melhoras em sua flexibilidade, que "acelera" a dissipação da energia de deformação armazenada devida à solicitação do carregamento (Bernucci et al., 2002).

Apesar das vantagens do emprego do asfalto-borracha, ainda devem ser solucionados dois problemas: a perda de trabalhabilidade da mistura devido ao aumento de viscosidade do ligante asfáltico e problemas relativos à estabilidade à estocagem do asfalto-borracha. Algumas soluções têm sido testadas a partir da adição de um óleo extensor (Faxina, 2006).

Já as misturas com polímeros tipo estireno-butadieno-estireno (SBS), em contra partida à obtenção de misturas mais flexíveis, mais resistentes à deformação permanente e às trincas térmicas, menos suscetíveis à temperatura, ainda se esbarra em problemas relacionados ao custo do produto. Alguns estudos têm mostrado que a combinação de ácido polifosfórico com esses polímeros permite reduzir a proporção de polímero a ser adicionada ao ligante asfáltico, o que reduz a viscosidade do ligante modificado, mas proporcionando propriedades reológicas tão adequadas quanto às do ligante asfáltico modificado apenas com o polímero (Martin e Baumgardner, 2006).

Outro tipo de material que vem sendo objeto de estudo em muitas pesquisas é o fíler (ou material de enchimento), que pode atuar como (a) material inerte, promovendo o 
fechamento da mistura e aumentando sua estabilidade (pó-de-pedra) ou como (b) material ativo, alterando a trabalhabilidade da mistura, enrijecendo o mástique e contribuindo para o aumento das resistências à deformação permanente, ao envelhecimento e ao dano por umidade (Gouveia, 2006).

A cal, em especial, tem vantagem em relação a outros fíleres (cimento Portland e o pó de pedra), que se deve ao tamanho das suas partículas, uma vez que, em geral, cerca de $80 \%$ delas têm diâmetros menores ou iguais a $20 \mu \mathrm{m}$ e, por isso, maiores quantidades de cal podem se concentrar no ligante asfáltico disponível/efetivo e promover mudanças nas suas características originais (Bernucci, 2007).

Os mecanismos pelos quais as cales atuam ainda não são completamente entendidos e as pesquisas destinadas à compreensão do seu efeito nas misturas asfálticas indicam comportamentos diversos e, por vezes, antagônicos, apontando ora benefícios, como os aumentos da estabilidade e das resistências ao envelhecimento e ao dano por umidade, ora malefícios, como o enrijecimento do mástique redundando na redução da resistência à fadiga do ligante e das misturas asfálticas e tendência de enrijecimento prematuro do ligante (Majidzadeh e Brovold, 1968; Hicks, 1991, Epps e Little, 2001; Sebaaly et al. 2001; Leite e Motta, 2002).

\subsection{ADIÇÃO DE CAL}

Um grande número de aditivos é usado para redução da sensibilidade ao dano por umidade da mistura asfáltica e stripping em todo o mundo. O mais utilizado é a cal hidratada. Outros aditivos muito utilizados são as aminas, polímeros, cimento portland, cinzas e escória de alto-forno. Muitos construtores preferem aditivos líquidos devido à facilidade de uso.

A cal hidratada cria benefícios múltiplos para a mistura asfáltica. A literatura apresenta uma grande quantidade de informação a respeito do uso da cal hidratada para melhorar a sensibilidade ao dano por umidade. No entanto, estudos recentes demonstram que a cal também gera outros efeitos na mistura asfáltica, especialmente quando a cal atua como um fíler ativo, antioxidante, e como um aditivo que reage com argilas finas. Esses mecanismos criam múltiplos benefícios para os pavimentos (Little, 2001): 
a) Cal hidratada atuando como um fíler mineral, endurecendo o ligante asfáltico e a mistura;

b) Melhora da resistência à fratura nas baixas temperaturas;

c) Altera favoravelmente a oxidação e interage com produtos da oxidação, reduzindo seus efeitos deletérios;

d) Altera propriedades plásticas dos finos com a melhora da estabilidade e da durabilidade da mistura asfáltica.

Desse modo, a cal hidratada é um aditivo que pode aumentar a vida útil do pavimento e melhorar o seu desempenho através de diversos mecanismos.

Segundo Little (2001), o efeito da cal como fíler no asfalto reduz o potencial de deformação em altas temperaturas, especialmente durante o início da vida útil do pavimento, quando é mais suscetível à deformação permanente. O fíler da cal hidratada geralmente endurece e reforça o filme de asfalto. Além disso, a cal deixa a mistura asfáltica menos sensível aos efeitos da umidade, melhorando a ligação agregado-asfalto, que sinergicamente melhora a resistência à deformação permanente. Como a mistura envelhece devido à oxidação, a cal hidratada reduz não somente a taxa de oxidação, mas também o dano resultante do produto da oxidação. Esse efeito mantém o asfalto com boa resistência e o torna altamente suscetível à ruptura por fadiga e térmica. Sinergicamente, o fíler afetado pela cal hidratada dispersa no asfalto melhora a resistência à fratura e às trincas.

Somando a esses efeitos, a adição da cal hidratada aos agregados que têm finos plásticos podem melhorar os mecanismos de troca catiônica, floculação/aglomeração e reações pozolânicas. Esse processo torna o agregado fino muito menos suscetível à umidade pela redução de sua capacidade de atrair e "reter" água (Little, 2001).

Diversos ensaios com ligantes e misturas asfálticas permitiram concluir melhora no desempenho do pavimento com o uso de cal hidratada em altas temperaturas 
(resistência à deformação permanente), resistência à ruptura por fadiga, e ruptura térmica. Lesueur, Little, and Epps ${ }^{3}, 1998$ apud Little, 2001 concluem que:

a) Cal hidratada não é simplesmente um fíler inerte, já que reage com asfalto, as partículas de cal geralmente absorvem componentes polares do ligante, essa absorção inter-camada faz da cal hidratada um aditivo muito efetivo. O nível de reação asfalto-cal é chamado de dependência do asfalto;

b) O fíler "ativo" responde sensivelmente às variações de temperatura conforme se intensifica esse efeito. Em altas temperaturas o efeito do fíler é mais pronunciado; e em temperaturas baixas, as variações de suas características são moderadas;

c) Uma interação físico-química entre a cal hidratada e o asfalto pode ser observada através de (a) modelos reológicos, (b) ressonância magnética nuclear, e (c) microscopia eletrônica de varredura;

d) A interação físico-química é o mecanismo fundamental que fornece uma base para explicar o efeito multifuncional da cal no asfalto. Esses efeitos incluem: (a) redução do endurecimento oxidativo, (b) melhora da resistência à deformação permanente, (c) melhora da ruptura nas baixas temperaturas, e (d) melhora da resistência à ruptura por fadiga.

A cal hidratada é um agente que melhora o desempenho de misturas asfálticas de várias maneiras. Nuñez et al. (2007) afirmam que a cal hidratada melhora a adesividade ligante-agregado, reduz a formação de afundamentos de trilhas de roda, bem como reduz o trincamento e o envelhecimento (oxidação) da camada asfáltica, contribuindo para a formação de pavimentos que apresentarão elevado desempenho por muitos anos. O grande conjunto de benefícios resultantes da adição de cal hidratada a misturas asfálticas tem como resultado a geração de um produto de elevado desempenho. Embora benefícios tenham sido descritos separadamente,

${ }^{3}$ LESUEUR, D., LITTLE, D.N. and EPPS, J.A. Effect of Hydrated Lime on the Rheology, Fracture and Aging of Bitumen and Asphalt. Paper Presented at Lhoist HMA Symposium, Dusseldorf, Germany, June 1998. 
todos trabalham complementando-se, contribuindo de várias maneiras na melhoria do produto final.

Johannson (1998) pesquisou uma extensa revisão na literatura sobre o uso da cal no pavimento asfáltico e conduziu uma pesquisa adicional na reação de cal com a mistura asfáltica. Algumas das principais conclusões foram:

a) Adição de dois por cento do peso da mistura asfáltica de cal produz um significante aumento lento da rigidez, mas não endurece o asfalto. Além disso, o asfalto modificado com cal demonstra um grande potencial para dissipar energia através da deformação (em baixas temperaturas) em relação ao asfalto não modificado. Esse é um efeito positivo em baixas temperaturas para evitar as trincas por fadiga;

b) Além do aumento do efeito do fíler na rigidez em baixas temperaturas, a energia que aumenta bruscamente no momento da ruptura, passa a ser contida por mais tempo, reduzindo a fragilidade da mistura asfáltica, essa energia é chamada de tenacidade à ruptura;

c) O uso da cal hidratada reduz mais o envelhecimento em altas temperaturas do que em baixas temperaturas.

Bianchetto et al. (2007) afirmam que apesar das vantagens, a adição de fíler deve ser racionalmente controlada por causa do tipo e conteúdo do fíler, que deve ser determinado de acordo com as propriedades físicas e volumétricas desejadas. Porém, o uso descontrolado e sem projeto do fíler pode causar um efeito contrário ao esperado para a mistura asfáltica. Por isso, a concentração de fíler crítica é atingida quando o mástique começa a apresentar características de endurecimento exacerbado, gerando uma mistura asfáltica mais frágil, prejudicando características que se esperava melhorar, como flexibilidade, coesão e durabilidade. Os autores concluíram que apesar das limitações, o efeito protetor do fíler na mistura asfáltica convencional com relação ao envelhecimento é compensatório, mesmo com o pequeno ganho que se obtém na viscosidade do pavimento.

Jimenez et al. (2008) observaram que não existe problema no uso de fíler de agregados calcários contanto que ocorra um controle rigoroso de sua 
homogeneidade e qualidade, especialmente se tratando dos finos e atividade química de seus componentes, permitindo estimar sua característica físicas e mecânicas.

Existem diversas maneiras de incorporação da cal na mistura asfáltica, duas das mais usuais na indústria do asfalto são a incorporação tida como "a seco", quando a cal é misturada ao agregado e posteriormente o ligante asfáltico é misturado ao agregado, e quando a incorporação da cal é feita diretamente ao ligante, e depois o agregado é inserido para formar a mistura asfáltica. Sebaaly et al. (2007) concluíram que com base nas propriedades mecânicas das misturas asfálicas aditivadas com cal misturada "a seco", ou diretamente ao ligante asfáltico, com relação ao dano a umidade, submetendo o corpo-de-prova ao condicionamento (AASHTO T 283), que a mistura "a seco" é mais estável, menos suscetível à deformação permanente, e menos suscetível ao dano por umidade, porém essa comparação apresenta um resultado de resistência à ruptura praticamente idêntica para ambos os modos de mistura da cal.

Neves Filho et al. (2007), à luz de resultados dos ensaios de módulo de resiliência e resistência à tração, utilizaram $3 \%$ em peso de cal hidratada e concluíram, comparativamente a quatro dopes ( $\mathrm{A}, \mathrm{B}, \mathrm{C}$ e D; não identificados pelos autores), aplicados como $0,5 \%$ em peso do ligante, que o dope $\mathrm{B}$ e a cal hidratada apresentaram maior eficiência na melhoria da adesividade entre o ligante asfáltico e o agregado.

Lutif et al. (2008) concluíram que a adição de cal seca em agregados préumedecidos parece ser o método mais eficiente de aplicação de cal hidratada. A mistura tratada com cal seca foi a mais resistente ao dano devido à umidade. A mistura tratada com lama de cal pode apresentar bom comportamento mecânico se for utilizada com um teor correto da relação cal/água. A perda de adesão das misturas foi reduzida quando a cal hidratada foi adicionada, o que indica que 0 tratamento com cal hidratada aumenta o poder ligante na interface CAP-agregado, reduzindo assim o dano devido à umidade. A adição de fíler mineral reduziu o dano à umidade em misturas asfálticas após serem submetidas a um ciclo de congelamento e descongelamento (C-D). No entanto, após múltiplos ciclos de C-D, o 
efeito da adição de fíler mineral não se mostrou eficaz no combate ao dano devido à umidade.

Segundo Nuñez et al. (2007), a adição de cal hidratada dá origem a misturas asfálticas a quente com maior módulo de resiliência (mais resistentes a deformações permanentes) e maior resistência à tração. As melhorias nessas propriedades mecânicas dependem significativamente da qualidade da cal. Cales com baixos teores de $\mathrm{Ca}(\mathrm{OH})_{2}$ não produzirão tais efeitos benéficos, um teor da ordem de $90 \%$ parece suficiente para otimizar a mistura asfáltica em termos de módulo de resiliência, resistência à tração e adesividade. Pequenos teores de cal são necessários para produzir misturas asfálticas de elevado desempenho. 0 teor de $1 \%$ mostrou-se suficiente para promover aumentos da ordem de $70 \%$ no módulo de resiliência e de $30 \%$ na resistência à tração. Mas esses resultados correspondem a cales com teores de $\mathrm{Ca}(\mathrm{OH})_{2}$ da ordem de $90 \%$. A adoção de um tempo de espera de 48 horas entre a mistura dos materiais e a compactação dos corpos-de-prova ("marinados") não trouxe benefícios adicionais em termos de módulo e resistência, exceto para a cal C (a de mais baixo teor de $\mathrm{Ca}(\mathrm{OH})_{2}$ ). Essa espera produziu, sim, melhora adicional na adesividade agregado-ligante.

A cal pode ser adicionada à mistura asfáltica durante o processo de produção por diversos métodos. Técnicas usuais de adição de cal na mistura asfáltica consistem na adição de cal seca no misturador no momento da adição do ligante asfáltico, porém a cal pode ser adicionada ao agregado pelo processo de "marinação" (adição da cal ao agregado e deixar descansar por 48 horas, recomenda-se o uso dentro de 45 dias), e só depois o ligante asfáltico se junta ao agregado para formar a mistura asfáltica. A cal não deve ser adicionada à mistura asfáltica antes de ser completada sua hidratação. Se acontecer, reagiria com $\mathrm{Ca}(\mathrm{OH})_{2}$ quando em contato com água durante a vida de serviço do pavimento. Essa reação $\left(\mathrm{CaO}\right.$ para $\left.\mathrm{Ca}(\mathrm{OH})_{2}\right)$ é expansiva e poderia criar uma variação do volume da mistura asfáltica e perda na resistência e desempenho (Little, 2001).

Ainda segundo esse autor, a cal pode ser adicionada à mistura asfáltica com o uso de misturadores de tambor ou recipiente apropriado. A cal seca pode ser adicionada ao agregado seco ou ao agregado úmido. Para a mistura da cal ao agregado com superfície úmida, a porcentagem em massa que utilizado pode aumentar de dois a 
três por cento acima da mistura da cal ao agregado com superfície seca. A umidade ioniza o agregado e ajuda a distribuí-lo na superfície do agregado. Agregado tratado com cal pode ser estocado por "marinação" ou pode ser misturado ao ligante asfáltico para produção da mistura asfáltica. O uso de lama de cal tem várias vantagens: melhorar a resistência da mistura asfáltica ao stripping, redução da poeira associada com a adição de cal seca ao agregado, e melhorar a distribuição da cal no agregado.

No entanto, o uso de lama de cal adiciona mais água do que é convencionalmente usado nas aplicações com cal convencionais e pode aumentar consideravelmente a quantidade de água do agregado, quando adicionado o ligante asfáltico para produção da mistura asfáltica, portanto é relevante e deve ser levada em consideração. Outro impecilho desse tipo de adição é de que o preparo da lama requer a aquisição ou aluguel de equipamento especializado para preparar a lama de cal no campo.

"Marinação" ou estoque de agregado tratado com cal facilita a utilização deste material. As vantagens da "marinação" são: a redução da umidade do agregado enquanto o agregado é estocado, a cal pode ser misturada ao agregado separada da produção da mistura asfáltica, reduzindo o tempo de produção da mistura asfáltica, o que pode proporcionar alguma vantagem econômica, e pode resultar no aumento da resistência à umidade (particularmente quando agregados têm argilas presentes na parte fina) (Litte, 2001).

Desvantagens da "marinação": manipulação adicional do agregado, local para estocagem de agregado tratado e não tratado, e a cal pode ser lavada do agregado durante a "marinação". Carbonatação da cal marinada ao agregado em estoque pode ser um grande problema, já que pode ocorrer na superfície da estocagem (Little, 2001).

Sumarizando os métodos de adição da cal hidratada ao asfalto, podem ser: com cal hidratada no agregado seco, com cal hidratada no agregado úmido e com lama de cal no agregado (devendo descontar a água contida no agregado, quando da adição da lama), os dois últimos com opção de "marinação". 


\subsection{MODIFICAÇÃO COM PPA}

A procura constante de novos materiais que melhorem o desempenho dos pavimentos asfálticos levou ao desenvolvimento e a utilização combinada de materiais que melhorem 0 desempenho dos asfaltos modificados que visam aumentar a utilização de ligantes asfálticos. Atualmente, além dos ligantes asfálticos convencionais, há uma gama de asfaltos modificados, que proporcionam opções para atender às necessidades oneradas pelas condições do clima, onde vai ser utilizado o asfalto.

Um material muito utilizado é o polímero, e para ser eficaz, deve ser misturado com o asfalto e melhorar a resistência em altas temperaturas, sem fazer com que o asfalto fique muito viscoso nas temperaturas de mistura ou muito quebradiço em baixas temperaturas. Se usado em asfalto de rodovias, deve ser capaz de ser processado por equipamentos convencionais, e não deve apresentar características de expansividade, e tanto fisicamente como quimicamente, o polímero contido no asfalto deve ser estável durante a estocagem, preservando suas propriedades no momento de sua aplicação em campo, e certamente esse polímero tem que ser solúvel no asfalto (Giavarini et al., 1996).

Outro material, apresentado como a panacéia da pavimentação asfáltica pelo próprio fabricante da patente (Innophos ${ }^{\circledR}$ ) é o ácido polifosfórico (PPA), tido como a solução para toda condição de contorno almejada para qualquer projeto de pavimento asfáltico, em qualquer situação de agressividade, salvo variações de concentração de uso do próprio material.

Muitas vezes o custo do polímero inviabiliza o seu uso, em função da quantidade utilizada para obtenção das propriedades desejadas para atender as características de projeto, por isso a combinação com outros materiais como o PPA tem sido estudado para reduzir a quantidade de polímero na mistura asfáltica.

A modificação de ligantes asfálticos por ácido polifosfórico não é uma prática recente (Baumgardner et al., 2005). Desde a década de 1970, ligantes asfálticos têm sido modificados com ácido polifosfórico, na tentativa de aumentar a viscosidade sem reduzir substancialmente a penetração, na tentativa de obter ligantes asfálticos com 
maior resistência à deformação permanente, sem prejudicar a resistência à formação de trincas de origem térmica.

Baumgardner et al. (2005) afirmam que mais recentemente, o ácido polifosfórico tem sido empregado para ampliar a faixa de temperatura de trabalho dos ligantes asfálticos, isto é, o grau de desempenho segundo a especificação Superpave. Segundo estes autores, a adição de ácido polifosfórico pode proporcionar melhoria das propriedades reológicas do ligante asfáltico nas temperaturas altas, sem afetar o "Performance Grade" (PG) do material nas temperaturas baixas.

Esses autores afirmam ainda que a classificação por desempenho, o PG é o mais indicado para grandes carregamentos, ou tráfegos lentos em altas temperaturas. Por exemplo, uma classificação padrão PG 64-22 para tráfego normal, poderia ser deslocada para PG 70-22 para tráfego lento e PG 76-22 para pesado lento ou condições interestaduais. Sobre essas modificações, as classificações de desempenho podem chegar a um PG 86-22, PG 92-22 e PG 98-22. Tipicamente, classificações de desempenho que extrapolam $90^{\circ} \mathrm{C}$ requerem modificação do asfalto. Enquanto que a modificação com o polímero é mais comum, o ácido polifosfórico também pode ser utilizado para melhorar as propriedades reológicas em altas temperaturas sem afetar a classificação em baixas temperaturas.

O PPA pode ser empregado como catalisador, aumentando o ponto de amolecimento sem alterar de forma expressiva a rigidez do asfalto, como aditivo direto, para melhorar o grau de desempenho em altas temperaturas, devido a relação entre os asfaltenos e o ácido polifosfórico, e como acelerador da reação entre o polímero e o ligante asfáltico, reduzindo a quantidade de polímero utilizada (Kodrat et al., 2007).

Em misturas com agregados do tipo granítico, o ácido polifósforico resulta em aumento da adesão e resistência à umidade; em agregados calcários, um bom desempenho à umidade é obtida com baixas porcentagens em peso de ácido polifosfórico (tipicamente menores que 1\%) (Maldonado et al., 2008). 


\subsubsection{Composição}

Os compostos básicos para a produção de PPA são o pentóxido de fósforo $\left(\mathrm{P}_{2} \mathrm{O}_{5}\right)$ e ácido fosfórico $\left(\mathrm{H}_{3} \mathrm{PO}_{4}\right)$. O fósforo é oxidado primeiro para pentóxido de fósforo, que cristaliza como $\mathrm{P}_{4} \mathrm{O}_{10}$. Uma vez que ele reage com água, o ácido fosfórico é produzido. Esse caminho para $\mathrm{O}_{3} \mathrm{PO}_{4}$ é conhecido como processo seco, que é usado para fornecer o material de alta pureza. O processo úmido fornece $\circ \mathrm{H}_{3} \mathrm{PO}_{4}$ da reação de ácido sulfúrico com o solo formado da rocha apatita, de formulação $\mathrm{Ca}_{3}\left(\mathrm{PO}_{4}\right)_{2} \mathrm{CaF}_{2}$ (Masson, 2008).

O PPA é um oligômero (conjunto de cadeias) de $\mathrm{H}_{3} \mathrm{PO}_{4}$. $\mathrm{O}$ material puro é produzido da dehidratação do $\mathrm{H}_{3} \mathrm{PO}_{4}$ em altas temperaturas ou pelo aquecimento de $\mathrm{P}_{2} \mathrm{O}_{5}$ disperso em $\mathrm{H}_{3} \mathrm{PO}_{4}$. $\mathrm{O}$ método da dehidratação produz cadeias curtas, assim como o método da dispersão usualmente produz cadeias com repetição de 10 unidades apenas (Masson, 2008).

O PPA é avaliado pela porcentagem de pentóxido de sódio em relação à de ácido presente no produto em questão, a nomenclatura é confusa por se tratar de uma porcentagem que pode exceder $100 \%$. Esse $100 \%$ do ácido fosfórico representa $72,4 \%$ (essa porcentagem é adotada como referência) de $\mathrm{P}_{2} \mathrm{O}_{5}$ em relação à porção ácida calculado pela relação de $\mathrm{P}_{2} \mathrm{O}_{5} / \mathrm{H}_{3} \mathrm{PO}_{4}$, similarmente, o ácido pirofosfórico $\left(\mathrm{H}_{4} \mathrm{P}_{2} \mathrm{O}_{7}\right)$ contém $79,8 \%$ de $\mathrm{P}_{2} \mathrm{O}_{5}$ calculado da relação $\mathrm{P}_{2} \mathrm{O}_{5} / \mathrm{H}_{4} \mathrm{P}_{2} \mathrm{O}_{7}$, que representa a partir da relação $79,8 \% / 72,4 \%=110 \%$, portanto esse ácido é classificado como $110 \%$.

\subsubsection{Reações com PPA}

Todos os ácidos fosfóricos são gerados na natureza sem a necessidade de oxidação, em contraste aos ácidos minerais, assim como o ácido nítrico, por exemplo. Na presença de água, a dissociação do ácido fosfórico e o rearranjo dos prótons seguem para o equilíbrio das cargas dos elementos envolvidos. Com o aumento do comprimento da cadeia, ocorre similarmente o aumento da sua acidez. O ácido polifosfórico dimérico, possui dois hidrogênios ácidos (elemento carregado positivamente, capaz de liberar um próton), o trimérico, três hidrogênios ácidos, assim, tão longa quanto pode ser a cadeia do ácido polifosfórico, mais ácido ele 
pode ser, em função da repetição de cada unidade que libera um próton e estabiliza a carga pela ressonância (Masson, 2008).

O PPA é misturado e reage com o asfalto. Com os muitos grupos funcionais do asfalto, no entanto, a reação exata entre o PPA e o asfalto pode somente ser inferida, já que o asfalto possui características químicas variáveis, em função de sua origem, processo de destilação, nível de pureza, e elementos misturados à cadeia carbônica do asfalto (Masson, 2008).

\subsubsection{Propriedades do PPA}

Filipis (1995) concluiu que o efeito da adição de $\mathrm{H}_{3} \mathrm{PO}_{4}$ e $\left(\mathrm{HPO}_{3}\right)_{\mathrm{n}}$ melhora a resistência ao envelhecimento de asfaltos naftênicos, com pequenas quantidades de componentes fosfóricos. Mesmo com a boa melhora na resistência ao envelhecimento, as maiores vantagens do uso do ácido polifosfórico na mistura asfáltica são a economia oriunda com o ganho na resistência e a melhora nas propriedades físicas, como a elasticidade, de baixas temperaturas.

Giavarini et al. (1996) concluíram que um asfalto modificado com um polímero heterofásico pode ser obtido por um pré-tratamento com uma pequena porção de ácido polifosfórico. De fato, o ácido melhora a homogeneização do polímero, produzindo boas características quanto à estabilidade e propriedades. A adição de 2 - 3\% de polímero em asfalto tratado com ácido é obtido um asfalto com mesma estabilidade e características de um asfalto sem tratamento com ácido, e com 5 $6 \%$ de polímero. Portanto o custo do tratamento é mais que contrabalanceado pela economia de polímero quando do uso de PPA, além disso, o produto obtido é estável durante a estocagem em altas temperaturas por longos períodos.

Baumgardner et al. (2005) estudaram dois asfaltos modificados com PPA e alteração na microestrutura e composição investigadas com Microscopia de Forças Atômicas (AFM), Cromatografia de permeação-gel (GPC) e Análise Química. O grau de desempenho de ambos os asfaltos foi aumentado pelo PPA, que foi observado no AFM como um endurecimento de umas das duas fases principais no asfalto, em um asfalto o PPA afetou a fase dispersa, em outra, afetou a matriz. O efeito do endurecimento do PPA é, portanto dependente do tipo de asfalto. 
Vários mecanismos foram estudados na tentativa de explicar o efeito da modificação com PPA no endurecimento de ligantes asfálticos: formação de canalículos de PPA, formação de cadeias aromáticas, cruzamento de ligação da vizinhança de segmentos do asfalto e a formação de conjunto de íons. Uma análise detalhada físico-química do asfalto modificado com PPA requer a determinação de qual mecanismo prevalece (Baumgardner et al., 2005).

Kodrat et al. (2007) concluíram que o efeito do PPA é significante nas propriedades da classificação Superpave, aumentando as propriedades de alta temperatura, dependendo da fonte do asfalto, e permanecendo inalteradas, para muitos ligantes asfálticos, as propriedades de baixa temperatura. Afirmam ainda que para a ruptura à fadiga a longo prazo na temperatura ambiente, houve um impacto negativo em suas propriedades, por isso, essa característica demanda todo cuidado quando o PPA é utilizado em áreas onde a ruptura por fadiga é o defeito dominante; em relação ao processo de envelhecimento e quanto à ruptura frágil, a modificação foi insignificante.

Maldonado et al. (2008) concluíram que a adição de pequenas concentrações fornece vários benefícios como aumento da classificação do grau de desempenho para as altas temperaturas, sem perdas nas propriedades nas baixas temperaturas, aumento na aderência do ligante asfáltico ao agregado, melhorando a sensibilidade à umidade da mistura asfáltica, resultando em benefícios anti-stripping similares aos obtidos da amina e da cal hidratada. Os mesmos autores afirmam também que não há efeitos prejudiciais da utilização do PPA quando usado junto com a cal hidratada e dos líquidos anti-striping, e que houve significante melhora da resistência à deformação permanente.

A classificação Superpave do grau de desempenho melhorou do PG 64-22 para o PG 64-28 e do PG 64-28 para PG 70-28 como resultado da modificação com 0,5\% de ácido polifosfórico (105\%) em peso e $0,45 \%$ de ácido polifosfórico $(115 \%)$ em peso, respectivamente. Estudos em relação à sensibilidade à umidade demontraram que o ácido melhora as propriedades quando adicionados a cal hidratada ou líquidos anti-strip. Os melhores resultados da sensibilidade à umidade resultaram da combinação entre ácido polifosfórico e cal hidratada (Maldonado et al., 2008). 
Leite et al. (2004) concluiu que a mistura asfáltica preparada com modificação por ácido teve fechamento dos agregados pela película de ligante asfáltico e resultaram em valor de resistência à tração da mesma ordem de grandeza daqueles obtidos com ligantes oriundos de cru naftênico (petróleo venezuelano) tipo CAP 85/100. Fernandes et al. (2008) concluíram que analisando as propriedades da mistura asfáltica em altas temperaturas o ligante modificado com ácido polifosfórico possui comportamento térmico semelhante ao do ligante modificado.

Formulações de misturas asfálticas típicas usadas na França com ligantes modificados com PPA com ou sem polímeros apresentaram desempenhos aceitáveis, e aumentou a rigidez do ligante sem afetar as propriedades de baixa temperatura, assim como a classificação Superpave do grau de desempenho aumentou a temperatura para altas e baixas temperaturas, aumentando a faixa de temperatura que podem ser submetido o pavimento sem prejudicar as propriedades da mistura asfáltica quando solicitado pelas cargas do tráfego, proporcionando o benefício do uso de PPA para aumentar a vida útil do pavimento (Christian, 2008). 


\section{MATERIAIS E MÉTODOS}

\subsection{INTRODUÇÃO}

Neste capítulo é apresentado o programa de experimentos desta pesquisa, que avaliou as propriedades mecânicas, volumétricas, e de durabilidade de misturas asfálticas densas compostas por diferentes tipos e concentrações de ligantes asfálticos, modificadores e aditivos.

Apresentam-se assim, as características dos agregados, ligantes asfálticos, aditivos e modificadores utilizados, as misturas asfálticas testadas são, basicamente, resultantes da combinação fatorial de dois fatores: o aditivo, cal hidratada, variando em três teores e o modificador, ácido polifosfórico, variando em três teores.

\subsection{AGREGADOS}

\subsubsection{Tipo e distribuição granulométrica}

Os agregados utilizados são de origem granítica, oriundos da Usina Paulista de Britagem Pedreira São Jerônimo Ltda, localizada na cidade de Valinhos, SP. Os agregados foram manipulados e enquadrados no centro faixa MIX IV-B do Asphalt Institute. O Tamanho Máximo Nominal (TMN) da granulometria utilizada é a $12,7 \mathrm{~mm}$.

A Faixa granulométrica MIX IV-B do Asphalt Institute é apresentada na Tabela 3.1.

Tabela 3. 1: Faixa Granulométrica MIX IV B do Asphalt Institute

\begin{tabular}{|c|c|c|c|}
\hline \multirow[b]{2}{*}{$\begin{array}{c}\text { Peneira } \\
\text { (mm) }\end{array}$} & \multicolumn{2}{|c|}{ Faixa Mix IV B } & \multirow[b]{2}{*}{$\begin{array}{c}\text { Centro da } \\
\text { faixa }\end{array}$} \\
\hline & $\begin{array}{l}\text { Limite } \\
\text { inferior }\end{array}$ & $\begin{array}{l}\text { Limite } \\
\text { superior }\end{array}$ & \\
\hline 25,4 & 100 & 100 & 100,0 \\
\hline 19,1 & 100 & 100 & 100,0 \\
\hline 12,7 & 85 & 100 & 92,5 \\
\hline 9,52 & 70 & 90 & 80,0 \\
\hline 4,76 & 50 & 70 & 60,0 \\
\hline 2,38 & 35 & 50 & 42,5 \\
\hline 0,59 & 18 & 29 & 23,5 \\
\hline 0,297 & 13 & 23 & 18,0 \\
\hline 0,149 & 8 & 16 & 12,0 \\
\hline 0,074 & 4 & 10 & 7,0 \\
\hline
\end{tabular}




\subsubsection{Características físicas}

Os agregados pétreos foram submetidos ao ensaio de "Abrasão Los Angeles - $A_{n}$ " (DNER - ME 35/98) na graduação $B$, sendo ensaiadas três amostras com essas condições. Os resultados obtidos foram de $24,3 \%$, de onde se conclui que o agregado atende à especificação do DNER, que estabelece desgaste igual ou inferior a $40 \%$.

Além dos ensaios de peneiramento e "Abrasão Los Angeles", os agregados foram submetidos aos ensaios de densidade aparente do agregado grosso (ASTM 127 01) e a densidade aparente do agregado miúdo (ASTM 128 - 01); assim, os ensaios foram realizados para as frações pó de pedra, pedrisco e pedra 1. Os resultados obtidos para a massa específica aparente, real e da absorção são apresentados nas Tabelas 3.3, 3.4 e 3.5 para o pó de pedra, pedrisco e pedra 1, respectivamente.

Tabela 3.2. Massas específicas e absorção do pó de pedra.

\begin{tabular}{lll}
\hline $\begin{array}{l}\text { Massa específica aparente } \\
\left(\mathrm{g} / \mathrm{cm}^{3}\right)\end{array}$ & $\begin{array}{l}\text { Absorção } \\
(\%)\end{array}$ & $\begin{array}{l}\text { Massa específica real } \\
\left(\mathrm{g} / \mathrm{cm}^{3}\right)\end{array}$ \\
\hline 2,487 & 2,63 & 2,661 \\
\hline
\end{tabular}

Tabela 3.3. Resultado do ensaio de Massa específica do pedrisco.

\begin{tabular}{llll}
\hline Amostra & $\begin{array}{l}\text { Massa específica aparente } \\
\left(\mathrm{g} / \mathrm{cm}^{3}\right)\end{array}$ & $\begin{array}{l}\text { Absorção } \\
(\%)\end{array}$ & $\begin{array}{l}\text { Massa específica real } \\
\left(\mathrm{g} / \mathrm{cm}^{3}\right)\end{array}$ \\
\hline 1 & 2,574 & 0,69 & 2,620 \\
2 & 2,561 & 0,94 & 2,624 \\
3 & 2,567 & 0,81 & 2,621 \\
\hline Média & 2,567 & 0,815 & 2,622 \\
\hline
\end{tabular}

Tabela 3.4. Resultado do ensaio de Massa específica da Pedra 1.

\begin{tabular}{cccc}
\hline Amostra & $\begin{array}{l}\text { Massa específica aparente } \\
\left(\mathrm{g} / \mathrm{cm}^{3}\right)\end{array}$ & $\begin{array}{l}\text { Absorção } \\
(\%)\end{array}$ & $\begin{array}{l}\text { Massa específica real } \\
\left(\mathrm{g} / \mathrm{cm}^{3}\right)\end{array}$ \\
\hline 1 & 2,613 & 0,46 & 2,644 \\
2 & 2,592 & 0,55 & 2,629 \\
3 & 2,597 & 0,49 & 2,631 \\
\hline Média & 2,601 & 0,496 & 2,635 \\
\hline
\end{tabular}

3.2.3 Procedimento de seleção, manuseio e preparação do agregado

Os agregados coletados na pedreira foram previamente secos em estufa por no mínimo $12 \mathrm{~h}$, posteriormente separados no peneirador mecânico, tomando os devidos cuidados com as peneiras de graduação menores ou iguais a $0,42 \mathrm{~mm}$, para 
proporcionar uma boa distribuição da frações em cada peneira, sendo o peneiramento feito manualmente.

Após a separação das quantidades de material de cada peneira que compõem a faixa MIX IV B do Asphalt Institute, os agregados foram colocados em sacos plásticos, nas quantidades suficientes para confecção de um corpo-de-prova (1200g), de maneira a se enquadrarem no centro da faixa MIX IV B, conforme proporções apresentadas na Tabela 3.6.

Tabela 3.5. Porcentagens e massa de cada fração do agregado para enquadramento no centro da faixa MIX IV B do Asphalt Institute.

\begin{tabular}{|c|c|c|c|}
\hline \multicolumn{4}{|c|}{ FAIXA MIX IV B } \\
\hline \multicolumn{2}{|c|}{ Abertura $(\mathrm{mm})$} & \multirow{2}{*}{$\%$ do material } & \multirow{2}{*}{ Massa do material $(\mathrm{Kg})$} \\
\hline Passado & Retido & & \\
\hline 25,4 & 19,1 & 0 & 0 \\
\hline 19,1 & 12,7 & 7,5 & 0,09 \\
\hline 12,7 & 9,52 & 12,5 & 0,15 \\
\hline 9,52 & 4,76 & 20 & 0,24 \\
\hline 4,76 & 2,38 & 17,5 & 0,21 \\
\hline 2,38 & 0,59 & 19 & 0,228 \\
\hline 0,59 & 0,297 & 5,5 & 0,066 \\
\hline 0,297 & 0,149 & 6 & 0,072 \\
\hline 0,149 & 0,074 & 5 & 0,06 \\
\hline \multirow[t]{2}{*}{0,074} & fundo & 7 & 0,084 \\
\hline & Total & 100 & 1,2 \\
\hline
\end{tabular}

\subsection{ADITIVOS E MODIFICADORES}

Nas misturas utilizou-se como aditivo a cal hidratada calcítica tipo $\mathrm{CH} 1$ em substituição de parte do material passante na peneira ${ }^{\circ} 200$ (abertura de $0,075 \mathrm{~mm}$ ), nas porcentagens de 1,5 e 3,0\% em peso de fíler substituído. A Tabela 3.7 mostra algumas características dessa cal. 
Tabela 3.6. Composição química e características granulométricas da cal utilizada

\begin{tabular}{|c|c|c|}
\hline Parâmetros & Porcentagens (\%) & Norma Técnica \\
\hline$\overline{P P C}$ & 24,71 & \multirow{6}{*}{ NBR $6473 / 2000$} \\
\hline $\mathrm{MgO}$ & 0,48 & \\
\hline $\mathrm{Al}_{2} \mathrm{O}_{3}$ & 0,34 & \\
\hline $\mathrm{SiO}_{2}$ & 0,86 & \\
\hline CaO TOTAL & 72,69 & \\
\hline $\mathrm{Fe}_{2} \mathrm{O}_{3}$ & 0,21 & \\
\hline CaO DISPONÍVEL & 68,10 & NBR 9554/93 \\
\hline $\mathrm{CO}_{2}$ & 1,13 & PO-0073* \\
\hline $\mathrm{CaCO}_{3}$ & 4,59 & NBR 13293 \\
\hline $\mathrm{Ca}(\mathrm{OH})_{2}$ & 90,06 & NBR 13294 \\
\hline S ( ENXOFRE ) & 0,18 & $\mathrm{PO}-0073^{*}$ \\
\hline $\mathrm{H}_{2} \mathrm{O}$ & 1,15 & NBR $6472 / 93$ \\
\hline \multicolumn{3}{|c|}{ * Procedimento interno - Combustão Direta } \\
\hline \multicolumn{3}{|l|}{ Granulometria } \\
\hline Malha & Retido acumulado & Norma Técnica \\
\hline $30 \#$ & 0,00 & \multirow{4}{*}{ NBR 9552/86 } \\
\hline $0,30 \mathrm{~mm}$ & 0,00 & \\
\hline $0,149 \mathrm{~mm}$ & 0,13 & \\
\hline $0,074 \mathrm{~mm}$ & 0,84 & \\
\hline
\end{tabular}

O modificador utilizado nesta pesquisa é um ácido polifosfórico - 105\% (Innovalt ${ }^{\circledR}$ E200) fornecido pela Innophos, localizada em Nashville, Tenesse, EUA e, segundo a empresa, o produto é especificado para atuar combinado a asfaltos modificados com polímeros e borracha de pneu, melhorando seu desempenho.

\subsection{LIGANTES ASFÁLTICOS}

Neste trabalho utilizou-se um ligante asfáltico tipo CAP 50/70 proveniente da Refinaria Henrique Lage (REVAP), localizada em São José dos Campos - SP. A partir deste ligante asfáltico foram produzidos dois outros ligantes, um com $0,6 \%$ e outro com $1,2 \%$ de ácido polifosfórico (PPA), em peso.

Os resultados dos ensaios de caracterização dos asfaltos são apresentados nas Tabelas 3.8 a 3.10, sendo que o detalhamento para determinação da viscosidade Brookfield é apresentado na Figura 3.2 e na Tabela 3.11 (ASTM D 2493). 
Tabela 3.7. Resultados dos ensaios de caracterização do asfalto puro

\begin{tabular}{|c|c|c|c|}
\hline \multicolumn{4}{|c|}{ CAP 50/70 puro } \\
\hline \multicolumn{2}{|l|}{ Característica } & \multicolumn{2}{|c|}{ Resultado } \\
\hline \multicolumn{2}{|c|}{ Penetração, $25^{\circ} \mathrm{C}, 5 \mathrm{~s}, 100 \mathrm{~g}$} & 5,8 & $\mathrm{~mm}$ \\
\hline \multicolumn{2}{|c|}{ Ponto de amolecimento } & 49,31 & ${ }^{\circ} \mathrm{C}$ \\
\hline \multicolumn{2}{|c|}{ Índice de Susceptibilidade Térmica } & $-1,025$ & \\
\hline \multirow{3}{*}{ Viscosidade Brookfield } & $135^{\circ} \mathrm{C}$ & 350 & $\mathrm{cP}$ \\
\hline & $150^{\circ} \mathrm{C}$ & 176 & $\mathrm{cP}$ \\
\hline & $177^{\circ} \mathrm{C}$ & 65 & $\mathrm{cP}$ \\
\hline
\end{tabular}

Tabela 3.8. Resultados dos ensaios de caracterização do asfalto modificado com $0,6 \%$ de PPA.

\begin{tabular}{|c|c|c|c|}
\hline \multicolumn{4}{|c|}{ CAP $50 / 70$ com $0,6 \%$ de PPA } \\
\hline \multicolumn{2}{|l|}{ Característica } & \multicolumn{2}{|c|}{ Resultado } \\
\hline \multicolumn{2}{|l|}{ Penetração, $25^{\circ} \mathrm{C}, 5 \mathrm{~s}, 100 \mathrm{~g}$} & 4,6 & $\mathrm{~mm}$ \\
\hline \multicolumn{2}{|c|}{ Ponto de amolecimento } & 53,27 & ${ }^{\circ} \mathrm{C}$ \\
\hline \multicolumn{2}{|c|}{ Índice de Susceptibilidade Térmica } & $-0,602$ & \\
\hline & $135^{\circ} \mathrm{C}$ & 476 & $\mathrm{cP}$ \\
\hline \multirow[t]{2}{*}{ Viscosidade Brookfield } & $150^{\circ} \mathrm{C}$ & 230 & $\mathrm{cP}$ \\
\hline & $177^{\circ} \mathrm{C}$ & 80 & $\mathrm{cP}$ \\
\hline
\end{tabular}

Tabela 3.9. Resultados dos ensaios de caracterização do asfalto modificado com $1,2 \%$ de PPA.

\begin{tabular}{cccc}
\hline \multicolumn{4}{c}{ CAP 50/70 com 1,2\% de PPA } \\
\hline Característica & \multicolumn{2}{c}{ Resultado } \\
\hline Penetração, $25^{\circ} \mathrm{C}, 5 \mathrm{~s}, 100 \mathrm{~g}$ & 3,7 & $\mathrm{~mm}$ \\
Ponto de amolecimento & 56,8 & ${ }^{\circ} \mathrm{C}$ \\
& & $-0,343$ & \\
Índice de Susceptibilidade Térmica & $135^{\circ} \mathrm{C}$ & 720 & $\mathrm{cP}$ \\
Viscosidade Brookfield & $150{ }^{\circ} \mathrm{C}$ & 328 & $\mathrm{cP}$ \\
& $177^{\circ} \mathrm{C}$ & 110 & $\mathrm{cP}$ \\
\hline
\end{tabular}

Observa-se nos dados apresentados nas Tabelas 3.8 a 3.10 que a adição de PPA causa diminuição da penetração e aumento no ponto de amolecimento, isto é, a susceptibilidade térmica do ligante asfáltico diminui, assim como há aumento crescente das temperaturas de mistura e compactação das misturas à medida que se aumenta o teor de PPA.

\subsection{CONFECÇÃO DOS CORPOS-DE-PROVA}

A maioria das misturas asfálticas a quente produzidas no Estados Unidos entre os anos 1940 e 1990 foram dosadas utilizando as metodologias Marshall ou Hveem (Roberts et al., 1996). Desde 1993, porém, as universidades e departamentos de transportes norte-americanos vêm utilizando a metodologia SUPERPAVE ${ }^{\circledR}$, ainda 
em fase de testes no Brasil. Na pesquisa SHRP várias mudanças foram realizadas. Foi proposta uma metodologia distinta que consiste basicamente em estimar um teor provável de projeto através da fixação do volume de vazios e do conhecimento da granulometria dos agregados disponíveis.

A maior diferença entre este novo procedimento e o Marshall é a forma de compactação. Enquanto na dosagem Marshall, a compactação é feita por impacto (golpes), na dosagem SUPERPAVE ${ }^{\circledR}$ é realizada por amassamento (giros). Outra diferença que pode ser citada entre os dois processos é a forma de escolha da granulometria da mistura de agregados (Bernucci et al., 2007).

O projeto de mistura é todo feito utilizando o Compactador Giratório SUPERPAVE ${ }^{\circledR}$ (CGS). Trata-se de um equipamento prático e com boa reprodutibilidade, que têm as seguintes características:

- Ângulo de rotação de $1,25 \pm 0,02^{\circ}$;

- Taxa de 30 rotações por minuto;

- Tensão de compressão vertical durante a rotação de $600 \mathrm{kPa}$;

- Capacidade de produzir corpos-de-prova com diâmetros de 150 e 100mm.

\subsubsection{Temperaturas de usinagem e compactação}

A temperatura do cimento asfáltico empregado na mistura deve ser determinada para cada tipo de ligante, em função da relação temperatura-viscosidade. As curvas da viscosidade versus temperatura dos ligantes utilizados nessa pesquisa são apresentadas na Figura 3.2. Nela se pode observar que a adição do ácido polifosfórico (PPA) alterou a viscosidade do ligante asfáltico original (CAP 50/70), sendo seu efeito mais intenso com o aumento de sua concentração no ligante. Entretanto, a temperatura do ligante não deve ser inferior a $107^{\circ} \mathrm{C}$ nem superior a $177^{\circ} \mathrm{C}$. 


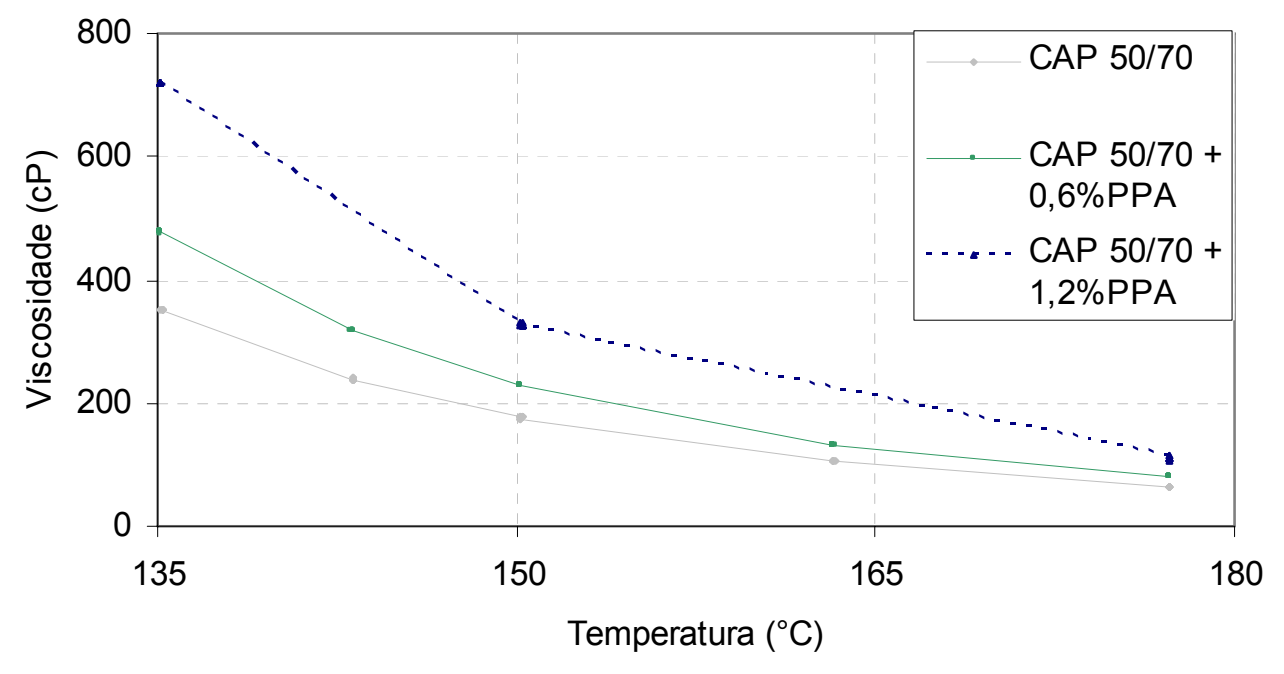

Figura 3.1. Viscosidades Brookfield dos ligantes utilizados na pesquisa

As temperaturas de usinagem e compactação (TUC) foram determinadas de acordo com a ASTM D 2493. A adoção da temperatura de usinagem observou a faixa de viscosidade de 150 a 190 cP e, para a compactação, 250 a 310 cP (ASTM D 4402), para garantir a trabalhabilidade, e não ocorra entupimento durante o bombeamento da mistura, respectivamente.

Tabela 3.10. Temperaturas de usinagem e compactação dos ligantes

\begin{tabular}{ccccc} 
& & \multicolumn{3}{c}{ Temperatura $\left({ }^{\circ} \mathrm{C}\right)$} \\
\cline { 2 - 5 } Operação & Faixa de & CAP 50/70 & CAP 50/70 + 0,6 & CAP 50/70 + 1,2 \\
& Viscosidade (cP) & (CAP Puro) & PPA & PPA \\
\hline \multirow{2}{*}{ Usinagem } & 150 & 149 & 156 & 167 \\
& 190 & 155 & 161 & 172 \\
\hline \multirow{2}{*}{ Compactação } & 250 & 142 & 144 & 152 \\
& 310 & 138 & 148 & 160 \\
\hline
\end{tabular}

A partir das TUC pode-se observar o impacto importante da adição do PPA, de modo que, em relação ao ligante asfáltico original, as temperaturas de usinagem e de compactação aumentaram em, aproximadamente, $6^{\circ} \mathrm{C}$ com adição de $0,6 \%$ de PPA de $16^{\circ} \mathrm{C}$ para a adição de $1,2 \%$ de PPA, exibindo um aumento da ordem de 1,1 a $1,3^{\circ} \mathrm{C}$ para cada $0,1 \%$ de PPA adicionado ao ligante asfáltico original.

\subsubsection{Determinação do teor de ligante de projeto}

Segundo Bernucci et al. (2007) o primeiro passo do procedimento SUPERPAVE $®$ consiste na escolha de três composições granulométricas com os materiais à 
disposição; e o passo seguinte é a compactação de corpos-de-prova (CGS) com um teor de tentativa para cada mistura (dois corpos-de-prova por mistura).

Esse passo não foi realizado, já que a metodologia SUPERPAVE® não foi aplicada integralmente, principalmente na primeira etapa, quando da escolha da composição granulométrica que melhor atendesse ao projeto devido premissa inicial, que era reproduzir uma distribuição granulométrica que tivesse uso frequente na região. Assim, foi adotado um teor de ligante inicial de 5\%, e um único tipo de distribuição granulométrica de agregado mineral, nesse caso, o agregado granítico.

As propriedades estimadas são comparadas aos critérios de projeto: $V_{v}=4 \%$ (para $\left.\mathrm{N}_{\text {projeto }}=100\right), \mathrm{VAM}>13 \%$ para TMN 12,7 mm, RBV entre 65 e 75\%, para fluxo de

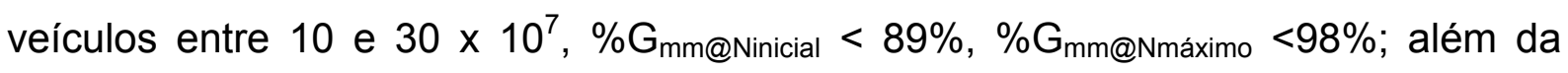
proporção pó/asfalto (que corresponde à razão do teor de material passante na peneira $\mathrm{N}^{\circ} 200$ e o teor de ligante, parâmetro que deve pertence ao intervalo de 0,6 a 1,8 (Motta et al., 1996).

Para a determinação do teor de ligante de projeto, realiza-se a compactação de três CP's no teor de ligante inicial $\left(P_{\text {li }}\right)$, além de três outros teores $( \pm 0,5$ e $+1,0 \%$ em relação ao $\left.\mathrm{P}_{\mathrm{li}}\right)$.

Para a realização da mistura, o agregado mineral foi aquecido em uma misturadora de massa adaptada para esta finalidade até a temperatura de usinagem para cada ligante estudado, que foi adicionado para homogeneização do material. Em seguida, foram separadas porções de $1.200,00 \mathrm{~g}$ e armazenados em tigelas metálicas, que foram acondicionadas em estufa pelo período de duas horas na temperatura de compactação, antes da compactação, a fim de simular o efeito do envelhecimento de curto prazo durante a usinagem (AASHTO TP 31). A sequência do procedimento de compactação é apresentada na Figura 3.3. 


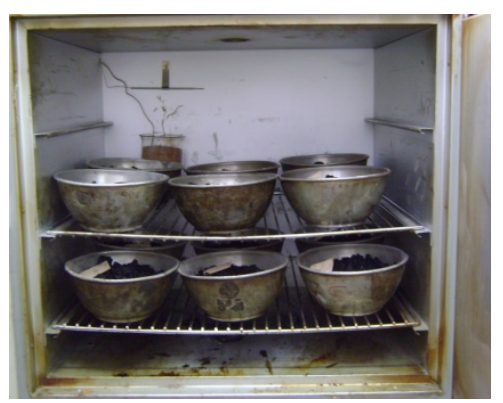

(a) Simulação do envelhecimento de curto prazo em estufa

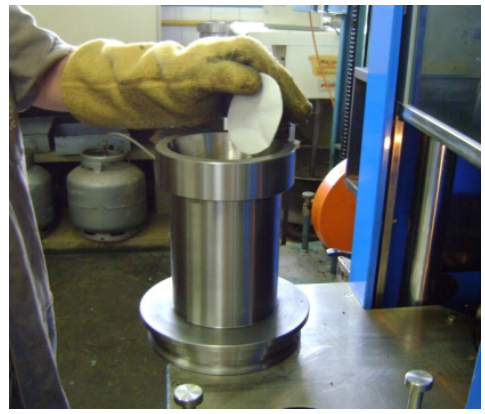

(c) Colocação do papel filtro no fundo do molde

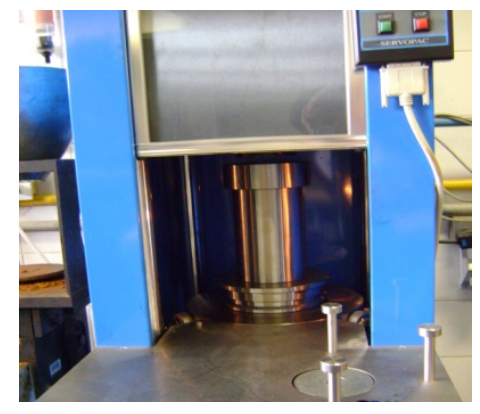

(e) Ajuste do cilindro no CG para compactação

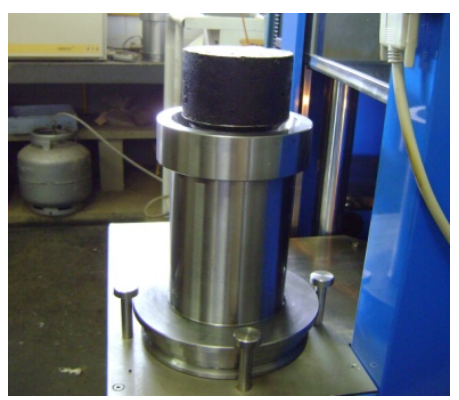

(g) Extração do corpo-de-prova após compactação e retirada do papel filtro

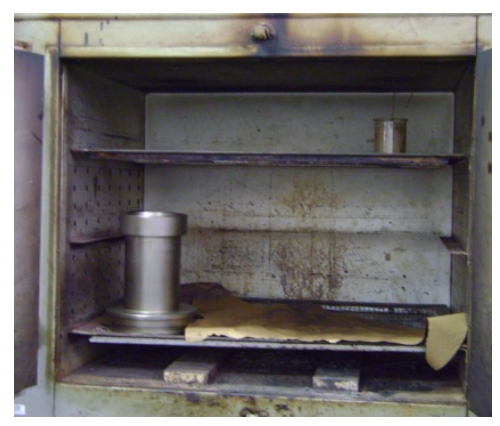

(b) Retirado do molde da estufa

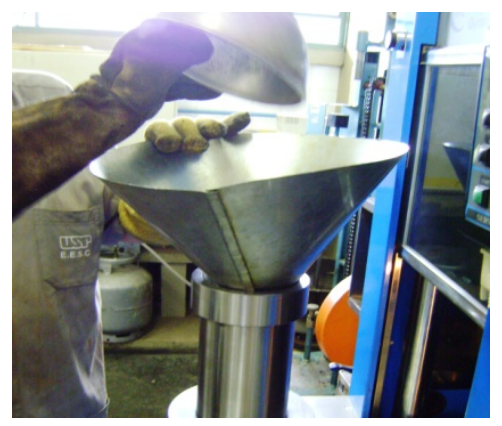

(d) Colocação da mistura no molde e papel filtro

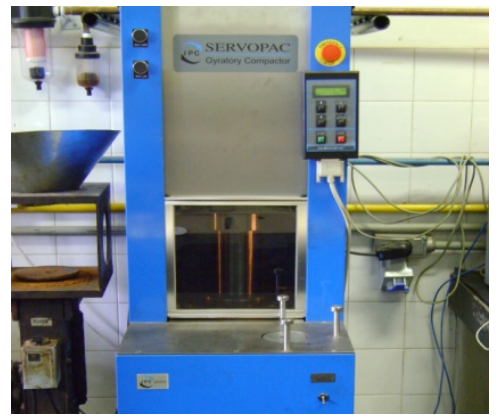

(f) Compactação do corpo-de-prova no CG

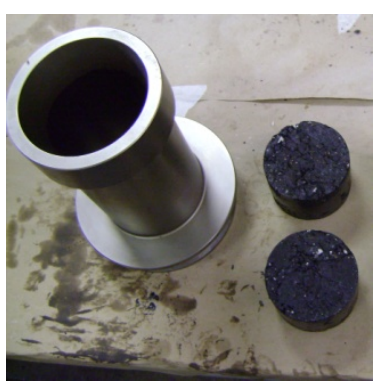

(h) Detalhe do cilindro e dos corpos-de-prova de $10 \mathrm{~cm}$ de diâmetro

Figura 3.2. Sequência do procedimento de compactação 
Após a compactação de um corpo-de-prova, é feita a pesagem (a seco, submersa e superfície saturada seca, depois do seu resfriamento) (ASTM D 3203-94) para

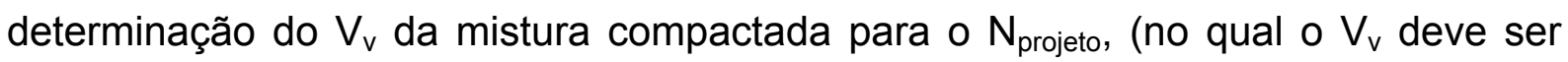
igual a 4\%). O $\mathrm{N}_{\text {inicial }}$ (representa a condição de compactação no início da sua vida

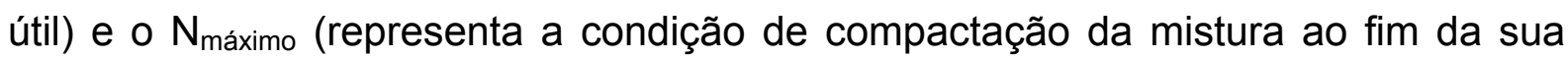
vida de serviço, e garante que a mistura não vai compactar sob o tráfego previsto e ter um comportamento plástico levando a deformações permanentes), usados para avaliar a compactabilidade da mistura, que são função do tráfego (N) (Bernucci et al., 2007), e variam conforme indicado na Tabela 3.12.

Tabela 3.11. Número de giros especificados pela norma de dosagem SUPERPAVE ${ }^{\circledR}$ (Bernucci et al., 2007)

\begin{tabular}{|c|c|c|c|}
\hline \multicolumn{3}{|c|}{ Parâmetros de compactação } & \multirow{2}{*}{ Tráfego } \\
\hline $\mathrm{N}_{\text {inicial }}$ & $\mathrm{N}_{\text {projeto }}$ & $\mathrm{N}_{\text {máximo }}$ & \\
\hline & 50 & 75 & Muito leve (local) \\
\hline 7 & 75 & 115 & Médio (rodovias coletoras) \\
\hline 8 & 100 & 160 & Médio a alto (vias principais, rodovias rurais) \\
\hline 9 & 125 & 205 & Alto volume de tráfego (interestaduais, muito pesado) \\
\hline
\end{tabular}

O número de giros adotado nesta pesquisa foi o de tráfego médio a alto, valor importante para determinação do critério de parada da moldagem dos corpos-deprova (vias principais, rodovias rurais). A avaliação da compactabilidade da mistura, trabalhabilidade e seu potencial de densificação, que depende do esqueleto mineral (agregados) são verificados lançando-se em gráfico a massa específica como percentual da $\mathrm{G}_{\mathrm{mm}}$ versus o número de giros (ou versus o logaritmo do número de giros).

O CGS cálcula $\circ \mathrm{G}_{\mathrm{mb}}$ a cada giro a partir da estimativa do volume do corpo-deprova, admitindo que o mesmo seja um cilindro de superfícies sem rugosidades ou imperfeições, o que não representa à realidade, agregando erros as informações obtidas do CGS. $O G_{m b}$ é corrigido em cada giro a partir do $G_{m b}$ no $N_{\text {máximo. }} A$ correção é feita pela seguinte fórmula:

$$
C=\frac{G_{m b(\text { medida })}}{G_{m b(\text { estimada })}}
$$

Onde: 


$$
\begin{aligned}
& C \text { = fator de correção; } \\
& G_{m b} \text { (medida) }=\text { massa específica aparente medida a } N_{\text {máximo; }} \\
& G_{m b} \text { (estimada) }=\text { massa específica aparente estimada a } N_{\text {máximo. }}
\end{aligned}
$$

\subsection{DELINEAMENTO DO EXPERIMENTO}

O programa de experimentos desta pesquisa foi desenvolvido com a finalidade de abranger alguns dos principais fatores influentes na durabilidade e em algumas propriedades mecânicas e relacionadas à suscetibilidade térmica e à sensibilidade à umidade de misturas asfálticas densas.

\subsection{PLANEJAMENTO DO EXPERIMENTO FATORIAL}

As misturas asfálticas testadas nesta pesquisa são, basicamente, resultantes da combinação fatorial de dois fatores: o aditivo, cal hidratada, variando em três níveis e o modificador, ácido polifosfórico, variando em três níveis. Nesta configuração (3x3×2), o programa experimental resultou em dezoito condições experimentais com três réplicas para cada condição (com volume de vazios de 4 e 7\%), ou seja, 6 corpos-de-prova que foram ensaiados em três temperaturas, resultando em 324 resultados de módulos de resiliência (MR).

- Fator 1: Aditivo - cal hidratada cálcica em três níveis (0; 1,5 e 3,0\% em peso);

- Fator 2: Modificador - ácido polifosfórico em três níveis (Puro - CAP 50/70; CAP $50 / 70+0,6 \%$ de ácido polifosfórico; CAP 50/70 + 1,2\% de ácido polifosfórico).

O procedimento experimental envolveu as seguintes etapas:

- Caracterização e preparação dos ligantes asfálticos modificados, considerando duas concentrações de ácido polifosfórico (0,6 e 1,2\%);

- Preparação da distribuição granulométrica dos agregados, com eventual subtituição de pó-de-pedra por cal, em dois teores (1,5 ou 3,0\%);

- Definição do teor de projeto das misturas asfálticas, conforme a metodologia SUPERPAVE $®$, AASHTO T 283, para tráfego de médio a pesado (100 giros e $V_{v}$ de $4 \%$ ); 
- Moldagem das réplicas para ensaio de determinação de módulo de resiliência (AASHTO TP 31) em três diferentes temperaturas $\left(10,25\right.$ e $\left.40^{\circ} \mathrm{C}\right)$.

\subsection{MÓDULO DE RESILIÊNCIA}

Uma forma de avaliar os efeitos dos condicionamentos térmicos num mesmo corpode-prova é o ensaio de módulo de resiliência, uma vez que esse ensaio não é destrutivo. $\mathrm{O}$ método de ensaio consiste da execução a $25^{\circ} \mathrm{C}$, a aplicação de 100 ciclos de carregamento de grandeza constante, com duração de 1,0 s, sendo que o mesmo tem um período de solicitação de $0,1 \mathrm{~s}$ e um período de repouso de $0,9 \mathrm{~s}$.

Com o objetivo de limitar os defeitos do aparato de realização do ensaio de módulo de resiliência, a carga inicial para cada combinação de corpos-de-prova é calibrada no ínicio de cada ensaio a fim de produzir deslocamentos da ordem de 0,0025 a 0,0030 milímetros. Esse detalhe de execução do ensaio tem sua importância em suma para preservar a integridade do material, sem ocasionar sinais de qualquer tipo de ruptura que venha alterar o arranjo da mistura, e modificar suas propriedades físicas.

O valor do módulo de resiliência é calculado de acordo com a norma do DNER 133/94, e é expressa por:

$$
M R=\frac{F}{\Delta \times h}(0,9976 \mu+0,2692)
$$

Onde:

MR é o módulo de resiliência em MPa;

F é a carga vertical repetida aplicada diametralmente ao corpo-de-prova, em $\mathrm{N}$;

$\Delta$ é o deslocamento total (correspondente à deformação elástica ou resiliente sofrida pelo corpo-de-prova, em direção à aplicação da carga), em mm;

H é a altura do corpo-de-prova, em mm;

$\mu$ é o coeficiente de Poisson. 
Outros parâmetros obtidos a partir de módulo de resiliência foram avaliados, a saber: recuperação retardada e atraso. A recuperação retardada (RR) representa a recuperação no período de repouso e está indiretamente relacionada a viscoelasticidade do material; com ela se podem verificar alterações de comportamento das misturas asfálticas quanto à forma de resposta resiliente e, inclusive, por exemplo, oberservar um aumento de valor de MR implica em misturas asfálticas mais elásticas ou mais viscosas (Furlan, 2006; Furlan et al., 2006; Furlan, 2008b). O parâmetro é obtido a partir das expressões abaixo:

$$
\begin{gathered}
R R=\frac{\left(M R_{I}-M R_{T}\right)}{M R_{I}} \times 100 \\
R R=\frac{\frac{\sigma}{\varepsilon_{I}}-\frac{\sigma}{\varepsilon_{T}}}{\frac{\sigma}{\varepsilon_{I}}}=\frac{\frac{\varepsilon_{T}-\varepsilon_{I}}{\varepsilon_{I} \varepsilon_{T}}}{\varepsilon_{I}}=\frac{\varepsilon_{T}-\varepsilon_{I}}{\varepsilon_{T}} \times 100
\end{gathered}
$$

Onde:

RR é a recuperação retardada, em \%;

$M R_{I}$ é o valor do módulo instantâneo, em MPa;

$\mathrm{MR}_{\mathrm{T}}$ é o valor do módulo total, em MPa;

$\sigma$ é a tensão aplicada;

$\varepsilon_{1}$ é a deformação total;

$\varepsilon_{\top}$ é a deformação elástica instantânea.

Outro parâmetro de rigidez determinado a partir dos ensaios de módulo de resiliência é chamado de atraso e é expresso em segundos. $O$ atraso é uma medida da defasagem entre os picos dos pulsos de carga e de deslocamento. Foi calculado com base na diferença de tempo entre ocorrências do ponto de carga máxima e o ponto de máximo de deslocamento. Esse parâmetro também tem relação com a visco-elasticidade do material, mas nesse caso a resposta é avaliada no período de carregamento, e o coeficiente de Poisson foi adotado como 0,35 , valor esse utilizado em retroanálises. Para a obtenção dos parâmetros de rigidez foram desenvolvidas rotinas especiais de cálculo pelo Prof. Dr. Glauco Túlio Pessa Fabbri da Escola de 
Engenharia de São Carlos, Departamento de Transportes, em linguagem Labview $7.1^{\circledR}$ e incorporadas ao programa de determinação do módulo de resiliência (Furlan et al., 2008).

\subsection{RESISTÊNCIA À TRAÇÃO POR COMPRESSÃO DIAMETRAL}

O ensaio para a determinação da resistência à tração por compressão diametral das misturas asfálticas é realizado de acordo com DNER ME 138/94 na temperatura de $25^{\circ} \mathrm{C}$. O ensaio foi executado em todos os corpos-de-prova, a fim de obter a resistência à tração, em termos médios, dos grupos de controle e condicionados, e posteriormente foram calculadas as relações de resistência à tração.

A resistência à tração é determinada a partir da expressão:

$$
\sigma_{R}=\frac{2 F}{\pi \cdot d \cdot h}
$$

Onde:

$\sigma_{\mathrm{R}}$ é a resistência à tração, em MPa;

F é a carga de ruptura, em $\mathrm{N}$;

d é o diâmetro médio do corpo-de-prova, em mm;

h é a altura média do corpo-de-prova, em mm.

\subsection{AVALIAÇÃO DA SUSCETIBILIDADE TÉRMICA DA MISTURA}

A temperatura e a ação da água são dois fatores que alteram significativamente a durabilidade das misturas asfálticas.

Os corpos-de-prova foram ensaiados em três temperaturas 10,25 e $40^{\circ} \mathrm{C}$ com a finalidade de observar se existe alguma particularidade de comportamento das misturas na faixa de temperaturas de serviço devido à presença de cal e/ou do ácido polifosfórico. 
Para garantir que os ensaios de módulo de resiliência fossem realizados nas temperaturas desejadas, os corpos-de-prova foram anteriormente colocados numa câmara climatizada com precisão de $\pm 1^{\circ} \mathrm{C}$, por no mínimo $12 \mathrm{~h}$.

Para a temperatura de $10^{\circ} \mathrm{C}$, como a mistura asfáltica fica muito rígida, para atingir os níveis de deslocamento com que foram ensaiados a $25^{\circ} \mathrm{C}$, implica no uso de cargas muito altas, correndo o risco de alterar as propriedades do material, por isso, nesse caso optou-se por aceitar um nível menor de deslocamentos, cerca de $0,0020 \mathrm{~mm}$, que é o suficiente para uma leitura de qualidade. No caso de $40^{\circ} \mathrm{C}$, os deslocamentos de $0,0020 \mathrm{~mm}$ também foram aceitos, devido à sensibilidade dos corpos-de-prova nessas condições; cargas altas podem causar alterações nas suas características físicas, assim, um deslocamento mínimo que já garanta a qualidade da leitura se torna aceitável.

\subsection{MÉTODOS DE ENSAIO PARA AVALIAÇÃO DOS DANOS POR UMIDADE}

A última etapa do projeto SUPERPAVE ${ }^{\circledR}$ Nível 1 é avaliar a sensibilidade à umidade do projeto da mistura final escolhida, o que foi feito por meio do teste AASHTO T 283, usado também na avaliação da adesividade. O método consiste na avaliação da variação de uma propriedade mecânica causada por danos por umidade. Corposde-prova são compactados até aproximadamente $7 \%$ de volume de vazios. Um subgrupo de três corpos-de-prova é considerado de controle e outro subgrupo de três corpos-de-prova é condicionado, sendo submetido a uma saturação a vácuo, seguida de um ciclo opcional de congelamento, seguida ainda de um ciclo de degelo de 24 horas a $60^{\circ} \mathrm{C}$. Todos os corpos-de-prova são testados para determinação da resistência à tração estática indireta (DNER-ME 138/94). A sensibilidade à água é avaliada pela relação da resistência média do subgrupo condicionado e do subgrupo de controle, sendo a relação mínima admissível (RRT) de 70\% a 80\% dependendo do órgão viário (Bernucci et al., 2007).

Foram executados ensaios de módulos de resiliência (de acordo com DNER-ME 133/94) seguindo os mesmos critérios de aceitação. Este procedimento foi adotado por ser um ensaio rápido, não destrutivo e, particularmente, com baixa dispersão, como dito anteriormente. Além disso, podem-se avaliar variações no módulo de resiliência dos corpos-de-prova decorrentes do condicionamento, o que não é 
possível com o ensaio de resistência à tração por compressão diametral (que destrói os corpos-de-prova), e avalia a variação das propriedades em termos médios dos grupos, e, portanto acumula dispersões de outras fontes, como por exemplo, procedimento de moldagem e variação de temperatura.

\subsection{MÉTODO DE ANÁLISE DOS RESULTADOS}

Os resultados obtidos dos ensaios de módulo de resiliência e de resistência à tração foram analisados com o uso do software Minitab® com a finalidade de compreender quais fatores são estatisticamente significativos nas propriedades observadas.

A ferramenta usada no software Minitab® foi a ANOVA, que usa o teste $F$ de Snedecor para análise dos efeitos significativos para os ensaios avaliados.

O teste $\mathrm{F}$ de Snedecor fornece a soma dos quadrados dos fatores e suas interações, que por sua vez estão relacionadas com as variações dos níveis de cada fator e suas respectivas interações. As tabelas do teste $F$ pode ser usada para comparar a estimativa de cada parâmetro dentro de cada significância ou probabilidade. Assim, para um nível de significância de $5 \%$, o valor da resposta do modelo tem $5 \%$ de chance de ter sido ao acaso (Gomes, 1973). 


\section{APRESENTAÇÃO E ANÁLISE DOS RESULTADOS}

\subsection{INTRODUÇÃO}

Neste capítulo são apresentados os resultados da dosagem para os três tipos de asfaltos (asfalto convencional - CAP 50/70, asfalto com adição de 0,6\% de PPA, asfalto com adição de $1,2 \%$ de PPA) e para as três combinações de aditivos (agregado puro, agregado com $1,5 \%$ de cal calcítica e agregado com 3,0\% de cal calcítica).

Do método de dosagem SUPERPAVE obteve-se os valores de massas específicas estimadas da mistura asfáltica $\left(G_{m b}\right)$, expressas como percentuais da massa específica máxima $\left(G_{m m}\right)$, volume de vazios $\left(V_{v}\right)$, vazios de agregado mineral (VAM), relação betume-vazios (RBV).

Do ensaio de módulo de resiliência obtiveram-se os valores de módulo de resiliência instantâneo e total calculados segundo o método do NCHRP, a recuperação retardada $(R R)$ e o atraso em segundos.

Do ensaio de resistência à tração por compressão diametral obteve-se os valores de resistência à tração, em termos médios, dos grupos de controle e condicionados, para uma posterior avaliação da sua relação, cuja finalidade é avaliar a suscetibilidade à umidade das misturas testadas.

\subsection{COMPACTAÇÃO SUPERPAVE ${ }^{\circledR}$}

Neste trabalho, o compactador SUPERPAVE ${ }^{\circledR}$ foi utilizado para determinar os teores de asfalto ótimos para a moldagem dos corpos-de-prova em cada uma das combinações estudadas. Realizou-se uma dosagem única, para a condição de CAP 50/70 com $0,6 \%$ de PPA e 1,5\% de cal calcítica, em função de ser a condição intermediária que mais se aproximava das demais combinações. Moldaram-se tréplicas dos corpos-de-prova para cada um dos quatro teores de asfalto utilizados na dosagem, para número de giros igual a 100. 
Na Tabela 4.1 apresenta-se um resumo dos valores dos volumes de vazios obtidos na dosagem em função do teor de ligante utilizado, para o número de giros do compactador igual a 100 . Os volumes de vazios foram calculados a partir das massas específicas aparentes "corrigidas" $\left(\mathrm{G}_{\mathrm{sb}}\right)$ dos corpos-de-prova, cujos valores encontram-se no ANEXO I.

Tabela 4. 1. Valores obtidos para a dosagem SUPERPAVE®.

\begin{tabular}{cc}
\hline $\begin{array}{c}\text { Teor de Ligante } \\
(\%)\end{array}$ & $\mathrm{V}_{\mathrm{v}}(\%)_{(\text {Nproj }=100)}$ \\
\hline 4,5 & 4,47 \\
5,0 & 2,64 \\
5,5 & 1,67 \\
6,0 & 1,53 \\
\hline
\end{tabular}

A Figura 10 apresenta a relação entre o volume de vazios e o teor de ligante para número de giros igual a 100. Observando-se essa figura, nota-se que o teor de ligante de projeto, para volume de vazios igual a 4,0\%, é igual a 4,63\%.

Vv $x$ Teor de Ligante $\left(\mathrm{N}_{\text {proj }}=100\right)$

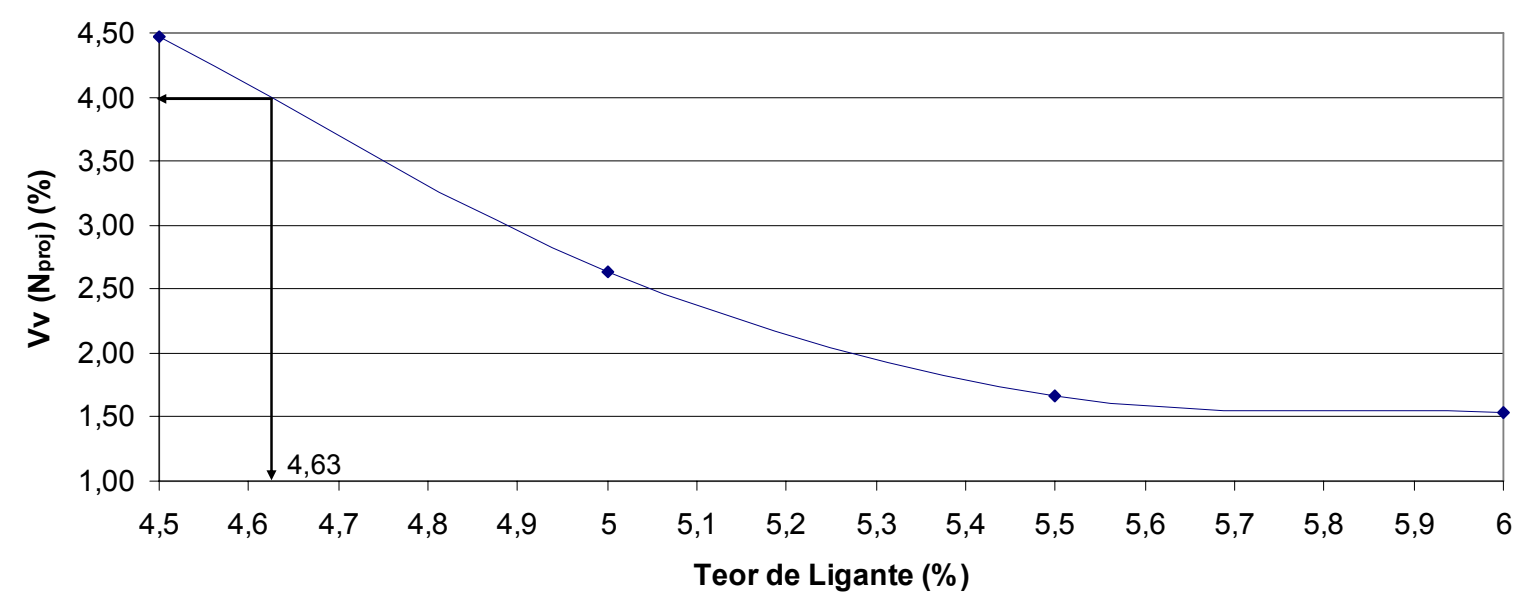

Figura 4.1. Volume de vazios versus teor de ligante para determinação do teor ideal.

\subsection{PRODUÇÃO DOS CORPOS-DE-PROVA}

Os corpos-de-prova foram moldados e as médias das principais propriedades

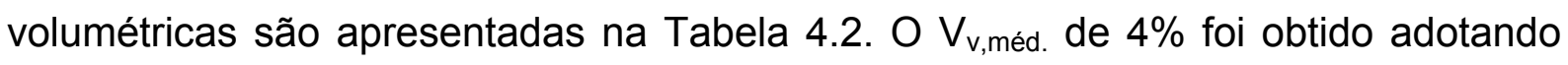
como critério de parada o número de giros de projeto $\left(\mathrm{N}_{\text {proj }}=100\right)$, e o $\mathrm{V}_{\mathrm{v} \text {,méd. }}$ de $7 \%$ foi obtido adotando como critério de parada a massa específica aparente respectiva 
para cada condição aditivo-modificador, registrada durante a dosagem no compactador giratório. No ANEXO II são apresentadas as propriedades obtidas dos 108 corpos-de-prova que foram confeccionados.

Tabela 4.2. Resumo dos resultados médio das propriedades da moldagem dos corpos-deprova para todas as combinações (média de 12 CP`s por condição).

\begin{tabular}{|c|c|c|c|c|c|c|c|c|}
\hline Aditivo & Modificador & $\begin{array}{l}G_{m b}(\text { est) } \\
\left(\mathrm{g} / \mathrm{cm}^{3}\right)\end{array}$ & $\begin{array}{l}G_{\mathrm{mb}(\mathrm{corr})} \\
\left(\mathrm{g} / \mathrm{cm}^{3}\right)\end{array}$ & $\begin{array}{c}\% G_{\text {mm@Nprojeto }} \\
(100)\end{array}$ & $\begin{array}{l}V_{v, \text { méd }} \\
(\%)\end{array}$ & $\begin{array}{r}G_{m m^{3}} \\
\left(\mathrm{~g} / \mathrm{cm}^{3}\right)\end{array}$ & $\begin{array}{c}\text { VAM } \\
(\%)\end{array}$ & RBV \\
\hline \multirow{6}{*}{$0 \%$ cal } & \multirow{2}{*}{$0 \%$ PPA } & 2,327 & 2,373 & 96,031 & 3,969 & 2,471 & 11,36 & 0,651 \\
\hline & & 2,226 & 2,296 & 92,916 & 7,084 & 2,471 & 14,24 & 0,503 \\
\hline & \multirow{2}{*}{ 0,6\% PPA } & 2,324 & 2,375 & 95,993 & 4,007 & 2,474 & 11,28 & 0,645 \\
\hline & & 2,217 & 2,286 & 92,391 & 7,609 & 2,474 & 14,61 & 0,479 \\
\hline & \multirow{2}{*}{$1,2 \%$ PPA } & 2,328 & 2,378 & 95,912 & 4,088 & 2,479 & 11,18 & 0,634 \\
\hline & & 2,233 & 2,325 & 93,765 & 6,235 & 2,479 & 13,17 & 0,530 \\
\hline \multirow{6}{*}{$\begin{array}{c}1,5 \% \\
\text { cal }\end{array}$} & \multirow{2}{*}{$0 \%$ PPA } & 2,329 & 2,373 & 96,002 & 3,998 & 2,472 & 11,35 & 0,648 \\
\hline & & 2,215 & 2,296 & 93,214 & 6,786 & 2,472 & 13,92 & 0,513 \\
\hline & \multirow{2}{*}{ 0,6\% PPA } & 2,317 & 2,373 & 95,927 & 4,073 & 2,473 & 11,38 & 0,642 \\
\hline & & 2,208 & 2,296 & 92,797 & 7,203 & 2,473 & 14,27 & 0,495 \\
\hline & \multirow{2}{*}{$1,2 \%$ PPA } & 2,309 & 2,366 & 95,733 & 4,267 & 2,471 & 11,62 & 0,633 \\
\hline & & 2,216 & 2,291 & 92,756 & 7,244 & 2,471 & 14,37 & 0,496 \\
\hline \multirow{6}{*}{$\begin{array}{c}3,0 \% \\
\text { cal }\end{array}$} & \multirow{2}{*}{$0 \%$ PPA } & 2,308 & 2,363 & 95,993 & 4,007 & 2,461 & 11,74 & 0,659 \\
\hline & & 2,208 & 2,283 & 92,773 & 7,227 & 2,461 & 14,70 & 0,509 \\
\hline & \multirow{2}{*}{ 0,6\% PPA } & 2,308 & 2,358 & 95,801 & 4,199 & 2,461 & 11,92 & 0,648 \\
\hline & & 2,208 & 2,282 & 92,719 & 7,281 & 2,461 & 14,75 & 0,507 \\
\hline & \multirow{2}{*}{$1,2 \%$ PPA } & 2,298 & 2,352 & 95,610 & 4,390 & 2,460 & 12,13 & 0,638 \\
\hline & & 2,208 & 2,281 & 92,726 & 7,274 & 2,460 & 14,78 & 0,508 \\
\hline
\end{tabular}

\subsection{AVALIAÇÃO DAS PROPRIEDADES MECÂNICAS OBTIDAS}

O ANEXO III apresenta as informações do Módulo de Resiliência total e Instantânea - NCHRP, Atraso e Defasagem para cada corpo-de-prova nas temperaturas de 10, 25 e $40^{\circ} \mathrm{C}$. Para análise gráfica apresentada a seguir, foi realizada uma seleção dos valores de Módulo de Resiliência (MR) para cada combinação de fatores, a partir do descarte dos valores que extrapolaram o intervalo do valor médio \pm um desvio padrão, assim os valores usados são apresentados no ANEXO IV. As Tabelas 4.3 e 4.4 apresentam os valores de MR, RR e atraso, em termos médios, para $4 \%$ e $7 \%$ de volume de vazios, respectivamente, para as condições experimentais testadas. 
Tabela 4.3. Módulos de resiliência total das misturas testadas a diferentes temperaturas para $\mathrm{V}_{\mathrm{v}}=4 \%$

\begin{tabular}{c|ccc|ccc|ccc}
\hline Temperatura $\left({ }^{\circ} \mathrm{C}\right)$ & \multicolumn{3}{|c|}{10} & \multicolumn{3}{c|}{25} & \multicolumn{3}{c}{40} \\
\hline Propriedades & $\begin{array}{c}\mathrm{MR} \\
(\mathrm{MPa})\end{array}$ & $\begin{array}{c}\mathrm{RR} \\
(\%)\end{array}$ & $\begin{array}{c}\text { Atraso } \\
\left(10^{-2} \mathrm{~s}\right)\end{array}$ & $\begin{array}{c}\mathrm{MR} \\
(\mathrm{MPa})\end{array}$ & $\begin{array}{c}\mathrm{RR} \\
(\%)\end{array}$ & $\begin{array}{c}\text { Atraso } \\
\left(10^{-2} \mathrm{~s}\right)\end{array}$ & $\begin{array}{c}\mathrm{MR} \\
(\mathrm{MPa})\end{array}$ & $\begin{array}{c}\mathrm{RR} \\
(\%)\end{array}$ & $\begin{array}{c}\text { Atraso } \\
\left(10^{-2} \mathrm{~s}\right)\end{array}$ \\
\hline $\begin{array}{c}\text { CAP Puro } \\
16246\end{array}$ & 13,13 & 4,03 & 5313 & 26,90 & 4,60 & 1011 & 26,12 & 4,90 \\
$\mathrm{CAP}+0,6 \%$ PPA & 16741 & 12,76 & 4,02 & 5351 & 22,26 & 4,39 & 2000 & 22,78 & 4,65 \\
CAP + 1,2\% PPA & 16876 & 11,66 & 4,01 & 8360 & 18,23 & 4,34 & 2707 & 20,29 & 4,43 \\
CAP + 1,5\% de cal & 15777 & 13,41 & 3,98 & 5183 & 23,72 & 4,46 & 1353 & 28,05 & 4,86 \\
$\begin{array}{c}\text { CAP + 1,5\% de cal } \\
+0,6 \% \text { de PPA }\end{array}$ & 15088 & 14,00 & 4,02 & 5995 & 23,98 & 4,46 & 1340 & 25,62 & 4,80 \\
$\begin{array}{c}\text { CAP + 1,5\% de cal } \\
+1,2 \% \text { de PPA }\end{array}$ & 15865 & 12,62 & 4,05 & 6530 & 22,92 & 4,37 & 1894 & 23,11 & 4,62 \\
$\begin{array}{c}\text { CAP + 3,0\% de cal } \\
\text { CAP + 3,0\% de cal } \\
+0,6 \% \text { de PPA }\end{array}$ & 14220 & 13,62 & 4,05 & 5737 & 25,58 & 4,57 & 1303 & 24,68 & 4,91 \\
$\begin{array}{c}\text { CAP + 3,0\% de cal } \\
+1,2 \% \text { de PPA }\end{array}$ & 18121 & 13,84 & 4,11 & 5513 & 23,10 & 4,44 & 1388 & 25,82 & 4,76 \\
\hline
\end{tabular}

Tabela 4.4. Módulos de resiliência total das misturas testadas a diferentes temperaturas para $\mathrm{V}_{\mathrm{v}}=7 \%$

\begin{tabular}{|c|c|c|c|c|c|c|c|c|c|}
\hline Temperatura $\left({ }^{\circ} \mathrm{C}\right)$ & \multicolumn{3}{|c|}{10} & \multicolumn{3}{|c|}{25} & \multicolumn{3}{|c|}{40} \\
\hline Propriedades & $\begin{array}{c}\text { MR } \\
(\mathrm{MPa})\end{array}$ & $\begin{array}{l}\text { RR } \\
(\%)\end{array}$ & $\begin{array}{l}\text { Atraso } \\
\left(10^{-2} \mathrm{~s}\right)\end{array}$ & $\begin{array}{c}\text { MR } \\
(\mathrm{MPa})\end{array}$ & $\begin{array}{l}\text { RR } \\
(\%)\end{array}$ & $\begin{array}{l}\text { Atraso } \\
\left(10^{-2} \mathrm{~s}\right)\end{array}$ & $\begin{array}{c}\text { MR } \\
(\mathrm{MPa})\end{array}$ & $\begin{array}{l}\text { RR } \\
(\%)\end{array}$ & $\begin{array}{l}\text { Atraso } \\
\left(10^{-2} \mathrm{~s}\right)\end{array}$ \\
\hline CAP & 12280 & 15,30 & 4,04 & 3352 & 27,13 & 4,68 & 896 & 20,49 & 4,84 \\
\hline CAF & 3126 & 13,46 & 4,04 & 5517 & 22,26 & 4,6 & 1481 & 21,34 & 4,77 \\
\hline $\mathrm{CA}$ & 318 & 10,64 & 4,00 & 7649 & 20,37 & 4,4 & 1860 & 21,31 & 4,65 \\
\hline CAI & 14121 & 13,26 & 4,0 & 4489 & 25,87 & 4,5 & 1274 & 25,47 & 4,85 \\
\hline $\begin{array}{l}1,5 \% \text { de cal } \\
6 \text { de PPA }\end{array}$ & 12863 & 15,38 & 4,09 & 5037 & 24,24 & 4,53 & 1467 & 24,31 & 4,79 \\
\hline $\begin{array}{r}\text { CAP }+1,5 \% d \\
+1,2 \% \text { de } P\end{array}$ & 14378 & 13,91 & 4,1 & 6068 & 22,11 & 4,3 & 1731 & 24,37 & 4,73 \\
\hline $\mathrm{CAP}+$ & 12088 & 15,79 & 4,11 & 4095 & 26,65 & 4,60 & 1051 & 23,15 & 4,76 \\
\hline+ & 1366 & 15,65 & 4,15 & 4571 & 24,22 & 4,47 & 1461 & 26,28 & 4,77 \\
\hline $\begin{array}{c}\text { CAP }+3,0 \% \text { de cal } \\
+1,2 \% \text { de PPA }\end{array}$ & 14129 & 13,11 & 4,04 & 5044 & 22,50 & 4,40 & 1584 & 26,50 & 4,82 \\
\hline
\end{tabular}

Observando-se os valores das Tabelas 4.3 e 4.4, nota-se que a temperatura é o principal fator responsável pela variação das propriedades avaliadas, seguida pelo aditivo e pelo modificador. Considerado a média de todas as condições experimentais, observa-se que na faixa de temperaturas de 10 a $25^{\circ} \mathrm{C}$, a perda de rigidez foi menos severa que na faixa de 25 a $40^{\circ} \mathrm{C}$, da ordem de 63 e $71 \%$, respectivamente, para $V_{v}=4 \%$ (Tabela 4.3), e de 63 e $72 \%$, respectivamente, para $V_{v}=7 \%$ (Tabela 4.4). Quanto aos parâmetros de rigidez, pode-se dizer que o aumento da temperatura causou o aumento tanto de RR quanto ao Atraso, isto é, as misturas asfálticas, de forma geral, tendem a apresentar respostas mais lentas frente ao carregamento e ao descarregamento. Em termos médios, os valores de 


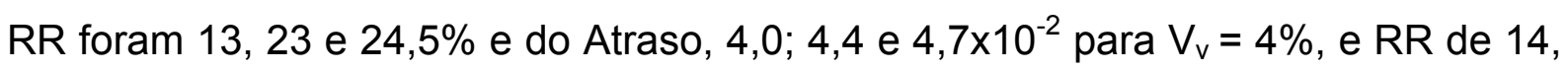
24 e 23,7 para $V_{v}=7 \%$, para as temperaturas de 10,25 e $40^{\circ} \mathrm{C}$, respectivamente.

A mistura de referência (CAP Puro) não apresentou as maiores perdas de rigidez em função do aumento da temperatura, mas, em contrapartida, apresentou os maiores ganhos nos parâmetros RR e Atraso, tanto para $V_{v}=4 \%$, quanto para $V_{v}=7 \%$.

Com relação ao volume de vazios, a variação de 4 para $7 \%$ causa uma redução média na rigidez de 13, 15 e 17\%, para as temperaturas de 10,25 e $40^{\circ} \mathrm{C}$, respectivamente. Em relação à $\mathrm{RR}$ e ao Atraso, houve um aumento de 8 e 1\%, 4 e $2 \%$, para as temperaturas de 10 e $25^{\circ} \mathrm{C}$, respectivamente, e redução de $3 \%$ para o $\mathrm{RR}$ e aumento de $1 \%$ para o Atraso para a temperatura de $40^{\circ} \mathrm{C}$. Nota-se que a tendência das misturas asfálticas, de forma geral, é apresentar respostas mais lentas frente ao carregamento e ao descarregamento, com o aumento da temperatura e o aumento do $V_{v}$ de 4 para $7 \%$, produz a mesma tendência se quanto à temperatura, com exceção de $40^{\circ} \mathrm{C}$, que mostrou respostas mais rápidas quanto às solicitações impostas.

Os valores de MR indicaram que a adição de PPA propicia aumento da rigidez e esse efeito é mais intenso com o incremento de sua concentração nas misturas asfálticas. A partir dos valores de RR e Atraso, nota-se que as misturas com PPA exibiram comportamento mais elástico, ou seja, houve redução desses parâmetros em função do aumento de MR resultante da redução da temperatura.

Para visualização do comportamento das propriedades e dos parâmetros apresentados nas Tabelas 4.3 e 4.4, a Figura 4.2 apresenta os gráficos com os resultados de todos os corpos-de-prova ensaiados nas três temperaturas, para os $V_{v}$ de $4 \%$ e 7\%. O gráfico da Figura 4.2a apresenta os valores do módulo total versus o instantâneo e tem a finalidade de evidenciar a alta qualidade da relação entre eles, o que é propriciado pelo método de cálculo (Protocolo da NCHRP 1-28). O gráfico da Figura $4.2 \mathrm{~b}$ e $4.2 \mathrm{c}$ apresentam as tendências de comportamento da RR e do Atraso em função de MR, lembrando que a variação de seus valores absolutos é decorrente principalmente da variação da temperatura. 


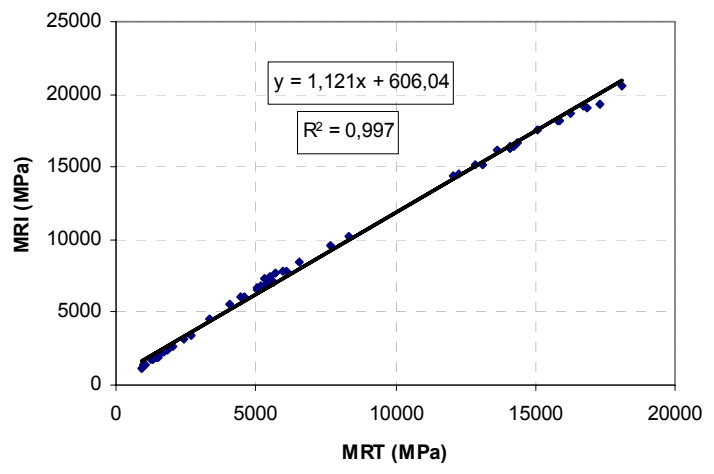

(a)

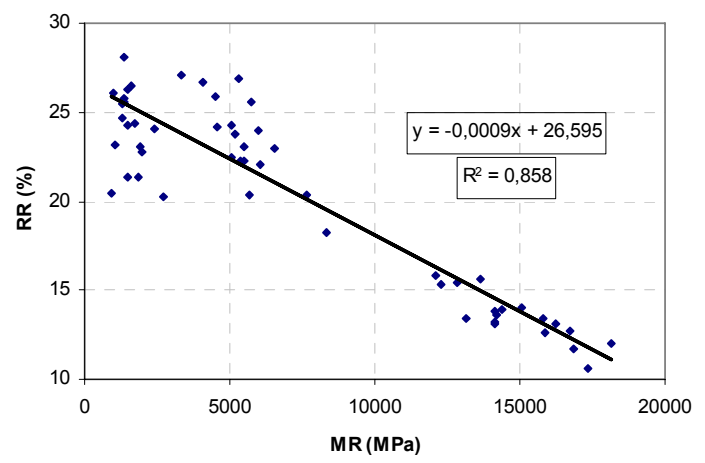

(b)

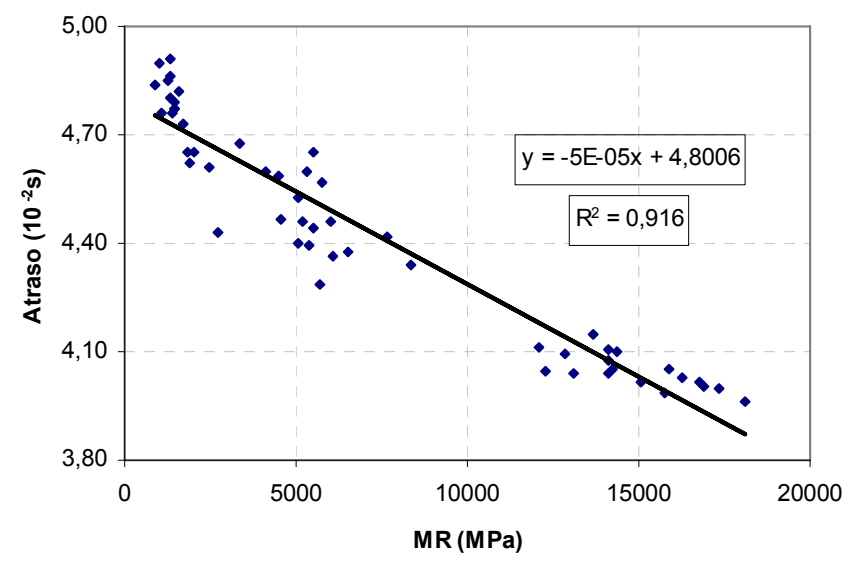

(c)

Figura 4.2. (a) Relação entre módulos instantâneo e total, (b) RR em função de MR e (c) Atraso em função de $M R$, para $V_{v}=4 \%$

A avaliação de resultados em termos médios confunde como cada mistura asfáltica reage sofre o efeito da temperatura, assim como vantagens e desvantagens da adição e concentração de dado produto. Assim, é feita uma análise considerando o efeito de cada fator e sua interação. Esta análise contempla as curvas de MR e RR em diferentes temperaturas, ou seja, somente a resposta da mistura na fase de descarregamento. Para o entendimento do efeito da adição de cal na suscetibilidade térmica das misturas asfálticas, as Figuras 4.3 e 4.4 apresentam curvas de MR e RR das misturas com CAP Puro, CAP + 0,6\% PPA e CAP + 1,2\% PPA. 
Nota-se que a rigidez das misturas aumenta com o aumento da concentração de PPA (0,6 para $1,2 \%)$, e esse aumento de rigidez é acompanhado por uma mudança na inclinação das curvas há um quase alinhamento dos tramos da mistura com CAP $+1,2 \%$ PPA, indicando que a influência da temperatura nessas misturas tem efeito praticamente constante no intervalo de 10 a $40^{\circ} \mathrm{C}$, diferentemente do que ocorre na mistura com CAP + 0,6\% PPA, que apresentou ganho de rigidez, mas manteve certo paralelismo com a curva de referência.

O comportamento das curvas de RR mostradas na Figuras 4.3 e 4.4 para $V_{v}$ igual a 4 e $7 \%$, respectivamente, concordam com o que se observou em termos de rigidez, uma vez que as misturas mais rígidas foram as que se apresentaram mais elásticas (redução de RR). Para ambas as concentrações de PPA adotadas, há redução do parâmetro RR, com exceção do CAP Puro, na temperatura de $40^{\circ} \mathrm{C}$ com $V_{v}=7 \%$, que inverte essa tendência, e se torna menos elástica. As misturas com PPA apresentaram os menores valores de RR dentre as testadas, atingindo valores próximos de $20 \%$ na temperatura de $40^{\circ} \mathrm{C}$ e uma variação de inclinação mais constante em todo intervalo de temperatura, para 4 e $7 \%$ de $V_{v}$, sendo assim, podese dizer que o PPA, nestas concentrações, contribuiu para a redução da suscetibilidade térmica das misturas asfálticas. 

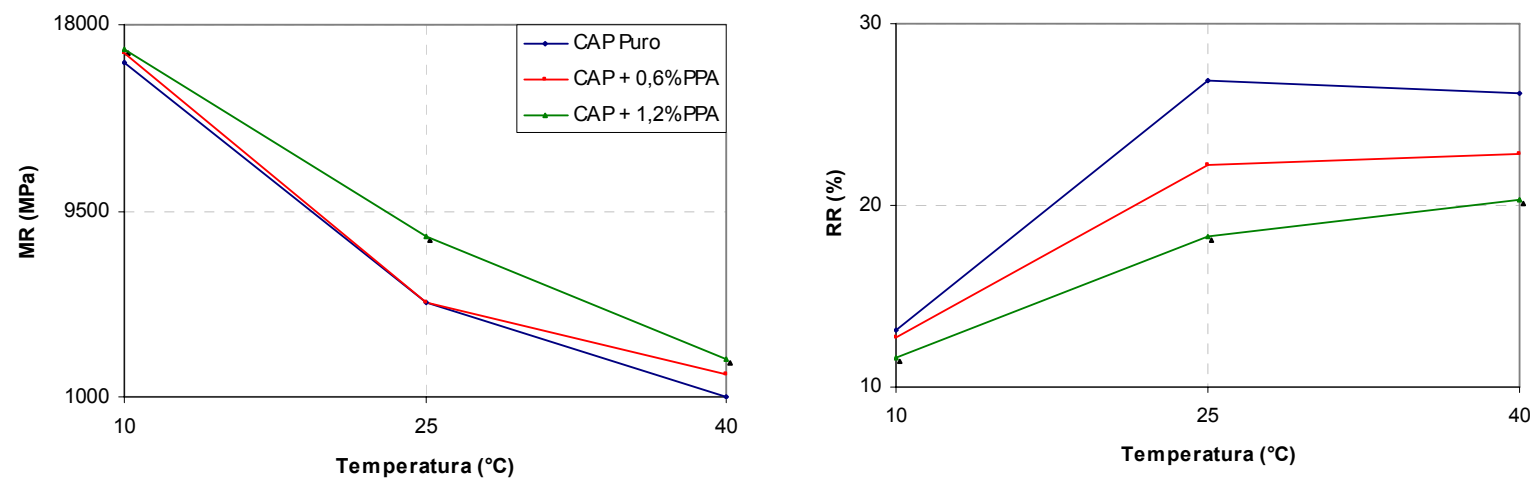

Figura 4.3. Efeito do PPA no MR e na RR em diferentes temperaturas para $4 \%$ de $V_{v}=4 \%$
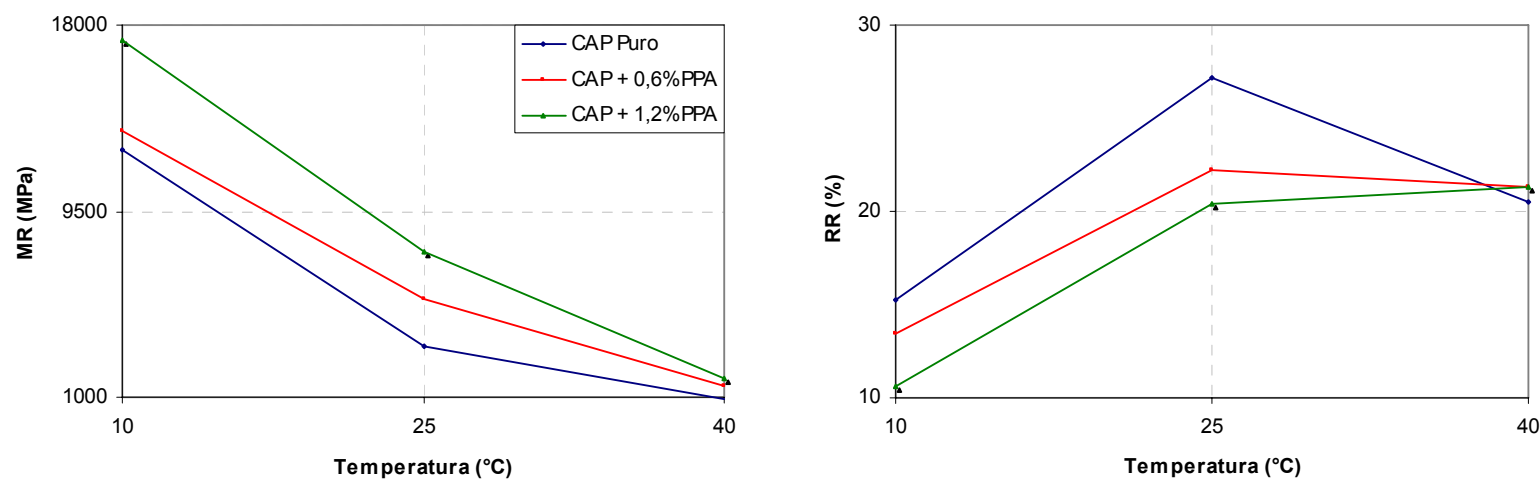

Figura 4.4. Efeito do PPA no MR e na RR em diferentes temperaturas para $V_{v}=7 \%$

As Figuras 4.5 e 4.6 apresentam as curvas MR e RR versus temperatura com cal e a mistura de referência, para $V_{v}$ igual a 4 e $7 \%$. Nota-se que o efeito da adição de cal é particularmente dependente da temperatura e é menos intenso do que se observou nas misturas com adição de PPA. Contudo, em termos de rigidez, vale destacar que a mistura com CAP $+3,0 \%$ cal exibiu valores menores de MR que as outras misturas na temperatura de $10^{\circ} \mathrm{C}$, e que ambas as misturas com cal apresentam valores de MR que convergem para o da mistura de referência na temperatura de $40^{\circ} \mathrm{C}$, fato observado para os $V_{v}$ igual a 4 e $7 \%$. 

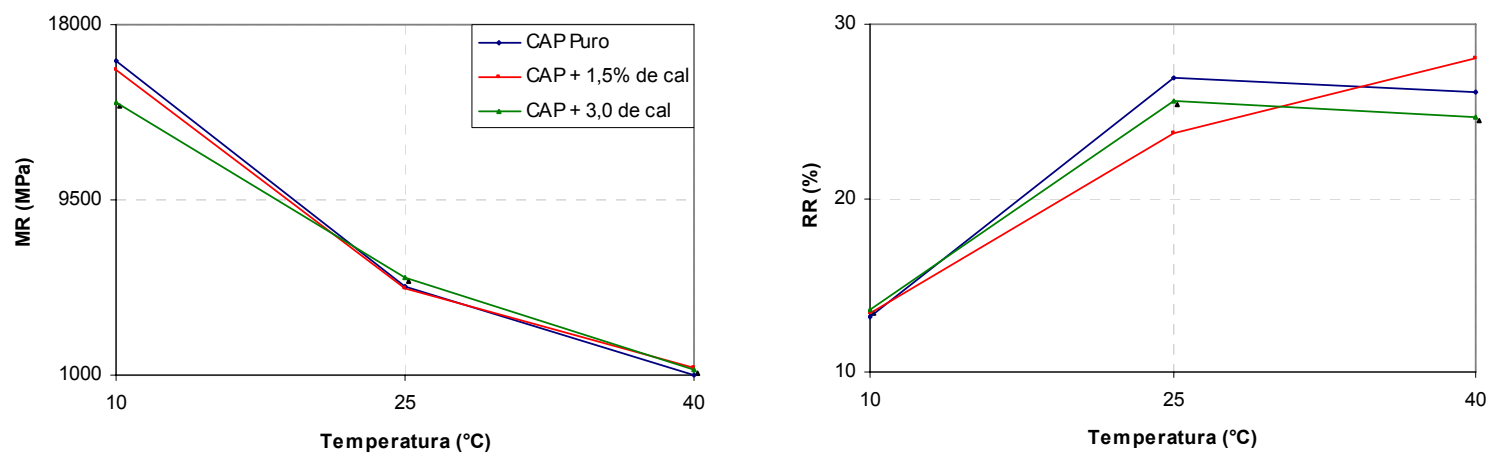

Figura 4.5. Efeito da cal no MR e na RR em diferentes temperaturas para $\quad V_{v}=4 \%$
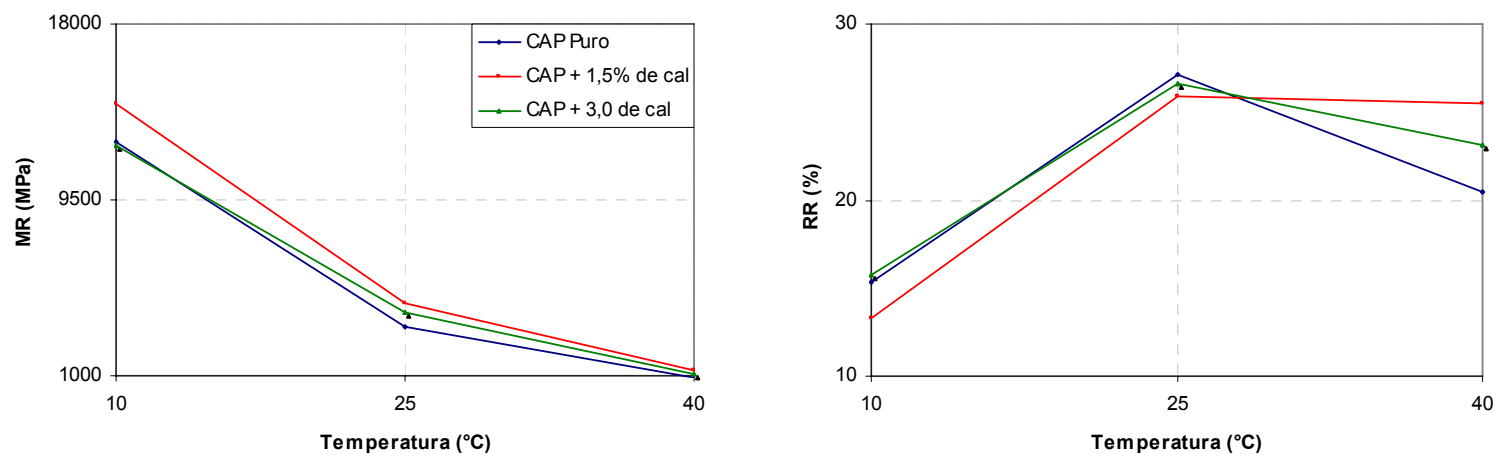

Figura 4.6. Efeito da cal no MR e na RR em diferentes temperaturas para $\quad V_{v}=7 \%$

Quanto à RR, percebe-se pela Figura 4.5, que há uma discreta tendência de redução desse parâmetro para a mistura com CAP $+1,5 \%$ cal e uma redução de sensibilidade desse parâmetro ao efeito da temperatura (dada pela mudança da inclinação da curva). Já a mistura com CAP $+3,0 \%$ de cal exibiu uma manutenção dos valores desse parâmetro em relação à mistura de referência, para $V_{v}=4 \%$. Nota-se pela Figura 4.6 , quanto à $R R$, que a $10^{\circ} \mathrm{C}$, a mistura com $\mathrm{CAP}+1,5 \%$ de cal tem o menor valor do parâmetro, porém existe uma tendência de inversão com o aumento da temperatura, característica essa que pode também ser observada com menor sensibilidade para o CAP $+3,0 \%$ de cal, para $\mathrm{V}_{\mathrm{v}}=7 \%$.

As tendências das curvas de $M R$ e $R R$ da mistura com cal sugerem três observações interessantes: 
- A cal não propicia variação importante na rigidez da mistura asfáltica, tanto para $V_{v}=4 \%$ quanto para $7 \%$;

- A mudança da inclinação das curvas de $M R$ e RR da mistura CAP + 1,2\% cal pode ser interpretada como uma redução da suscetibilidade témica do material, principalmente nas temperaturas 10 a $25^{\circ} \mathrm{C}$;

- A diferença entre tendências de comportamento apresentadas pelas misturas com 1,5 e 3,0\% de cal parece sinalizar uma concentração mais indicada (ponto ótimo) para faixas específicas de temperaturas.

Para visualizar o efeito combinado das misturas contendo PPA e cal, a Figura 4.7 apresenta os gráficos de MR e RR das misturas com CAP + 0,6\% PPA e CAP + $1,2 \%$ PPA e as duas concentrações de cal (1,5 e 3,0\%) em relação à mistura de referência, para $V_{v}=4 \%$. Com relação às misturas com CAP + 0,6\% PPA, observase a predominância do efeito (mais intenso) da presença e do aumento da concentração de PPA expressa pelo aumento da rigidez e pela redução da RR e esse efeito é mais evidente na mistura com $3,0 \%$ de cal, já nas misturas com CAP + 1,2\% PPA, o predomínio dos efeitos do PPA na rigidez e na RR foi mais discreto. 

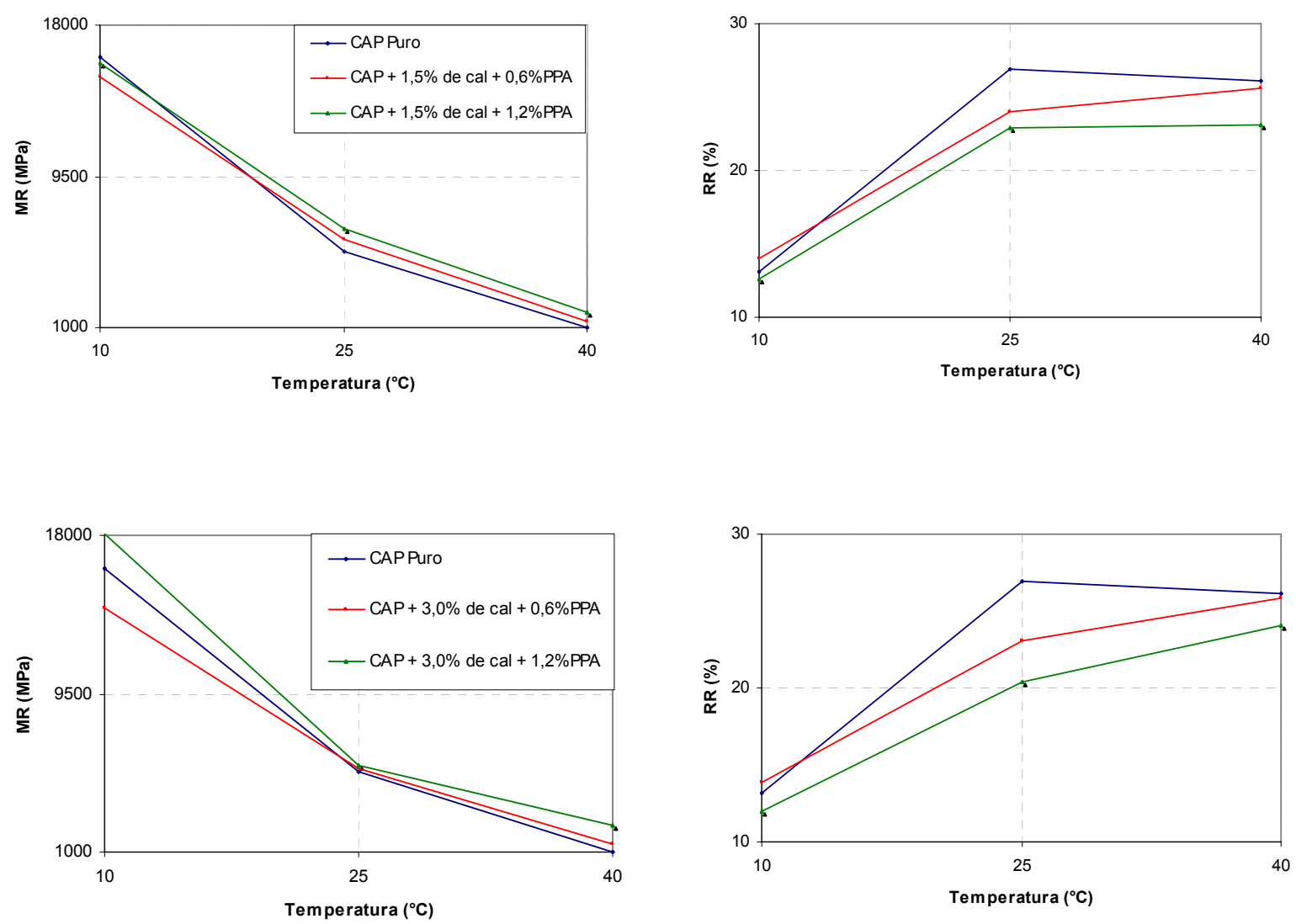

Figura 4.7. Efeito da interação entre PPA e a cal no MR e na RR em diferentes temperaturas para $\mathrm{V}_{\mathrm{v}}=4 \%$

Para visualizar o efeito combinado das misturas contendo PPA e cal para $V_{v}=7 \%$, a Figura 4.8 apresenta os gráficos de MR e RR das misturas com CAP + 0,6\% PPA e CAP + 1,2\% PPA e as duas concentrações de cal (1,5 e 3,0\%) em relação à mistura de referência. Com relação às misturas com CAP + 0,6\% PPA, observa-se a predominância do efeito (mais intenso) da presença e do aumento da concentração de PPA expressa pelo aumento da rigidez e pela redução da RR nas temperaturas de 10 e $25^{\circ} \mathrm{C}$, nota-se a inversão dessa característica em relação ao CAP Puro para a temperatura de $40^{\circ} \mathrm{C}$, e esse efeito é confirmado na mistura com 3,0\% de cal, já nas misturas com CAP $+1,2 \%$ PPA, o predomínio dos efeitos do PPA na rigidez e na RR teve a mesma ordem de grandeza. 

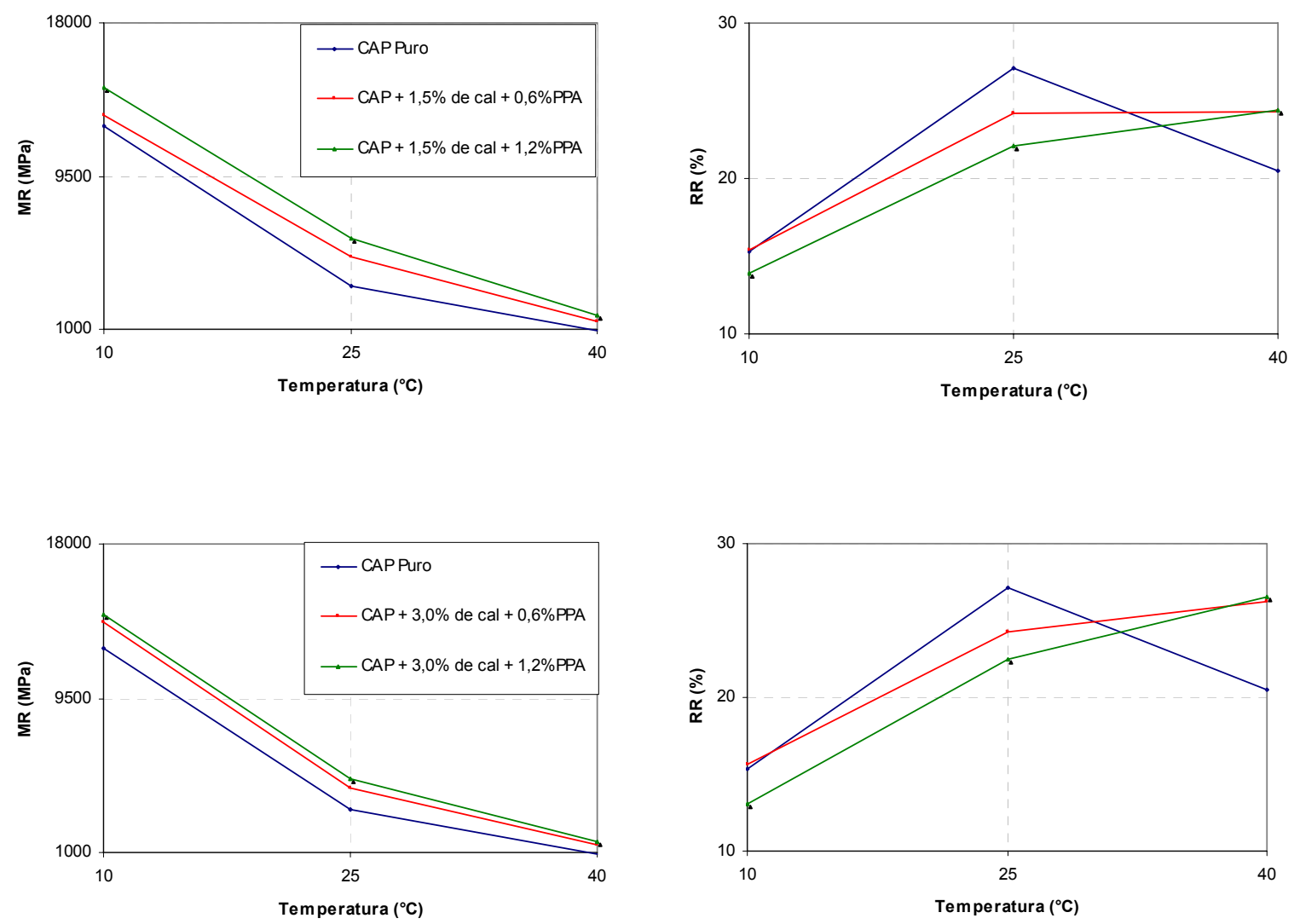

Figura 4.8. Efeito da interação entre PPA e a cal no MR e na RR em diferentes temperaturas para $\mathrm{V}_{\mathrm{v}}=7 \%$

A fim de se compreender melhor a influência da concentração dos modificadores no MR e na RR, as Figuras 4.9 e 4.10 apresentam, respectivamente, as curvas de variação de MR e RR em função do aumento da concentração de cal e de PPA nas diferentes temperaturas. Este tipo de gráfico mostra a forma como cada modificador atua na rigidez e na recuperação da mistura asfáltica. Das Figuras 4.9 e 4.10 é possível dizer que o PPA propicia um incremento de rigidez nas misturas para todas as temperaturas testadas, tanto para $V_{v}=4 \%$ quanto para $7 \%$. Já a cal tende a imprimir um efeito mais discreto e, no caso da temperatura de $10^{\circ} \mathrm{C}$, esse efeito é contrário, ou seja, o aumento da concentração de cal causa redução de MR para $V_{V}$ $=4 \%$, e esse efeito mais expressivo para $V_{v}=7 \%$. O distanciamento entre as curvas evidencia, mais uma vez, que a suscetibilidade térmica, em termos absolutos, é maior na faixa de temperaturas mais amenas (de 10 a $25^{\circ} \mathrm{C}$ ). 

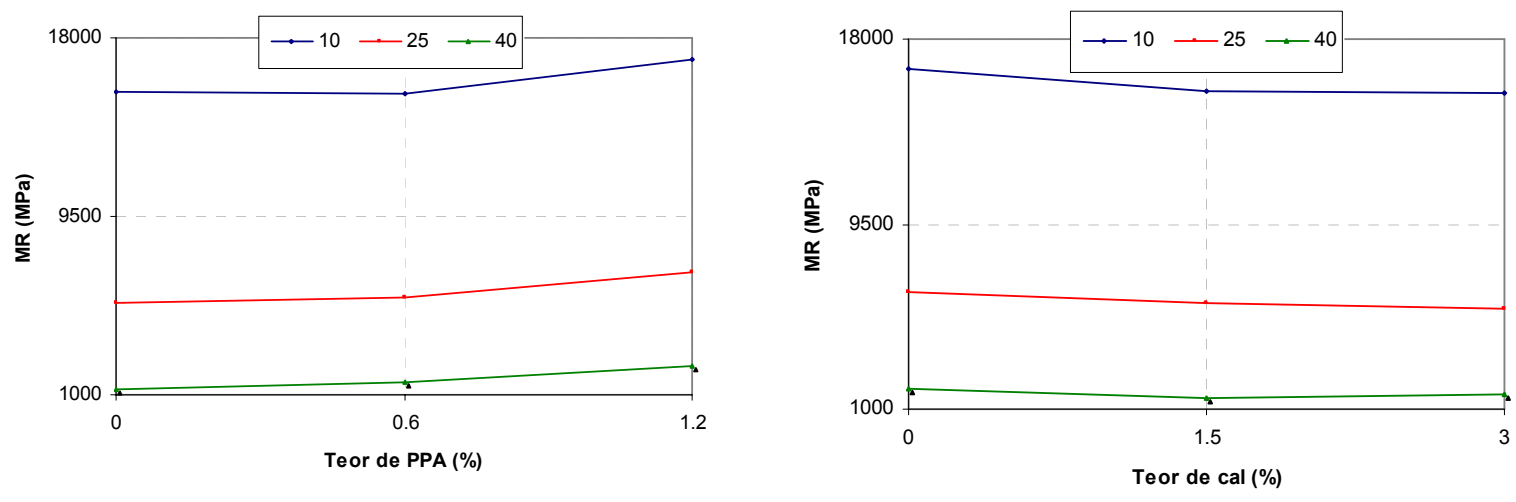

Figura 4.9. Efeito do aumento da concentração de cal e PPA no MR em diferentes temperaturas para $\mathrm{V}_{\mathrm{v}}=4 \%$
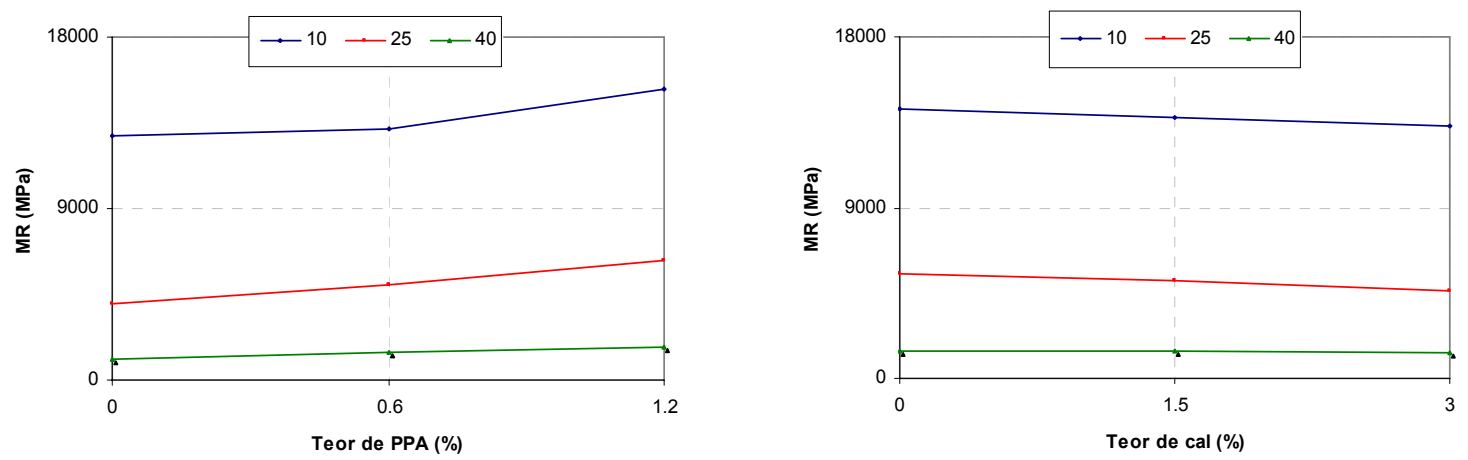

Figura 4.10. Efeito do aumento da concentração de cal no MR e PPA no MR em diferentes temperaturas para $\mathrm{Vv}=7 \%$
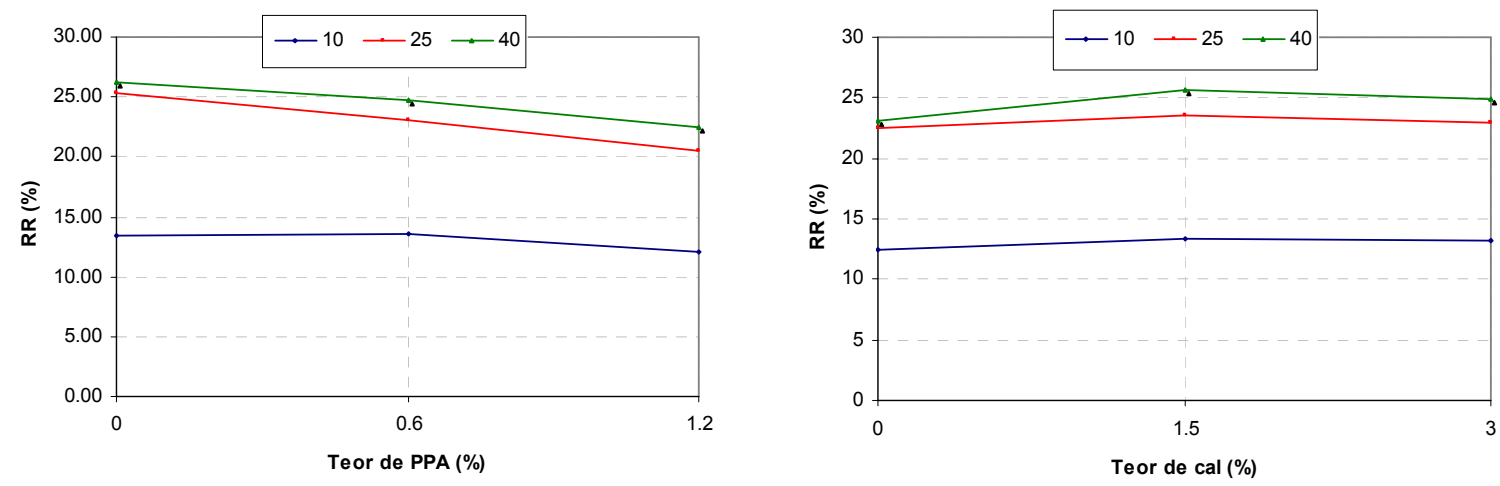

Figura 4.11. Efeito do aumento da concentração de cal e PPA na RR em diferentes temperaturas para $V_{v}=4 \%$ 

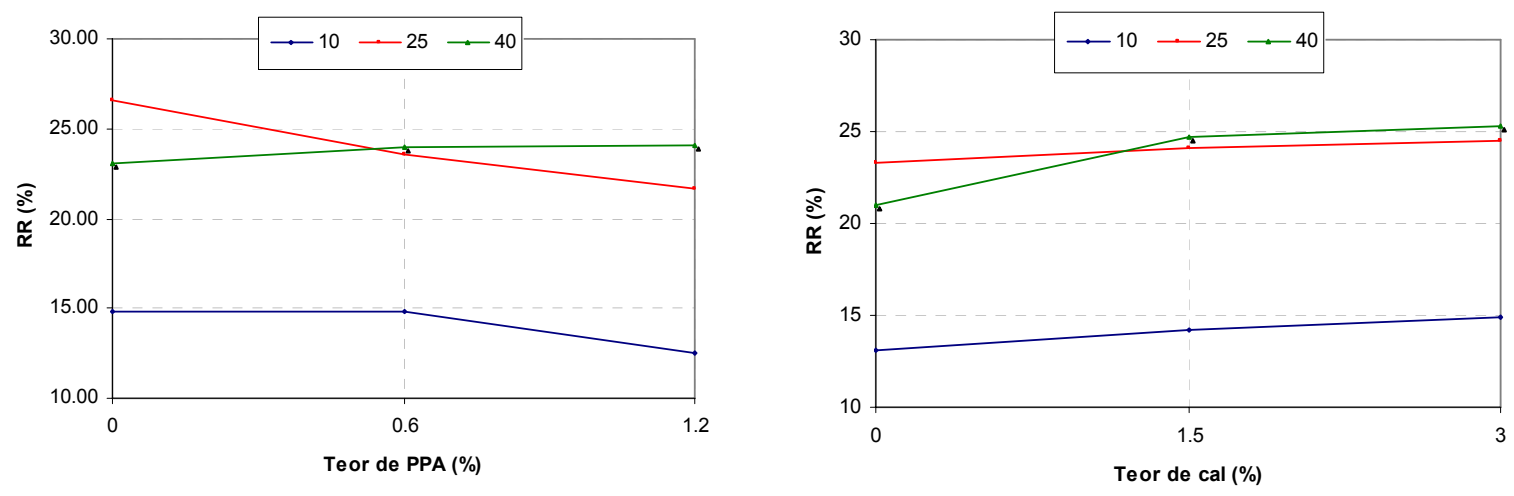

Figura 4.12. Efeito do aumento da concentração de cal e PPA na RR em diferentes temperaturas para $\mathrm{V}_{\mathrm{v}}=7 \%$

Das Figuras 4.11 e 4.12, observa-se que a flexibilidade das misturas asfálticas não pode ser melhorada com a adição de PPA, mas essa tendência se inverte para a temperatura de $40^{\circ} \mathrm{C}$, para o volume de vazio igual a $7 \%$. No caso das misturas com cal, o aumento da sua concentração e a ocorrência do ganho de flexibilidade é mais dependente da temperatura, de tal forma que na faixa de temperatura de 10 a $25^{\circ} \mathrm{C}$, independentemente do teor de cal adicionado, há um correspondente aumento de flexibilidade, enquanto que na faixa de 25 a $40^{\circ} \mathrm{C}$, o efeito da adição de cal só se dá para teores de até $1,5 \%$, sugerindo um teor máximo de cal a ser utilizado em misturas asfálticas, tanto para $4 \%$ quanto para $7 \%$ de $\mathrm{V}_{\mathrm{v}}$.

$\mathrm{Na}$ Tabela 4.5, apresentam-se as propriedades das misturas asfálticas submetidas ao procedimento de umidade induzida, ou seja, com condicionamento e sem condicionamento (dito grupo de controle), para corpos-de-prova com 7\% de volume de vazios. Verifica-se o efeito do condicionamento para as diferentes concentrações de aditivos e modificadores utilizados. 
Tabela 4.5. Módulos de resiliência das misturas submetidas ao procedimento de umidade induzida $\left(\mathrm{V}_{\mathrm{v}}=7 \%\right)$.

\begin{tabular}{|c|c|c|c|c|c|c|}
\hline \multirow{2}{*}{$\frac{\text { Temperatura }\left({ }^{\circ} \mathrm{C}\right)}{\text { Propriedades }}$} & \multicolumn{3}{|c|}{$\begin{array}{c}25 \\
\text { (Sem condicionamento) }\end{array}$} & \multicolumn{3}{|c|}{$\begin{array}{c}25 \\
\text { (Com condicionamento) }\end{array}$} \\
\hline & $\begin{array}{c}\mathrm{MR} \\
(\mathrm{MPa})\end{array}$ & $\begin{array}{l}\mathrm{RR} \\
(\%)\end{array}$ & $\begin{array}{l}\text { Atraso } \\
\left(10^{-2} \mathrm{~s}\right)\end{array}$ & $\begin{array}{c}\mathrm{MR} \\
(\mathrm{MPa})\end{array}$ & $\begin{array}{l}\mathrm{RR} \\
(\%)\end{array}$ & $\begin{array}{l}\text { Atraso } \\
\left(10^{-2} \mathrm{~s}\right)\end{array}$ \\
\hline CAP Puro & 3352 & 26,77 & 4,67 & 3810 & 27,20 & 4,54 \\
\hline $\mathrm{CAP}+0,6 \% \mathrm{PPA}$ & 5517 & 25,28 & 4,65 & 5145 & 23,61 & 4,49 \\
\hline $\mathrm{CAP}+1,2 \% \mathrm{PPA}$ & 7649 & 20,37 & 4,42 & 6899 & 19,27 & 4,34 \\
\hline $\mathrm{CAP}+1,5 \%$ de cal & 4489 & 25,80 & 4,59 & 6003 & 24,12 & 4,43 \\
\hline $\begin{array}{c}\text { CAP }+1,5 \% \text { de cal }+ \\
0,6 \% \text { de PPA }\end{array}$ & 5037 & 24,16 & 4,52 & 7903 & 18,87 & 4,27 \\
\hline $\begin{array}{c}\text { CAP }+1,5 \% \text { de cal }+ \\
1,2 \% \text { de PPA }\end{array}$ & 6068 & 22,49 & 4,40 & 6822 & 18,88 & 4,26 \\
\hline CAP $+3,0 \%$ de cal & 4095 & 26,95 & 4,61 & 5473 & 24,51 & 4,44 \\
\hline $\begin{array}{c}\text { CAP }+3,0 \% \text { de cal }+ \\
0,6 \% \text { de PPA }\end{array}$ & 4571 & 24,21 & 4,48 & 4777 & 24,53 & 4,44 \\
\hline $\begin{array}{c}\text { CAP }+3,0 \% \text { de cal }+ \\
1,2 \% \text { de PPA } \\
\end{array}$ & 5044 & 21,76 & 4,36 & 8511 & 17,66 & 4,27 \\
\hline
\end{tabular}

Nas Figuras 4.13 e 4.14, apresentam-se os efeitos do condicionamento para diferentes concentrações de cal e PPA, respectivamente. Nota-se que a adição de cal melhora significativamente a rigidez com o condicionamento, em relação ao grupo de puro, chamado de "Sem cal", que para concentrações menores de cal $(1,5 \%$ de cal), os valores médios absolutos obtidos foram melhores quando comparados com maiores concentrações de cal (3,0\% de cal), mesmo que mantido o paralelismo entre estas duas retas. Em relação à $R R$, nota-se que a mistura tende a se tornar mais elástica para misturas com 1,5\% de cal, com diminuição do "ganho" de elasticidade para misturas com 3,0\% de cal, quando condicionado (Figura 4.13). Com relação à modificação com PPA (Figura 4.14), nota-se que para maiores concentrações de PPA, a mistura se torna mais rígida, ficando evidente que, além de mantido o paralelismo entre as curvas das concentrações de 0,6 e 1,2\% de PPA, existe uma melhora da suscetibilidade ao dano por umidade, devido à distância entre elas. Quanto ao parâmetro RR, a mistura, quando condicionada, tende a se tornar mais elástica com o aumento da concentração de PPA. 

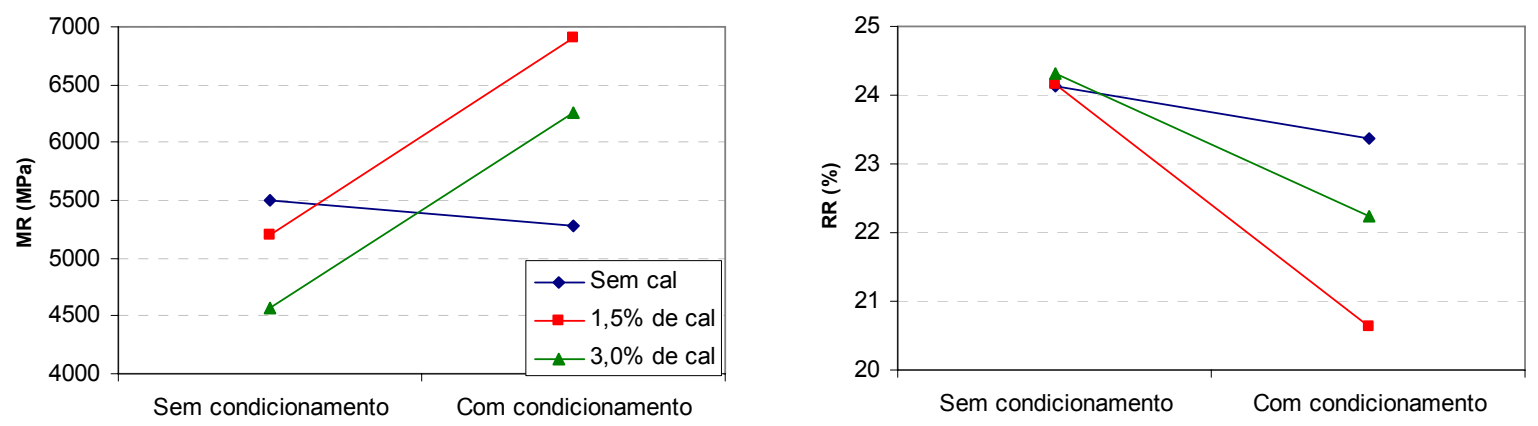

Figura 4.13. Efeito do condicionamento no MR e RR para diferentes concentrações de PPA
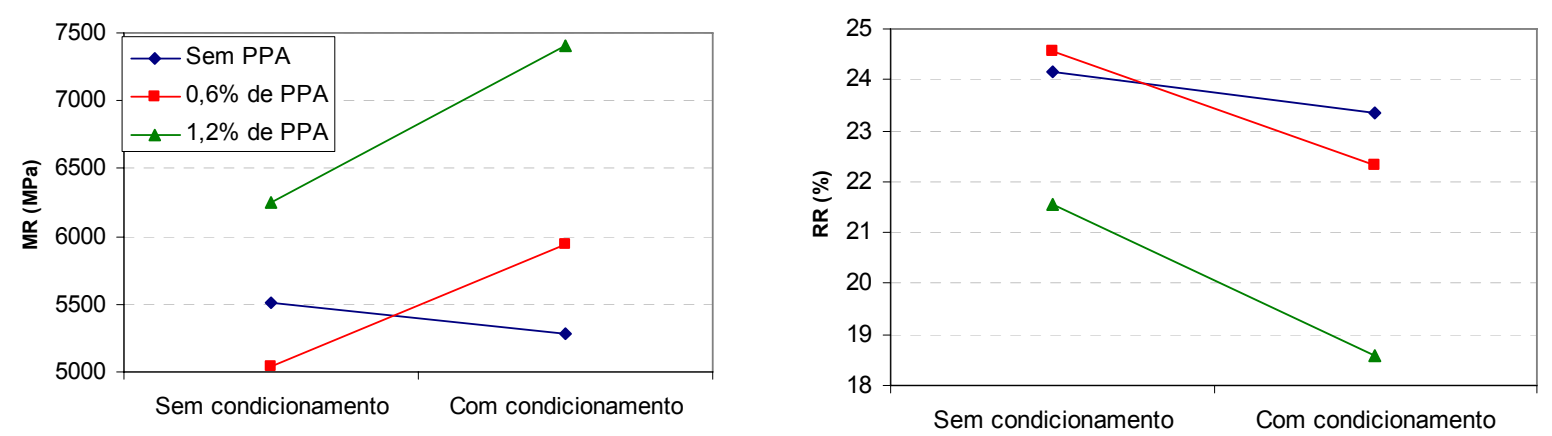

Figura 4.14. Efeito do condicionamento no MR e RR para diferentes concentrações de cal

A interação entre a adição da cal e a modificação com PPA pode ser observada nas Figuras 4.15 e 4.16. Nelas nota-se o efeito predominante do aumento da concentração de PPA no aumento da rigidez e, para a $R R$, a mistura se torna mais elástica com 0 aumento da concentração de PPA, considerando-se o condicionamento da mistura estudada, com exceção do CAP $+3,0 \%$ de cal $+0,6 \%$ de PPA que manteve as características de rigidez e de elasticidade evidenciada pela aproximação da curva à horizontal. 

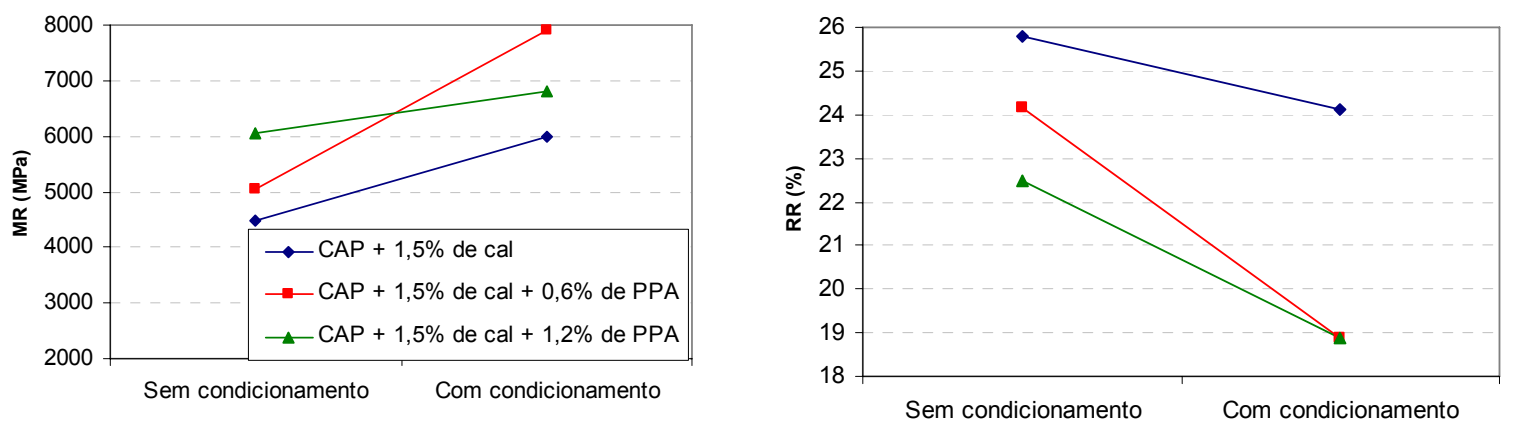

Figura 4.15. Efeito da interação entre PPA e cal em função do condicionamento para MR e RR
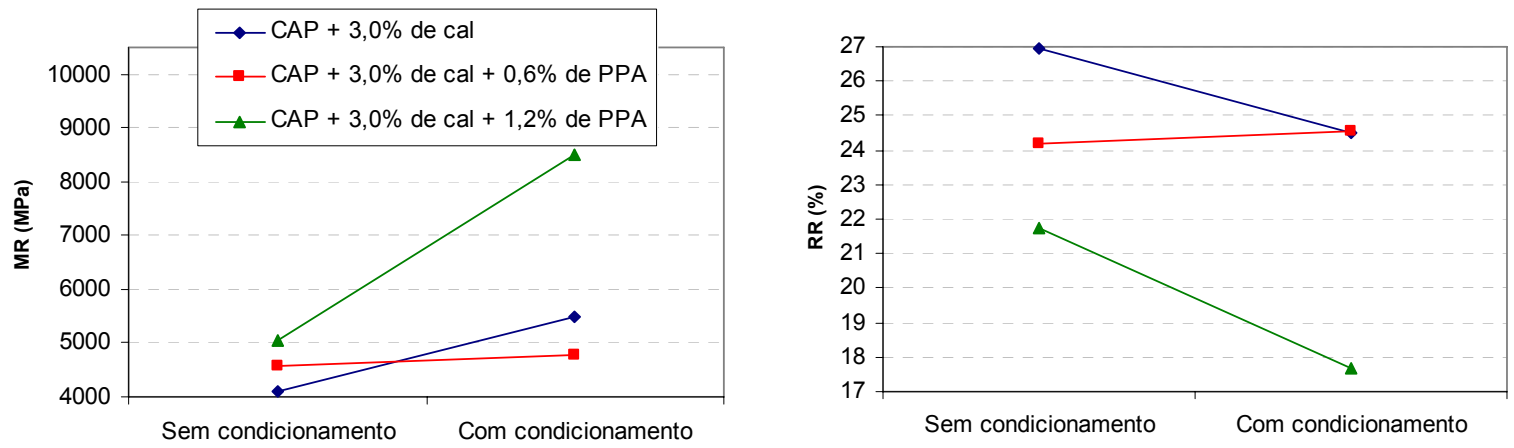

Figura 4.16. Efeito da interação entre PPA e cal em função do condicionamento para MR e RR

Na Figura 4.17 são apresentadas as curvas do parâmetro Atraso em função do condicionamento. O Atraso pode ser interpretado como o tempo decorrido entre o pico de carregamento do corpo-de-prova e a leitura do máximo deslocamento pelo LVDT, caracterizando de maneira qualitativa a tendência mais viscosa da mistura, em função do aumento tempo. Nota-se que a cal "sugere" a concentração a ser utilizada na mistura o valor de $1,5 \%$, e que a modificação com PPA tende a proporcionar uma maior elasticidade conforme se aumenta a concentração de PPA; já o efeito da interação entre o PPA e a cal, proporciona misturas mais elásticas, com exceção do CAP $+3,0 \%$ de cal $+0,6 \%$ de PPA, que mantém sua característica elástica com o condicionamento. Em resumo, a análise da interação entre a cal e o PPA sugere concentrações máximas de 1,5\%, e 0,6\% de PPA. 

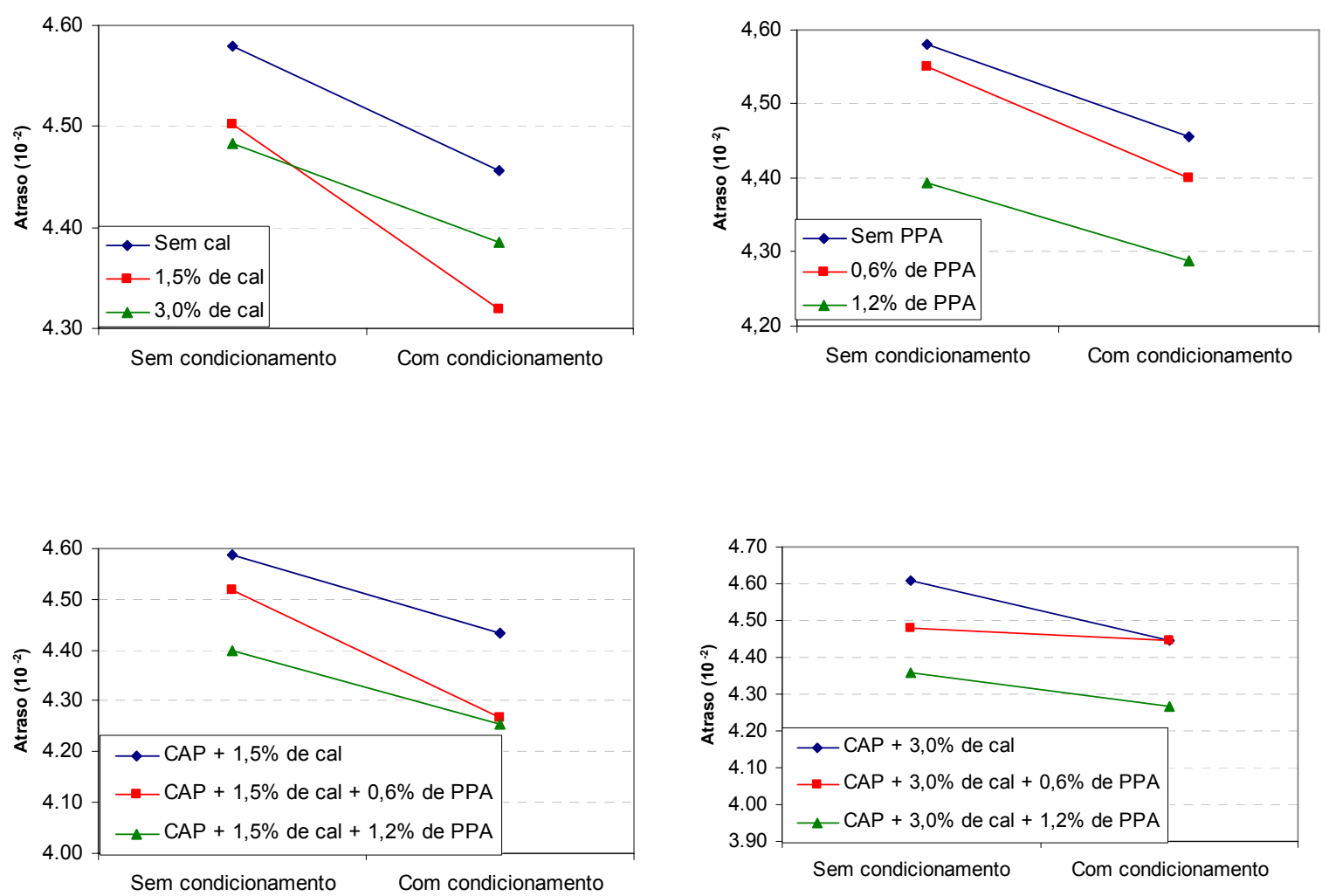

Figura 4.17. Variação do Atraso em função da interação de PPA e cal

\subsection{APRESENTAÇÃO E DICUSSÃO DOS RESULTADOS DA RESISTÊNCIA À TRAÇÃO E DO EFEITO DO CONDICIONAMENTO PARA O MR, RR E ATRASO}

Na Tabela 4.6 são apresentadas as propriedades originais das misturas asfálticas produzidas para a análise da influência do volume de vazios e do condicionamento no dano por umidade na resistência à tração. Os valores das propriedades são apresentados em termos médios para grupos de 3 corpos-de-prova. As séries de informações chamadas de "Sem cal" e "Sem PPA" representam a média destas séries. De maneira geral, pode-se observar que os valores das propriedades das misturas com $4 \%$ de $V_{v}$ são maiores que os de $7 \%$, e que as propriedades quanto ao condicionamento esteve sempre associada ao aumento ou manutenção das propriedades testadas. Vale lembrar que essas misturas foram moldadas e foram submetidas ao condicionamento conforme recomendações da AASHTO T 283. 
Tabela 4.6. Propriedades das misturas asfálticas com diferentes $V_{v}$

\begin{tabular}{|c|c|c|c|c|c|c|c|c|c|c|}
\hline \multirow{3}{*}{ Propriedades } & \multirow{2}{*}{\multicolumn{3}{|c|}{$\begin{array}{c}4 \\
\text { Sem } \\
\text { condicionamento }\end{array}$}} & \multicolumn{7}{|c|}{7} \\
\hline & & & & \multicolumn{3}{|c|}{ Sem condicionamento } & \multicolumn{3}{|c|}{ Com condicionamento } & \multirow{2}{*}{$\begin{array}{l}\text { RRT } \\
\text { (Cond.) }\end{array}$} \\
\hline & $\begin{array}{l}\mathrm{RR} \\
(\%)\end{array}$ & $\begin{array}{l}\text { Atraso } \\
\left(10^{-2} \mathrm{~s}\right)\end{array}$ & $\begin{array}{l}\text { RT } \\
(\%)\end{array}$ & $\begin{array}{l}\text { RR } \\
(\%)\end{array}$ & $\begin{array}{l}\text { Atraso } \\
\left(10^{-2} \mathrm{~s}\right)\end{array}$ & $\begin{array}{c}\mathrm{RT} \\
(\mathrm{MPa})\end{array}$ & $\begin{array}{l}\text { RR } \\
(\%)\end{array}$ & $\begin{array}{l}\text { Atraso } \\
\left(10^{-2} \mathrm{~s}\right)\end{array}$ & $\begin{array}{c}\mathrm{RT} \\
(\mathrm{MPa})\end{array}$ & \\
\hline $\begin{array}{c}\text { CAP Puro } \\
\text { CAP }+0.6 \%\end{array}$ & 26,90 & 4,6 & 1,67 & 26,77 & 4,7 & 1,19 & 27,20 & 4,5 & 1,11 & 0,93 \\
\hline $\begin{array}{c}\text { PPA } \\
\text { CAP }+1,2 \%\end{array}$ & 22,26 & 4,4 & 1,73 & 25,28 & 4,7 & 1,26 & 23,61 & 4,5 & 1,28 & 1,01 \\
\hline $\begin{array}{c}\text { PPA } \\
\text { CAP + } 1,5 \%\end{array}$ & 18,23 & 4,3 & 1,94 & 20,37 & 4,4 & 1,58 & 19,27 & 4,3 & 1,53 & 0,97 \\
\hline $\begin{array}{c}\text { de cal } \\
\text { CAP + 1,5\% }\end{array}$ & 23,72 & 4,5 & 1,46 & 25,80 & 4,6 & 1,13 & 24,12 & 4,4 & 1,22 & 1,08 \\
\hline $\begin{array}{c}\text { de cal }+0,6 \% \\
\text { de PPA } \\
\text { CAP + 1,5\% }\end{array}$ & 23,98 & 4,5 & 1,56 & 24,16 & 4,5 & 1,12 & 18,87 & 4,3 & 1,20 & 1,07 \\
\hline $\begin{array}{c}\text { de cal }+1,2 \% \\
\text { de PPA } \\
\text { CAP }+3,0 \%\end{array}$ & 22,92 & 4,4 & 1,88 & 22,49 & 4,4 & 1,19 & 18,88 & 4,3 & 1,49 & 1,25 \\
\hline $\begin{array}{c}\text { de cal } \\
\text { CAP }+3,0 \%\end{array}$ & 25,58 & 4,6 & 1,42 & 26,95 & 4,6 & 1,10 & 24,51 & 4,4 & 1,14 & 1,04 \\
\hline $\begin{array}{c}\text { de cal }+0,6 \% \\
\text { de PPA } \\
\text { CAP }+3,0 \%\end{array}$ & 23,10 & 4,4 & 1,69 & 24,21 & 4,5 & 1,20 & 24,53 & 4,4 & 1,22 & 1,01 \\
\hline de PPA & 20,37 & 4,3 & 1,74 & 21,76 & 4,4 & 1,25 & 17,66 & 4,3 & 1,26 & 1,01 \\
\hline
\end{tabular}

Para visualizar o comportamento mecânico das misturas, na Figura 4.18 são apresentadas as curvas de RT e Atraso em função da variação de $V_{v}$. Nela nota-se que a resistência à ruptura por tração das misturas apresenta reduções importantes devido ao aumento do volume de vazios, com certo paralelismo entre a curva do grupo de referência $\mathrm{e}$ as duas concentrações de cal, que perderam aproximadamente $25 \%$ da resistência de ruptura à tração com a variação do $V_{v}$ de 4 para $7 \%$, sendo que as misturas com cal apresentam valores de RT muito próximos e com reduções também parecidas em função do aumento de $V_{v}$. Analisando-se $o$ Atraso nota-se que com a variação do $V_{v}$, houve um aumento desse parâmetro, e que aumento da concentração de cal o reduz, indicando tendência de manutenção das propriedades elásticas da mistura com o uso da cal. 

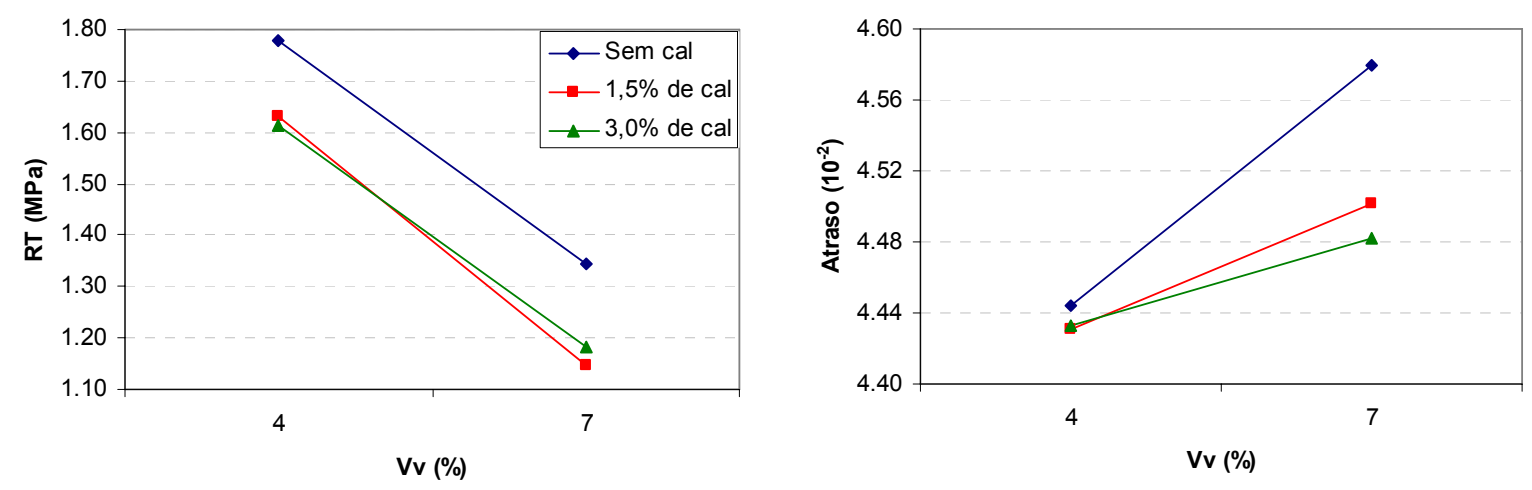

Figura 4.18. Efeito do aumento da concentração de cal na RT e no Atraso

Para visualização do efeito do aumento da concentração de PPA, na Figura 4.19 apresentam-se as curvas do grupo de controle e com duas concentrações de PPA. Nela nota-se que para $\mathrm{V}_{\mathrm{v}}=4 \%$, a modificação com 0,6 e 1,2\% de PPA ocasionou aumento no valor da RT de 10 e $23 \%$, respectivamente. Já para $\mathrm{V}_{\mathrm{v}}=7 \%$ comparado a $4 \%$, houve reduções da ordem de 23,28 e $28 \%$, para os grupos de controle, $0,6 \%$ de PPA e 1,2\% de PPA, respectivamente; com os grupos com PPA apresentando reduções maiores da $\mathrm{RT}$. Em relação ao Atraso, para $\mathrm{V}_{\mathrm{v}}=4 \%$ comparando-se ao grupo de controle, houve diminuição de 3 e $5 \%$, para 0,6 e 1,2\% de PPA, respectivamente; já variando-se o $\mathrm{V}_{\mathrm{v}}$ de 4 para $7 \%$, houve aumentos no Atraso de 1,$7 ; 4,5$ e 2,3\%, para os grupos de controle, 0,6 e 1,2\% de PPA, respectivamente.
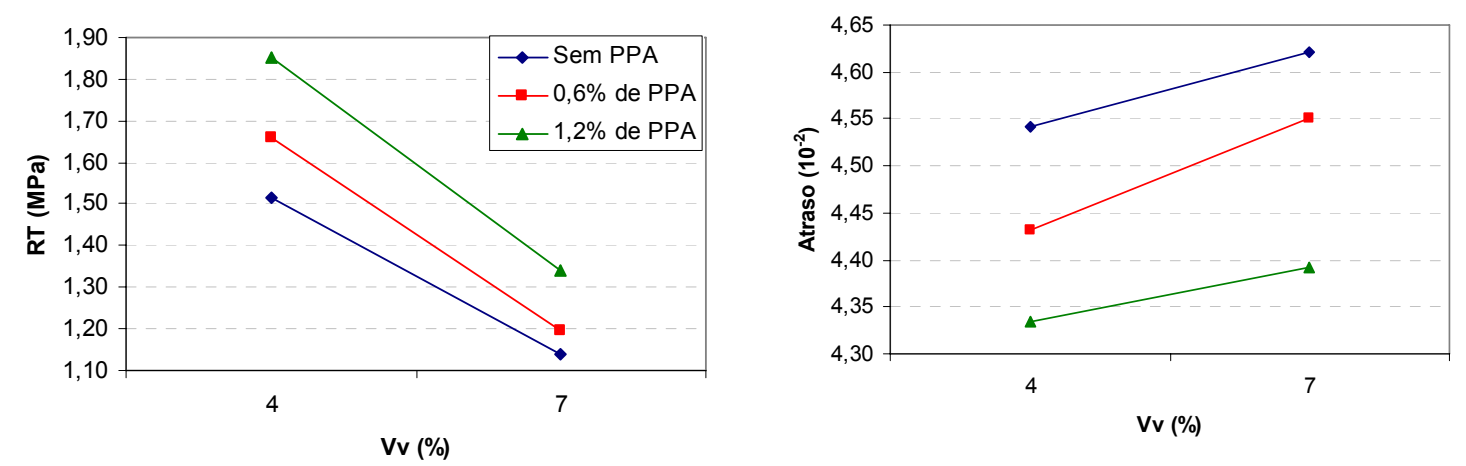

Figura 4.19. Efeito do aumento da concentração de PPA no RT e no Atraso

A Figura 4.20 mostra o efeito da interação entre a cal e o PPA. Nela se nota para $V_{v}$ $=4 \%$ e $1,5 \%$ de cal, aumento da RT de 6,8 e 28,8\% para as concentrações de 0,6 e 
1,2\% de PPA, em relação ao grupo sem PPA; já para 3,0\% de cal, houve aumento da RT de 19 e 22,5\% para as concentrações de 0,6 e 1,2\% de PPA, em relação ao grupo sem PPA. Para $V_{v}=7 \%$ e $1,5 \%$ de cal houve aumento na RT de 0,9 e 5,3\% para as concentrações de 0,6 e $1,2 \%$ de PPA, em relação ao grupo sem PPA, e para 3,0\% de cal ocorreram aumentos de 9 e 13,6\% para as concentrações de 0,6 e $1,2 \%$ de PPA. No caso do Atraso, de uma maneira geral, a presença do PPA produz uma resposta mais rápida (mais elástico) independente dos teores de cal ou PPA utilizados e do volume de vazios, a exceção da mistura com $4 \%$ de vazios, $1,5 \%$ de cal e $0,6 \%$ de PPA.
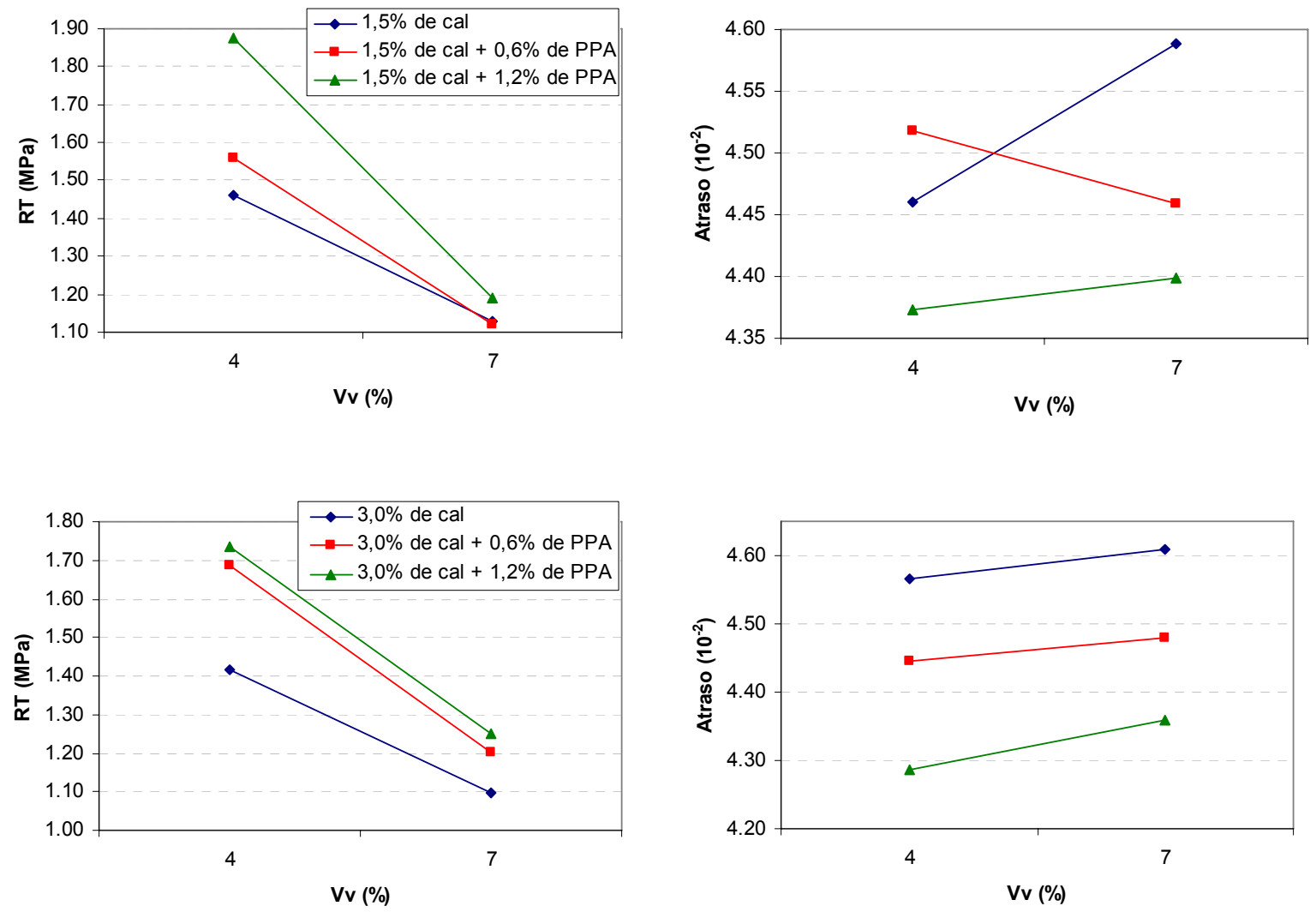

Figura 4.20. Efeito da interação entre o PPA e a cal na RT e no Atraso para diferentes $V_{v}$

A Figura 4.21 apresenta os efeitos dos aumentos da concentrações de cal e PPA na Recuperação Retardada. Nota-se que o Gráfico que analisa a cal isaladamente, que $1,5 \%$ de cal é a concentração com melhor desempenho se comparado com o grupo de controle e 3,0\% de cal. Já para o gráfico com o PPA, as misturas asfálticas com melhores flexibilidades foram as de $0,6 \%$ de PPA. O efeito combinado, analisando a 
concentração de 1,5\% de cal, nota-se que a melhor flexibilidade é conseguida com $0,6 \%$ de PPA, já para 3,0\% de cal, o aumento da concentração de PPA indica diminuição da flexibilidade da mistura asfáltica.
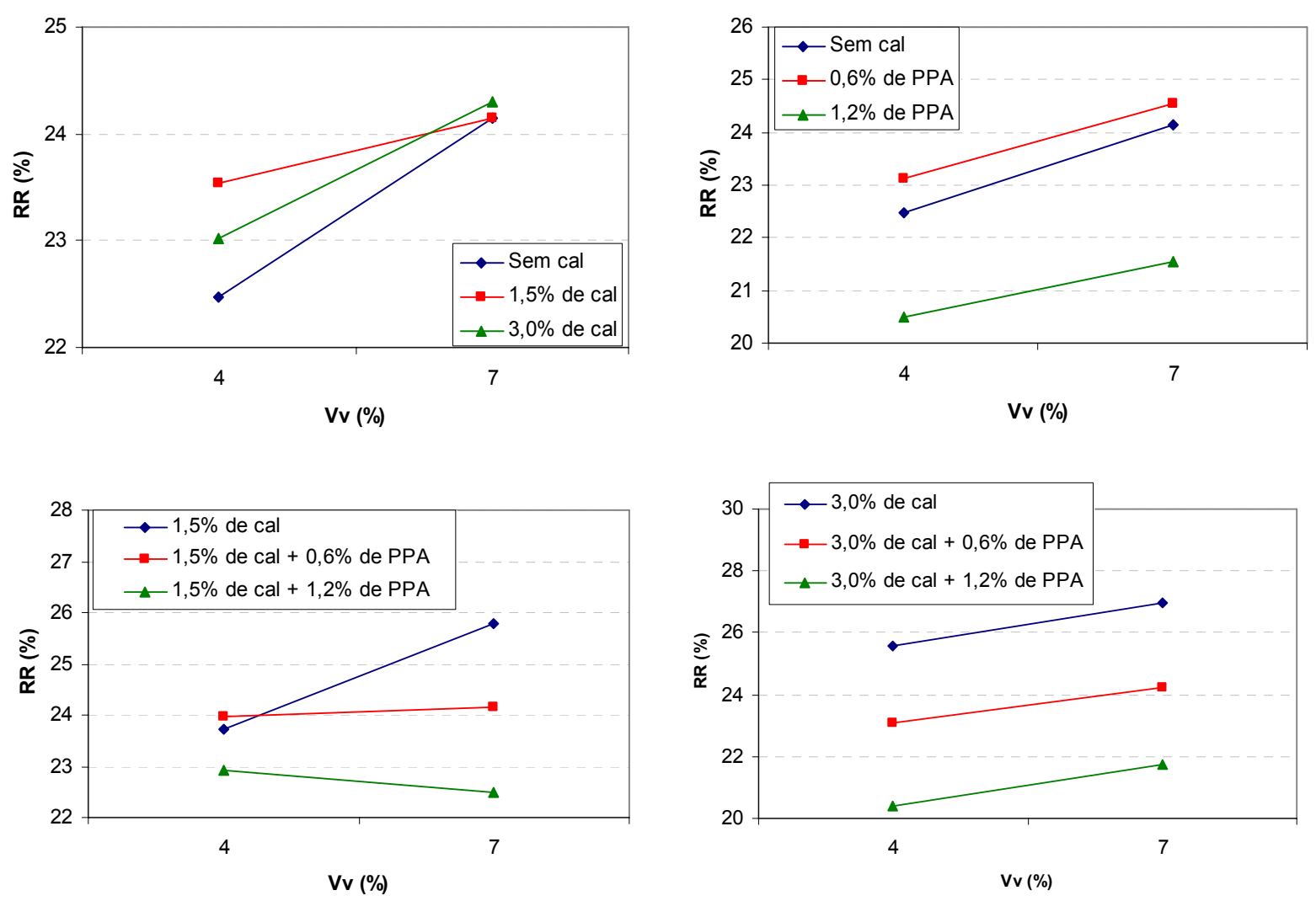

Figura 4.21. Efeito isodado e da interação entre o PPA e a cal na RR diferentes $V_{v}$

A Figura 4.22 apresenta os efeitos dos aumentos das concentrações de cal e PPA na resistência à tração sem e com condicionamento. Com relação ao efeito da adição de cal nos valores da RT, para as misturas na condição sem condicionamento, quando comparados ao grupo sem cal, eles apresentaram diminuição do valor médio em 15 e 18\% para 1,5 e 3,0\% de cal, respectivamente. Já após o condicionamento, ainda em relação ao efeito da cal, houve diminuição significativa da RT somente para a mistura com 3\% de cal, com redução da ordem de $8 \%$, em relação à de controle. Com relação ao efeito do PPA, nota-se que sem condicionamento, a modificação com 0,6 e 1,2\% de PPA alterou significativamente a RT da mistura, com aumento da RT da ordem de 5 e 18\%; respectivamente; já para 
as misturas condicionadas, comparadas à não condicionada, houve um aumento da RT da ordem de $6 \%$ para a com $0,6 \%$ de PPA e $23 \%$ para a com $1,2 \%$ de PPA.
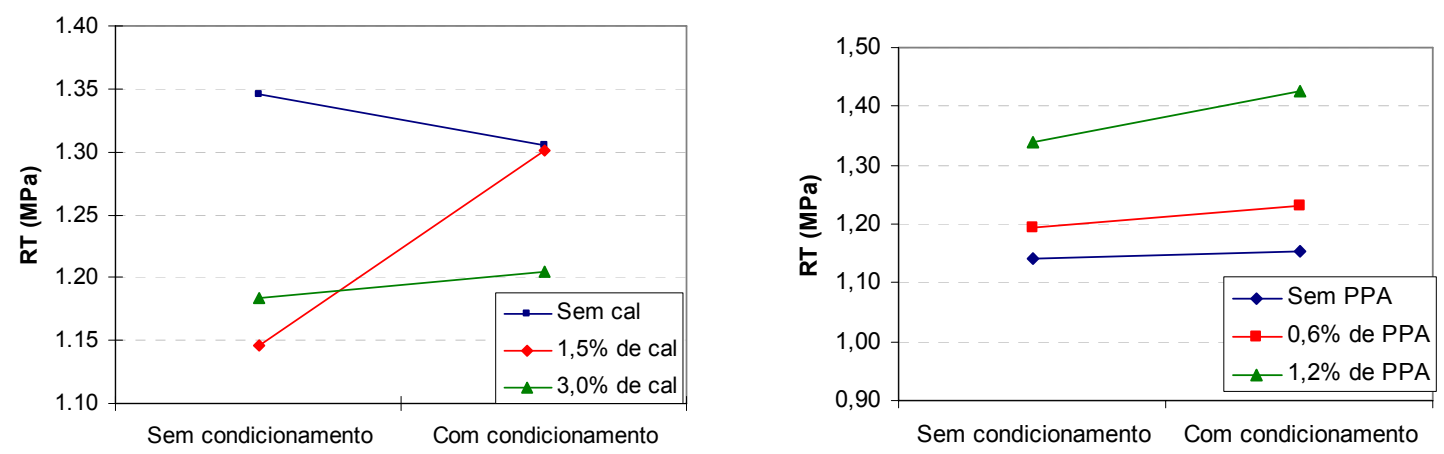

Figura 4.22. Efeitos do aumento da concentração de cal e PPA na RT

Na Figura 4.23 apresenta-se o efeito da interação entre a modificação com PPA e a adição de cal na RT das misturas asfálticas. Para as misturas com 1,5\% de cal a utilização de 0,6\% de PPA causou a redução da RT em, aproximadamente, 1\% para a mistura não condicionada e em torno de $2 \%$ para a condicionada; já o uso de 1,2\% de PPA com 1,5\% de cal levou ao aumento da RT em 6\% e 22\% para as misturas não condicionada e condicionada, respectivamente. No caso das misturas com $3 \%$ de cal houve aumento da RT tanto 0,6 (aproximadamente 9\%) como para 1,2\% de PPA (aproximadamente 15\%), sem ou com condicionamento. 

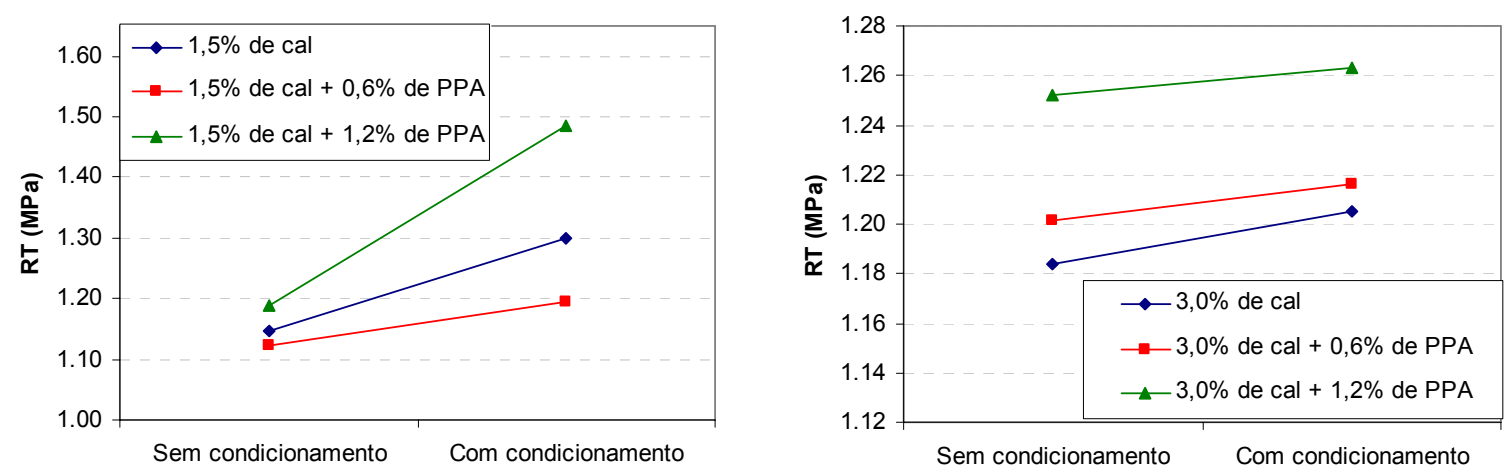

Figura 4.23. Efeito da interação entre o PPA e a cal na RT para as misturas sem e com condicionamento

$\mathrm{Na}$ Figura 4.24 mostra a relação de resistência à tração (RRT) de misturas asfálticas. Considerando-se que misturas asfálticas que apresentarem valores de RRT maiores ou iguais a $70 \%$ (ou $80 \%$ ) poderiam ser consideradas não suscetíveis à ação da umidade, todas as composições aqui testadas apresentaram desempenho satisfatório. Observando-se essa figura, notam-se também as seguintes tendências: apenas a modificação do asfalto com PPA mantém os valores da RT; apenas a adição da cal à mistura eleva ligeiramente a resistência à tração após o condicionamento; a combinação da cal com o PPA mantém ou eleva da RT após o condicionamento, notadamente para $1,5 \%$ de cal. 


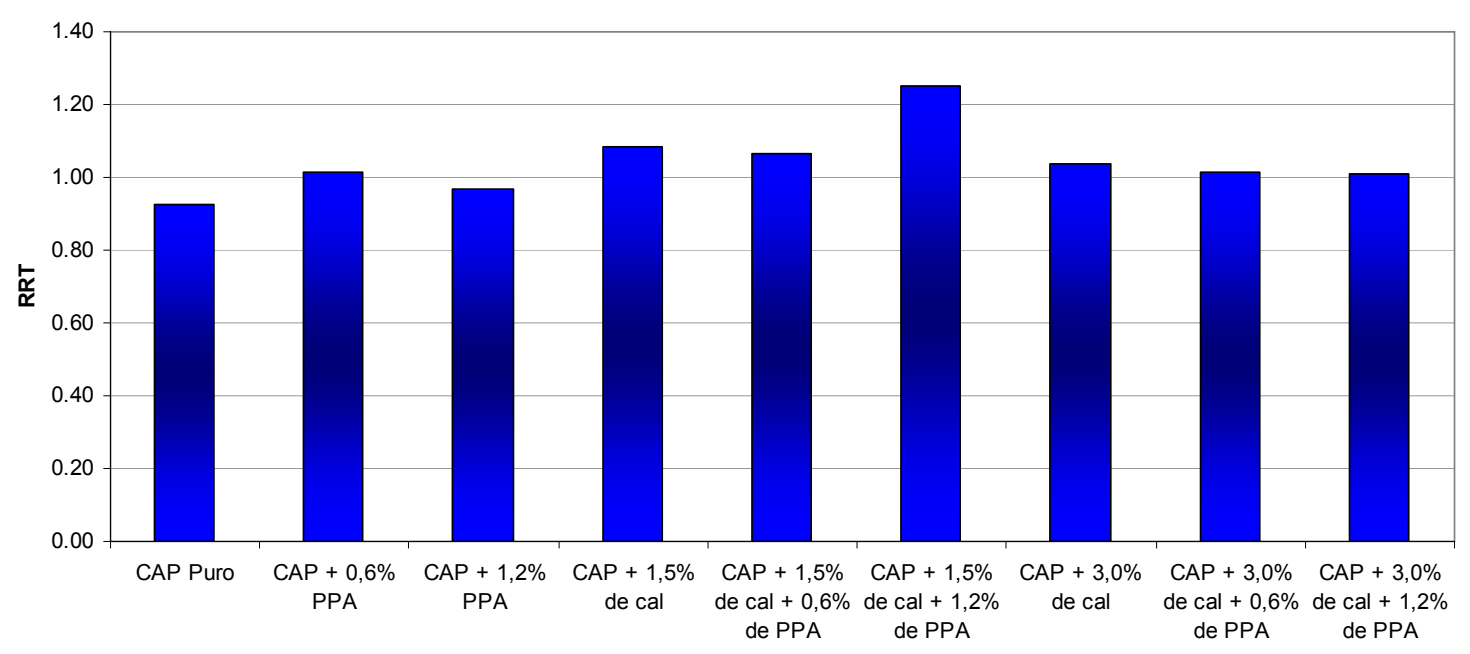

Figura 4.24. Relação de resistência à tração (RRT) das misturas (efeito do condicionamento)

\subsection{VISUALIZAÇÃO DO TIPO DE DANO PELO REGISTRO FOTOGRÁFICO}

O registro fotográfico dos corpos-de-prova após a ruptura por compressão diametral (determinação da RT) mostrou-se uma ferramenta muito interessante para a visualização do efeito do volume de vazios e do uso dos aditivos. Observando-se as Figuras 4.25 a 4.27, nota-se que a porcentagem de exposição de agregados em relação à sua área total é, em geral maior nos corpos-de-prova com $7 \%$ de $V_{v}$, e o tipo de ruptura que ocorre é a ruptura adesiva (ligação entre agregado/asfalto).

Analisando-se a Figura 4.26, nota-se que o aumento da concentração de ácido polifosfórico, ocasionou o aumento da concentração da ruptura de agregados nas extremidades do corpo-de-prova, indicando ruptura por cisalhamento causado pelas "facas" do equipamento durante o ensaio de RT. 

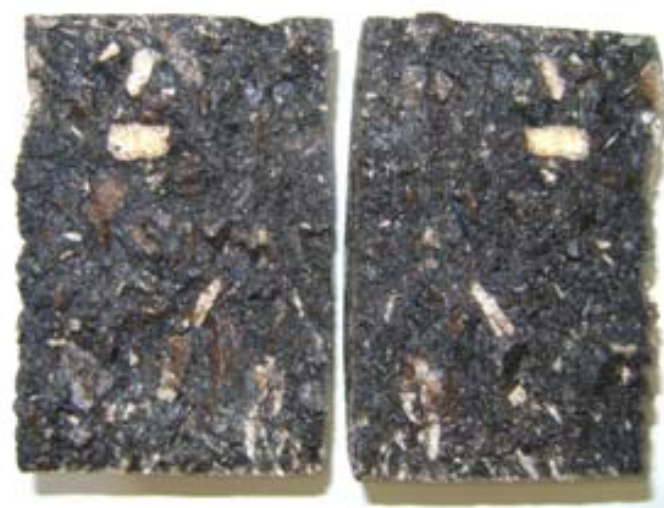

(a) $4 \%$ Vv CAP Puro
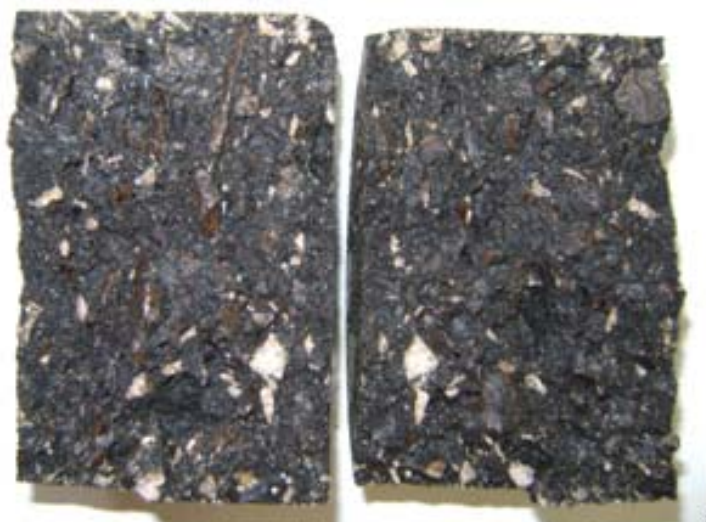

(c) $4 \%$ Vv 0,6\% PPA
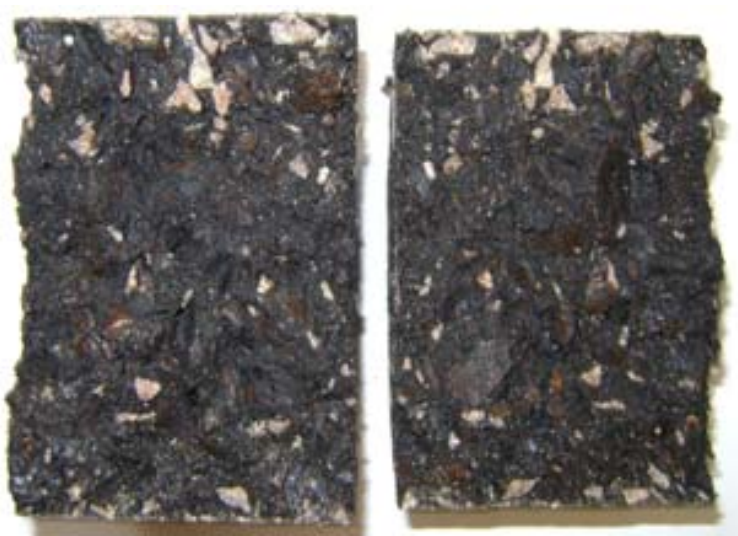

(e) $4 \%$ Vv $1,2 \%$ PPA
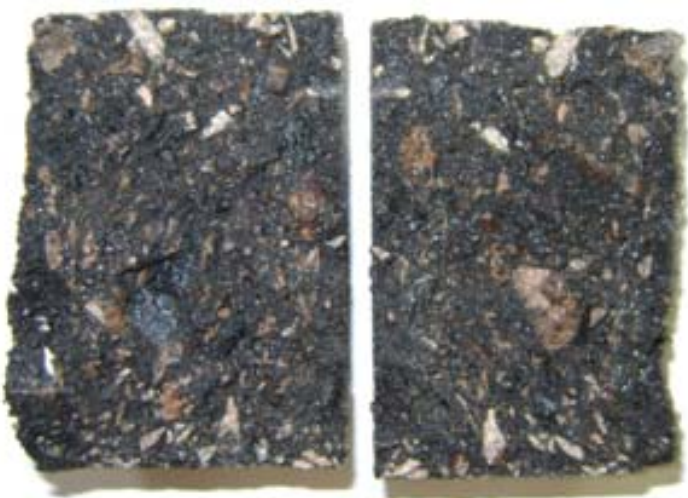

(b) $7 \%$ Vv CAP Puro

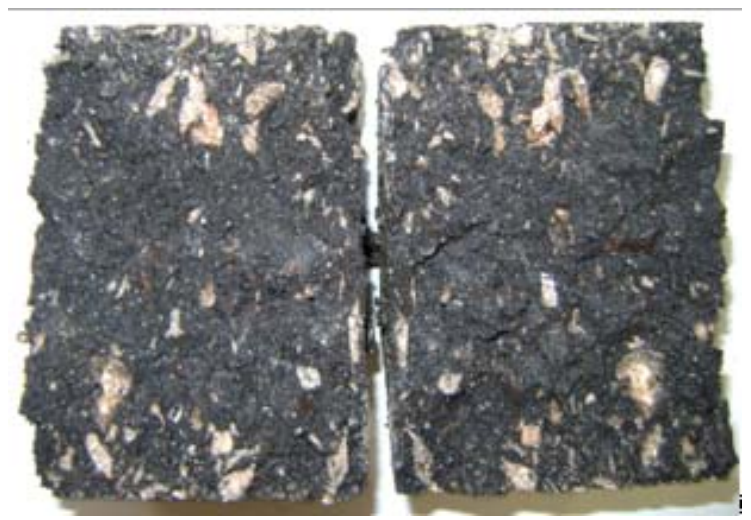

(d) $7 \%$ Vv 0,6\% PPA

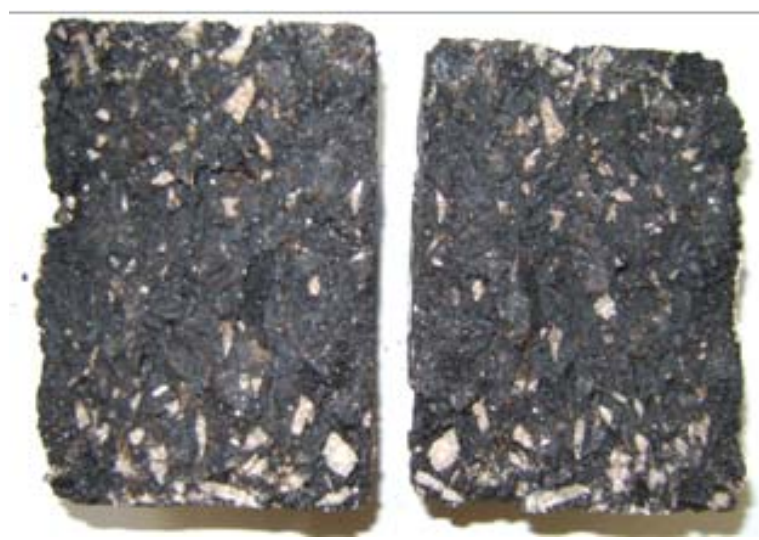

(f) $7 \%$ Vv $1,2 \%$ PPA

Figura 4.25. Superfícies de ruptura de corpos-de-prova sem cal com CAP Puro para 4\% (a) e 7\% (b) de $V_{v} 0,6 \%$ de PPA para $4 \%$ (c) e $7 \%$ (d) de $V_{v}$ e com $1,2 \%$ de PPA para $4 \%$ (e) e $7 \%$ (f) de $V_{v}$ 


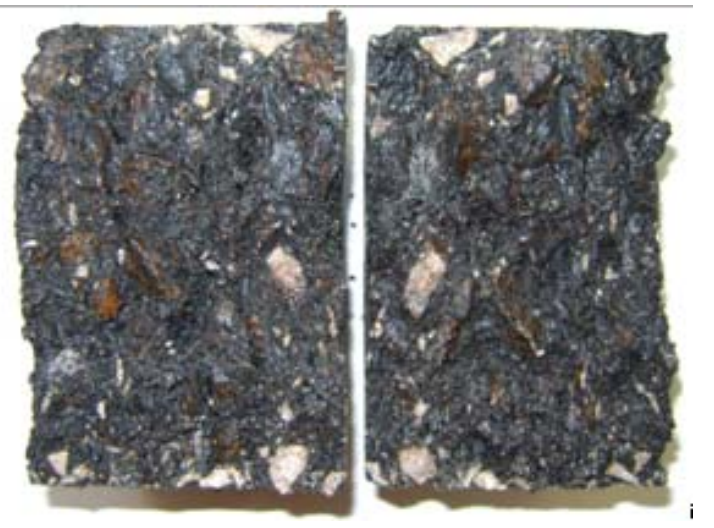

(a) $4 \%$ Vv CAP Puro $1,5 \%$ cal
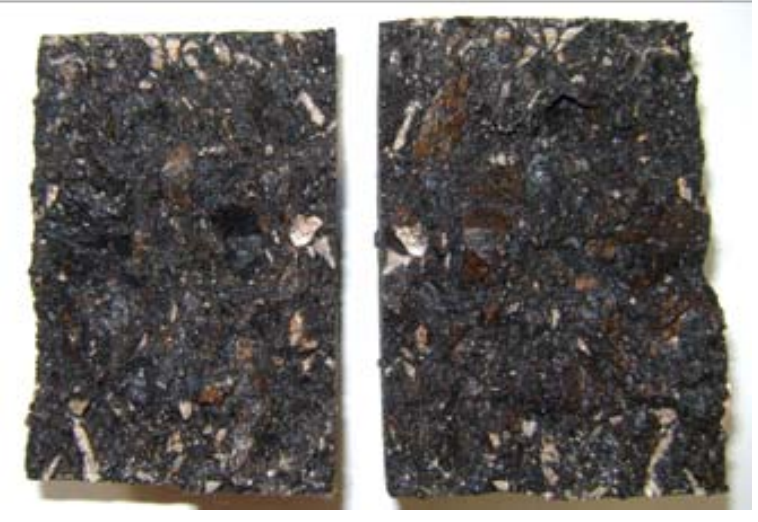

(c) $4 \%$ Vv $0,6 \%$ PPA $1,5 \%$ cal

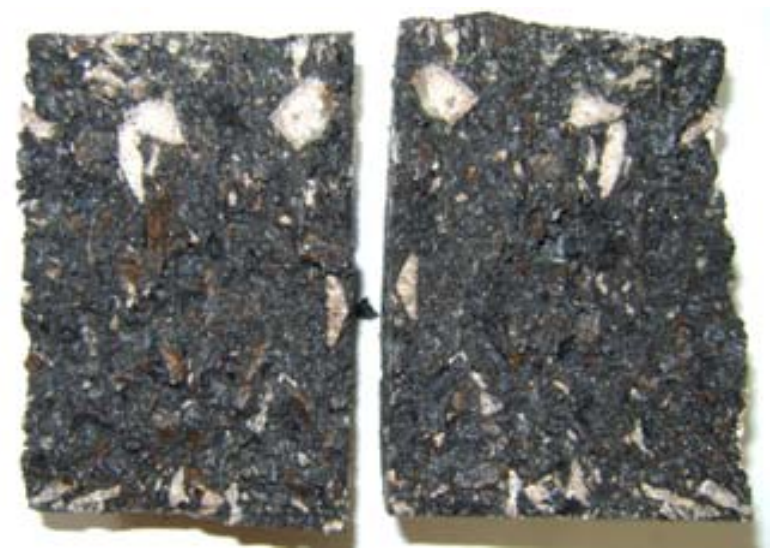

(e) $4 \%$ Vv $1,2 \%$ PPA $1,5 \%$ cal
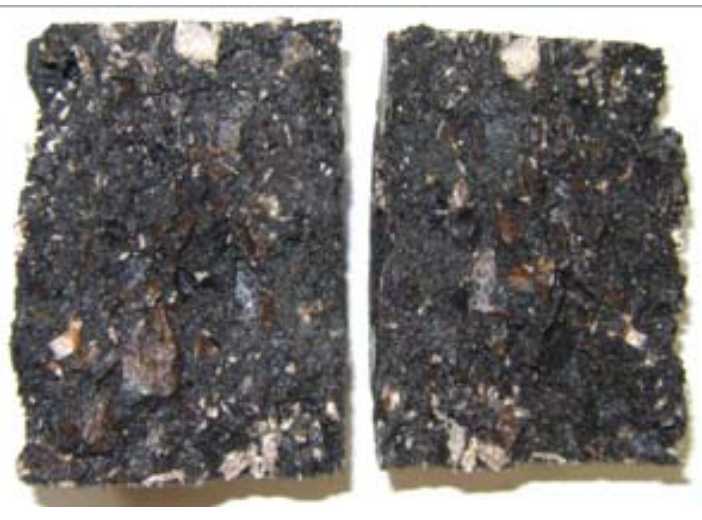

(b) $7 \%$ Vv CAP Puro $1,5 \%$ cal
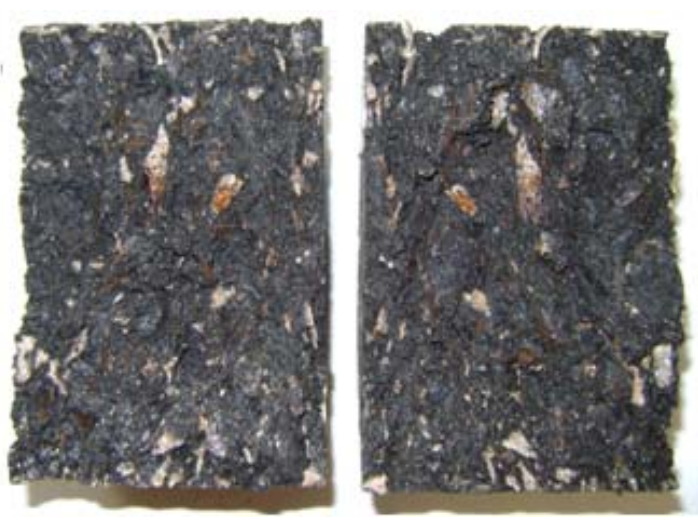

(d) $7 \%$ Vv $0,6 \%$ PPA $1,5 \%$ cal
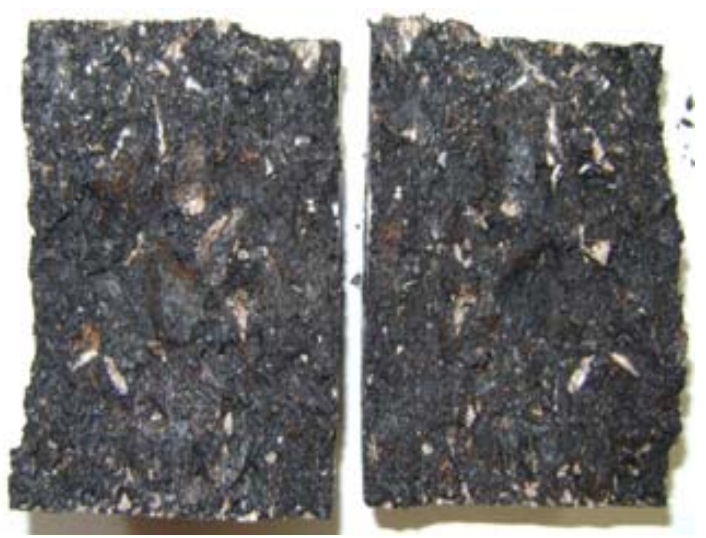

(f) $7 \%$ Vv $1,2 \%$ PPA $1,5 \%$ cal

Figura 4.26. Superfícies de ruptura de corpos-de-prova com 1,5\% de cal com CAP Puro para 4\% (a) e $7 \%$ (b) de $V_{v}, 0,6 \%$ de PPA para $4 \%$ (c) e $7 \%$ (d) de $V_{v}$ e com $1,2 \%$ de PPA para $4 \%$ (e) e $7 \%$ (f) de $V_{v}$ 


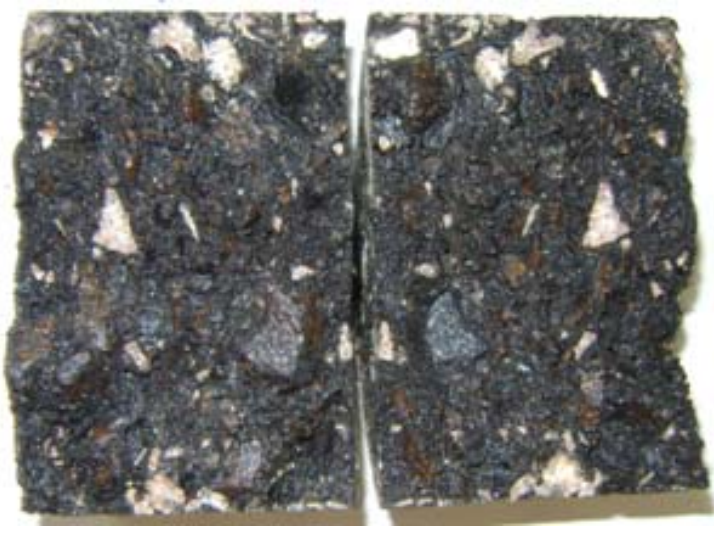

(a) $4 \%$ Vv CAP Puro $3 \%$ cal

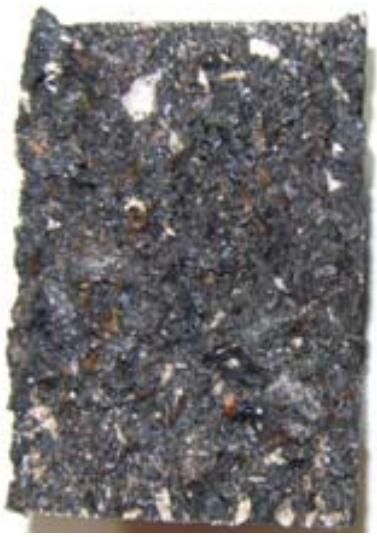

(c) $4 \% \mathrm{Vv} 0,6 \%$ PPA $3 \%$ cal

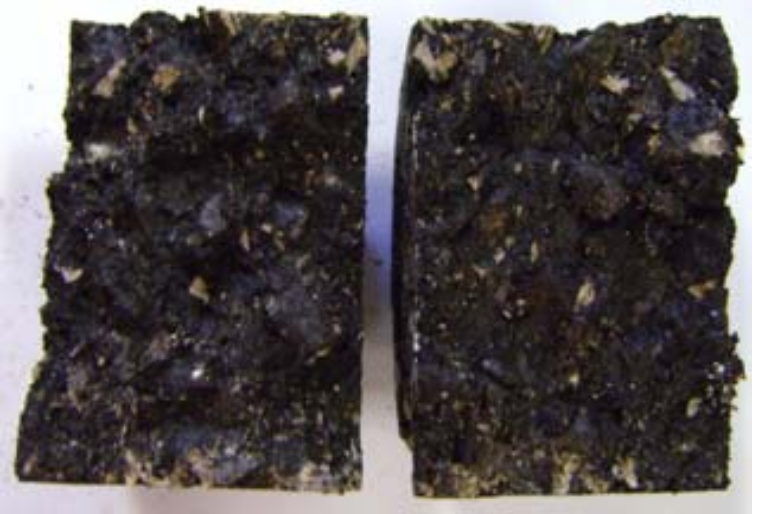

(e) $4 \%$ Vv $1,2 \%$ PPA $3 \%$ cal

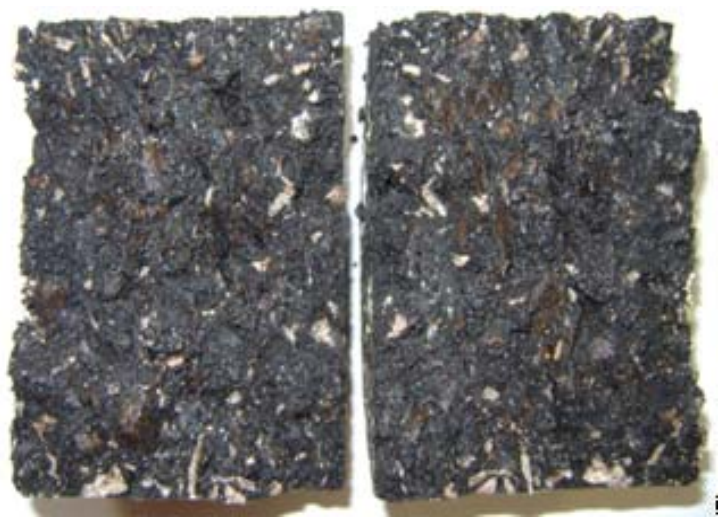

(b) $7 \%$ Vv CAP Puro $3 \%$ cal

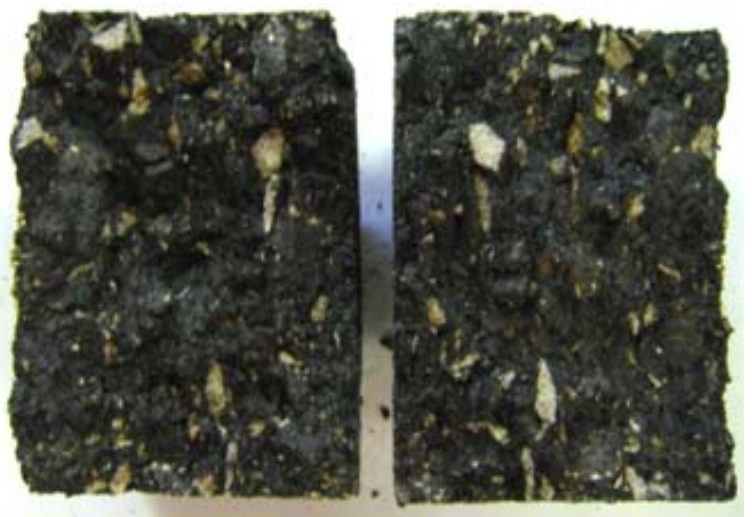

(d) $7 \%$ Vv $0,6 \%$ PPA $3 \%$ cal

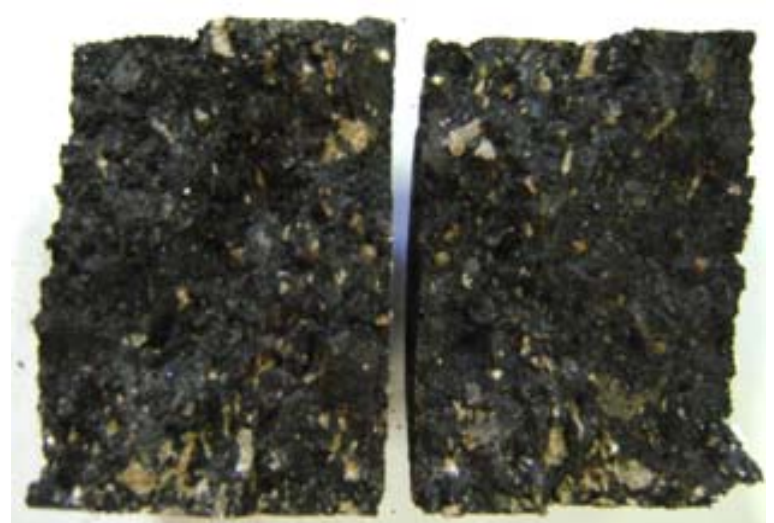

(f) $7 \%$ Vv $1,2 \%$ PPA $3 \%$ cal

Figura 4.27. Superfícies de ruptura de corpos-de-prova com 3,0\% de cal com CAP Puro com 4\% (a) e $7 \%$ (b) de $V_{v}, 0,6 \%$ de PPA com $4 \%$ (c) e $7 \%$ (d) de $V_{v}$ e com $1,2 \%$ de PPA com $4 \%$ (e) e $7 \%$ (f) de $V_{v}$ 
$\mathrm{Na}$ Figura 4.26, a adição de $1,5 \%$ de cal, proporcionou uma diminuição da quantidade de agregados expostos, situação que acusa melhora de adesividade da mistura, se comparada à Figura 4.25 (a) e (b), sem cal. Com o aumento da concentração de PPA, ainda observando-se a Figura 4.26, nota-se que também houve aumento de agregados rompidos próximo das bordas dos corpos-de-prova, como o já observado na Figura 4.25.

Já na Figura 4.27, nota-se que há pequena ou quase nenhuma exposição de superfície dos agregados nas faces de ruptura analisadas, indicando aumento da adesão entre o ligante e o agregado, o que reduziu a ruptura do tipo adesiva, com aumento da do tipo coesiva.

\subsection{ANÁLISE DA SIGNIFICÂNCIA DOS FATORES}

Com os resultados obtidos dos ensaios de módulo de resiliência e resistência à tração foram feitos gráficos e análises estatísticas com o software Minitab® com a finalidade de compreender quais fatores são estatisticamente significativos nas propriedades observadas.

Apresenta-se, a seguir, os resultados das análises ANOVA feitas para $\circ \mathrm{MR}_{\text {total }}$ (MRT), a RR, o Atraso, a RT e o $\mathrm{MR}_{\text {instantâneo }}(\mathrm{MRI})$.

$\mathrm{Na}$ Tabela 4.7 e na Figura 4.28 são apresentados os resultados das análises estatísticas para o MR total. Nessa tabela pode-se notar que os fatores significativos na variação do valor do MR total são o volume de vazios, o teor de PPA e a temperatura, além da combinação de alguns desses fatores, onde os valores da estatística $p$ é inferior 0,005 . Já na Figura 4.28 podem ser vistas as influências dos fatores e suas interações nos valores do MR total. 
Tabela 4.7: Análise da significância dos fatores e suas interações no MR total calculado segundo a NCHRP.

\begin{tabular}{|c|c|c|c|c|c|c|}
\hline Variáveis & SegSS & Adj $S S$ & Adj MS & $F$ & $P$ & Significância \\
\hline Volume de vazios & 67721653 & 67721653 & 67721653 & 41.57 & 0.000 & Sim \\
\hline Teor de cal & 11846104 & 11846104 & 5923052 & 3.64 & 0.028 & Nẫo \\
\hline Teor de PPA & 99049430 & 99049430 & 49524715 & 30.40 & 0.000 & Sim \\
\hline Temperatura & $9,53 \mathrm{E}+09$ & $9,53 \mathrm{E}+09$ & $4,76 \mathrm{E}+09$ & 2923.82 & 0.000 & Sim \\
\hline Volume de vazios*Teor de cal & 524009 & 524009 & 262005 & 0.16 & 0.852 & Nẵo \\
\hline Volume de vazios*Teor de PPA & 7465762 & 7465762 & 3732881 & 2.29 & 0.103 & Nẫo \\
\hline Volume de vazios*Temperatura & 27847874 & 27847874 & 13923937 & 8.55 & 0.000 & Sim \\
\hline Teor de cal*Teor de PPA & 27260782 & 27260782 & 6815196 & 4.18 & 0.003 & Sim \\
\hline Teor de cal*Temperatura & 2431604 & 2431604 & 607901 & 0.37 & 0.828 & Nẫo \\
\hline Teor de PPA*Temperatura & 18520837 & 18520837 & 4630209 & 2.84 & 0.025 & Nẫo \\
\hline $\begin{array}{l}\text { Volume de vazios*Teor de } \\
\text { cal'Teor de PPA }\end{array}$ & 69 & 69 & 67 & 1.27 & 283 & Nẫo \\
\hline $\begin{array}{l}\text { Volume de vazios*Teor de } \\
\text { cal*Temperatura }\end{array}$ & 784594 & 784594 & 196148 & 0.12 & 0.975 & Nẵo \\
\hline $\begin{array}{l}\text { Volume de vazios*Teor de } \\
\text { PPA*Temperatura }\end{array}$ & 5737088 & 5737088 & 1434272 & 0.88 & 0.476 & Nẫo \\
\hline $\begin{array}{l}\text { Teor de calTeor de } \\
\text { PPA*Temperatura }\end{array}$ & 24610467 & 24610467 & 3076308 & 1.89 & 0.062 & Nẫo \\
\hline $\begin{array}{l}\text { Volume de vazios*Teor de } \\
\text { cal*Teor de PPA*Temperatura }\end{array}$ & 253 & 25304694 & 3163087 & 1.94 & 0.054 & Nẵo \\
\hline
\end{tabular}

Legenda: Seq SS (sequential sums of squares) = soma dos quadrados em sequência; Adj SS (adjusted sums of squares) = soma dos quadrados ajustado; Adj MS (ajusted mean squares) = quadrado médio ajustado; $F$ = estatística de teste. 


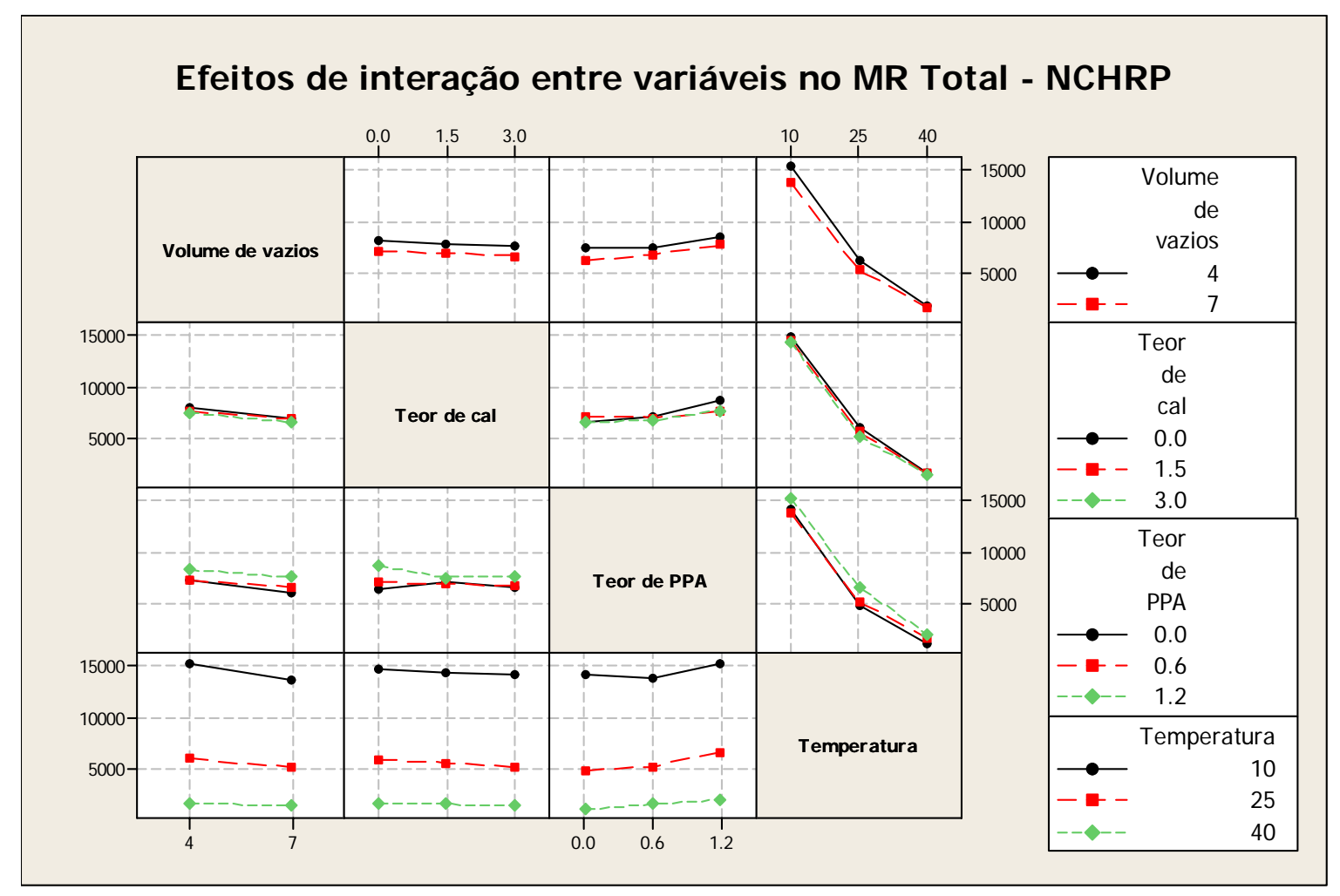

Figura 4.28. Efeitos da interação entre fatores no MR total calculado pela NCHRP.

Na Tabela 4.8 e na Figura 4.29 são apresentados os resultados das análises estatísticas para a Recuperação Retardada (RR). Na Tabela 4.8 nota-se que os fatores significativos na variação do valor da RR são o teor de cal, teor de PPA e a temperatura, além da combinação de alguns desses fatores, onde os valores da estatística $p$ é inferior a 0,005. Já a Figura 4.29 permite observar as influências dos fatores e suas interações nos valores da RR. 
Tabela 4.8: Análise da significância dos fatores e suas interações na RR.

\begin{tabular}{|c|c|c|c|c|c|c|}
\hline Variáveis & SegSS & Adj SS & Adj MS & $F$ & $P$ & Significância \\
\hline Volume de vazios & 0.000838 & 0.000838 & 0.000838 & 2.33 & 0.128 & Nẫo \\
\hline Teor de cal & 0.021086 & 0.021086 & 0.010543 & 29.31 & 0.000 & Sim \\
\hline Teor de PPA & 0.041997 & 0.041997 & 0.020999 & 58.38 & 0.000 & Sim \\
\hline Temperatura & 0.764091 & 0.764091 & 0.382045 & 1062.13 & 0.000 & Sim \\
\hline Volume de vazios*Teor de cal & 0.001371 & 0.001371 & 0.000686 & 1.91 & 0.151 & Nẫo \\
\hline Volume de vazios*Teor de PPA & 0.002582 & 0.002582 & 0.001291 & 3.59 & 0.029 & Não \\
\hline Volume de vazios*Temperatura & 0.010326 & 0.010326 & 0.005163 & 14.35 & 0.000 & Sim \\
\hline Teor de cal*Teor de PPA & 0.004551 & 0.004551 & 0.001138 & 3.16 & 0.015 & Nẵo \\
\hline Teor de cal*Temperatura & 0.015008 & 0.015008 & 0.003752 & 10.43 & 0.000 & Sim \\
\hline Teor de PPA*Temperatura & 0.016440 & 0.016440 & 0.004110 & 11.43 & 0.000 & Sim \\
\hline $\begin{array}{l}\text { Volume de vazios*Teor de } \\
\text { calTeor de PPA }\end{array}$ & 0.001691 & 0.001691 & 0.0 & 1.18 & 0.322 & Nẫ \\
\hline $\begin{array}{l}\text { Volume de vazios*Teor de } \\
\text { calTemperatura }\end{array}$ & 0.003175 & 0.003175 & 0.000794 & 2.21 & 0.069 & Nẫo \\
\hline $\begin{array}{l}\text { Volume de vazios*Teor de } \\
\text { PPA*Temperatura }\end{array}$ & 0.008277 & 0.008277 & 0.002069 & 5.75 & 0.000 & Sim \\
\hline $\begin{array}{l}\text { Teor de cal*Teor de } \\
\text { PPA*Temperatura }\end{array}$ & 0.01 & 374 & 797 & 5.00 & 0.000 & Sim \\
\hline $\begin{array}{l}\text { Volume de vazios*Teor de } \\
\text { calTeor de PPA*Temperatura }\end{array}$ & 0.005003 & 0.005003 & 0.000625 & 1.74 & 0.090 & Nẫo \\
\hline
\end{tabular}

Legenda: Seq SS (sequential sums of squares) = soma dos quadrados em sequência; Adj SS (adjusted sums of squares) = soma dos quadrados ajustado; Adj MS (ajusted mean squares) = quadrado médio ajustado; $F$ = estatística de teste. 


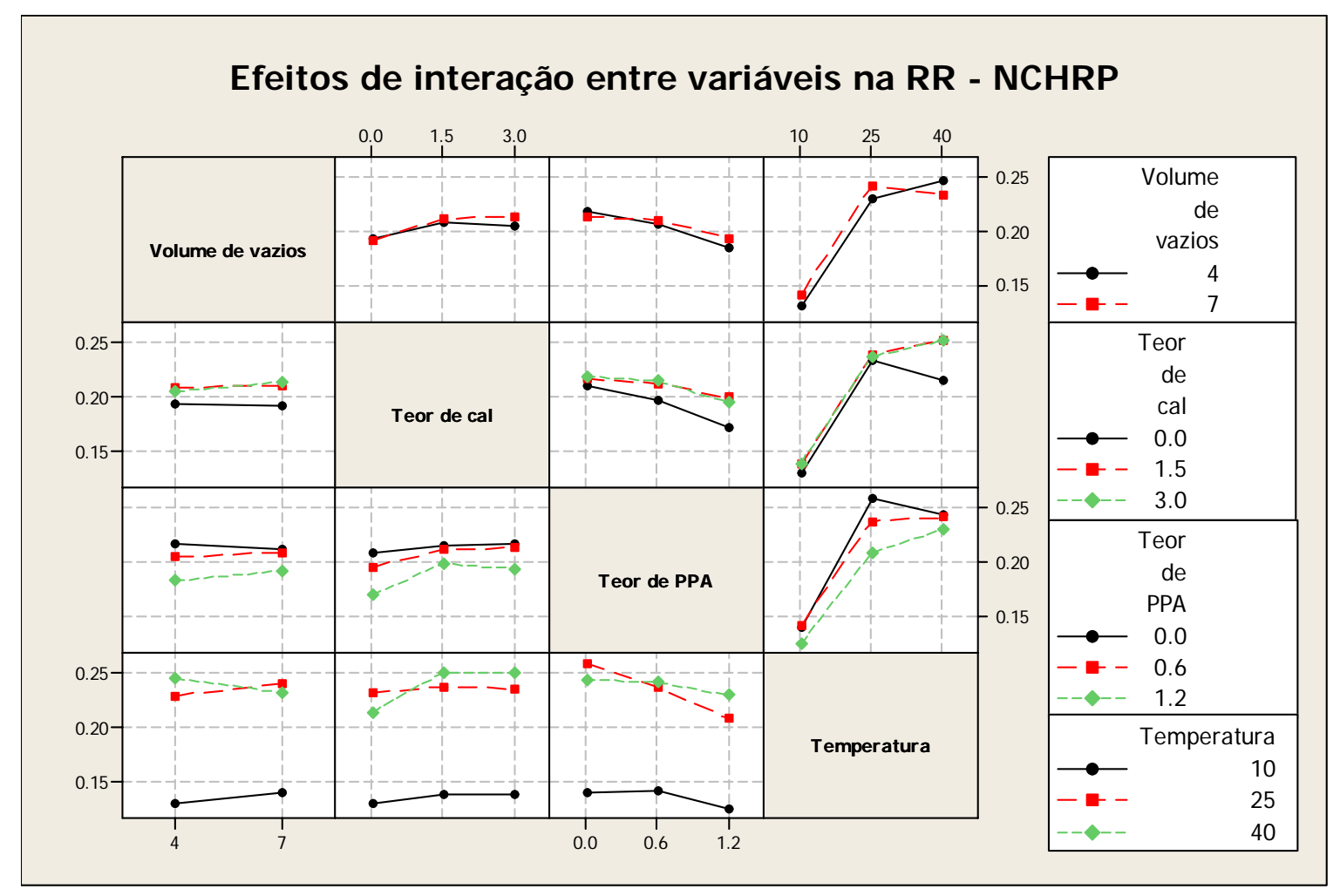

Figura 4.29. Efeitos dos fatores e suas interações entre variáveis na RR.

Na Tabela 4.9 e na Figura 4.30 são apresentados os resultados das análises estatísticas para o Atraso médio. Nessa tabela pode-se notar que os fatores significativos na variação do Atraso médio são o volume de vazios, o teor de PPA e a temperatura, além da combinação de alguns desses fatores, onde os valores da estatística $p$ é inferior a 0,005. Já a Figura 4.30 permite observar as influências dos fatores e suas interações nos valores do Atraso médio. 
Tabela 4.9: Análise da significância dos fatores e suas interações no Atraso Médio.

\begin{tabular}{|c|c|c|c|c|c|c|}
\hline Variáveis & Seg SS & Adj $S S$ & Adj MS & $F$ & $P$ & Significância \\
\hline Volume de vazios & 0.0000218 & 30.0000218 & 0.0000218 & 23.65 & 0.000 & Sim \\
\hline Teor de cal & 0.0000044 & 40.0000044 & 0.0000022 & 2.38 & 0.095 & Nẫo \\
\hline Teor de PPA & 0.0001317 & 0.0001317 & 0.0000659 & 71.52 & 0.000 & Sim \\
\hline Temperatura & 0.0028677 & 0.0028677 & 0.0014339 & 1556.88 & 0.000 & Sim \\
\hline Volume de vazios*Teor de cal & 0.0000012 & 20.0000012 & 0.0000006 & 0.67 & 0.511 & Não \\
\hline Volume de vazios*Teor de PPA & 0.0000041 & 0.0000041 & 0.0000021 & 2.24 & 0.108 & Não \\
\hline Volume de vaziosTemperatura & 0.0000036 & 50.0000036 & 0.0000018 & 1.93 & 0.147 & Nẫo \\
\hline Teor de cal'Teor de PPA & 0.0000110 & 0.0000110 & 0.0000027 & 2.98 & 0.020 & Nã̃o \\
\hline Teor de cal`Temperatura & 0.0000159 & 90.0000159 & 0.0000040 & 4.32 & 0.002 & Sim \\
\hline Teor de PPA*Temperatura & 0.0000442 & 20.0000442 & 0.0000110 & 12.00 & 0.000 & Sim \\
\hline $\begin{array}{l}\text { Volume de vazios*Teor de } \\
\text { cal*Teor de PPA }\end{array}$ & 0 & 30.0000 & 0.0000022 & 2.39 & 0.051 & Nẫo \\
\hline $\begin{array}{l}\text { Volume de vazios*Teor de } \\
\text { cal*Temperatura }\end{array}$ & 0.0000076 & 50.00000 & 0.0000019 & 2.06 & 0.086 & Nẫo \\
\hline $\begin{array}{l}\text { Volume de vazios*Teor de } \\
\text { PPA*Temperatura }\end{array}$ & 0.0000 & 0.0000 & 0.0000043 & 4.62 & 0.001 & Sim \\
\hline $\begin{array}{l}\text { Teor de cal*Teor } \\
\text { PPA*Temperatura }\end{array}$ & 0.0000 & 0.0000 & 0.0000022 & 2.40 & 0.016 & Nẫo \\
\hline $\begin{array}{l}\text { Volume de vazios*Teor de } \\
\text { calTeor de PPA*Temperatura }\end{array}$ & 0.0 & 20.00 & 0.0000007 & 0.71 & 0.686 & Nẫo \\
\hline
\end{tabular}

Legenda: Seq SS (sequential sums of squares) = soma dos quadrados em sequência; Adj SS (adjusted sums of squares) = soma dos quadrados ajustado; Adj MS (ajusted mean squares) = quadrado médio ajustado; $\mathrm{F}$ = estatística de teste. 


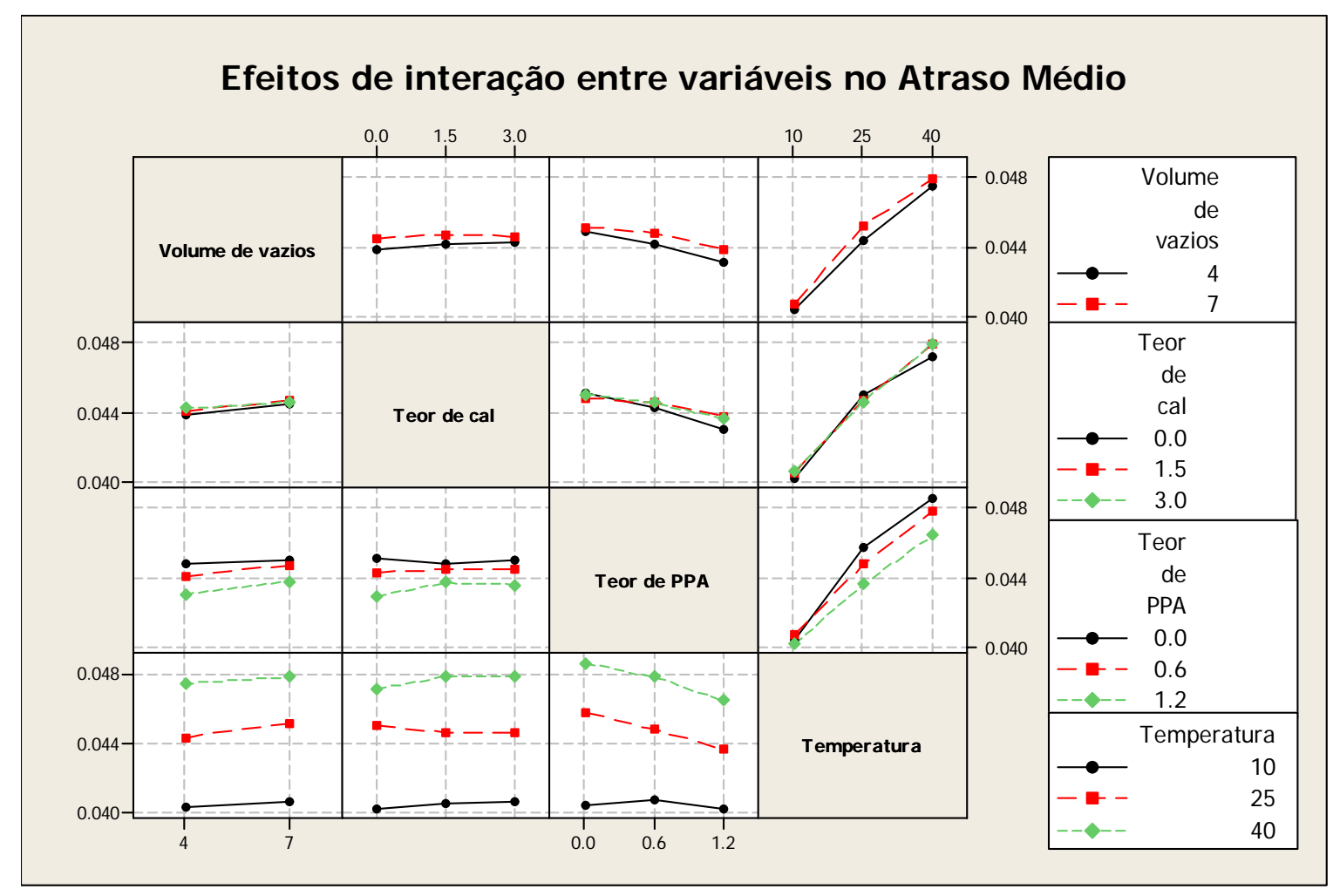

Figura 4.30. Efeitos de interação entre variáveis no Atraso Médio.

$\mathrm{Na}$ Tabela 4.10 e na Figura 4.31 são apresentados os resultados das análises estatísticas para a Resistência à Tração (RT). A Tabela 4.10 mostra que os fatores significativos na variação do valor da RT são o teor de cal, teor de PPA e o volume de vazios, além de evidenciar que o condicionamento, para os ensaios que foram executados, não foi significativo estatisticamente. Na Figura 4.31 podem ser vistas as influências dos fatores e suas interações nos valores da RT.

Tabela 4.10: Análise da significância dos fatores na RT.

\begin{tabular}{l|c|c|c|c|c|c}
\hline \multicolumn{1}{c}{ Variáveis } & Seg SS & Adj SS & Adj MS & $F$ & $P$ & Significância \\
\hline Volume de vazios & 49.224 & 36.387 & 36.387 & 280.63 & 0.000 & Sim \\
\hline Teor de cal & 0.4616 & 0.4616 & 0.2308 & 17.80 & 0.000 & Sim \\
\hline Teor de PPA & 15.200 & 15.200 & 0.7600 & 58.61 & 0.000 & Sim \\
\hline Condicionamento & 0.0277 & 0.0277 & 0.0277 & 2.13 & 0.147 & Năo \\
\hline
\end{tabular}

Legenda: Seq SS (sequential sums of squares) = soma dos quadrados em sequência; Adj SS (adjusted sums of squares) = soma dos quadrados ajustado; Adj MS (ajusted mean squares) $=$ quadrado médio ajustado; $\mathrm{F}=$ estatística de teste. 


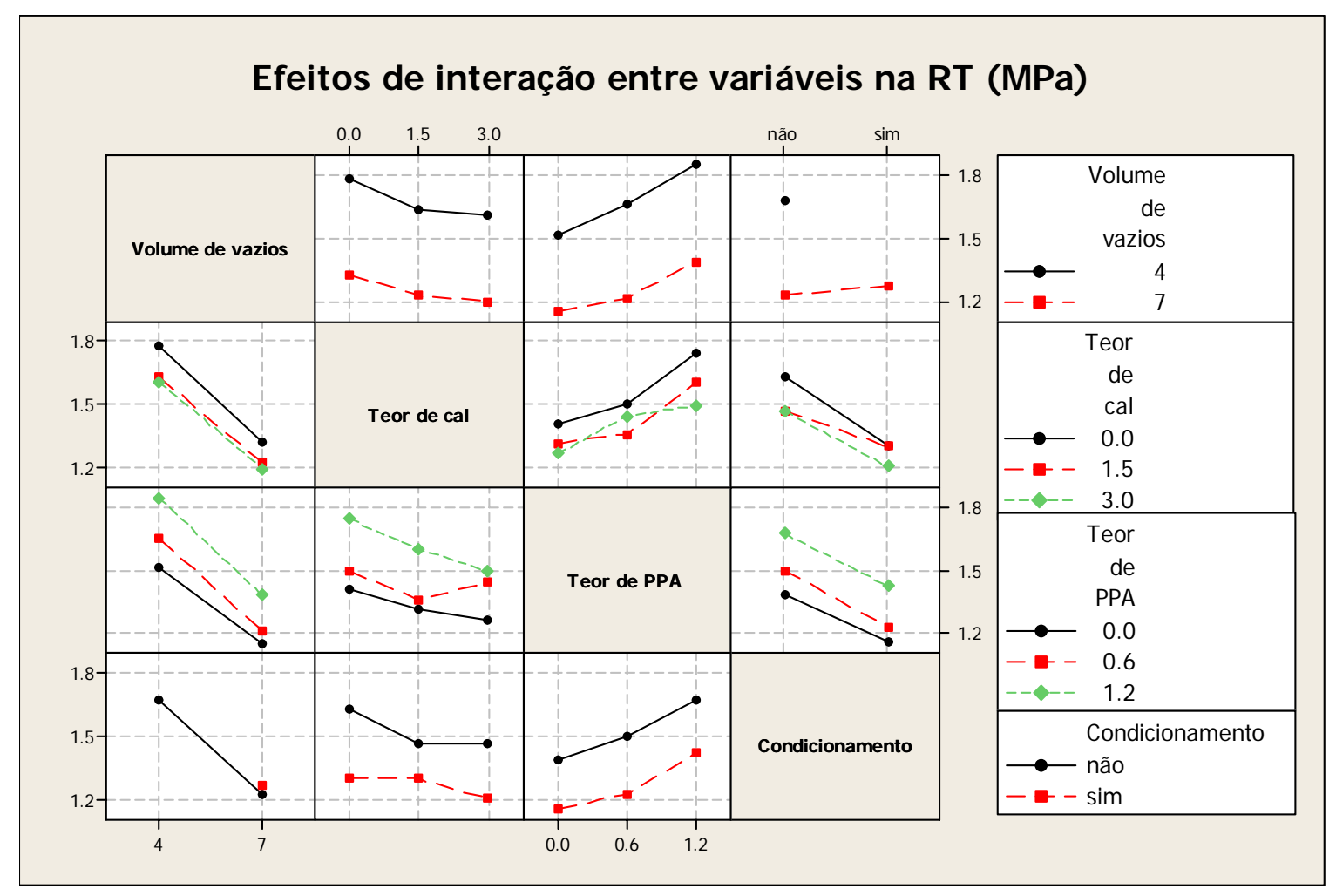

Figura 4.31. Efeitos de interação entre fatores na RT.

Na Tabela 4.11 e na Figura 4.32 são apresentados os resultados das análises estatísticas para o MR instantâneo. Nessa tabela pode-se notar que os fatores significativos na variação do valor do MR instantâneo são o volume de vazios, o teor de PPA e a temperatura, à semelhança do encontrado para o MR total, além da combinação de alguns desses fatores, onde os valores da estatística $p$ é inferior a 0,005. Já na Figura 4.32 podem ser vistas as influências dos fatores e suas interações nos valores do MR instantâneo. 
Tabela 4.11: Análise da significância dos fatores e suas interações no MR instatâneo calculado segundo a NCHRP.

\begin{tabular}{|c|c|c|c|c|c|c|}
\hline Variáveis & SegSS & Adj SS & Adj MS & $F$ & $P$ & Significância \\
\hline Volume de vazios & 85565994 & 85565994 & 85565994 & 39.00 & 0.000 & Sim \\
\hline Teor de cal & 11836748 & 11836748 & 5918374 & 2.70 & 0.069 & Nẵo \\
\hline Teor de PPA & $1,05 E+08$ & $1,05 E+08$ & 52401765 & 23.89 & 0.000 & Sim \\
\hline Temperatura & $1,20 \mathrm{E}+10$ & $1,20 E+10$ & $6,02 \mathrm{E}+09$ & 2743.99 & 0.000 & Sim \\
\hline Volume de vazios*Teor de cal & 886718 & 886718 & 443359 & 0.20 & 0.817 & Nã̃o \\
\hline Volume de vazios*Teor de PPA & 11362776 & 11362776 & 5681388 & 2.59 & 0.077 & Nẫo \\
\hline Volume de vazios ${ }^{\star}$ Temperatura & 26789072 & 26789072 & 13394536 & 6.11 & 0.003 & Sim \\
\hline Teor de cal*Teor de PPA & 27224344 & 27224344 & 886 & 3.10 & 0.016 & Nẫo \\
\hline Teor de cal*Temperatura & 4713012 & 4713012 & 1178253 & 0.54 & 0.709 & Nẩo \\
\hline Teor de PPA*Temperatura & 17976733 & 17976733 & 4494183 & 2.05 & 0.088 & Nẫo \\
\hline $\begin{array}{l}\text { Volume de vazios*Teor de } \\
\text { cal*Teor de PPA }\end{array}$ & 11061318 & 11061318 & 2765329 & 1.26 & 0.286 & Nẫo \\
\hline $\begin{array}{l}\text { Volume de vazios*Teor de } \\
\text { cal*Temperatura }\end{array}$ & 1679425 & 1679425 & 419856 & 0.19 & 0.943 & Nẫo \\
\hline $\begin{array}{l}\text { Volume de vazios*Teor de } \\
\text { PPA*Temperatura }\end{array}$ & 6810477 & 6810477 & 1702619 & 0.78 & 0.542 & Nẫo \\
\hline $\begin{array}{l}\text { Teor de cal*Teor de } \\
\text { PPA*Temperatura }\end{array}$ & 30873020 & 30873020 & 3859127 & 1.76 & 0.085 & Nẵo \\
\hline $\begin{array}{l}\text { Volume de vazios*Teor de } \\
\text { cal*Teor de PPA*Temperatura }\end{array}$ & 344 & 34481049 & 4310131 & 1.96 & 0.051 & Nẫo \\
\hline
\end{tabular}

Legenda: Seq SS (sequential sums of squares) = soma dos quadrados em sequência; Adj SS (adjusted sums of squares) $=$ soma dos quadrados ajustado; Adj MS (ajusted mean squares) = quadrado médio ajustado; $\mathrm{F}$ = estatística de teste. 
Efeitos de interação entre variáveis no MR I nastantâneo - NCHRP

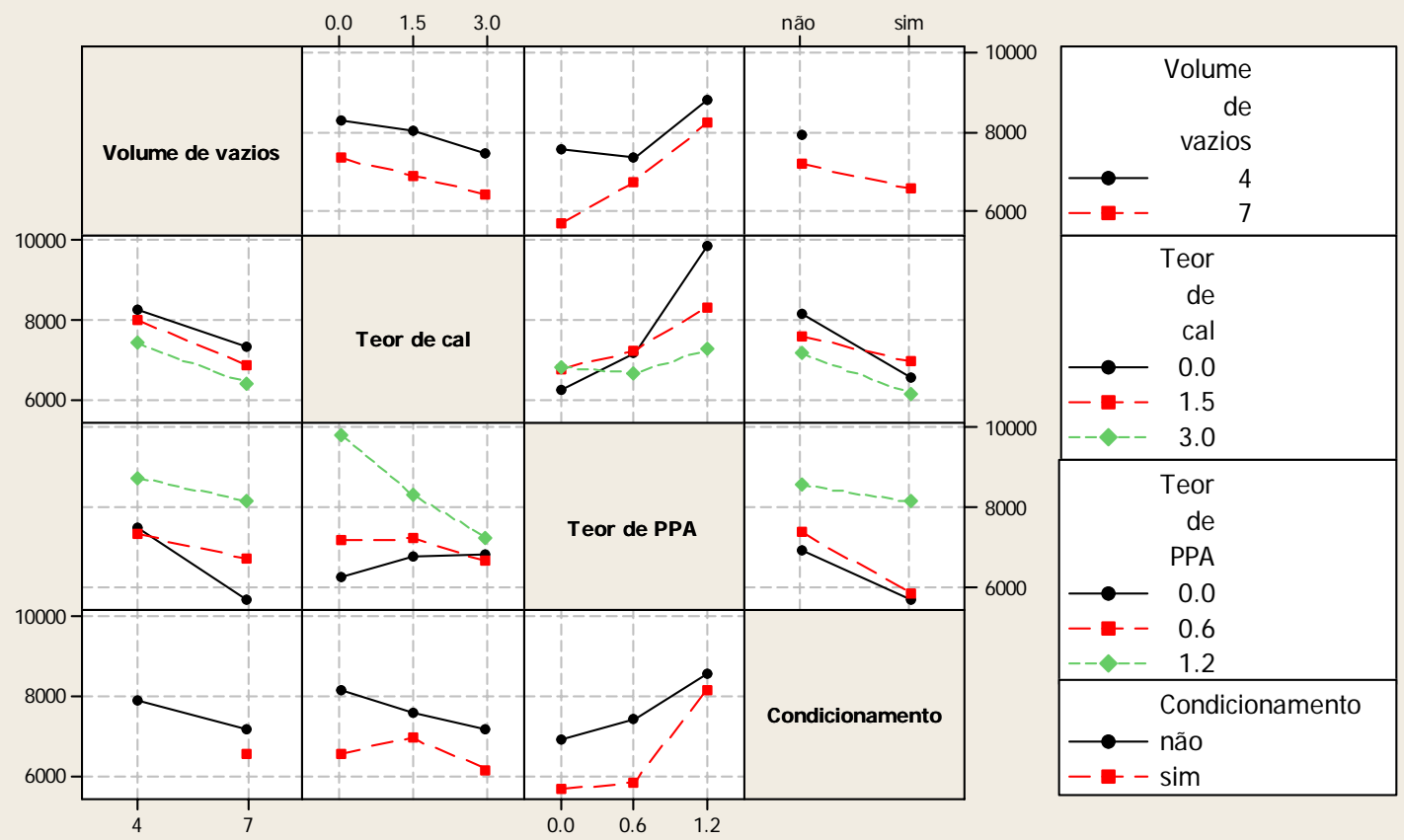

Figura 4.32. Efeitos de interação entre fatores no MR instantâneo. 


\subsection{CONCLUSÕES}

Neste trabalho, foram avaliadas as influências da adição de cal à mistura asfáltica e da modificação do ligante asfáltico com ácido polifosfórico e suas interações na suscetibilidade térmica de misturas asfálticas densas. Foram monitorados os módulos de resiliência, calculados através protocolo do NCHRP, e a recuperação retardada, de nove misturas asfálticas, empregando ligantes asfálticos modificados com 0,6 e $1,2 \%$ de PPA e misturas asfálticas com 1,5 e 3,0\% de cal.

De acordo com os dados analisados, podem-se fazer as seguintes considerações:

Quanto à rigidez das misturas asfálticas:

- independente do tipo de mistura, a variação da temperatura foi o fator mais importante na redução da rigidez;

- misturas com ligantes modificados com PPA apresentam rigidezes maiores que a com ligante convencional, sendo que a influência desse modificador na redução da rigidez é mais intensa com o aumento de sua concentração no ligante asfáltico;

- misturas com cal apresentam variações pequenas ou manutenção da rigidez da mistura com ligante convencional, exceto na temperatura de $10^{\circ} \mathrm{C}$;

- a mistura com ligantes contendo concentrações, tanto de PPA quanto de cal, apresentam tendência de aumento de rigidez, com predomínio de efeito do PPA, ou seja, há aumento de rigidez das misturas asfálticas quando comparadas com a que contem ligante convencional;

- a adição de $1,5 \%$ de cal melhorou tanto a suscetibilidade ao dano por umidade mistura asfáltica, quanto os valores médios absolutos obtidos;

- o aumento da concentração de PPA melhora a rigidez e a suscetibilidade ao dano por umidade;

- o efeito combinado do aditivo e do modificador, a critério de comparação, as que apresentaram melhores condições de suscetibilidade ao dano por umidade foram $1,5 \%$ de cal $+0,6 \%$ de PPA e $3,0 \%$ de cal $+1,2 \%$ de PPA. 
Quanto à recuperação retardada das misturas asfálticas:

- o aumento da temperatura propicia o aumento da parcela visco-elástica na recuperação das misturas asfálticas;

- a adição de PPA torna a mistura mais flexível e esse efeito também se mostra dependente da concentração de modificador, uma vez que apresentam menores valores de recuperação retardada com o aumento de 0,6 para 1,2\% de PPA;

- a adição de cal tem efeito discreto sobre a flexibilidade das misturas, mas esse efeito pode ser potencializado com o uso de teores mais adequados $(1,5 \%)$;

- as adições de cal e PPA reduziram os valores da recuperação retardada, sendo que a intensidade do efeito do PPA predomina sobre a da cal.

Quanto à resistência a ruptura por tração por compressão diametral (RT) das misturas asfálticas:

- de maneira geral, em termos médios, os valores de RT para $4 \%$ de $\mathrm{V}_{\mathrm{v}}$ é maior que para $7 \%$;

- o uso da cal diminui a resistência à tração (RT) e mantêm as propriedades elásticas da mistura asfáltica;

- as misturas com maior suscetibilidade ao dano por umidade foram obtidas para a concentração de $1,5 \%$ de cal;

- o efeito combinado dos materiais que obtiveram resultados mais expressivos para suscetibilidade ao dano por umidade foi de $1,5 \%$ de cal $+1,2 \%$ de PPA;

- os melhores valores da relação resistência à tração (RRT) foram obtidos para maiores concentrações de PPA, exceto quando combinado a cal;

- a RRT devido ao condicionamento apresentou valores significativos para adição de $1,5 \%$ de cal.

Quanto ao registro fotográfico:

- ocorreu melhora de adesividade com adição de $1,5 \%$ de cal;

- o aumento da concentração de PPA diminui a quantidade de agregados rompidos na face de ruptura do corpo-de-prova. 


\subsection{SUGESTÕES PARA TRABALHOS FUTUROS:}

- Repetir os ensaios realizados nessa pesquisa com diferentes concentrações de ácido polifosfórico e da cal hidratada, de forma a se obter melhores especificações ao uso destes materiais.

- Utilizar ácidos polifosfóricos de outra classe para comparação de eficiência com o usado nessa pesquisa (Exemplo: 110, 115 e 120\%).

- Para as mesmas condições e fatores usados nessas pesquisa, analisar propriedades que representem a suscetibilidade à fadiga. 


\section{REFERÊNCIAS BIBLIOGRÁFICAS}

AASHTO - AMERICAN ASSOCIATION OF STATE HIGHWAY AND TRANSPORTATION OFFICIALS. T 283: Standard method of test for resistance of compacted Hot Mix Asphalt (HMA) to Moisture-Induced Damage. USA, 2007.

AASHTO - AMERICAN ASSOCIATION OF STATE HIGHWAY AND

TRANSPORTATION OFFICIALS. TP 31-94 - Standard Test Method for

Determining the Resilient Modulus of Bituminous Mixtures by indirect Tension, Washington, D. C., 31p, 1994.

AASHTO - AMERICAN ASSOCIATION OF STATE HIGHWAY AND TRANSPORTATION OFFICIALS. T 312: Preparing and determining the density of the hot-mix asphalt (HMA) specimens by means of the Superpave Gyratory Compactor. USA, 2003.

ADORJÁNYI, K., Water sensitivity evaluation of ac mixes with antistripping additives by different mechanical tests, 4th Euroahphalt \& Eurobitumen Congress, Copenhagen, Dinamarca, 2008.

ANDERSON, D.A. et al. (1991), Physical properties os asphalt cement and the development of permance-related specifications, Journal of the Association os Asphalt Paving Technologists, White Bear Lake, v. 60, p. 437-456.

ASPHALT INSTITUTE. The Asphalt Handbook. Manual Series n 4 (MS-4), 1989.

ASTM - AMERICAN SOCIETY FOR TESTING AND MATERIALS. Edição publicada sob a designação ASTM C 1252 - 03. Standard test methods for Uncompacted Void Content of Fine Aggregate (as Influenced by Particle Shape, Surface Texture, and Grading). American Society for Testing and Materials. Philadelphia, 1990.

ASTM - AMERICAN SOCIETY FOR TESTING AND MATERIALS. C 127: Standard test method for density, relative density (specific gravity), and absorption of coarse aggregate. USA, 1998. 
ASTM - AMERICAN SOCIETY FOR TESTING AND MATERIALS. C 128: Standard test method for density, relative density (specific gravity), and absorption of fine aggregates. USA, 1997.

ASTM - AMERICAN SOCIETY FOR TESTING AND MATERIALS. Edição publicada sob a designação ASTM D 113 - 99. Standard test method for Ductility of Bituminous Materials. American Society for Testing and Materials. Philadelphia, 1990.

ASTM - AMERICAN SOCIETY FOR TESTING AND MATERIALS. Edição publicada sob a designação ASTM D 36 - 95 (Reapproved 2000). Standard test method for Softening Point of Bitumen (Ring-and-Ball Apparatus). American Society for Testing and Materials. Philadelphia, 1990.

ASTM - AMERICAN SOCIETY FOR TESTING AND MATERIALS. Edição publicada sob a designação ASTM D 2041 - 90. Standard test method for theoretical maximum specific gravity and density of bituminous paving mixtures. USA, 2000.

ASTM - AMERICAN SOCIETY FOR TESTING AND MATERIALS. Edição publicada sob a designação ASTM D 4402 - 02. Standard test method for Viscosity Determination of Asphalt at Elevated Temperatures Using a Rotacional Viscometer. American Society for Testing and Materials. Philadelphia, 1990.

ASTM - AMERICAN SOCIETY FOR TESTING AND MATERIALS. Edição publicada sob a designação ASTM D 4791 - 99. Standard test method for Flat Particles, Elongated Particles, or Flat and Elongated Particles in Coarse Aggregate. American Society for Testing and Materials. Philadelphia, 1990.

ASTM - AMERICAN SOCIETY FOR TESTING AND MATERIALS. Edição publicada sob a designação ASTM D 5 - 05a. Standard test method for Penetration of Bituminous Materials. American Society for Testing and Materials. Philadelphia, 1990.

ASTM- AMERICAN SOCIETY FOR TESTING AND MATERIALS. Edição publicada sob a designação ASTM D 5821 - 01. Standard test method for Determining the 
Percentage of Fracured Particles in Coarse Aggregate. American Society for Testing and Materials. Philadelphia, 1990.

ASTM - AMERICAN SOCIETY FOR TESTING AND MATERIALS. Edição publicada sob a designação ASTM D 92 - 02b. Standard test method for Flash and Fire by Cleveland Open Cup Tester. American Society for Testing and Materials. Philadelphia, 1990.

ASTM - AMERICAN SOCIETY FOR TESTING AND MATERIALS. D 3203-94: Standard test method for percent air voids in compacted dense and open bituminous paving mixtures. USA, 1994.

ASTM - AMERICAN SOCIETY FOR TESTING AND MATERIALS. D 4123-82: Standard method of indirect tension test for resilient modulus of bituminous mixtures. USA, 1982.

BAUMGARDNER, G. L., MASSON, J. F., HARDEE, J. R., MENAPACE, A. M., WILLIAMS, A. G., Polyphosphoric acid modified asphalt: Proposed mechanisms, 2005.

BERNUCCI, L.B.; MOTTA, L.M.G.; CERATTI, J.A.P.; SOARES, J.B. Pavimentação asfáltica - Formação básica para engenheiros. Rio de Janeiro, 2007.

BERNUCCI, L.L.B.; CAMPOS, O.S.; DOMINGUES, F.A.A.; CASTRO NETO, A.M.; RABAÇA, S.R. Influência do tipo de asfalto no comportamento à deformação de misturas asfálticas. In: $9^{\circ}$ Congresso Ibero-Latinoamericano del Asfalto, Asunción, Paraguay: Anais, 1997. Tomo 1, nov., p.459-467.

BERNUCCI, L.L.B.; MOURA, E.; FURLAN, A.P.; MOTTA, R.S.; LEITE, F.C.; FARIA, V.C. Efeito do teor e do tipo de ligante na formação de trilhas de roda em misturas asfálticas. In: $19^{\circ}$ Encontro de Asfalto, Rio de Janeiro, RJ, 2008.

BERTOLLO, S. A. M. ; FERNANDES JUNIOR, J. L. ; BERNUCCI, L. L. B. ; MOURA, EDSON DE . Avaliação laboratorial de mistura asfáltica densa modificada com adição de borracha. Transportes (Rio de Janeiro), Rio de Janeiro, RJ, v. 10, n. 1, p. 65-83, 2002. 
BIANCHETOO, H.; MIRÓ, R.; PÉREZ-JIMÉNEZ, F.; MARTíNEZ, A.H. Effect of Calcareous Fillers on Bituminous Mix Aging. Transportation Research Record: Journal of the Transportation Research Board, $n^{\circ}$ 1998, Transportation Research Board of the National Academies, Washington, 2007, p.140-148.

CHISTIAN, S., JEAN-VALERY, M., STEPHANIE, P., NICOLAS, P., Properties and Performances of asphalt binders and asphalt mixes modified with polyphosphoric acid, 4th Euroahphalt \& Eurobitumen Congress, Copenhagen, Dinamarca, 2008.

COELHO, V. Contribuição ao estudo das deformações permanentes, nas condições do Brasil, em camadas de concreto asfáltico de pavimentação. Tese (Doutorado) - Escola de Engenharia de São Carlos, Universidade de São Paulo. 281p. São Carlos, 2004.

COMINSKY, R.J.; KILLINGSWORTH, B.M.; ANDERSON, R.M.; ANDERSON, D.A.; CROCKFORD, W.W. Quality control and acceptance of Superpave-designed hot mix asphalt. National Cooperative Highway Research Program, n. 409, p. 1-26, 1998.

COMINSKY, R.R.; LEAHY, F.B.; HARRIGAN, E.G. Level one mix design:Materials selection, compaction, and conditioning. Relatório Técnico SHRP-a-408, Strategic Highway Research Program (SHRP), 1994.

CURTIS, C. W.; ENSLEY, K.; EPPS, J.; Fundamental Properties of AsphaltAggregate Interactions Including Adhesion and Adsortion; SHRP-A-341; Strategic Highway Research Program; National Research Council; Washington, D.C.; 1993.

D’ANGELO, J.; ANDERSON, R.M.; Material Production, Mix Design, and Pavement Design Effects on Moisture Damage. Moisture Sensitivity of Asphalt Pavements: A National Seminar, TOPIC 5, Federal Highway Administration, 2003.

DNER - DEPARTAMENTO NACIONAL DE ESTRADAS DE RODAGEM. ME 004 (1994). Material asfáltico - determinação da viscosidade "Saybolt-Furol" a alta temperatura: método de ensaio. Rio de Janeiro: IPR, 1994. 
DNER - DEPARTAMENTO NACIONAL DE ESTRADAS DE RODAGEM. ME 035 (1994). Agregados: determinação da absorção e da densidade de agregado graúdo. Rio de Janeiro, 1999.

DNER - DEPARTAMENTO NACIONAL DE ESTRADAS DE RODAGEM. ME 078 (1994). Agregado graúdo - adesividade a ligante betuminoso. Departamento Nacional de Estradas de Rodagem, Rio de Janeiro.

DNER - DEPARTAMENTO NACIONAL DE ESTRADAS DE RODAGEM. ME 079 (1994). Agregado - adesividade a ligante betuminoso. Departamento Nacional de Estradas de Rodagem, Rio de Janeiro.

DNER - DEPARTAMENTO NACIONAL DE ESTRADAS DE RODAGEM. ME 133 (1994). Agregado - determinação do Módulo de Resiliência. Departamento Nacional de Estradas de Rodagem, Rio de Janeiro.

DNER - DEPARTAMENTO NACIONAL DE ESTRADAS DE RODAGEM. ME 138 (1994). Misturas Betuminosas - Determinação da Resistência à Tração por Comporessão Diametral. Departamento Nacional de Estradas de Rodagem, Rio de Janeiro

EDWARDS, Y., Influence os waxes on bitumen and asphalt concrete mixture performance, Road materials and pavement design, Vol 10/2, pg. 313-335, 2009.

EPPS, J.A.; LITTLE, D.N. The benefits of Hydrated Lime in Hot Mix Asphalt. Prepared for National Lime Association, 48p, 2001.

FAXINA, A.L. Estudo da viabilidade técnica do uso do resíduo de óleo de xisto como óleo extensor em ligantes asfalto-borracha. Tese (Doutorado). Universidade de São Paulo, EESC/USP, São Carlos, SP, 2006.

FERNANDES, J.L.; ROQUE, R.; TIA, M.; CASANOVA, L. Evaluation of uncompacted void content of fine aggregate as a quality indicator of materials used in Superpave mixtures. Transportation Research Board, 2000.

FERNANDES, P. R. N., SOUSA, C. R., SOARES, S. A., Análise do comportamento térmico de ligante asfáltico puro e modificado com ácido 
polifosfórico, Anais do XXII Congresso Nacional de Pesquisa e Ensino em Transporte. Associação Nacional de Pesquisa e Ensino em Transportes (ANPET), Fortaleza/CE, 2008.

FILIPPIS, P., GIAVARINI, C., SCARSELLA, M., Improving the aging resistance of straight-run bitumens by addiotion of phosphorus compounds, Fuel Vol. $74, \mathrm{n}^{\circ}$ 6, pg. 836-841, 1995.

FURLAN, A.P. Considerações acerca da adesão e da suceptibilidade à umidade de misturas asfálticas densas à luz de algumas propriedades mecânicas. Tese (Doutorado). Universidade de São Paulo, EESC/USP, São Carlos, SP, 2006.

FURLAN, A. P., FABBRI, G. T. P., GIGANTE, A. C., BERNUCCI, L. L. B, Considerações sobre a suscetibilidade à umidade de misturas asfálticas densas, $38^{\mathrm{a}}$ Reunião Anual de Pavimentação/ $12^{\circ}$ Encontro Nacional de Conservação Rodoviária, Recife, PE - Brasil, 2008a.

FURLAN, A. P., FABBRI, G. T. P., GIGANTE, A. C., BERNUCCI, L. L. B, Considerações sobre o efeito da cal na resiliência de misturas asfálticas densas, $38^{a}$ Reunião Anual de Pavimentação/ $12^{\circ}$ Encontro Nacional de Conservação Rodoviária, Recife, PE - Brasil, 2008b.

FURLAN, A. P.; IWANAGA, FÁBIO ISSAO ; GIGANTE, ANTONIO CARLOS ; FABBRI, GLAUCO TULIO PESSA. Influência do modo de preparo e do tipo de fíler nas propriedades das misturas asfálticas densas. In: XXI Congresso Brasileiro de Pesquisa e Ensino em Transportes, 2007, Panorana Nacional da Pesquisa e Ensino de Transportes. p. 1-12, Rio de janeiro, RJ, 2007.

FHWA. Distress identification manual for the long-term pavement performance program. Federal Highway Administration. U.S. Department of Transportation $4^{\circ}$ Edition Revised. 154 p. Mclean, 2003.

GIAVARINI, C., FILIPPIS, P., SANTARELLI, M. L., SCARSELLA, M., Production of stable polyphopylene-modified bitumens, Fuel Vol. 75, $n^{\circ}$ 6, pg 681-686, 1996.

GOMES, F. P., (1973). Estatística experimental. 5a Edição. Editora Nobel. 430p. São Paulo, 1973. 
GOUVEIA, L. T., FURLAN, A. P., PARREIRA, A. B., FERNANDES JUNIOR, J. L., FABBRI, G. T. P., Considerações acerca da absorção de asfalto pelos agregados e sua influência na suscetibilidade à umidade. Anais do XVIII Congresso Nacional de Pesquisa e Ensino em Transporte, Associação Nacional de Pesquisa e Ensino em Transportes (ANPET), Florianópolis, SC, 2004.

GOUVEIA, L.T. Avaliação do ensaio de angularidade do agregado fino (faa) da especificação Superpave. Dissertação (Mestrado), Universidade de São Paulo Escola de Engenharia de São Carlos, SP, 2002.

GOUVEIA, L.T. Influência de Propriedades dos Agregados no Comportamento de Misturas Asfálticas. Tese (Doutorado) - Escola de Engenharia de São Carlos, Universidade de São Paulo. 293p. São Carlos, 2006.

HERRINGTON, P.R.; WU, Y.; FORBES,M.C.; Rheological Modification of Bitumen with Maleic Anhydride and Dicarboxylic Acids. Fuel, v. 78, p. 101-110, 1999.

HICKS, G.H. Moisture damage in asphalt concrete. NCHRP 175 - National Highway Research, Program Synthesis of Highway Practice Transportation Research Board, 1991.

HILLS, J.F. The Creep of Asphalt Mixes. Journal of the Institute of Petroleum, Volume 59, number 570, 1973.

HUBER, G. A. Methods to Achieve Rut-Resistant Durable Pavements. National Cooperative Highway Research Program, Synthesis of Highway Practice 274, 1999.

ILDEFONSO, J. S. Análise da viabilidade técnica da utilização do copolímero etileno acetato de vinila (EVA) descartado pela indústria calçadista em misturas asfálticas (Processo seco). Dissertação (Mestrado). Universidade de São Paulo, EESC/USP, São Carlos, SP, 2007.

JIMÉNEZ, F. P., BARRAL, M., SÁNCHEZ, J. A. S., JANSORO, J. A. N., Effect of the nature and filler content on cohesion, adhesiveness and rheolegical behavior of the bituminous mastics, 4th Euroahphalt \& Eurobitumen Congress, Copenhagen, Dinamarca, 2008. 
JOHANNSON, L., Bitumen Aging and Hydrated Lime, Ph.D., Dissertation, Kungl Tekniska Hogkolan, Royal Institute of Technology, 1998.

KANDHAL, P.S., CHAKRABORTY, S. Effect of Asphalt Film Thickness on Short and Long Term Aging of Asphalt Paving Mixtures. Presented at the $75^{\text {th }}$ Annual Meeting of the Transportation Research Board, Washington, D.C., January 1996.

KANDHAL, P.S.; PARKER JR., F. Aggregate tests related to asphalt concrete performance in pavements. National Cooperative Highway Research Program. $\mathrm{n}$. 405, 1998.

KODRAT, I., SOHN, D., HESP, S. A. M., Comparison of polyphosphoric acidmodified asphalt binders with straight and polymer-modified materials, Transportation Research Record: Journal of the Transportation Research Board, $\mathrm{n}^{\circ}$ 1998, Washington D. C., 2007, pg. 47-55.

\section{LEITE, L. F. M., BITTENCOURT, C. P., NASCIMENTO, L. A. H., Efeito do ácido} polifosfórico no desempenho dos ligantes rodoviários. Anais do XVIII Congresso Nacional de Pesquisa e Ensino em Transporte, Associação Nacional de Pesquisa e Ensino em Transportes (ANPET), Florianópolis, SC, 2004.

LEITE, L.F.M.; MOTTA, L.M.G. O efeito do filer nas características do ligante asfáltico. In: Anais do XVI. Congresso de Pesquisa e Ensino em Transportes, Associação Nacional de Pesquisa e Ensino em Transportes (ANPET), p.183-194. Natal, RN, 2002.

LESUEUR, D., LITTLE, D. N. AND EPPS, J. A., Effect of Hydrated Lime on the Rheology, Frature and Aging of Bitumen and Asphalt Mixtures, Paper Presented at Lhoist HMA Symposium, Dusseldorf, Germany, June 1998.

LITTLE, D. N., EPPS, J. A., The benefits of hydrated lime in hot mix asphalt. National Lime Association, The Versatile Chemical, 2001.

LITTLE, D.N. Analysis of the influence of low density polyethylene modification (novophalt) of asphalt concrete on mixture shear and creep deformation potential. Polymer Modified Asphalt binders. American Society for Testing and Materials, ASTM STP 1108, p.186-202, 1992. 
LITTLE D. N.; JONES IV D. R.; Chemical and Mechanical Processes of Moisture Damage in Hot-Mix Asphalt Pavements; Moisture Sensitivity of Asphalt Pavements - A National Seminar; Transportation Research Board, 2003.

LOTTMAN, R. P. NCHRP Report 192: Predicting Moisture-Induced Damage to Asphaltic Concrete, Transportation Research Board, National Research Council, 24p. Washington, 1978.

LUTIF, J. E. S.; KIM, Y-R; SOARES, B. S.; Influência do método de adição de cal hidratada em misturas asfálticas para reduzir os danos devido à umidade em pavimentos flexíveis. Anais do XXII Congresso Nacional de Pesquisa e Ensino em Transporte, Associação Nacional de Pesquisa e Ensino em Transportes (ANPET), Fortaleza/CE, 2008.

MAJIDZADEH, K. e BROVOLD, F.N. State of the art: Effect of water on bitumenaggregate mixtures. Highway Research Board, Special Report n.98,77, 1968.

MALDONADO, R., FEE, D., Bitumen modification with polyphosphoric acid, 4th Euroahphalt \& Eurobitumen Congress, Copenhagen, Dinamarca, 2008.

MANUAL DO ASFALTO. Instituto do Asfalto. Série do Manual N 4 (MS-4), 1989. MEDINA, J; \& MOTTA, L.M. Mecânica dos Pavimentos. Rio de Janeiro, Editora UFRJ, 2005.

MARQUES, G.L.O. Utilização do módulo de resiliência como critério de dosagem de mistura asfáltica, efeito da compactação por impacto e giratório. Tese (Doutorado). Universidade Federal do Rio de Janeiro, COPPE/UFRJ, Rio de Janeiro, RJ, 2004.

MARTIN, J.V.; BAUMGARDNER, G. A new method to produce polymer asphalt with crumb rubber and polyphosphoric acid, combining recycling and performance. Asphalt Rubber - Proceedings, Brazili, Brazil, p.903-930, 2006.

MASSON, J-F., Brief review of the chemistry of polyphosphoric acid (PPA) and bitumen, Energy \& Fuels, 2637-2640, 2008. 
MOTTA, L.M.G.; LEITE, F.L.M.; CONSTANTINO, R.S.; TONIAL, I.A. Curso sobre o programa SHRP: Aplicação a ligantes, agregados e misturas betuminosas. Instituto Brasileiro de Petróleo. Rio de Janeiro, RJ, 1996.

MOTTA, L.M.G.; PINTO, S.. O uso de ensaios estáticos na definição de parâmetros de comportamento das misturas asfálticas. $12^{\circ}$ Encontro de Asfalto, p. 152-178, 1994.

MOTTA, L.M.G.; TONIAL, I.; LEITE, L.M.; CONSTANTINO, R.S.; BUKOWSKI, J.R.; MCGENNIS, R.B.; ANDERSON, M.; KENNEDY, T.W.; SOLAIMANIAN, M. Princípios do Projeto e Análise Superpave de Misturas Asfálticas. Instituto Brasileiro de Petróleo, Rio de Janeiro, RJ, 1994.

NCHRP - NATIONAL COOPERATIVE HIGHWAY RESEARCH PROGRAM. Incorporation of reclaimed asphalt pavement in the Superpave system. NCHRP 9-12, 2000.

NEVES FILHO, A. S., PINTO, S., CARNEIRO, L. A. V., Influência da adição de dopes na adesividade em misturas asfálticas a quente, $38^{a}$ Reunião Anual de Pavimentação/ $12^{\circ}$ Encontro Nacional de Conservação Rodoviária, Manaus, AM Brasil, 2007.

NÚÑEZ, W. P., CERATTI, J. A. V. P., TSUKUDA, R. S., Produzindo misturas asfálticas de elevado desempenho com emprego de cal hidratada, $38^{a}$ Reunião Anual de Pavimentação/ $12^{\circ}$ Encontro Nacional de Conservação Rodoviária, Manaus, AM - Brasil, 2007.

PETERSEN, J.C. Chemical Composition of Asphalt as Related to Asphalt Durability: State of the Art. In Transportation Research Record 999, TRB, National Research Council, Washington, D.C., 1984, p.13-30, 1984.

PILATI, F. Análise dos efeitos da borracha moída de pneu e do resíduo de óleo de xisto sobre algumas propriedades mecânicas de misturas asfálticas densas. Dissertação (Mestrado). Universidade de São Paulo, EESC/USP, São Carlos, SP, 2008. 
ROBERTS, F.L.; KANDHAL, P.S.; BROWN, E.R.; LEE, D.Y.; KENNEDY, T.W. Hot mix asphalt materials, mixture design, and construction. $1^{\mathrm{a}}$ ed. Napa Education Foundation. Lenham, Maryland, 1991.

ROBERTS, F.L.; KANDHAL, P.S.; BROWN, E.R.; LEE, D-Y.; KENNEDY, T.W. Hot mix asphalt materials, mixture, design, and construction. 2. ed. Lanham: Napa Education Foundation, 1996.

SANTANNA-GRECO, J. A., FABBRI, G. T. P., Avaliação dos efeitos do envelhecimento e da adição de modificadores ao ligante na deformação permanente sofrida por misturas asfálticas densas, Anais do XVIII Congresso Nacional de Pesquisa e Ensino em Transporte, Associação Nacional de Pesquisa e Ensino em Transportes (ANPET), Florianópolis, SC, 2004.

SEBAALY, P. E., LITTLE D., HAJJ, E. Y., BHASIN, A., Impact of Lime and Liquid Antistrip Agents on Properties of Idaho Hot-Mix Asphalt Mixture, Transportation Research Record: Journal os the Transportation Research Board, n 1998, Washington, D.C., pg. 65-74, 2007.

SEBAALY, P.E.; McCANN. M; HITTI, E.; EPPS, J. Performance of lime in hot mix asphalt pavements. Pavements/Material Program - Department of Civil Engineering - University of Nevada Technical Report Documentation Page 101; . Distribuition Statement: Unrestricted. Nevada, 2001.

SENÇO, W.; Manual de técnicas de pavimentação (vol.1). Ed.; Pini, São Paulo, 1997.

SILVA, L. S.; FORTE, M. M. C.; FARCAS, F. D. F.; BARTOLOMEO, P.; Simulação e Envelhecimento UV em ligantes asfálticos, $17^{\circ}$ Encontro de Asfalto do Instituto Brasileiro de Petróleo e Gás - IBP, 2004.

SOSNOVSKE, D.A., AbWAHAB, Y.; BELL, C.A; Role of asphalt and agregate in the aging of bituminous mixtures, Transportation Research Record. n. 1386, p. 10-21. Washington, D.C., 1993. 
Terrel, R.L. e Al-SWAILMI (1993); Role os Pessimum Voids concept in understanding Mixture Damage to Asphalt Concrete Mixtures, Transportation Research Record 1386, p. 31-37, Washington, D.C.

WU, Y.; PARKER JR., R.; KANDHAL, P.S. Aggregate toughness/abrasion resistance and durability/soundness tests related to asphalt concrete performance in pavements. Transportation Research Record, n. 1638, p. 85 - 93, 1998. 
ANEXO I - MASSAS ESPECÍFICAS "CORRIGIDA" APARENTE E MÁXIMA MEDIDA 
Tabela I. 1. Determinação dos valores da massa específica aparente "corrigida".

\begin{tabular}{ccccc}
\hline $\begin{array}{c}\text { Teor de Ligante } \\
(\%)\end{array}$ & CP & Peso seco $(\mathrm{g})$ & Peso Imerso $(\mathrm{g})$ & $\mathrm{G}_{\mathrm{sb}}\left(\mathrm{g} / \mathrm{cm}^{3}\right)$ \\
\hline \multirow{2}{*}{4,5} & T11 & 1251,51 & 728,7 & 2,394 \\
& T12 & 1257,1 & 727,8 & 2,375 \\
& T13 & 1252,36 & 725,1 & 2,375 \\
& T21 & 1268,81 & 737,5 & 2,388 \\
5,0 & T22 & 1286,06 & 749,2 & 2,396 \\
& T23 & 1258,69 & 732,7 & 2,393 \\
& T31 & 1264,71 & 735,1 & 2,388 \\
5,5 & T32 & 1265,37 & 735,3 & 2,387 \\
& T33 & 1266,59 & 736,1 & 2,388 \\
& T41 & 1267,75 & 734,9 & 2,379 \\
6,0 & T42 & 1273,7 & 738,6 & 2,380 \\
& T43 & 1268,53 & 735,6 & 2,380 \\
\hline
\end{tabular}

Tabela I. 2. Determinação dos valores da massa específica aparente "corrigida".

\begin{tabular}{cccc}
\hline $\mathrm{CP}$ & $\begin{array}{c}\text { Peso seco } \\
(\mathrm{g})\end{array}$ & $\begin{array}{c}\text { Peso Imerso } \\
(\mathrm{g})\end{array}$ & $\mathrm{G}_{\mathrm{sb}}\left(\mathrm{g} / \mathrm{cm}^{3}\right)$ \\
\hline 1 & 1252,1 & 726,1 & 2,380 \\
2 & 1248,9 & 725,3 & 2,385 \\
3 & 1251,4 & 724,7 & 2,376 \\
4 & 1254,0 & 727,2 & 2,380 \\
5 & 1255,0 & 723,3 & 2,360 \\
6 & 1255,7 & 724,6 & 2,364 \\
7 & 1251,4 & 722,3 & 2,365 \\
8 & 1252,9 & 725,7 & 2,377 \\
9 & 1252,7 & 720,5 & 2,354 \\
10 & 1255,1 & 726,9 & 2,376 \\
11 & 1256,3 & 723,6 & 2,358 \\
12 & 1254,9 & 721,5 & 2,353 \\
13 & 1253,7 & 723,2 & 2,363 \\
14 & 1253,7 & 726,2 & 2,377 \\
15 & 1255,4 & 730,1 & 2,390 \\
16 & 1254,5 & 727,1 & 2,379 \\
17 & 1254,5 & 723,8 & 2,364 \\
18 & 1252,2 & 721,6 & 2,360 \\
\hline
\end{tabular}


Tabela I. 3. Calculo do Gmm para 1,5\% de cal e 0,6\% de PPA para diferentes teores de ligante.

\begin{tabular}{|l|r|r|r|r}
\hline Teor de Ligante & $4,5 \%$ LA & $5 \%$ LA & $5,5 \%$ LA & $6,0 \%$ LA \\
\hline Modificador & \multicolumn{4}{|c}{$0,6 \%$ de PPA } \\
\hline Aditivo & \multicolumn{4}{|c|}{$1,5 \%$ de cal } \\
\hline A & 1254,5 & 1261,3 & 1267,6 & 1274,5 \\
\hline E & 4329,6 & 4328,9 & 4327 & 4327,2 \\
\hline$D$ & 3588,5 & 3589,4 & 3587,3 & 3585,5 \\
\hline $\mathrm{G}_{\text {min }}$ & 2,452 & 2,425 & 2,409 & 2,400 \\
\hline
\end{tabular}

Tabela I. 4. Cálculo do $\mathrm{Gmm}$ para todas as combinacoes de fatores.

\begin{tabular}{|c|c|c|c|c|c|c|c|c|c|}
\hline \multirow{3}{*}{$\begin{array}{l}\text { Teor de ligante } \\
\text { Modificador } \\
\end{array}$} & \multicolumn{9}{|c|}{$4,67 \%\llcorner A$} \\
\hline & \multicolumn{3}{|c|}{$0 \%$ de PPA } & \multicolumn{3}{|c|}{$0,6 \%$ de PPA } & \multicolumn{3}{|c|}{$12 \%$ de PPA } \\
\hline & $0 \%$ de cal & $1,5 \%$ de cal & $3,0 \%$ de cal & $0 \%$ de cal & $1,5 \%$ de cal & $3,0 \%$ de cal & $0 \%$ de cal & $1,5 \%$ de cal & $3,0 \%$ de cal \\
\hline A & 1553,4 & 1592 & 1662,3 & 1792,9 & 1553,6 & 1622,7 & 1541,2 & 1536,6 & 1548 \\
\hline$E$ & 4515 & 4536,5 & 4575,4 & 4656,7 & 4513,9 & 4551,1 & 4506,3 & 4501,6 & 4506,1 \\
\hline D & 3592 & 3590,2 & 3590,2 & 3590,2 & 3590,2 & 3589,4 & 3588,5 & 3588,5 & 3589 \\
\hline $\mathrm{G}_{\operatorname{mm}}(\mathrm{g} / \mathrm{cm} 3)$ & 2,471 & 2,472 & 2,461 & 2,474 & 2,473 & 2,461 & 2,479 & 2,471 & 2,460 \\
\hline
\end{tabular}


ANEXO II - PROPRIEDADES OBTIDAS DA MOLDAGEM 
Tabela II. 1. Resultado das propriedades da moldagem dos corpos-de-prova.

\begin{tabular}{|c|c|c|c|c|c|c|c|c|c|c|c|}
\hline Aditivo & Modificador & $C P$ & $\begin{array}{l}\text { Aitura } \\
(\mathrm{mm})\end{array}$ & $\begin{array}{l}G m b \text { (est) } \\
(g / c m 3)\end{array}$ & $\begin{array}{l}\text { Gmb (corr) } \\
(g / c m 3)\end{array}$ & $\begin{array}{l}\text { \%Gmm } 0 \\
\text { Nprojeto (100) }\end{array}$ & $\begin{array}{l}V V \\
(\%)\end{array}$ & $\begin{array}{l}\text { W,méd } \\
(\%)\end{array}$ & $\begin{array}{l}\text { Gmm } \\
\text { médio } \\
(g / c m 3)\end{array}$ & $\begin{array}{l}\text { VAM } \\
\text { (\%) }\end{array}$ & $\begin{array}{l}R B V \\
\text { (\%) }\end{array}$ \\
\hline \multirow{36}{*}{$\begin{array}{l}0 \% \\
\text { cal }\end{array}$} & \multirow{12}{*}{$0 \% \mathrm{PPA}$} & 1 & 65,87 & 2,328 & 2,371 & 95,94 & 4,06 & \multirow{6}{*}{3,97} & \multirow{6}{*}{2,471} & 11,45 & 0,65 \\
\hline & & 2 & 65,84 & 2,328 & 2,371 & 95,96 & 4,04 & & & 11,43 & 0,65 \\
\hline & & 3 & 65,79 & 2,331 & 2,376 & 96,18 & 3,82 & & & 11,23 & 0,66 \\
\hline & & 4 & 65,73 & 2,328 & 2,376 & 96,18 & 3,82 & & & 11,23 & 0,66 \\
\hline & & 5 & 65,96 & 2,324 & 2,376 & 96,16 & 3,84 & & & 11,24 & 0,66 \\
\hline & & 6 & 65,8 & 2,323 & 2,366 & 95,77 & 4,23 & & & 11,61 & 0,64 \\
\hline & & 7 & 68,68 & 2,231 & 2,301 & 93,13 & 6,87 & \multirow{6}{*}{7,08} & \multirow{6}{*}{2,471} & 14,04 & 0,51 \\
\hline & & 8 & 68,96 & 2,223 & 2,286 & 92,53 & 7,47 & & & 14,60 & 0,49 \\
\hline & & 9 & 68,7 & 2,224 & 2,306 & 93,32 & 6,68 & & & 13,87 & 0,52 \\
\hline & & 10 & 68,63 & 2,228 & 2,297 & 92,98 & 7,02 & & & 14,18 & 0,50 \\
\hline & & 11 & 68,73 & 2,225 & 2,283 & 92,39 & 7,61 & & & 14,72 & 0,48 \\
\hline & & 12 & 68,65 & 2,228 & 2,302 & 93,15 & 6,85 & & & 14,02 & 0,51 \\
\hline & \multirow{12}{*}{$0,6 \%$ PPA } & 13 & 65,78 & 2,325 & 2,378 & 96,10 & 3,90 & \multirow{6}{*}{4,01} & \multirow{6}{*}{2,474} & 11,18 & 0,65 \\
\hline & & 14 & 65,63 & 2,328 & 2,377 & 96,10 & 3,90 & & & 11,19 & 0,65 \\
\hline & & 15 & 65,87 & 2,320 & 2,371 & 95,82 & 4,18 & & & 11,45 & 0,63 \\
\hline & & 16 & 65,73 & 2,330 & 2,381 & 96,23 & 3,77 & & & 11,06 & 0,66 \\
\hline & & 17 & 65,83 & 2,321 & 2,372 & 95,87 & 4,13 & & & 11,40 & 0,64 \\
\hline & & 18 & 65,87 & 2,320 & 2,371 & 95,84 & 4,16 & & & 11,43 & 0,64 \\
\hline & & 19 & 68,96 & 2,216 & 2,285 & 92,37 & 7,63 & \multirow{6}{*}{7,61} & \multirow{6}{*}{2,474} & 14,64 & 0,48 \\
\hline & & 20 & 68,94 & 2,216 & 2,279 & 92,12 & 7,88 & & & 14,86 & 0,47 \\
\hline & & 21 & 68,93 & 2,217 & 2,289 & 92,53 & 7,47 & & & 14,48 & 0,48 \\
\hline & & 22 & 68,91 & 2,217 & 2,285 & 92,34 & 7,66 & & & 14,66 & 0,48 \\
\hline & & 23 & 68,93 & 2,217 & 2,292 & 92,64 & 7,36 & & & 14,38 & 0,49 \\
\hline & & 24 & 68,91 & 2,217 & 2,285 & 92,35 & 7,65 & & & 14,65 & 0,48 \\
\hline & \multirow{12}{*}{$1,2 \%$ PPA } & 25 & 65,43 & 2,337 & 2,385 & 96,19 & 3,81 & \multirow{6}{*}{4,09} & \multirow{6}{*}{2,479} & 10,92 & 0,65 \\
\hline & & 26 & 65,66 & 2,329 & 2,376 & 95,85 & 4,15 & & & 11,24 & 0,63 \\
\hline & & 27 & 65,79 & 2,328 & 2,373 & 95,74 & 4,26 & & & 11,34 & 0,62 \\
\hline & & 28 & 66,02 & 2,320 & 2,375 & 95,79 & 4,21 & & & 11,29 & 0,63 \\
\hline & & 29 & 65,69 & 2,330 & 2,377 & 95,89 & 4,11 & & & 11,20 & 0,63 \\
\hline & & 30 & 65,74 & 2,324 & 2,380 & 96,02 & 3,98 & & & 11,08 & 0,64 \\
\hline & & 31 & 67,62 & 2,260 & 2,321 & 93,62 & 6,38 & \multirow{6}{*}{6,23} & \multirow{6}{*}{2,479} & 13,31 & 0,52 \\
\hline & & 32 & 68,65 & 2,226 & 2,289 & 92,34 & 7,66 & & & 14,49 & 0,47 \\
\hline & & 33 & 68,69 & 2,228 & 2,307 & 93,05 & 6,95 & & & 13,83 & 0,50 \\
\hline & & 34 & 68,72 & 2,227 & 2,324 & 93,76 & 6,24 & & & 13,17 & 0,53 \\
\hline & & 35 & 68,71 & 2,229 & 2,370 & 95,59 & 4,41 & & & 11,47 & 0,62 \\
\hline & & 36 & 68,73 & 2,227 & 2,336 & 94,22 & 5,78 & & & 12,74 & 0,55 \\
\hline
\end{tabular}


Continuação da Tabela II.1

\begin{tabular}{|c|c|c|c|c|c|c|c|c|c|c|c|}
\hline Aditivo & Modificador & $C P$ & $\begin{array}{l}\text { Aitura } \\
(\mathrm{mm})\end{array}$ & $\begin{array}{l}G m b \text { (est) } \\
(g / \mathrm{cm} 3)\end{array}$ & $\begin{array}{l}\text { Gmb (corr) } \\
(g \circ \mathrm{cm})\end{array}$ & $\begin{array}{l}\text { \%Gmm@ } \\
\text { Nprojeto (100) }\end{array}$ & $\begin{array}{l}V / V \\
(\%)\end{array}$ & $\begin{array}{l}\text { W, méd } \\
\text { (\%) }\end{array}$ & $\begin{array}{l}\text { Gmm } \\
\text { médio } \\
(g / \mathrm{cm} 3)\end{array}$ & $\begin{array}{l}\text { VAM } \\
\text { (\%) }\end{array}$ & $\begin{array}{l}R B V \\
\text { (\%) }\end{array}$ \\
\hline \multirow{36}{*}{$\begin{array}{l}1,5 \% \\
\text { cal }\end{array}$} & \multirow{12}{*}{$0 \%$ PPA } & 37 & 65,36 & 2,338 & 2,371 & 95,90 & 4,10 & \multirow{6}{*}{4,00} & \multirow{6}{*}{2,472} & 11,44 & 0,64 \\
\hline & & 38 & 65,57 & 2,330 & 2,372 & 95,94 & 4,06 & & & 11,40 & 0,64 \\
\hline & & 39 & 65,66 & 2,327 & 2,376 & 96,12 & 3,88 & & & 11,24 & 0,65 \\
\hline & & 40 & 65,5 & 2,333 & 2,377 & 96,15 & 3,85 & & & 11,21 & 0,66 \\
\hline & & 41 & 65,69 & 2,326 & 2,377 & 96,16 & 3,84 & & & 11,20 & 0,66 \\
\hline & & 42 & 65,77 & 2,323 & 2,367 & 95,75 & 4,25 & & & 11,58 & 0,63 \\
\hline & & 43 & 69,24 & 2,207 & 2,301 & 93,43 & 6,57 & \multirow{6}{*}{6,79} & \multirow{6}{*}{2,472} & 13,72 & 0,52 \\
\hline & & 44 & 68,93 & 2,217 & 2,286 & 92,82 & 7,18 & & & 14,28 & 0,50 \\
\hline & & 45 & 68,88 & 2,218 & 2,306 & 93,61 & 6,39 & & & 13,55 & 0,53 \\
\hline & & 46 & 68,94 & 2,216 & 2,297 & 93,28 & 6,72 & & & 13,86 & 0,52 \\
\hline & & 47 & 68,93 & 2,217 & 2,283 & 92,69 & 7,31 & & & 14,40 & 0,49 \\
\hline & & 48 & 68,9 & 2,218 & 2,302 & 93,45 & 6,55 & & & 13,71 & 0,52 \\
\hline & \multirow{6}{*}{$0,6 \%$ PPA } & 49 & 65,55 & 2,331 & 2,371 & 95,83 & 4,17 & \multirow{6}{*}{4,07} & \multirow{6}{*}{2,473} & 11,47 & 0,64 \\
\hline & & 50 & 66,04 & 2,314 & 2,372 & 95,87 & 4,13 & & & 11,43 & 0,64 \\
\hline & & 51 & 65,79 & 2,322 & 2,376 & 96,04 & 3,96 & & & 11,27 & 0,65 \\
\hline & & 52 & 65,97 & 2,316 & 2,377 & 96,07 & 3,93 & & & 11,25 & 0,65 \\
\hline & & 53 & 66,28 & 2,305 & 2,377 & 96,08 & 3,92 & & & 11,23 & 0,65 \\
\hline & & 54 & 65,99 & 2,315 & 2,367 & 95,67 & 4,33 & & & 11,61 & 0,63 \\
\hline & \multirow{6}{*}{$0,6 \%$ PPA } & 55 & 69,22 & 2,207 & 2,301 & 93,01 & 6,99 & \multirow{6}{*}{7,20} & \multirow{6}{*}{2,473} & 14,07 & 0,50 \\
\hline & & 56 & 69,17 & 2,209 & 2,286 & 92,41 & 7,59 & & & 14,63 & 0,48 \\
\hline & & 57 & 69,17 & 2,209 & 2,306 & 93,20 & 6,80 & & & 13,90 & 0,51 \\
\hline & & 58 & 69,18 & 2,209 & 2,297 & 92,86 & 7,14 & & & 14,21 & 0,50 \\
\hline & & 59 & 69,2 & 2,208 & 2,283 & 92,28 & 7,72 & & & 14,75 & 0,48 \\
\hline & & 60 & 69,19 & 2,208 & 2,302 & 93,03 & 6,97 & & & 14,05 & 0,50 \\
\hline & \multirow{12}{*}{$1,2 \%$ PPA } & 61 & 66,03 & 2,314 & 2,368 & 95,80 & 4,20 & \multirow{6}{*}{4,27} & \multirow{6}{*}{2,471} & 11,56 & 0,64 \\
\hline & & 62 & 66,29 & 2,305 & 2,365 & 95,71 & 4,29 & & & 11,65 & 0,63 \\
\hline & & 63 & 66,49 & 2,298 & 2,362 & 95,59 & 4,41 & & & 11,76 & 0,62 \\
\hline & & 64 & 66,18 & 2,309 & 2,367 & 95,76 & 4,24 & & & 11,60 & 0,63 \\
\hline & & 65 & 65,8 & 2,322 & 2,371 & 95,93 & 4,07 & & & 11,44 & 0,64 \\
\hline & & 66 & 66,21 & 2,308 & 2,363 & 95,61 & 4,39 & & & 11,74 & 0,63 \\
\hline & & 67 & 68,89 & 2,218 & 2,301 & 93,43 & 6,57 & \multirow{6}{*}{7,24} & \multirow{6}{*}{2,471} & 13,75 & 0,52 \\
\hline & & 68 & 68,95 & 2,216 & 2,286 & 92,52 & 7,48 & & & 14,59 & 0,49 \\
\hline & & 69 & 68,97 & 2,215 & 2,294 & 92,83 & 7,17 & & & 14,31 & 0,50 \\
\hline & & 70 & 68,98 & 2,215 & 2,295 & 92,85 & 7,15 & & & 14,29 & 0,50 \\
\hline & & 71 & 68,93 & 2,217 & 2,285 & 92,47 & 7,53 & & & 14,63 & 0,49 \\
\hline & & 72 & 68,98 & 2,215 & 2,285 & 92,44 & 7,56 & & & 14,66 & 0,48 \\
\hline
\end{tabular}

Continua... 
Continuação da Tabela II.1

\begin{tabular}{|c|c|c|c|c|c|c|c|c|c|c|c|}
\hline Aditivo & Modificador & $C P$ & $\begin{array}{l}\text { Aitura } \\
(\mathrm{mm})\end{array}$ & $\begin{array}{l}G m b \text { (est) } \\
(g / c m 3)\end{array}$ & $\begin{array}{l}G m b(c o r r) \\
(g / c m 3)\end{array}$ & $\begin{array}{l}\% G m m \propto \\
\text { Nprojeto (100) }\end{array}$ & $\begin{array}{l}V / V \\
\text { (\%) }\end{array}$ & $\begin{array}{l}\text { W, méd } \\
\text { (\%) }\end{array}$ & $\begin{array}{l}G m m \\
\text { médio } \\
(g / c m 3)\end{array}$ & $\begin{array}{l}\text { VAM } \\
\text { (\%) }\end{array}$ & $\begin{array}{l}R B V \\
\text { (\%) }\end{array}$ \\
\hline \multirow{36}{*}{$\begin{array}{l}3,0 \% \\
\text { cal }\end{array}$} & \multirow{12}{*}{$0 \%$ PPA } & 73 & 65,82 & 2,321 & 2,370 & 96,28 & 3,72 & \multirow{6}{*}{4,01} & \multirow{6}{*}{2,461} & 11,48 & 0,68 \\
\hline & & 74 & 66,4 & 2,301 & 2,366 & 96,13 & 3,87 & & & 11,62 & 0,67 \\
\hline & & 75 & 66,36 & 2,302 & 2,359 & 95,83 & 4,17 & & & 11,89 & 0,65 \\
\hline & & 76 & 66,06 & 2,313 & 2,358 & 95,82 & 4,18 & & & 11,90 & 0,65 \\
\hline & & 77 & 66,4 & 2,301 & 2,359 & 95,85 & 4,15 & & & 11,88 & 0,65 \\
\hline & & 78 & 66,13 & 2,310 & 2,364 & 96,04 & 3,96 & & & 11,70 & 0,66 \\
\hline & & 79 & 69,17 & 2,209 & 2,284 & 92,80 & 7,20 & \multirow{6}{*}{7,23} & \multirow{6}{*}{2,461} & 14,68 & 0,51 \\
\hline & & 80 & 69,18 & 2,209 & 2,279 & 92,60 & 7,40 & & & 14,87 & 0,50 \\
\hline & & 81 & 69,23 & 2,207 & 2,274 & 92,40 & 7,60 & & & 15,05 & 0,49 \\
\hline & & 82 & 69,2 & 2,208 & 2,293 & 93,18 & 6,82 & & & 14,33 & 0,52 \\
\hline & & 83 & 69,17 & 2,209 & 2,277 & 92,51 & 7,49 & & & 14,95 & 0,50 \\
\hline & & 84 & 69,22 & 2,207 & 2,293 & 93,17 & 6,83 & & & 14,34 & 0,52 \\
\hline & \multirow{12}{*}{$0,6 \%$ PPA } & 85 & 66,1 & 2,311 & 2,357 & 95,76 & 4,24 & \multirow{6}{*}{4,20} & \multirow{6}{*}{2,461} & 11,95 & 0,65 \\
\hline & & 86 & 66,08 & 2,312 & 2,361 & 95,91 & 4,09 & & & 11,82 & 0,65 \\
\hline & & 87 & 66,33 & 2,303 & 2,358 & 95,79 & 4,21 & & & 11,93 & 0,65 \\
\hline & & 88 & 66,37 & 2,302 & 2,354 & 95,65 & 4,35 & & & 12,06 & 0,64 \\
\hline & & 89 & 66,18 & 2,309 & 2,358 & 95,82 & 4,18 & & & 11,90 & 0,65 \\
\hline & & 90 & 66,21 & 2,308 & 2,360 & 95,89 & 4,11 & & & 11,84 & 0,65 \\
\hline & & 91 & 69,19 & 2,208 & 2,291 & 93,06 & 6,94 & \multirow{6}{*}{7,28} & \multirow{6}{*}{2,461} & 14,43 & 0,52 \\
\hline & & 92 & 69,25 & 2,206 & 2,299 & 93,39 & 6,61 & & & 14,13 & 0,53 \\
\hline & & 93 & 69,17 & 2,209 & 2,278 & 92,54 & 7,46 & & & 14,91 & 0,50 \\
\hline & & 94 & 69,17 & 2,209 & 2,276 & 92,48 & 7,52 & & & 14,97 & 0,50 \\
\hline & & 95 & 69,23 & 2,207 & 2,275 & 92,41 & 7,59 & & & 15,03 & 0,50 \\
\hline & & 96 & 69,23 & 2,207 & 2,275 & 92,42 & 7,58 & & & 15,03 & 0,50 \\
\hline & \multirow{12}{*}{$1,2 \%$ PPA } & 97 & 66,28 & 2,305 & 2,354 & 95,68 & 4,32 & \multirow{6}{*}{4,39} & \multirow{6}{*}{2,460} & 12,06 & 0,64 \\
\hline & & 98 & 66,21 & 2,308 & 2,357 & 95,78 & 4,22 & & & 11,97 & 0,65 \\
\hline & & 99 & 66,82 & 2,287 & 2,349 & 95,48 & 4,52 & & & 12,24 & 0,63 \\
\hline & & 100 & 66,41 & 2,301 & 2,351 & 95,57 & 4,43 & & & 12,17 & 0,64 \\
\hline & & 101 & 66,43 & 2,300 & 2,353 & 95,65 & 4,35 & & & 12,09 & 0,64 \\
\hline & & 102 & 66,73 & 2,290 & 2,350 & 95,50 & 4,50 & & & 12,23 & 0,63 \\
\hline & & 103 & 69,13 & 2,210 & 2,258 & 91,79 & 8,21 & \multirow{6}{*}{7,27} & \multirow{6}{*}{2,460} & 15,64 & 0,47 \\
\hline & & 104 & 69,23 & 2,207 & 2,276 & 92,49 & 7,51 & & & 14,99 & 0,50 \\
\hline & & 105 & 69,2 & 2,208 & 2,294 & 93,23 & 6.77 & & & 14,32 & 0,53 \\
\hline & & 106 & 69,23 & 2,207 & 2,279 & 92,63 & 7,37 & & & 14,87 & 0,50 \\
\hline & & 107 & 69,25 & 2,206 & 2,284 & 92,83 & 7,17 & & & 14,68 & 0,51 \\
\hline & & 108 & 69,23 & 2,207 & 2,298 & 93,39 & 6,61 & & & 14,17 & 0,53 \\
\hline
\end{tabular}


ANEXO III - MÓDULOS DE RESILIÊNCIA PARA AS TEMPERATURAS DE 10, 25 E $40^{\circ} \mathrm{C}$. 
Tabela III. 1. Módulo de Resiliência para todos os fatores a $40^{\circ} \mathrm{C}$.

\begin{tabular}{|c|c|c|c|c|c|c|c|}
\hline Aditivo & Modificador & $V /(\%)$ & $C P n^{\circ}$ & $\begin{array}{l}\text { Mod. Res. Total - } \\
\text { MCHRP }\end{array}$ & $\begin{array}{l}\text { Mod. Res. Instant. } \\
\text { - MCHRP }\end{array}$ & $\begin{array}{l}\text { ((MRi - MRt)/MRI) } \\
\text { - MCHRP }\end{array}$ & $\begin{array}{l}\text { Atraso } \\
\text { Médio }\end{array}$ \\
\hline \multirow{54}{*}{ 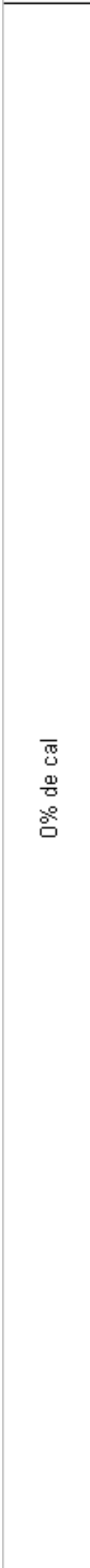 } & \multirow{18}{*}{$\begin{array}{l}x \\
0 \\
\frac{1}{2} \\
\frac{0}{0} \\
\circ \\
8\end{array}$} & \multirow{9}{*}{4} & 1 & 1406,40 & 1872,23 & 0,25 & 0,05 \\
\hline & & & 2 & 1061,90 & 1481,37 & 0,28 & 0,05 \\
\hline & & & 3 & 1105,50 & 1509,20 & 0,27 & 0,05 \\
\hline & & & 4 & 961,77 & 1280,87 & 0,25 & 0,05 \\
\hline & & & 5 & 893,57 & 1197,20 & 0,25 & 0,05 \\
\hline & & & 6 & 1030,00 & 1375,20 & 0,25 & 0,05 \\
\hline & & & Média & 1076,52 & 1452,68 & 0,26 & 0,05 \\
\hline & & & Desvio & 178,15 & 237,00 & 0,01 & 0,00 \\
\hline & & & Relação & 16,55 & 16,31 & 5,22 & 0,94 \\
\hline & & \multirow{9}{*}{7} & 7 & 928,03 & 1201,37 & 0,23 & 0,05 \\
\hline & & & 8 & 859,53 & 1096,90 & 0,22 & 0,05 \\
\hline & & & 9 & 1351,75 & 1446,65 & 0,07 & 0,05 \\
\hline & & & 10 & 888,85 & 1139,35 & 0,22 & 0,05 \\
\hline & & & 11 & 769,05 & 987,95 & 0,22 & 0,05 \\
\hline & & & 12 & 1035,20 & 1201,05 & 0,14 & 0,05 \\
\hline & & & Média & 972,07 & 1178,88 & 0,18 & 0,05 \\
\hline & & & \begin{tabular}{|l} 
Desvio \\
\end{tabular} & 205,37 & 153,26 & 0,06 & 0,00 \\
\hline & & & Relação & 21,13 & 13,00 & 34,98 & 1,42 \\
\hline & \multirow{18}{*}{$\begin{array}{l}x \\
0 \\
0 \\
\frac{0}{0} \\
\circ \\
0 \\
0 \\
0\end{array}$} & \multirow{9}{*}{4} & 13 & 2412,05 & 3156,90 & 0,24 & 0,05 \\
\hline & & & 14 & 2072,70 & 2679,55 & 0,23 & 0,05 \\
\hline & & & 15 & 3477,60 & 4362,50 & 0,20 & 0,05 \\
\hline & & & 16 & 1810,90 & 2335,10 & 0,22 & 0,05 \\
\hline & & & 17 & 2204,30 & 2844,20 & 0,23 & 0,05 \\
\hline & & & 18 & 1500,45 & 1941,25 & 0,23 & 0,05 \\
\hline & & & Média & 2246,33 & 2886,58 & 0,22 & 0,05 \\
\hline & & & Desvio & 681,37 & 835,92 & 0,01 & 0,00 \\
\hline & & & Relação & 30,33 & 28,96 & 4,95 & 3,16 \\
\hline & & \multirow{9}{*}{7} & 19 & 1256,15 & 1566,85 & 0,20 & 0,05 \\
\hline & & & 20 & 1344,70 & 1636,10 & 0,18 & 0,05 \\
\hline & & & 21 & 2304,30 & 2883,30 & 0,20 & 0,05 \\
\hline & & & 22 & 2020,40 & 2681,15 & 0,25 & 0,05 \\
\hline & & & 23 & 1557,15 & 1925,10 & 0,19 & 0,05 \\
\hline & & & 24 & 1226,80 & 1640,00 & 0,25 & 0,05 \\
\hline & & & Média & 1618,25 & 2055,42 & 0,21 & 0,05 \\
\hline & & & Desvio & 446,16 & 579,83 & 0,03 & 0,00 \\
\hline & & & Relação & 27,57 & 28,21 & 14,52 & 1,88 \\
\hline & \multirow{18}{*}{ 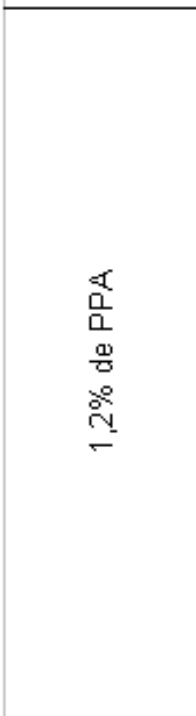 } & \multirow{9}{*}{4} & 25 & 2678,65 & 3292,80 & 0,19 & 0,04 \\
\hline & & & 26 & 2131,35 & 2788,85 & 0,24 & 0,04 \\
\hline & & & 27 & 2695,35 & 3383,50 & 0,20 & 0,04 \\
\hline & & & 28 & 2931,65 & 3615,75 & 0,19 & 0,04 \\
\hline & & & 29 & 3097,05 & 3873,05 & 0,20 & 0,05 \\
\hline & & & 30 & 1872,70 & 2365,15 & 0,21 & 0,05 \\
\hline & & & Média & 2567,79 & 3219,85 & 0,20 & 0,04 \\
\hline & & & Desvio & 472,17 & 553,49 & 0,02 & 0,00 \\
\hline & & & Relação & 18,39 & 17,19 & 8,55 & 2,41 \\
\hline & & \multirow{9}{*}{7} & 31 & 1954,70 & 2460,10 & 0,21 & 0,05 \\
\hline & & & 32 & 1602,10 & 2015,95 & 0,21 & 0,05 \\
\hline & & & 33 & 2686,85 & 3356,45 & 0,20 & 0,04 \\
\hline & & & 34 & 2020,50 & 2571,15 & 0,21 & 0,04 \\
\hline & & & 35 & 1468,15 & 1826,70 & 0,20 & 0,05 \\
\hline & & & 36 & 1863,50 & 2412,60 & 0,23 & 0,05 \\
\hline & & & Média & 1932,63 & 2440,49 & 0,21 & 0,05 \\
\hline & & & Desvio & 425,87 & 531,83 & 0,01 & 0,00 \\
\hline & & & Relação & 22,04 & 21,79 & 5,43 & 4,62 \\
\hline
\end{tabular}


Continuação da Tabela III.1

\begin{tabular}{|c|c|c|c|c|c|c|c|}
\hline Aditivo & Modificadc & $V / V(\%)$ & $C P n^{\circ}$ & $\begin{array}{l}\text { Mod. Res. Total - } \\
\text { MCHRP }\end{array}$ & $\begin{array}{l}\text { Mod. Res. Instant. } \\
\text { - MCHRP }\end{array}$ & $\begin{array}{l}((M R i-M R t) / M R I) \\
-M C H R P\end{array}$ & $\begin{array}{l}\text { Atraso } \\
\text { Médio }\end{array}$ \\
\hline \multirow{54}{*}{ 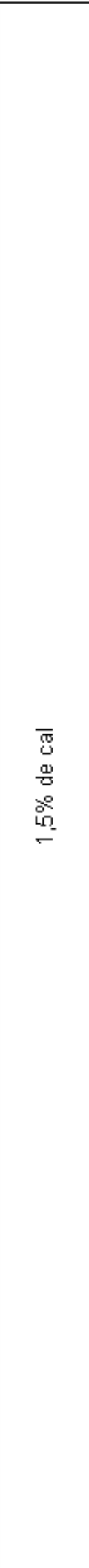 } & \multirow{18}{*}{ 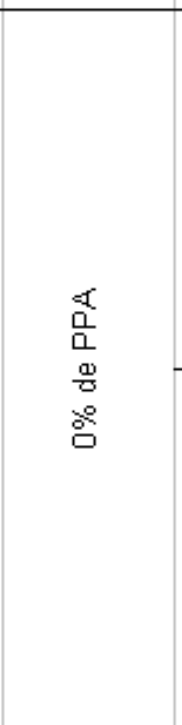 } & \multirow{9}{*}{4} & 37 & 1509,60 & 2108,45 & 0,28 & 0,05 \\
\hline & & & 38 & 1275,35 & 1797,95 & 0,29 & 0,05 \\
\hline & & & 39 & 1279,15 & 1739,70 & 0,26 & 0,05 \\
\hline & & & 40 & 1159,20 & 1636,70 & 0,29 & 0,05 \\
\hline & & & 41 & 1768,60 & 2529,60 & 0,30 & 0,05 \\
\hline & & & 42 & 1541,90 & 2116,00 & 0,27 & 0,05 \\
\hline & & & Média & 1422,30 & 1988,07 & 0,28 & 0,05 \\
\hline & & & $\begin{array}{l}\text { Desvio } \\
\end{array}$ & 225,01 & 330,27 & 0,01 & 0,00 \\
\hline & & & Relação & 15,82 & 16,61 & 4,79 & 1,26 \\
\hline & & \multirow{9}{*}{7} & 43 & 1032,45 & 1380,15 & 0,25 & 0,05 \\
\hline & & & 44 & 1141,40 & 1539,45 & 0,26 & 0,05 \\
\hline & & & 45 & 1417,40 & 1909,95 & 0,26 & 0,05 \\
\hline & & & 46 & 1312,75 & 1744,00 & 0,25 & 0,05 \\
\hline & & & 47 & 976,35 & 1356,05 & 0,28 & 0,05 \\
\hline & & & 48 & 1467,45 & 1976,55 & 0,26 & 0,05 \\
\hline & & & Média & 1224,63 & 1651,03 & 0,26 & 0,05 \\
\hline & & & Desvio & 204,64 & 266,27 & 0,01 & 0,00 \\
\hline & & & Relação & 16,71 & 16,13 & 4,33 & 1,24 \\
\hline & \multirow{18}{*}{ 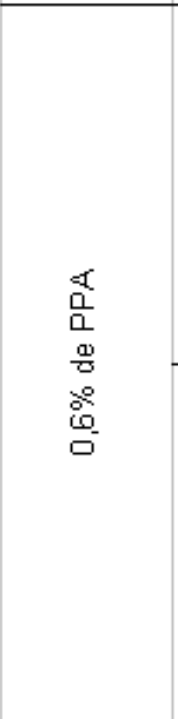 } & \multirow{9}{*}{4} & 49 & 1212,55 & 1620,10 & 0,25 & 0,05 \\
\hline & & & 50 & 1198,90 & 1626,95 & 0,26 & 0,05 \\
\hline & & & 51 & 1151,90 & 1495,25 & 0,23 & 0,05 \\
\hline & & & 52 & 1883,50 & 2558,85 & 0,26 & 0,05 \\
\hline & & & 53 & 1615,40 & 2215,10 & 0,27 & 0,05 \\
\hline & & & 54 & 1522,10 & 2071,20 & 0,27 & 0,05 \\
\hline & & & Média & 1430,73 & 1931,24 & 0,26 & 0,05 \\
\hline & & & Desvio & 292,08 & 417,98 & 0,01 & 0,00 \\
\hline & & & Relação & 20,41 & 21,64 & 5,79 & 1,43 \\
\hline & & \multirow{9}{*}{7} & 55 & 1423,55 & 1934,75 & 0,26 & 0,05 \\
\hline & & & 56 & 1319,35 & 1749,80 & 0,25 & 0,05 \\
\hline & & & 57 & 3584,70 & 4625,95 & 0,23 & 0,05 \\
\hline & & & 58 & 1574,75 & 2048,65 & 0,23 & 0,05 \\
\hline & & & 59 & 1621,95 & 2126,40 & 0,24 & 0,05 \\
\hline & & & 60 & 1394,50 & 1826,35 & 0,24 & 0,05 \\
\hline & & & Média & 1819,80 & 2385,32 & 0,24 & 0,05 \\
\hline & & & Desvio & 872,06 & 1106,36 & 0,01 & 0,00 \\
\hline & & & Relação & 47,92 & 46,38 & 5,72 & 2,26 \\
\hline & \multirow{18}{*}{$\begin{array}{l}\frac{1}{2} \\
\frac{1}{\square} \\
\frac{0}{0} \\
\stackrel{8}{\circ} \\
\stackrel{-}{-}\end{array}$} & \multirow{9}{*}{4} & 61 & 1893,65 & 2350,45 & 0,19 & 0,05 \\
\hline & & & 62 & 1683,85 & 2222,90 & 0,24 & 0,05 \\
\hline & & & 63 & 1955,60 & 2498,65 & 0,22 & 0,05 \\
\hline & & & 64 & 2537,15 & 3318,70 & 0,24 & 0,05 \\
\hline & & & 65 & 2038,55 & 2698,30 & 0,24 & 0,05 \\
\hline & & & 66 & 1898,00 & 2553,75 & 0,26 & 0,05 \\
\hline & & & Média & 2001,13 & 2607,13 & 0,23 & 0,05 \\
\hline & & & $\begin{array}{l}\text { Desvio } \\
\end{array}$ & 287,63 & 385,43 & 0,02 & 0,00 \\
\hline & & & Relação & 14,37 & 14,78 & 9,69 & 1,11 \\
\hline & & \multirow{9}{*}{7} & 67 & 1890,25 & 2545,00 & 0,26 & 0,05 \\
\hline & & & 68 & 1349,45 & 1858,30 & 0,27 & 0,05 \\
\hline & & & 69 & 2974,85 & 3886,70 & 0,23 & 0,05 \\
\hline & & & 70 & 1922,45 & 2444,75 & 0,21 & 0,05 \\
\hline & & & 71 & 1761,45 & 2314,05 & 0,24 & 0,05 \\
\hline & & & 72 & 1730,35 & 2261,95 & 0,24 & 0,05 \\
\hline & & & Média & 1938,13 & 2551,79 & 0,24 & 0,05 \\
\hline & & & $\begin{array}{l}\text { Desvio } \\
\end{array}$ & 547,40 & 694,97 & 0,02 & 0,00 \\
\hline & & & Relação & 28,24 & 27,23 & 8,58 & 1,73 \\
\hline
\end{tabular}

Continua... 
Continuação da Tabela III.1

\begin{tabular}{|c|c|c|c|c|c|c|c|c|c|}
\hline Aditivo & Modificado & $V / V(\%)$ & $C P n^{\circ}$ & $\begin{array}{l}\text { Mod. Res. } \\
\text { MCHRP }\end{array}$ & Tota! - & $\begin{array}{l}\text { Mod. Res } \\
\text { - MCHRP }\end{array}$ & instant. & $\begin{array}{l}((M R i-M R t) / M R i) \\
- \text { NCHRP }\end{array}$ & $\begin{array}{l}\text { Atraso } \\
\text { Médio }\end{array}$ \\
\hline \multirow{54}{*}{ 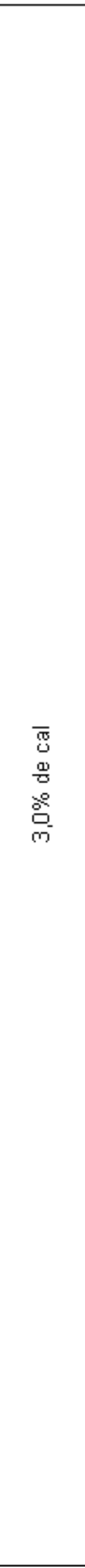 } & \multirow{18}{*}{ 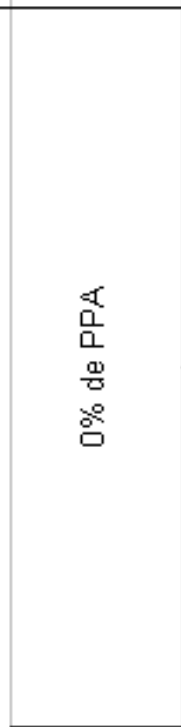 } & \multirow{9}{*}{4} & 73 & & 1350,15 & & 1892,25 & 0,29 & 0,05 \\
\hline & & & 74 & & 1079,20 & & 1475,15 & 0,27 & 0,05 \\
\hline & & & 75 & & 1419,65 & & 1909,60 & 0,26 & 0,05 \\
\hline & & & 76 & & 822,35 & & 1133,20 & 0,27 & 0,05 \\
\hline & & & 77 & & 1105,05 & & 1431,85 & 0,23 & 0,05 \\
\hline & & & 78 & & 1559,30 & & 1934,75 & 0,19 & 0,05 \\
\hline & & & $\begin{array}{l}\text { Média } \\
\end{array}$ & & 1222,62 & & 1629,47 & 0,25 & 0,05 \\
\hline & & & \begin{tabular}{|l|} 
Desvio \\
\end{tabular} & & 269,46 & & 331,62 & 0,03 & 0,00 \\
\hline & & & Relação & & 22,04 & & 20,35 & 13,66 & 1,83 \\
\hline & & \multirow{9}{*}{7} & 79 & & 1039,60 & & 1339,20 & 0,22 & 0,05 \\
\hline & & & 80 & & 1127,35 & & 1460,60 & 0,23 & 0,05 \\
\hline & & & 81 & & 1079,90 & & 1382,30 & 0,22 & 0,05 \\
\hline & & & 82 & & 1076,40 & & 1384,85 & 0,22 & 0,05 \\
\hline & & & 83 & & 932,65 & & 1267,00 & 0,26 & 0,05 \\
\hline & & & 84 & & 807,65 & & 1097,30 & 0,26 & 0,05 \\
\hline & & & Média & & 1010,59 & & 1321,88 & 0,24 & 0,05 \\
\hline & & & \begin{tabular}{|l|} 
Desvio \\
\end{tabular} & & 119,05 & & 126,97 & 0,02 & 0,00 \\
\hline & & & Relação & & 11,78 & & 9,61 & 8,94 & 1,58 \\
\hline & \multirow{18}{*}{ 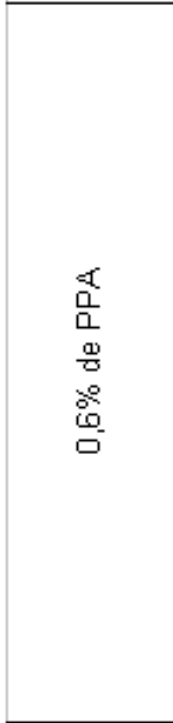 } & \multirow{9}{*}{4} & 85 & & 1871,90 & & 2548,10 & 0,27 & 0,05 \\
\hline & & & 86 & & 1497,35 & & 2061,80 & 0,27 & 0,05 \\
\hline & & & 87 & & 1625,85 & & 2218,40 & 0,27 & 0,05 \\
\hline & & & 88 & & 1294,95 & & 1659,65 & 0,22 & 0,05 \\
\hline & & & 89 & & 1256,05 & & 1713,30 & 0,27 & 0,05 \\
\hline & & & 90 & & 1267,25 & & 1720,00 & 0,26 & 0,05 \\
\hline & & & Média & & 1468,89 & & 1986,88 & 0,26 & 0,05 \\
\hline & & & \begin{tabular}{|l|} 
Desvio \\
\end{tabular} & & 246,61 & & 354,21 & 0,02 & 0,00 \\
\hline & & & Relação & & 16,79 & & 17,83 & 7,60 & 0,86 \\
\hline & & \multirow{9}{*}{7} & 91 & & 1266,60 & & 1740,00 & 0,27 & 0,05 \\
\hline & & & 92 & & 1389,95 & & 1943,40 & 0,28 & 0,05 \\
\hline & & & 93 & & 1493,25 & & 1939,50 & 0,23 & 0,05 \\
\hline & & & 94 & & 1481,00 & & 1994,20 & 0,26 & 0,05 \\
\hline & & & 95 & & 1464,90 & & 2003,60 & 0,27 & 0,05 \\
\hline & & & 96 & & 1475,60 & & 2028,30 & 0,27 & 0,05 \\
\hline & & & Média & & 1428,55 & & 1941,50 & 0,26 & 0,05 \\
\hline & & & Desvio & & 87,40 & & 104,67 & 0,02 & 0,00 \\
\hline & & & Relaçäo & & 6,12 & & 5,39 & 7,15 & 2,17 \\
\hline & \multirow{18}{*}{ 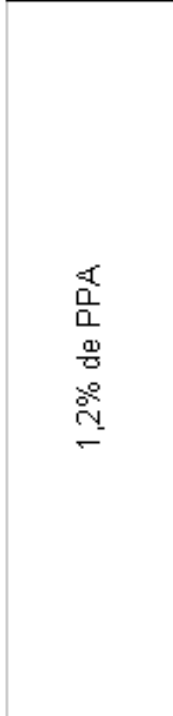 } & \multirow{9}{*}{4} & 97 & & 2723,25 & & 3614,80 & 0,25 & 0,05 \\
\hline & & & 98 & & 2223,80 & & 2926,65 & 0,24 & 0,05 \\
\hline & & & 99 & & 2529,25 & & 3211,15 & 0,21 & 0,05 \\
\hline & & & 100 & & 2277,55 & & 3104,80 & 0,27 & 0,05 \\
\hline & & & 101 & & 2433,25 & & 3194,55 & 0,24 & 0,05 \\
\hline & & & 102 & & 1588,10 & & 2142,45 & 0,26 & 0,05 \\
\hline & & & Média & & 2295,87 & & 3032,40 & 0,24 & 0,05 \\
\hline & & & Desvio & & 390,50 & & 491,09 & 0,02 & 0,00 \\
\hline & & & Relaçäo & & 17,01 & & 16,19 & 7,73 & 1,49 \\
\hline & & \multirow{9}{*}{7} & 103 & & 1306,55 & & 1688,15 & 0,23 & 0,05 \\
\hline & & & 104 & & 1436,85 & & 1926,75 & 0,25 & 0,05 \\
\hline & & & 105 & & 2137,50 & & 2866,50 & 0,25 & 0,05 \\
\hline & & & 106 & & 2226,10 & & 2803,05 & 0,21 & 0,05 \\
\hline & & & 107 & & 1341,15 & & 1828,25 & 0,27 & 0,05 \\
\hline & & & 108 & & 1697,85 & & 2510,10 & 0,32 & 0,05 \\
\hline & & & Média & & 1691,00 & & 2270,47 & 0,26 & 0,05 \\
\hline & & & Desvio & & 405,10 & & 519,44 & 0,04 & 0,00 \\
\hline & & & Relação & & 23,96 & & 22,88 & 15,74 & 5,24 \\
\hline
\end{tabular}


Tabela III. 2. Módulo de Resiliência para todos os fatores a $25^{\circ} \mathrm{C}$.

\begin{tabular}{|c|c|c|c|c|c|c|c|}
\hline Aditivo & Modificadc & $c V v(\%)$ & $\operatorname{CP} n^{\circ}$ & $\begin{array}{l}\text { Mod. Res. Total - } \\
\text { MCHRP }\end{array}$ & $\begin{array}{l}\text { Mod. Res. Instant. } \\
\text { - MCHRP }\end{array}$ & $\begin{array}{l}\text { ((MRi - MRt)/MRi) } \\
\text { - MCHRP }\end{array}$ & $\begin{array}{l}\text { Atraso } \\
\text { Médio }\end{array}$ \\
\hline \multirow{54}{*}{ 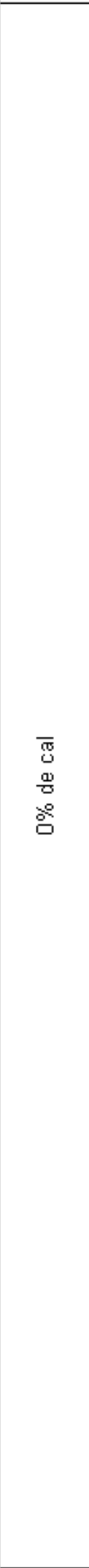 } & \multirow{18}{*}{ 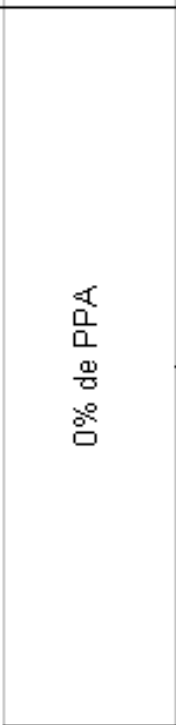 } & \multirow{9}{*}{4} & 1 & 5745,73 & 7763,03 & 0,26 & 0,05 \\
\hline & & & 2 & 5683,53 & 7837,20 & 0,27 & 0,05 \\
\hline & & & 3 & 4778,23 & 6406,03 & 0,25 & 0,05 \\
\hline & & & 4 & 7089,40 & 9659,23 & 0,27 & 0,05 \\
\hline & & & 5 & 4426,57 & 6170,90 & 0,28 & 0,05 \\
\hline & & & 6 & 5397,60 & 7286,83 & 0,26 & 0,05 \\
\hline & & & Média & 5520,18 & 7520,54 & 0,27 & 0,05 \\
\hline & & & Desvio & 927,52 & 1253,10 & 0,01 & 0,00 \\
\hline & & & Relação & 16,80 & 16,66 & 4,02 & 1,76 \\
\hline & & \multirow{9}{*}{7} & 7 & 3352,37 & 4677,63 & 0,28 & 0,05 \\
\hline & & & 8 & 3346,20 & 4600,67 & 0,27 & 0,05 \\
\hline & & & 9 & 4233,60 & 5619,33 & 0,25 & 0,05 \\
\hline & & & 10 & 3252,67 & 4436,43 & 0,27 & 0,05 \\
\hline & & & 11 & 3457,77 & 4687,03 & 0,26 & 0,05 \\
\hline & & & 12 & 4355,27 & 6003,80 & 0,27 & 0,05 \\
\hline & & & Média & 3666,31 & 5004,15 & 0,27 & 0,05 \\
\hline & & & Desvio & 492,36 & 643,43 & 0,01 & 0,00 \\
\hline & & & Relação & 13,43 & 12,86 & 4,71 & 2,26 \\
\hline & \multirow{18}{*}{ 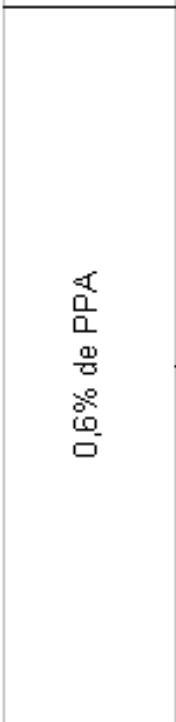 } & \multirow{9}{*}{4} & 13 & 4103,86 & 5489,24 & 0,24 & 0,04 \\
\hline & & & 14 & 4693,97 & 6047,73 & 0,22 & 0,04 \\
\hline & & & 15 & 4912,17 & 6254,07 & 0,21 & 0,04 \\
\hline & & & 16 & 5990,35 & 7632,60 & 0,22 & 0,04 \\
\hline & & & 17 & 7081,13 & 9023,83 & 0,22 & 0,04 \\
\hline & & & 18 & 5807,60 & 7610,80 & 0,24 & 0,05 \\
\hline & & & Média & 5431,51 & 7009,71 & 0,22 & 0,04 \\
\hline & & & Desvio & 1072,51 & 1312,57 & 0,01 & 0,00 \\
\hline & & & Relação & 19,75 & 18,73 & 5,50 & 1,91 \\
\hline & & \multirow{9}{*}{7} & 19 & 5881,88 & 8312,93 & 0,29 & 0,05 \\
\hline & & & 20 & 4516,17 & 6057,13 & 0,25 & 0,05 \\
\hline & & & 21 & 9318,33 & 12339,63 & 0,25 & 0,05 \\
\hline & & & 22 & 4415,65 & 5757,90 & 0,23 & 0,04 \\
\hline & & & 23 & 4411,27 & 5829,10 & 0,24 & 0,05 \\
\hline & & & 24 & 4556,03 & 6064,17 & 0,25 & 0,05 \\
\hline & & & Média & 5516,55 & 7393,48 & 0,25 & 0,05 \\
\hline & & & \begin{tabular}{|l} 
Desvio \\
\end{tabular} & 1946,48 & 2607,11 & 0,02 & 0,00 \\
\hline & & & Relação & 35,28 & 35,26 & 7,47 & 3,16 \\
\hline & \multirow{18}{*}{$\begin{array}{l}\frac{1}{0} \\
\frac{0}{\square} \\
\frac{\Phi}{\circ} \\
\stackrel{8}{\circ} \\
\stackrel{-}{-}\end{array}$} & \multirow{9}{*}{4} & 25 & 10065,43 & 11943,30 & 0,16 & 0,04 \\
\hline & & & 26 & 4212,78 & 5151,03 & 0,18 & 0,04 \\
\hline & & & 27 & 8884,54 & 10868,81 & 0,18 & 0,04 \\
\hline & & & 28 & 8483,80 & 10648,83 & 0,20 & 0,04 \\
\hline & & & 29 & 9947,00 & 11943,33 & 0,17 & 0,05 \\
\hline & & & 30 & 8568,13 & 10742,80 & 0,20 & 0,04 \\
\hline & & & Média & 8360,28 & 10216,35 & 0,18 & 0,04 \\
\hline & & & Desvio & 2142,91 & 2549,99 & 0,02 & 0,00 \\
\hline & & & Relação & 25,63 & 24,96 & 10,11 & 3,32 \\
\hline & & \multirow{9}{*}{7} & 31 & 9244,57 & 11577,10 & 0,20 & 0,04 \\
\hline & & & 32 & 5566,47 & 7192,93 & 0,23 & 0,04 \\
\hline & & & 33 & 10299,23 & 12025,60 & 0,14 & 0,04 \\
\hline & & & 34 & 8284,87 & 10103,87 & 0,18 & 0,05 \\
\hline & & & 35 & 7827,50 & 10216,53 & 0,23 & 0,04 \\
\hline & & & 36 & 4671,80 & 6126,03 & 0,24 & 0,04 \\
\hline & & & Média & 7649,07 & 9540,34 & 0,20 & 0,04 \\
\hline & & & Desvio & 2154,36 & 2377,71 & 0,04 & 0,00 \\
\hline & & & Relação & 28,17 & 24,92 & 17,97 & 2,29 \\
\hline
\end{tabular}


Continuação da Tabela III.2

\begin{tabular}{|c|c|c|c|c|c|c|c|c|}
\hline Aditivo & Modificad & $V /(\%)$ & $C P n^{\circ}$ & $\begin{array}{l}\text { Mod. Res } \\
\text { MCHRP }\end{array}$ & Total - & $\begin{array}{l}\text { Mod. Res instant. } \\
\text { - NCHRP }\end{array}$ & $\begin{array}{l}((M R i-M R t) / M R i) \\
- \text { MCHRP }\end{array}$ & $\begin{array}{l}\text { Atraso } \\
\text { Médio }\end{array}$ \\
\hline \multirow{54}{*}{ 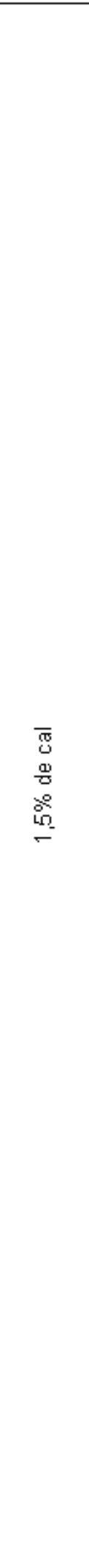 } & \multirow{18}{*}{$\begin{array}{l}\frac{x}{2} \\
\text { 뭄 } \\
\text { 웡 } \\
\text { 움 }\end{array}$} & \multirow{9}{*}{4} & 37 & & 5024,67 & 6480,87 & 0,22 & 0,04 \\
\hline & & & 38 & & 5638,20 & 7603,80 & 0,26 & 0,05 \\
\hline & & & 39 & & 5191,33 & 6832,40 & 0,24 & 0,04 \\
\hline & & & 40 & & 5215,83 & 6730,73 & 0,22 & 0,04 \\
\hline & & & 41 & & 6899,03 & 9151,83 & 0,25 & 0,04 \\
\hline & & & 42 & & 4846,33 & 6362,17 & 0,24 & 0,05 \\
\hline & & & Média & & 5469,23 & 7193,63 & 0,24 & 0,04 \\
\hline & & & Desvio & & 748,32 & 1053,27 & 0,01 & 0,00 \\
\hline & & & Relaçäo & & 13,68 & 14,64 & 5,38 & 1,53 \\
\hline & & \multirow{9}{*}{7} & 43 & & 4690,40 & 6465,43 & 0,27 & 0,05 \\
\hline & & & 44 & & 4690,40 & 6465,43 & 0,27 & 0,05 \\
\hline & & & 45 & & 4572,67 & 6060,90 & 0,25 & 0,05 \\
\hline & & & 46 & & 5698,07 & 7484,50 & 0,24 & 0,05 \\
\hline & & & 47 & & 4515,00 & 6045,70 & 0,25 & 0,05 \\
\hline & & & 48 & & 4175,97 & 5655,13 & 0,26 & 0,05 \\
\hline & & & Média & & 4723,75 & 6362,85 & 0,26 & 0,05 \\
\hline & & & Desvio & & 513,42 & 627,98 & 0,01 & 0,00 \\
\hline & & & Relaçäo & & 10,87 & 9,87 & 5,79 & 1,19 \\
\hline & \multirow{18}{*}{ 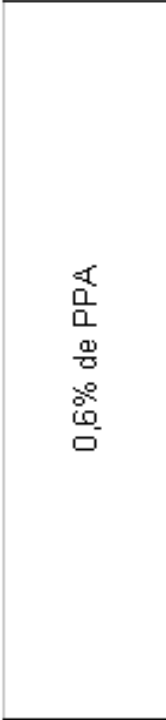 } & \multirow{9}{*}{4} & 49 & & 5460,80 & 7189,87 & 0,24 & 0,04 \\
\hline & & & 50 & & 6251,97 & 8260,17 & 0,24 & 0,05 \\
\hline & & & 51 & & 5090,47 & 6696,37 & 0,24 & 0,04 \\
\hline & & & 52 & & 8192,35 & 10539,03 & 0,22 & 0,04 \\
\hline & & & 53 & & 5703,93 & 7601,40 & 0,25 & 0,05 \\
\hline & & & 54 & & 5268,00 & 6967,48 & 0,24 & 0,04 \\
\hline & & & Média & & 5994,58 & 7875,72 & 0,24 & 0,04 \\
\hline & & & Desvio & & 1149,89 & 1414,38 & 0,01 & 0,00 \\
\hline & & & Relação & & 19,18 & 17,96 & 3,80 & 1,60 \\
\hline & & \multirow{9}{*}{7} & 55 & & 4773,40 & 6385,07 & 0,25 & 0,05 \\
\hline & & & 56 & & 4954,33 & 6558,80 & 0,24 & 0,05 \\
\hline & & & 57 & & 5730,53 & 7389,83 & 0,22 & 0,04 \\
\hline & & & 58 & & 4969,58 & 6433,65 & 0,23 & 0,04 \\
\hline & & & 59 & & 5452,33 & 7231,63 & 0,25 & 0,05 \\
\hline & & & 60 & & 4153,80 & 5580,50 & 0,26 & 0,05 \\
\hline & & & Média & & 5005,66 & 6596,58 & 0,24 & 0,05 \\
\hline & & & Desvio & & 549,27 & 653,86 & 0,01 & 0,00 \\
\hline & & & Relação & & 10,97 & 9,91 & 5,27 & 1,91 \\
\hline & \multirow{18}{*}{ 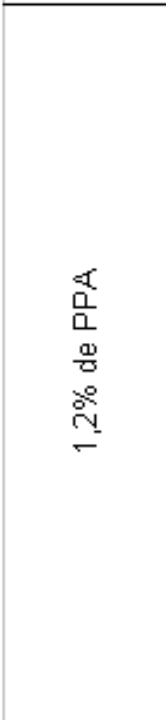 } & \multirow{9}{*}{4} & 61 & & 6472,47 & 8353,13 & 0,22 & 0,04 \\
\hline & & & 62 & & 7040,40 & 9238,90 & 0,24 & 0,04 \\
\hline & & & 63 & & 6176,70 & 8064,27 & 0,23 & 0,04 \\
\hline & & & 64 & & 6225,70 & 7913,50 & 0,21 & 0,04 \\
\hline & & & 65 & & 8970,63 & 11518,23 & 0,22 & 0,04 \\
\hline & & & 66 & & 6734,58 & 8832,80 & 0,24 & 0,04 \\
\hline & & & Média & & 6936,75 & 8986,81 & 0,23 & 0,04 \\
\hline & & & Desvio & & 1047,58 & 1334,17 & 0,01 & 0,00 \\
\hline & & & Relaçäo & & 15,10 & 14,85 & 4,37 & 1,31 \\
\hline & & \multirow{9}{*}{7} & 67 & & 6037,15 & 7732,60 & 0,22 & 0,04 \\
\hline & & & 68 & & 4404,93 & 5834,90 & 0,25 & 0,05 \\
\hline & & & 69 & & 6796,24 & 8487,34 & 0,20 & 0,04 \\
\hline & & & 70 & & 7210,90 & 9242,50 & 0,22 & 0,04 \\
\hline & & & 71 & & 5864,70 & 7476,57 & 0,22 & 0,04 \\
\hline & & & 72 & & 5573,83 & 7440,80 & 0,25 & 0,05 \\
\hline & & & Média & & 5981,29 & 7702,45 & 0,22 & 0,04 \\
\hline & & & Desvio & & 984,25 & 1148,56 & 0,02 & 0,00 \\
\hline & & & Relaçäo & & 16,46 & 14,91 & 8,65 & 3,23 \\
\hline
\end{tabular}


Continuação da Tabela III.2

\begin{tabular}{|c|c|c|c|c|c|c|c|c|}
\hline Aditivo & Modificad & $=V / V(\%)$ & $C P n^{\circ}$ & $\begin{array}{l}\text { Mod. Res. } \\
\text { NCHRP }\end{array}$ & Total - & $\begin{array}{l}\text { Mod. Res. Instant. } \\
\text { - MCHRP }\end{array}$ & $\begin{array}{l}((M R i-M R t) / M R) \\
-N C H R P\end{array}$ & $\begin{array}{l}\text { Atraso } \\
\text { Médio }\end{array}$ \\
\hline \multirow{54}{*}{ 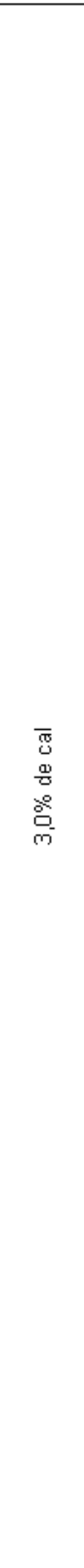 } & \multirow{18}{*}{$\begin{array}{l}\frac{1}{0} \\
\text { 뭄 } \\
\text { 몽 } \\
\text { 음 }\end{array}$} & \multirow{9}{*}{4} & 73 & & 5479,43 & 7426,73 & 0,26 & 0,05 \\
\hline & & & 74 & & 5032,27 & 6824,50 & 0,26 & 0,05 \\
\hline & & & 75 & & 5598,73 & 7418,10 & 0,25 & 0,05 \\
\hline & & & 76 & & 4571,60 & 6428,67 & 0,29 & 0,05 \\
\hline & & & 77 & & 7409,10 & 10111,30 & 0,27 & 0,05 \\
\hline & & & 78 & & 6837,73 & 9157,07 & 0,25 & 0,05 \\
\hline & & & Média & & 5821,48 & 7894,39 & 0,26 & 0,05 \\
\hline & & & Desvio & & 1086,74 & 1431,61 & 0,01 & 0,00 \\
\hline & & & Relação & & 18,67 & 18,13 & 5,59 & 0,85 \\
\hline & & \multirow{9}{*}{7} & 79 & & 3792,40 & 5210,93 & 0,27 & 0,05 \\
\hline & & & 80 & & 3807,87 & 5169,20 & 0,26 & 0,05 \\
\hline & & & 81 & & 5446,33 & 7383,40 & 0,26 & 0,05 \\
\hline & & & 82 & & 4689,35 & 6345,95 & 0,26 & 0,05 \\
\hline & & & 83 & & 4090,70 & 5597,70 & 0,27 & 0,05 \\
\hline & & & 84 & & 3432,40 & 4828,80 & 0,29 & 0,05 \\
\hline & & & Média & & 4209,84 & 5756,00 & 0,27 & 0,05 \\
\hline & & & Desvio & & 736,65 & 951,07 & 0,01 & 0,00 \\
\hline & & & Relaçäo & & 17,50 & 16,52 & 3,95 & 1,61 \\
\hline & \multirow{18}{*}{ 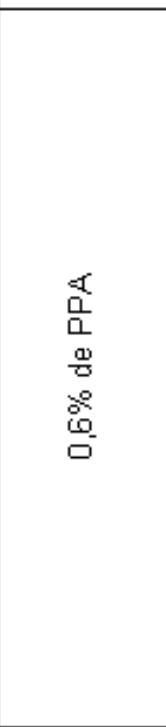 } & \multirow{9}{*}{4} & 85 & & 5765,00 & 7454,93 & 0,23 & 0,05 \\
\hline & & & 86 & & 5758,07 & 7612,53 & 0,24 & 0,05 \\
\hline & & & 87 & & 5379,93 & 6971,33 & 0,23 & 0,04 \\
\hline & & & 88 & & 5196,17 & 6815,63 & 0,24 & 0,04 \\
\hline & & & 89 & & 5024,67 & 6463,13 & 0,22 & 0,04 \\
\hline & & & 90 & & 5953,00 & 7707,10 & 0,23 & 0,04 \\
\hline & & & Média & & 5512,81 & 7170,78 & 0,23 & 0,04 \\
\hline & & & Desvio & & 367,08 & 496,02 & 0,01 & 0,00 \\
\hline & & & Relação & & 6,66 & 6,92 & 3,34 & 1,31 \\
\hline & & \multirow{9}{*}{7} & 91 & & 5329,45 & 6988,35 & 0,24 & 0,05 \\
\hline & & & 92 & & 4259,53 & 5616,93 & 0,24 & 0,05 \\
\hline & & & 93 & & 6635,38 & 8490,38 & 0,22 & 0,04 \\
\hline & & & 94 & & 4388,33 & 5764,57 & 0,24 & 0,04 \\
\hline & & & 95 & & 4308,60 & 5751,87 & 0,25 & 0,04 \\
\hline & & & 96 & & 3160,17 & 4300,80 & 0,27 & 0,05 \\
\hline & & & Média & & 4680,24 & 6152,15 & 0,24 & 0,04 \\
\hline & & & Desvio & & 1179,40 & 1427,65 & 0,02 & 0,00 \\
\hline & & & Relação & & 25,20 & 23,21 & 6,42 & 0,89 \\
\hline & \multirow{18}{*}{ 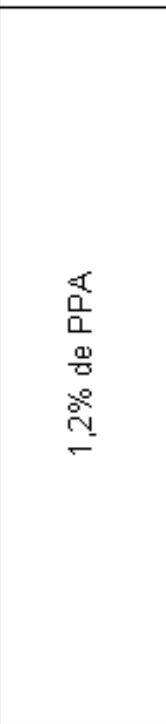 } & \multirow{9}{*}{4} & 97 & & 4350,27 & 5398,57 & 0,19 & 0,04 \\
\hline & & & 98 & & 7520,90 & 9263,13 & 0,19 & 0,04 \\
\hline & & & 99 & & 5017,90 & 6346,67 & 0,21 & 0,04 \\
\hline & & & 100 & & 4952,50 & 6209,25 & 0,20 & 0,04 \\
\hline & & & 101 & & 7042,35 & 8551,40 & 0,18 & 0,04 \\
\hline & & & 102 & & 5659,57 & 7316,30 & 0,23 & 0,04 \\
\hline & & & Média & & 5757,25 & 7180,89 & 0,20 & 0,04 \\
\hline & & & \begin{tabular}{|l|} 
Desvio \\
\end{tabular} & & 1260,58 & 1486,54 & 0,02 & 0,00 \\
\hline & & & Relação & & 21,90 & 20,70 & 8,76 & 1,60 \\
\hline & & \multirow{9}{*}{7} & 103 & & 4857,83 & 6204,93 & 0,22 & 0,04 \\
\hline & & & 104 & & 4597,87 & 6027,63 & 0,24 & 0,04 \\
\hline & & & 105 & & 7094,90 & 8869,63 & 0,20 & 0,04 \\
\hline & & & 106 & & 7280,85 & 9172,55 & 0,21 & 0,04 \\
\hline & & & 107 & & 6344,23 & 8120,23 & 0,22 & 0,05 \\
\hline & & & 108 & & 4374,93 & 5663,18 & 0,23 & 0,04 \\
\hline & & & Média & & 5758,43 & 7343,03 & 0,22 & 0,04 \\
\hline & & & Desvio & & 1305,31 & 1557,51 & 0,01 & 0,00 \\
\hline & & & Relação & & 22,67 & 21,21 & 6,27 & 2,00 \\
\hline
\end{tabular}


Tabela III. 3. Módulo de Resiliência para todos os fatores a $25^{\circ} \mathrm{C}$ e condicionamento.

\begin{tabular}{|c|c|c|c|c|c|c|c|c|}
\hline Aditivo & Modificador & $V /(\%)$ & $C P n^{\circ}$ & $\begin{array}{l}\text { Mod. Res. } \\
\text { NCHRP }\end{array}$ & Total - & $\begin{array}{l}\text { Mod. Res instant. } \\
\text { - NCHRP }\end{array}$ & $\begin{array}{l}((M R i-M R t) / M R i) \\
\text { - MCHRP }\end{array}$ & $\begin{array}{l}\text { Atraso } \\
\text { Médio }\end{array}$ \\
\hline \multirow{18}{*}{$\begin{array}{l}\overline{0} \\
0 \\
\text { 뭉 } \\
\stackrel{\circ}{\circ}\end{array}$} & \multirow{6}{*}{ 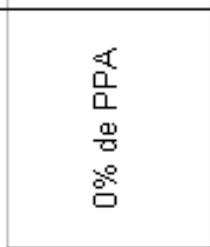 } & \multirow{6}{*}{7} & 10 & & 3252,67 & 4436,43 & 0,27 & 0,05 \\
\hline & & & 11 & & 3457,77 & 4687,03 & 0,26 & 0,05 \\
\hline & & & 12 & & 4355,27 & 6003,80 & 0,27 & 0,05 \\
\hline & & & Média & & 3666,31 & 5004,15 & 0,27 & 0,05 \\
\hline & & & Desvio & & 492,36 & 643,43 & 0,01 & 0,00 \\
\hline & & & Relaçăo & & 13,43 & 12,86 & 4,71 & 2,26 \\
\hline & \multirow{6}{*}{ 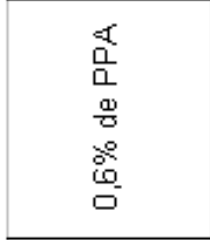 } & \multirow{6}{*}{7} & 22 & & 4415,65 & 5757,90 & 0,23 & 0,04 \\
\hline & & & 23 & & 4411,27 & 5829,10 & 0,24 & 0,05 \\
\hline & & & 24 & & 4556,03 & 6064,17 & 0,25 & 0,05 \\
\hline & & & Média & & 5516,55 & 7393,48 & 0,25 & 0,05 \\
\hline & & & \begin{tabular}{|l|} 
Desvio \\
\end{tabular} & & 1946,48 & 2607,11 & 0,02 & 0,00 \\
\hline & & & Relação & & 35,28 & 35,26 & 7,47 & 3,16 \\
\hline & \multirow{6}{*}{ 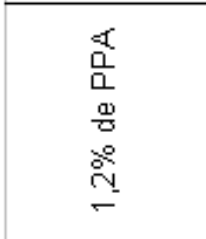 } & \multirow{6}{*}{7} & 34 & & 8284,87 & 10103,87 & 0,18 & 0,05 \\
\hline & & & 35 & & 7827,50 & 10216,53 & 0,23 & 0,04 \\
\hline & & & 36 & & 4671,80 & 6126,03 & 0,24 & 0,04 \\
\hline & & & Média & & 7649,07 & 9540,34 & 0,20 & 0,04 \\
\hline & & & Desvio & & 2154,36 & 2377,71 & 0,04 & 0,00 \\
\hline & & & Relação & & 28,17 & 24,92 & 17,97 & 2,29 \\
\hline \multirow{18}{*}{ 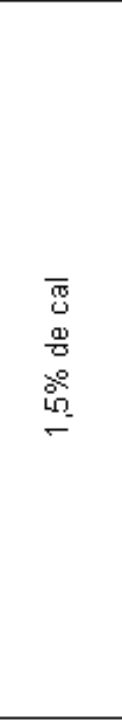 } & \multirow{6}{*}{ 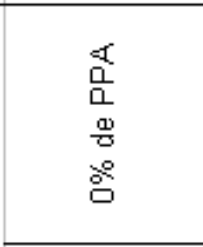 } & \multirow{6}{*}{7} & 46 & & 5698,07 & 7484,50 & 0,24 & 0,05 \\
\hline & & & 47 & & 4515,00 & 6045,70 & 0,25 & 0,05 \\
\hline & & & 48 & & 4175,97 & 5655,13 & 0,26 & 0,05 \\
\hline & & & Média & & 4723,75 & 6362,85 & 0,26 & 0,05 \\
\hline & & & \begin{tabular}{|l|} 
Desvio \\
\end{tabular} & & 513,42 & 627,98 & 0,01 & 0,00 \\
\hline & & & Relaçäo & & 10,87 & 9,87 & 5,79 & 1,19 \\
\hline & \multirow{6}{*}{ 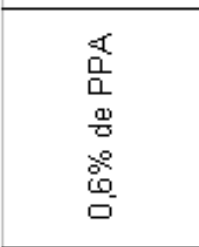 } & \multirow{6}{*}{7} & 58 & & 4969,58 & 6433,65 & 0,23 & 0,04 \\
\hline & & & 59 & & 5452,33 & 7231,63 & 0,25 & 0,05 \\
\hline & & & 60 & & 4153,80 & 5580,50 & 0,26 & 0,05 \\
\hline & & & Média & & 5005,66 & 6596,58 & 0,24 & 0,05 \\
\hline & & & Desvio & & 549,27 & 653,86 & 0,01 & 0,00 \\
\hline & & & Relaçäo & & 10,97 & 9,91 & 5,27 & 1,91 \\
\hline & \multirow{6}{*}{ 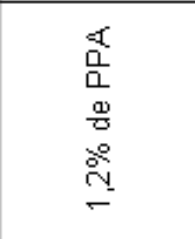 } & \multirow{6}{*}{7} & 70 & & 7210,90 & 9242,50 & 0,22 & 0,04 \\
\hline & & & 71 & & 5864,70 & 7476,57 & 0,22 & 0,04 \\
\hline & & & 72 & & 5573,83 & 7440,80 & 0,25 & 0,05 \\
\hline & & & Média & & 5981,29 & 7702,45 & 0,22 & 0,04 \\
\hline & & & Desvio & & 984,25 & 1148,56 & 0,02 & 0,00 \\
\hline & & & Relaçäo & & 16,46 & 14,91 & 8,65 & 3,23 \\
\hline \multirow{18}{*}{ 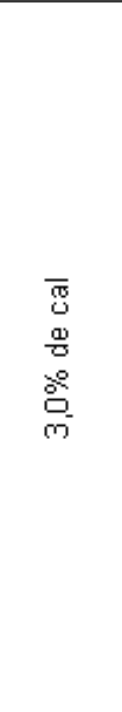 } & \multirow{6}{*}{ 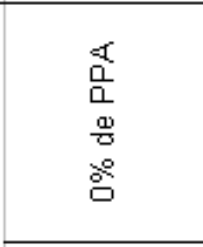 } & \multirow{6}{*}{7} & 82 & & 4689,35 & 6345,95 & 0,26 & 0,05 \\
\hline & & & 83 & & 4090,70 & 5597,70 & 0,27 & 0,05 \\
\hline & & & 84 & & 3432,40 & 4828,80 & 0,29 & 0,05 \\
\hline & & & Média & & 4209,84 & 5756,00 & 0,27 & 0,05 \\
\hline & & & \begin{tabular}{|l|} 
Desvio \\
\end{tabular} & & 736,65 & 951,07 & 0,01 & 0,00 \\
\hline & & & Relaçăo & & 17,50 & 16,52 & 3,95 & 1,61 \\
\hline & & & 94 & & 4388,33 & 5764,57 & 0,24 & 0,04 \\
\hline & 뭄 & & 95 & & 4308,60 & 5751,87 & 0,25 & 0,04 \\
\hline & 崩 & 7 & 96 & & 3160,17 & 4300,80 & 0,27 & 0,05 \\
\hline & \& & $\gamma$ & Média & & 4680,24 & 6152,15 & 0,24 & 0,04 \\
\hline & 象 & & Desvio & & 1179,40 & 1427,65 & 0,02 & 0,00 \\
\hline & & & Relaçäo & & 25,20 & 23,21 & 6,42 & 0,89 \\
\hline & & & 106 & & 7280,85 & 9172,55 & 0,21 & 0,04 \\
\hline & 0 & & 107 & & 6344,23 & 8120,23 & 0,22 & 0,05 \\
\hline & 荘 & 7 & 108 & & 4374,93 & 5663,18 & 0,23 & 0,04 \\
\hline & $\approx$ & $r$ & Média & & 5758,43 & 7343,03 & 0,22 & 0,04 \\
\hline & $\approx$ & & Desvio & & 1305,31 & 1557,51 & 0,01 & 0,00 \\
\hline & & & Relaçäo & & 22,67 & 21,21 & 6,27 & 2,00 \\
\hline
\end{tabular}


Tabela III. 4. Módulo de Resiliência para todos os fatores a $10^{\circ} \mathrm{C}$.

\begin{tabular}{|c|c|c|c|c|c|c|c|}
\hline Aditivo & Modificadc & $=V /(\%)$ & $C P n^{\circ}$ & $\begin{array}{l}\text { Mod. Res. Total - } \\
\text { MCHRP }\end{array}$ & $\begin{array}{l}\text { Mod. Res. Instant. } \\
\text { - MCHRP }\end{array}$ & $\begin{array}{l}\text { ((MRi - MRt }) / M R i) \\
\text { - MCHRP }\end{array}$ & $\begin{array}{l}\text { Atraso } \\
\text { Médio }\end{array}$ \\
\hline \multirow{54}{*}{$\begin{array}{l}\overline{8} \\
\mathrm{O} \\
\text { 몽 } \\
\stackrel{8}{\circ}\end{array}$} & \multirow{18}{*}{$\begin{array}{l}\frac{x}{0} \\
0 \\
\frac{0}{0} \\
\circ \\
\circ\end{array}$} & \multirow{9}{*}{4} & 1 & 16274,53 & 18708,27 & 0,13 & 0,04 \\
\hline & & & 2 & 14451,83 & 16522,43 & 0,13 & 0,04 \\
\hline & & & 3 & 16496,33 & 19034,57 & 0,13 & 0,04 \\
\hline & & & 4 & 17127,60 & 19690,80 & 0,13 & 0,04 \\
\hline & & & 5 & 16088,70 & 18490,20 & 0,13 & 0,04 \\
\hline & & & 6 & 16125,83 & 18574,53 & 0,13 & 0,04 \\
\hline & & & Média & 16094,14 & 18503,47 & 0,13 & 0,04 \\
\hline & & & Desvio & 890,01 & 1064,28 & 0,00 & 0,00 \\
\hline & & & Relação & 5,53 & 5,75 & 2,07 & 2,06 \\
\hline & & \multirow{9}{*}{7} & 7 & 13170,67 & 15256,93 & 0,14 & 0,04 \\
\hline & & & 8 & 11481,70 & 13540,10 & 0,15 & 0,04 \\
\hline & & & 9 & 12187,53 & 14185,97 & 0,14 & 0,04 \\
\hline & & & 10 & 12993,23 & 15651,63 & 0,17 & 0,04 \\
\hline & & & 11 & 12012,20 & 14234,57 & 0,16 & 0,04 \\
\hline & & & 12 & 11831,83 & 14130,53 & 0,16 & 0,04 \\
\hline & & & Média & 12279,53 & 14499,96 & 0,15 & 0,04 \\
\hline & & & $\begin{array}{l}\text { Desvio } \\
\end{array}$ & 666,39 & 790,72 & 0,01 & 0,00 \\
\hline & & & Relação & 5,43 & 5,45 & 8,26 & 1,35 \\
\hline & \multirow{18}{*}{ 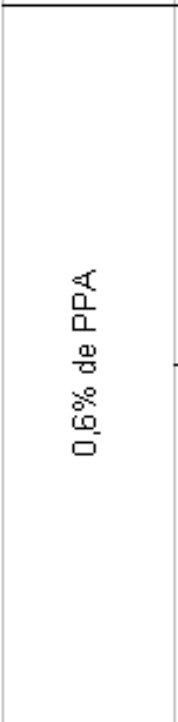 } & \multirow{9}{*}{4} & 13 & 11371,90 & 13139,10 & 0,13 & 0,04 \\
\hline & & & 14 & 12094,53 & 14154,63 & 0,15 & 0,04 \\
\hline & & & 15 & 17441,67 & 19819,20 & 0,12 & 0,04 \\
\hline & & & 16 & 17409,87 & 20044,03 & 0,13 & 0,04 \\
\hline & & & 17 & 16130,30 & 18359,57 & 0,12 & 0,04 \\
\hline & & & 18 & 15983,07 & 18530,00 & 0,14 & 0,04 \\
\hline & & & Média & 15071,89 & 17341,09 & 0,13 & 0,04 \\
\hline & & & Desvio & 2667,85 & 2956,62 & 0,01 & 0,00 \\
\hline & & & Relação & 17,70 & 17,05 & 7,41 & 0,97 \\
\hline & & \multirow{9}{*}{7} & 19 & 12699,87 & 14710,27 & 0,14 & 0,04 \\
\hline & & & 20 & 12547,63 & 14564,47 & 0,14 & 0,04 \\
\hline & & & 21 & 14522,20 & 16527,43 & 0,12 & 0,04 \\
\hline & & & 22 & 13799,57 & 15820,40 & 0,13 & 0,04 \\
\hline & & & 23 & 13325,33 & 15300,03 & 0,13 & 0,04 \\
\hline & & & 24 & 13256,70 & 15435,43 & 0,14 & 0,04 \\
\hline & & & Média & 13358,55 & 15393,01 & 0,13 & 0,04 \\
\hline & & & Desvio & 728,22 & 725,62 & 0,01 & 0,00 \\
\hline & & & Relação & 5,45 & 4,71 & 5,72 & 0,62 \\
\hline & \multirow{18}{*}{$\begin{array}{l}\frac{1}{2} \\
\frac{1}{1} \\
\text { 뭉 } \\
\stackrel{\circ}{\circ} \\
\stackrel{-}{-}\end{array}$} & \multirow{9}{*}{4} & 25 & 11349,00 & 12719,90 & 0,11 & 0,04 \\
\hline & & & 26 & 17959,73 & 20086,20 & 0,11 & 0,04 \\
\hline & & & 27 & 17756,57 & 20566,20 & 0,14 & 0,04 \\
\hline & & & 28 & 15861,20 & 18073,97 & 0,12 & 0,04 \\
\hline & & & 29 & 16067,50 & 17961,00 & 0,11 & 0,04 \\
\hline & & & 30 & 16733,50 & 18863,77 & 0,11 & 0,04 \\
\hline & & & Média & 15954,58 & 18045,17 & 0,12 & 0,04 \\
\hline & & & $\begin{array}{l}\text { Desvio } \\
\end{array}$ & 2412,77 & 2812,75 & 0,01 & 0,00 \\
\hline & & & Relação & 15,12 & 15,59 & 10,66 & 2,79 \\
\hline & & \multirow{9}{*}{7} & 31 & 16290,47 & 18474,90 & 0,12 & 0,04 \\
\hline & & & 32 & 10987,23 & 12691,70 & 0,13 & 0,04 \\
\hline & & & 33 & 16433,83 & 18256,33 & 0,10 & 0,04 \\
\hline & & & 34 & 17524,20 & 19178,80 & 0,09 & 0,04 \\
\hline & & & 35 & 16423,83 & 18785,47 & 0,13 & 0,04 \\
\hline & & & 36 & 19917,93 & 22184,93 & 0,10 & 0,04 \\
\hline & & & Média & 16262,92 & 18262,02 & 0,11 & 0,04 \\
\hline & & & Desvio & 2927,07 & 3084,72 & 0,02 & 0,00 \\
\hline & & & Relação & 18,00 & 16,89 & 16,23 & 1,14 \\
\hline
\end{tabular}


Continuação da Tabela III.4

\begin{tabular}{|c|c|c|c|c|c|c|c|}
\hline Aditivo & Modificadc & $V V(\%)$ & $C P n^{\circ}$ & $\begin{array}{l}\text { Mod. Res. Total - } \\
\text { MCHRP }\end{array}$ & $\begin{array}{l}\text { Mod. Res. Instant. } \\
\text { - MCHRP }\end{array}$ & $\begin{array}{l}((M R i-M R t) / M R i) \\
-M C H R P\end{array}$ & $\begin{array}{l}\text { Atraso } \\
\text { Médio }\end{array}$ \\
\hline \multirow{54}{*}{ 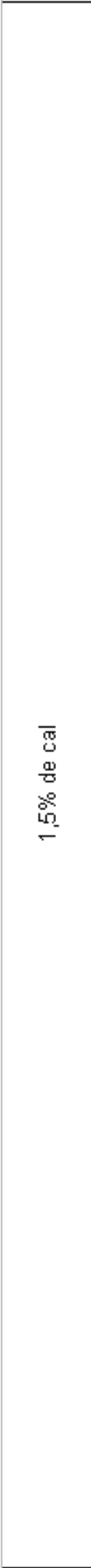 } & \multirow{18}{*}{$\begin{array}{l}x \\
0 \\
0 \\
\frac{1}{0} \\
0 \\
8 \\
0\end{array}$} & \multirow{9}{*}{4} & 37 & 16588,30 & 19392,03 & 0,14 & 0,04 \\
\hline & & & 38 & 13368,93 & 15076,43 & 0,11 & 0,04 \\
\hline & & & 39 & 15310,13 & 17733,10 & 0,14 & 0,04 \\
\hline & & & 40 & 14677,73 & 16948,03 & 0,13 & 0,04 \\
\hline & & & 41 & 19855,90 & 22056,57 & 0,10 & 0,04 \\
\hline & & & 42 & 16532,77 & 18818,33 & 0,12 & 0,04 \\
\hline & & & Média & 16055,63 & 18337,42 & 0,12 & 0,04 \\
\hline & & & Desvio & 2219,29 & 2370,87 & 0,02 & 0,00 \\
\hline & & & Relação & 13,82 & 12,93 & 13,31 & 1,33 \\
\hline & & \multirow{9}{*}{7} & 43 & 13653,83 & 15848,37 & 0,14 & 0,04 \\
\hline & & & 44 & 14503,23 & 16413,43 & 0,12 & 0,04 \\
\hline & & & 45 & 15508,63 & 18357,90 & 0,16 & 0,04 \\
\hline & & & 46 & 13752,47 & 15980,90 & 0,14 & 0,04 \\
\hline & & & 47 & 13894,73 & 16249,10 & 0,14 & 0,04 \\
\hline & & & 48 & 14799,10 & 16890,93 & 0,12 & 0,04 \\
\hline & & & Média & 14352,00 & 16623,44 & 0,14 & 0,04 \\
\hline & & & \begin{tabular}{|l} 
Desvio \\
\end{tabular} & 723,40 & 924,96 & 0,01 & 0,00 \\
\hline & & & Relação & 5,04 & 5,56 & 10,34 & 1,13 \\
\hline & \multirow{18}{*}{ 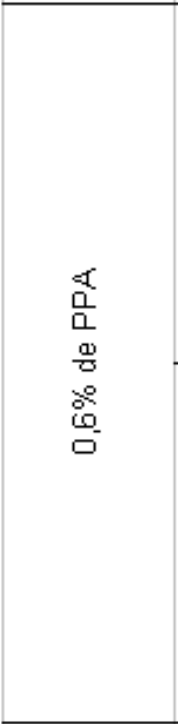 } & \multirow{9}{*}{4} & 49 & 11706,30 & 13417,00 & 0,13 & 0,04 \\
\hline & & & 50 & 15172,03 & 17231,07 & 0,12 & 0,04 \\
\hline & & & 51 & 13778,83 & 16151,50 & 0,15 & 0,04 \\
\hline & & & 52 & 17820,33 & 21351,60 & 0,17 & 0,04 \\
\hline & & & 53 & 16283,97 & 19047,27 & 0,14 & 0,04 \\
\hline & & & 54 & 15118,77 & 17761,27 & 0,15 & 0,04 \\
\hline & & & Média & 14980,04 & 17493,28 & 0,14 & 0,04 \\
\hline & & & \begin{tabular}{|l} 
Desvio \\
\end{tabular} & 2096,85 & 2678,00 & 0,02 & 0,00 \\
\hline & & & Relação & 14,00 & 15,31 & 11,55 & 2,28 \\
\hline & & \multirow{9}{*}{7} & 55 & 14138,53 & 16600,37 & 0,15 & 0,04 \\
\hline & & & 56 & 12855,93 & 15275,30 & 0,16 & 0,04 \\
\hline & & & 57 & 12533,60 & 14789,53 & 0,15 & 0,04 \\
\hline & & & 58 & 12819,93 & 14984,37 & 0,14 & 0,04 \\
\hline & & & 59 & 12394,73 & 14665,20 & 0,15 & 0,04 \\
\hline & & & 60 & 13709,97 & 16300,83 & 0,16 & 0,04 \\
\hline & & & Média & 13075,45 & 15435,93 & 0,15 & 0,04 \\
\hline & & & \begin{tabular}{|l|} 
Desvio \\
\end{tabular} & 693,28 & 817,99 & 0,01 & 0,00 \\
\hline & & & Relação & 5,30 & 5,30 & 3,77 & 1,69 \\
\hline & \multirow{18}{*}{ 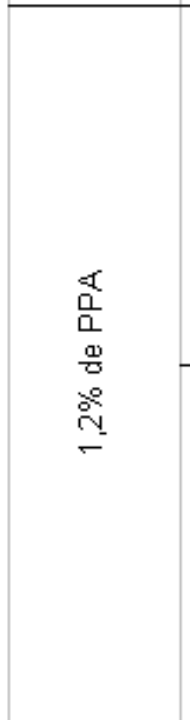 } & \multirow{9}{*}{4} & 61 & 11593,57 & 13293,43 & 0,13 & 0,04 \\
\hline & & & 62 & 15581,33 & 17885,80 & 0,13 & 0,04 \\
\hline & & & 63 & 16908,17 & 19274,77 & 0,12 & 0,04 \\
\hline & & & 64 & 16396,87 & 18618,47 & 0,12 & 0,04 \\
\hline & & & 65 & 16106,57 & 18599,07 & 0,13 & 0,04 \\
\hline & & & 66 & 14334,37 & 16405,37 & 0,13 & 0,04 \\
\hline & & & Média & 15153,48 & 17346,15 & 0,13 & 0,04 \\
\hline & & & \begin{tabular}{|l|} 
Desvio \\
\end{tabular} & 1952,45 & 2214,00 & 0,01 & 0,00 \\
\hline & & & Relação & 12,88 & 12,76 & 4,02 & 2,16 \\
\hline & & \multirow{9}{*}{7} & 67 & 15194,73 & 17884,70 & 0,15 & 0,04 \\
\hline & & & 68 & 12911,40 & 15026,43 & 0,14 & 0,04 \\
\hline & & & 69 & 15322,93 & 17455,83 & 0,12 & 0,04 \\
\hline & & & 70 & 14825,33 & 17053,43 & 0,13 & 0,04 \\
\hline & & & 71 & 12244,73 & 14473,43 & 0,15 & 0,04 \\
\hline & & & 72 & 13633,30 & 16070,27 & 0,15 & 0,04 \\
\hline & & & Média & 14022,07 & 16327,35 & 0,14 & 0,04 \\
\hline & & & \begin{tabular}{|l|} 
Desvio \\
\end{tabular} & 1285,01 & 1372,70 & 0,01 & 0,00 \\
\hline & & & Relação & 9,16 & 8,41 & 9,11 & 3,39 \\
\hline
\end{tabular}


Continuação da Tabela III.4

\begin{tabular}{|c|c|c|c|c|c|c|c|}
\hline Aditivo & Modificado & $V / V(\%)$ & $C P n^{\circ}$ & $\begin{array}{l}\text { Mod. Res. Total - } \\
\text { MCHRP }\end{array}$ & $\begin{array}{l}\text { Mod. Res. Instant. } \\
\text { - MCHRP }\end{array}$ & $\begin{array}{l}((M R i-M R t) / M R i) \\
\text { - MCHRP }\end{array}$ & $\begin{array}{l}\text { Atraso } \\
\text { Médio }\end{array}$ \\
\hline \multirow{54}{*}{ 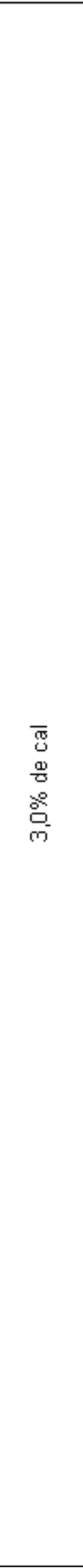 } & \multirow{18}{*}{$\begin{array}{l}x \\
\frac{0}{\square} \\
\text { 몽 } \\
\text { 욤 }\end{array}$} & \multirow{9}{*}{4} & 73 & 13420,53 & 15750,47 & 0,15 & 0,04 \\
\hline & & & 74 & 16231,50 & 18691,43 & 0,13 & 0,04 \\
\hline & & & 75 & 13993,27 & 16176,63 & 0,13 & 0,04 \\
\hline & & & 76 & 13866,57 & 15664,73 & 0,11 & 0,04 \\
\hline & & & 77 & 13586,60 & 16015,07 & 0,15 & 0,04 \\
\hline & & & 78 & 16587,03 & 19357,70 & 0,14 & 0,04 \\
\hline & & & Média & 14614,25 & 16942,67 & 0,14 & 0,04 \\
\hline & & & \begin{tabular}{|l|} 
Desvio \\
\end{tabular} & 1409,47 & 1636,60 & 0,01 & 0,00 \\
\hline & & & Relação & 9,64 & 9,66 & 9,76 & 2,22 \\
\hline & & \multirow{9}{*}{7} & 79 & 16235,83 & 18623,60 & 0,13 & 0,04 \\
\hline & & & 80 & 11712,10 & 14068,97 & 0,17 & 0,04 \\
\hline & & & 81 & 13160,83 & 15392,70 & 0,15 & 0,04 \\
\hline & & & 82 & 12268,10 & 14485,77 & 0,15 & 0,04 \\
\hline & & & 83 & 12305,93 & 14636,17 & 0,16 & 0,04 \\
\hline & & & 84 & 10991,27 & 13157,47 & 0,16 & 0,04 \\
\hline & & & Média & 12779,01 & 15060,78 & 0,15 & 0,04 \\
\hline & & & \begin{tabular}{|l|} 
Desvio \\
\end{tabular} & 1839,27 & 1893,20 & 0,01 & 0,00 \\
\hline & & & Relação & 14,39 & 12,57 & 9,55 & 1,58 \\
\hline & \multirow{18}{*}{ 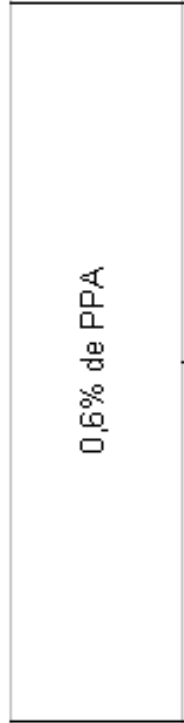 } & \multirow{9}{*}{4} & 85 & 14839,13 & 17353,63 & 0,14 & 0,04 \\
\hline & & & 86 & 14085,43 & 16071,03 & 0,12 & 0,04 \\
\hline & & & 87 & 13801,90 & 15806,63 & 0,13 & 0,04 \\
\hline & & & 88 & 13829,40 & 16338,70 & 0,15 & 0,04 \\
\hline & & & 89 & 13716,80 & 16055,10 & 0,15 & 0,04 \\
\hline & & & 90 & 14370,23 & 16609,33 & 0,13 & 0,04 \\
\hline & & & Média & 14107,15 & 16372,41 & 0,14 & 0,04 \\
\hline & & & \begin{tabular}{|l|} 
Desvio \\
\end{tabular} & 430,85 & 553,48 & 0,01 & 0,00 \\
\hline & & & Relação & 3,05 & 3,38 & 8,74 & 1,40 \\
\hline & & \multirow{9}{*}{7} & 91 & 14628,70 & 17241,73 & 0,15 & 0,04 \\
\hline & & & 92 & 11691,70 & 13870,67 & 0,16 & 0,04 \\
\hline & & & 93 & 16039,10 & 18281,40 & 0,12 & 0,04 \\
\hline & & & 94 & 13030,17 & 15487,50 & 0,16 & 0,04 \\
\hline & & & 95 & 13988,60 & 16668,27 & 0,16 & 0,04 \\
\hline & & & 96 & 13002,43 & 15390,50 & 0,16 & 0,04 \\
\hline & & & Média & 13730,12 & 16156,68 & 0,15 & 0,04 \\
\hline & & & \begin{tabular}{|l} 
Desvio \\
\end{tabular} & 1508,66 & 1562,96 & 0,01 & 0,00 \\
\hline & & & Relação & 10,99 & 9,67 & 9,48 & 2,97 \\
\hline & \multirow{18}{*}{ 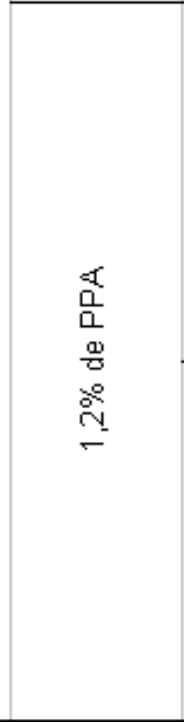 } & \multirow{9}{*}{4} & 97 & 11006,97 & 12486,67 & 0,12 & 0,04 \\
\hline & & & 98 & 15830,03 & 17613,43 & 0,10 & 0,04 \\
\hline & & & 99 & 16574,43 & 19071,83 & 0,13 & 0,04 \\
\hline & & & 100 & 19417,77 & 22746,57 & 0,15 & 0,04 \\
\hline & & & 101 & 20465,35 & 22808,10 & 0,10 & 0,04 \\
\hline & & & 102 & 18318,73 & 20799,13 & 0,12 & 0,04 \\
\hline & & & Média & 16935,55 & 19254,29 & 0,12 & 0,04 \\
\hline & & & \begin{tabular}{|l|} 
Desvio \\
\end{tabular} & 3377,42 & 3892,01 & 0,02 & 0,00 \\
\hline & & & Relação & 19,94 & 20,21 & 14,23 & 1,06 \\
\hline & & \multirow{9}{*}{7} & 103 & 13708,10 & 15462,90 & 0,11 & 0,04 \\
\hline & & & 104 & 13482,90 & 15748,60 & 0,14 & 0,04 \\
\hline & & & 105 & 14712,43 & 17001,57 & 0,13 & 0,04 \\
\hline & & & 106 & 14353,20 & 16537,97 & 0,13 & 0,04 \\
\hline & & & 107 & 14982,20 & 17082,73 & 0,12 & 0,04 \\
\hline & & & 108 & 13532,60 & 15735,23 & 0,14 & 0,04 \\
\hline & & & Média & 14128,57 & 16261,50 & 0,13 & 0,04 \\
\hline & & & Desvio & 643,26 & 703,75 & 0,01 & 0,00 \\
\hline & & & Relação & 4,55 & 4,33 & 8,58 & 1,21 \\
\hline
\end{tabular}




\section{ANEXO IV - MÓDULOS DE RESILIÊNCIA DESCARTANDO OS FORA DA MÉDIA \pm UM DESVIO \\ PADRÃO.}


Tabela IV. 1. Módulo de Resiliência Total e Instantânea para todos os fatores a $40^{\circ} \mathrm{C}$, descartando ensaios fora de um desvio padrão em relação à média.

\begin{tabular}{|c|c|c|c|c|c|c|c|}
\hline Aditivo & Modificadc & $V / \%(\%)$ & $C P n^{\circ}$ & $\begin{array}{l}\text { Mod. Res. Total - } \\
\text { MCHRP }\end{array}$ & $\begin{array}{l}\text { Mod. Res. Instant. } \\
\text { - MCHRP }\end{array}$ & $\begin{array}{l}\text { ((MRi - MRt)/MRi) } \\
- \text { NCHRP }\end{array}$ & $\begin{array}{l}\text { Atraso } \\
\text { Médio }\end{array}$ \\
\hline \multirow{47}{*}{$\begin{array}{l}\overline{\mathrm{D}} \\
\mathrm{O} \\
\mathrm{D} \\
\mathrm{O} \\
\mathrm{8}\end{array}$} & \multirow{16}{*}{ 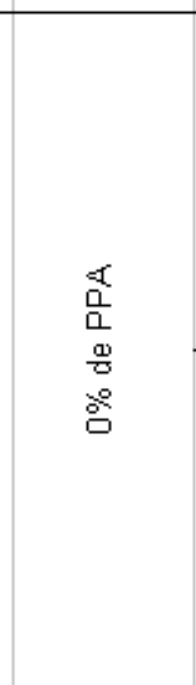 } & & 2 & 1061,90 & 1481,37 & 0,28 & 0,05 \\
\hline & & & 3 & 1105,50 & 1509,20 & 0,27 & 0,05 \\
\hline & & & 4 & 961,77 & 1280,87 & 0,25 & 0,05 \\
\hline & & & 5 & 893,57 & 1197,20 & 0,25 & 0,05 \\
\hline & & & 6 & 1030,00 & 1375,20 & 0,25 & 0,05 \\
\hline & & & Média & 1010,55 & 1368,77 & 0,26 & 0,05 \\
\hline & & & $\begin{array}{l}\text { Desvio } \\
\end{array}$ & 83,81 & 131,91 & 0,01 & 0,00 \\
\hline & & & Relação & 8,29 & 9,64 & 5,38 & 0,48 \\
\hline & & \multirow{8}{*}{7} & 7 & 928,03 & 1201,37 & 0,23 & 0,05 \\
\hline & & & 8 & 859,53 & 1096,90 & 0,22 & 0,05 \\
\hline & & & 10 & 888,85 & 1139,35 & 0,22 & 0,05 \\
\hline & & & 11 & 769,05 & 987,95 & 0,22 & 0,05 \\
\hline & & & 12 & 1035,20 & 1201,05 & 0,14 & 0,05 \\
\hline & & & Média & 896,13 & 1125,32 & 0,20 & 0,05 \\
\hline & & & Desvio & 97,34 & 88,59 & 0,04 & 0,00 \\
\hline & & & Relação & 10,86 & 7,87 & 18,25 & 1,59 \\
\hline & \multirow{16}{*}{ 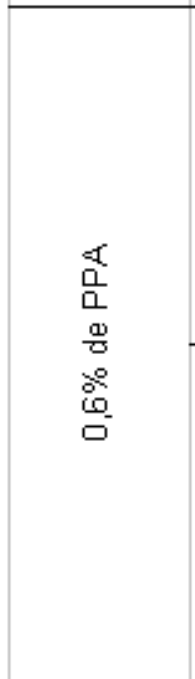 } & \multirow{8}{*}{4} & 13 & 2412,05 & 3156,90 & 0,24 & 0,05 \\
\hline & & & 14 & 2072,70 & 2679,55 & 0,23 & 0,05 \\
\hline & & & 16 & 1810,90 & 2335,10 & 0,22 & 0,05 \\
\hline & & & 17 & 2204,30 & 2844,20 & 0,23 & 0,05 \\
\hline & & & 18 & 1500,45 & 1941,25 & 0,23 & 0,05 \\
\hline & & & Média & 2000,08 & 2591,40 & 0,23 & 0,05 \\
\hline & & & Desvio & 354,30 & 469,00 & 0,00 & 0,00 \\
\hline & & & Relação & 17,71 & 18,10 & 2,04 & 2,01 \\
\hline & & \multirow{8}{*}{7} & 19 & 1256,15 & 1566,85 & 0,20 & 0,05 \\
\hline & & & 20 & 1344,70 & 1636,10 & 0,18 & 0,05 \\
\hline & & & 22 & 2020,40 & 2681,15 & 0,25 & 0,05 \\
\hline & & & 23 & 1557,15 & 1925,10 & 0,19 & 0,05 \\
\hline & & & 24 & 1226,80 & 1640,00 & 0,25 & 0,05 \\
\hline & & & Média & 1481,04 & 1889,84 & 0,21 & 0,05 \\
\hline & & & Desvio & 328,06 & 463,29 & 0,03 & 0,00 \\
\hline & & & Relação & 22,15 & 24,51 & 15,85 & 1,75 \\
\hline & \multirow{15}{*}{ 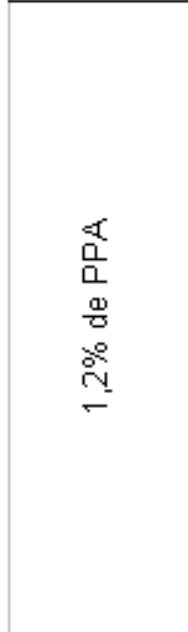 } & \multirow{8}{*}{4} & 25 & 2678,65 & 3292,80 & 0,19 & 0,04 \\
\hline & & & 26 & 2131,35 & 2788,85 & 0,24 & 0,04 \\
\hline & & & 27 & 2695,35 & 3383,50 & 0,20 & 0,04 \\
\hline & & & 28 & 2931,65 & 3615,75 & 0,19 & 0,04 \\
\hline & & & 29 & 3097,05 & 3873,05 & 0,20 & 0,05 \\
\hline & & & Média & 2706,81 & 3390,79 & 0,20 & 0,04 \\
\hline & & & Desvio & 365,69 & 404,71 & 0,02 & 0,00 \\
\hline & & & Relação & 13,51 & 11,94 & 9,52 & 2,60 \\
\hline & & \multirow{7}{*}{7} & 31 & 1954,70 & 2460,10 & 0,21 & 0,05 \\
\hline & & & 32 & 1602,10 & 2015,95 & 0,21 & 0,05 \\
\hline & & & 34 & 2020,50 & 2571,15 & 0,21 & 0,04 \\
\hline & & & 36 & 1863,50 & 2412,60 & 0,23 & 0,05 \\
\hline & & & Média & 1860,20 & 2364,95 & 0,21 & 0,05 \\
\hline & & & \begin{tabular}{|l|} 
Desvio \\
\end{tabular} & 183,71 & 241,97 & 0,01 & 0,00 \\
\hline & & & Relação & 9,88 & 10,23 & 4,87 & 4,73 \\
\hline
\end{tabular}

Continua... 
Continuação da Tabela IV.1

\begin{tabular}{|c|c|c|c|c|c|c|c|c|c|}
\hline Aditivo & Modificadc & $V / V(\%)$ & $C P n^{\circ}$ & $\begin{array}{l}\text { Mod. Res. } \\
\text { MCHRP }\end{array}$ & Total - & $\begin{array}{l}\text { Mod. Res. } \\
\text { - NCHRP }\end{array}$ & instant. & $\begin{array}{l}\text { ((MRi - MRt)/MRi) } \\
\text { - NCHRP }\end{array}$ & $\begin{array}{l}\text { Atraso } \\
\text { Médio }\end{array}$ \\
\hline \multirow{48}{*}{ 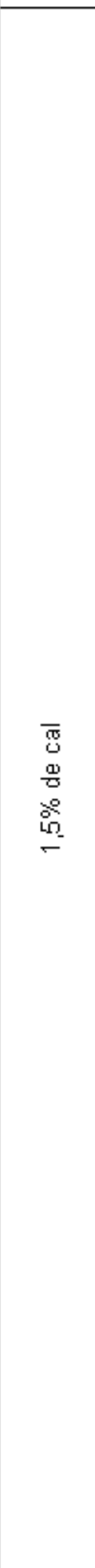 } & \multirow{16}{*}{$\begin{array}{l}x \\
\frac{1}{1} \\
\frac{0}{2} \\
8 \\
8\end{array}$} & \multirow{8}{*}{4} & 37 & & 1509,60 & & 2108,45 & 0,28 & 0,05 \\
\hline & & & 38 & & 1275,35 & & 1797,95 & 0,29 & 0,05 \\
\hline & & & 39 & & 1279,15 & & 1739,70 & 0,26 & 0,05 \\
\hline & & & 40 & & 1159,20 & & 1636,70 & 0,29 & 0,05 \\
\hline & & & 42 & & 1541,90 & & 2116,00 & 0,27 & 0,05 \\
\hline & & & Média & & 1353,04 & & 1879,76 & 0,28 & 0,05 \\
\hline & & & Desvio & & 165,26 & & 219,94 & 0,01 & 0,00 \\
\hline & & & Relação & & 12,21 & & 11,70 & 4,27 & 1,13 \\
\hline & & \multirow{8}{*}{7} & 43 & & 1032,45 & & 1380,15 & 0,25 & 0,05 \\
\hline & & & 44 & & 1141,40 & & 1539,45 & 0,26 & 0,05 \\
\hline & & & 45 & & 1417,40 & & 1909,95 & 0,26 & 0,05 \\
\hline & & & 46 & & 1312,75 & & 1744,00 & 0,25 & 0,05 \\
\hline & & & 48 & & 1467,45 & & 1976,55 & 0,26 & 0,05 \\
\hline & & & Média & & 1274,29 & & 1710,02 & 0,25 & 0,05 \\
\hline & & & $\begin{array}{l}\text { Desvio } \\
\end{array}$ & & 184,00 & & 250,04 & 0,00 & 0,00 \\
\hline & & & Relação & & 14,44 & & 14,62 & 1,94 & 1,03 \\
\hline & \multirow{16}{*}{ 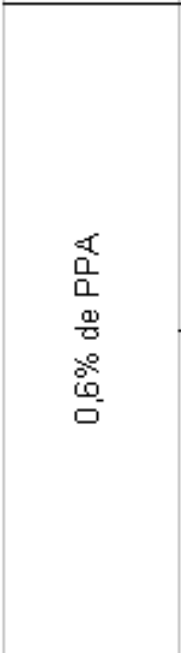 } & \multirow{8}{*}{4} & 49 & & 1212,55 & & 1620,10 & 0,25 & 0,05 \\
\hline & & & 50 & & 1198,90 & & 1626,95 & 0,26 & 0,05 \\
\hline & & & 51 & & 1151,90 & & 1495,25 & 0,23 & 0,05 \\
\hline & & & 53 & & 1615,40 & & 2215,10 & 0,27 & 0,05 \\
\hline & & & 54 & & 1522,10 & & 2071,20 & 0,27 & 0,05 \\
\hline & & & Média & & 1340,17 & & 1805,72 & 0,26 & 0,05 \\
\hline & & & Desvio & & 212,45 & & 316,57 & 0,02 & 0,00 \\
\hline & & & Relaçäo & & 15,85 & & 17,53 & 6,36 & 1,28 \\
\hline & & \multirow{8}{*}{7} & 55 & & 1423,55 & & 1934,75 & 0,26 & 0,05 \\
\hline & & & 56 & & 1319,35 & & 1749,80 & 0,25 & 0,05 \\
\hline & & & 58 & & 1574,75 & & 2048,65 & 0,23 & 0,05 \\
\hline & & & 59 & & 1621,95 & & 2126,40 & 0,24 & 0,05 \\
\hline & & & 60 & & 1394,50 & & 1826,35 & 0,24 & 0,05 \\
\hline & & & Média & & 1466,82 & & 1937,19 & 0,24 & 0,05 \\
\hline & & & Desvio & & 127,05 & & 154,62 & 0,01 & 0,00 \\
\hline & & & Relação & & 8,66 & & 7,98 & 5,34 & 2,49 \\
\hline & \multirow{16}{*}{ 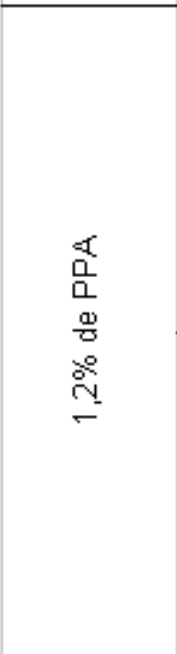 } & \multirow{8}{*}{4} & 61 & & 1893,65 & & 2350,45 & 0,19 & 0,05 \\
\hline & & & 62 & & 1683,85 & & 2222,90 & 0,24 & 0,05 \\
\hline & & & 63 & & 1955,60 & & 2498,65 & 0,22 & 0,05 \\
\hline & & & 65 & & 2038,55 & & 2698,30 & 0,24 & 0,05 \\
\hline & & & 66 & & 1898,00 & & 2553,75 & 0,26 & 0,05 \\
\hline & & & Média & & 1893,93 & & 2464,81 & 0,23 & 0,05 \\
\hline & & & Desvio & & 131,21 & & 183,83 & 0,03 & 0,00 \\
\hline & & & Relaçäo & & 6,93 & & 7,46 & 10,84 & 0,97 \\
\hline & & \multirow{8}{*}{7} & 67 & & 1890,25 & & 2545,00 & 0,26 & 0,05 \\
\hline & & & 68 & & 1349,45 & & 1858,30 & 0,27 & 0,05 \\
\hline & & & 70 & & 1922,45 & & 2444,75 & 0,21 & 0,05 \\
\hline & & & 71 & & 1761,45 & & 2314,05 & 0,24 & 0,05 \\
\hline & & & 72 & & 1730,35 & & 2261,95 & 0,24 & 0,05 \\
\hline & & & Média & & 1730,79 & & 2284,81 & 0,24 & 0,05 \\
\hline & & & Desvio & & 228,32 & & 262,95 & 0,02 & 0,00 \\
\hline & & & Relação & & 13,19 & & 11,51 & 9,38 & 1,77 \\
\hline
\end{tabular}

Continua... 
Continuação da Tabela IV.1

\begin{tabular}{|c|c|c|c|c|c|c|c|}
\hline Aditivo & Modificadc & $V / V(\%)$ & $C P n^{\circ}$ & $\begin{array}{l}\text { Mod. Res. Total - } \\
\text { MCHRP }\end{array}$ & $\begin{array}{l}\text { Mod. Res. Instant. } \\
\text { - MCHRP }\end{array}$ & $\begin{array}{l}\text { ((MRi - MRtt/MRi) } \\
- \text { MCHRP }\end{array}$ & $\begin{array}{l}\text { Atraso } \\
\text { Médio }\end{array}$ \\
\hline \multirow{48}{*}{ 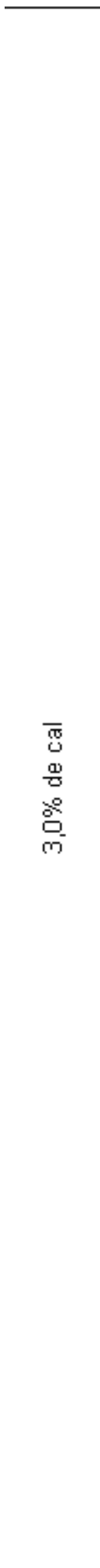 } & \multirow{16}{*}{ 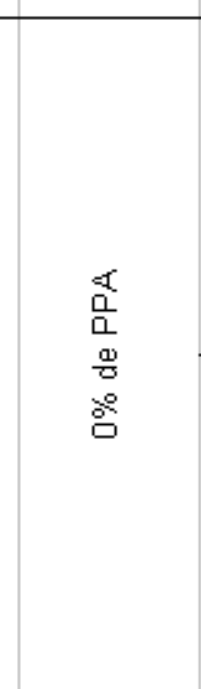 } & \multirow{8}{*}{4} & 73 & 1350,15 & 1892,25 & 0,29 & 0,05 \\
\hline & & & 74 & 1079,20 & 1475,15 & 0,27 & 0,05 \\
\hline & & & 75 & 1419,65 & 1909,60 & 0,26 & 0,05 \\
\hline & & & 77 & 1105,05 & 143185 & 0,23 & 0,05 \\
\hline & & & 78 & 1559,30 & 1934,75 & 0,19 & 0,05 \\
\hline & & & Média & 1302,67 & 1728,72 & 0,25 & 0,05 \\
\hline & & & $\begin{array}{l}\text { Desvio } \\
\end{array}$ & 206,63 & 252,16 & 0,04 & 0,00 \\
\hline & & & Relaçäo & 15,86 & 14,59 & 14,70 & 1,96 \\
\hline & & \multirow{8}{*}{7} & 79 & 1039,60 & 1339,20 & 0,22 & 0,05 \\
\hline & & & 80 & 1127,35 & 1460,60 & 0,23 & 0,05 \\
\hline & & & 81 & 1079,90 & 1382,30 & 0,22 & 0,05 \\
\hline & & & 82 & 1076,40 & 1384,85 & 0,22 & 0,05 \\
\hline & & & 83 & 932,65 & 1267,00 & 0,26 & 0,05 \\
\hline & & & Média & 1051,18 & 1366,79 & 0,23 & 0,05 \\
\hline & & & Desvio & 73,22 & 70,86 & 0,02 & 0,00 \\
\hline & & & Relação & 6,97 & 5,18 & 7,97 & 1,73 \\
\hline & \multirow{16}{*}{ 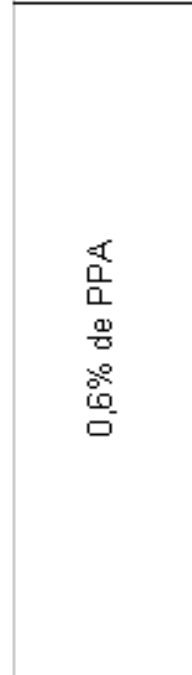 } & \multirow{8}{*}{4} & 86 & 1497,35 & 2061,80 & 0,27 & 0,05 \\
\hline & & & 87 & 1625,85 & 2218,40 & 0,27 & 0,05 \\
\hline & & & 88 & 1294,95 & 1659,65 & 0,22 & 0,05 \\
\hline & & & 89 & 1256,05 & 1713,30 & 0,27 & 0,05 \\
\hline & & & 90 & 1267,25 & 1720,00 & 0,26 & 0,05 \\
\hline & & & Média & 1388,29 & 1874,63 & 0,26 & 0,05 \\
\hline & & & Desvio & 165.21 & 24968 & 0,02 & 0,00 \\
\hline & & & Relação & 11,90 & 13,32 & 8,45 & 0,88 \\
\hline & & \multirow{8}{*}{7} & 92 & 1389,95 & 1943,40 & 0,28 & 0,05 \\
\hline & & & 93 & 1493,25 & 1939,50 & 0,23 & 0,05 \\
\hline & & & 94 & 1481,00 & 1994,20 & 0,26 & 0,05 \\
\hline & & & 95 & 1464,90 & 2003,60 & 0,27 & 0,05 \\
\hline & & & 96 & 1475,60 & 2028,30 & 0,27 & 0,05 \\
\hline & & & Média & 1460,94 & 1981,80 & 0,26 & 0,05 \\
\hline & & & $\begin{array}{l}\text { Desvio } \\
\end{array}$ & 40,98 & 38,91 & 0,02 & 0,00 \\
\hline & & & Relaçäo & 2,80 & 1,96 & 7,88 & 2,41 \\
\hline & \multirow{16}{*}{ 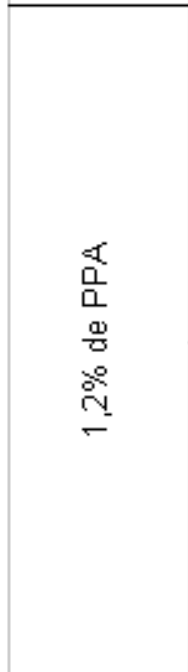 } & \multirow{8}{*}{4} & 97 & 2723,25 & 3614,80 & 0,25 & 0,05 \\
\hline & & & 98 & 2223,80 & 2926,65 & 0,24 & 0,05 \\
\hline & & & 99 & 2529,25 & 3211,15 & 0,21 & 0,05 \\
\hline & & & 100 & 2277,55 & 3104,80 & 0,27 & 0,05 \\
\hline & & & 101 & 2433,25 & 3194,55 & 0,24 & 0,05 \\
\hline & & & Média & 2437,42 & 3210,39 & 0,24 & 0,05 \\
\hline & & & Desvio & 200,84 & 252,71 & 0,02 & 0,00 \\
\hline & & & Relaçäo & 8,24 & 7,87 & 8,06 & $\overline{1,41}$ \\
\hline & & \multirow{8}{*}{7} & 103 & 1306,55 & 1688,15 & 0,23 & 0,05 \\
\hline & & & 104 & 1436,85 & 1926,75 & 0,25 & 0,05 \\
\hline & & & 105 & 2137,50 & 2866,50 & 0,25 & 0,05 \\
\hline & & & 107 & 1341,15 & 1828,25 & 0,27 & 0,05 \\
\hline & & & 108 & 1697,85 & 2510,10 & 0,32 & 0,05 \\
\hline & & & Média & 1583,98 & 2163,95 & 0,26 & 0,05 \\
\hline & & & Desvio & 345,30 & 502,18 & 0,04 & 0,00 \\
\hline & & & Relaçäo & 21,80 & 23,21 & 13,59 & 5,80 \\
\hline
\end{tabular}


Tabela IV. 2. Módulo de Resiliência para todos os fatores a $25^{\circ} \mathrm{C}$, descartando ensaios fora de um desvio padrão em relação à média.

\begin{tabular}{|c|c|c|c|c|c|c|c|}
\hline Aditivo & Modificad & $=V / v(\%)$ & $C P n^{\circ}$ & $\begin{array}{l}\text { Mod. Res. Total - } \\
\text { MCHRP }\end{array}$ & $\begin{array}{l}\text { Mod. Res. instant. } \\
\text { - MCHRP }\end{array}$ & $\begin{array}{l}((M R i-M R t) / M R i) \\
-M C H R P\end{array}$ & $\begin{array}{l}\text { Atraso } \\
\text { Médio }\end{array}$ \\
\hline \multirow{48}{*}{ 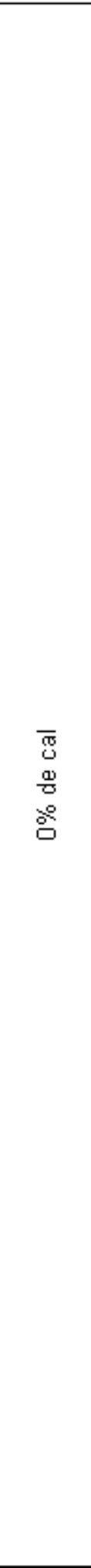 } & \multirow{14}{*}{$\begin{array}{l}\frac{x}{0} \\
\text { 뭄 } \\
\frac{0}{0} \\
8 \\
8\end{array}$} & \multirow{7}{*}{4} & 1 & 5745,73 & 7763,03 & 0,26 & 0,05 \\
\hline & & & 2 & 5683,53 & 7837,20 & 0,27 & 0,05 \\
\hline & & & 5 & 4426,57 & 6170,90 & 0,28 & 0,05 \\
\hline & & & 6 & 5397,60 & 7286,83 & 0,26 & 0,05 \\
\hline & & & Média & 5313,36 & 7264,49 & 0,27 & 0,05 \\
\hline & & & Desvio & 610,32 & 768,76 & 0,01 & 0,00 \\
\hline & & & Relação & 11,49 & 10,58 & 4,26 & 2,13 \\
\hline & & \multirow{7}{*}{7} & 7 & 3352,37 & 4677,63 & 0,28 & 0,05 \\
\hline & & & 8 & 3346,20 & 4600,67 & 0,27 & 0,05 \\
\hline & & & 10 & 3252,67 & 4436,43 & 0,27 & 0,05 \\
\hline & & & 11 & 3457,77 & 4687,03 & 0,26 & 0,05 \\
\hline & & & Média & 3352,25 & 4600,44 & 0,27 & 0,05 \\
\hline & & & Desvio & 83,84 & 115,98 & 0,01 & 0,00 \\
\hline & & & Relação & 2,50 & 2,52 & 3,35 & 1,22 \\
\hline & \multirow{16}{*}{ 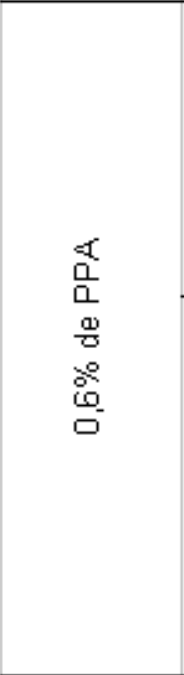 } & \multirow{7}{*}{4} & 14 & 4693,97 & 6047,73 & 0,22 & 0,04 \\
\hline & & & 15 & 4912,17 & 6254,07 & 0,21 & 0,04 \\
\hline & & & 16 & 5990,35 & 7632,60 & 0,22 & 0,04 \\
\hline & & & 18 & 5807,60 & 7610,80 & 0,24 & 0,05 \\
\hline & & & Média & 5351,02 & 6886,30 & 0,22 & 0,04 \\
\hline & & & Desvio & 643,30 & 853,38 & 0,01 & 0,00 \\
\hline & & & Relação & 12,02 & 12,39 & 4,70 & 2,35 \\
\hline & & \multirow{9}{*}{7} & 19 & 5881,88 & 8312,93 & 0,29 & 0,05 \\
\hline & & & 20 & 4516,17 & 6057,13 & 0,25 & 0,05 \\
\hline & & & 21 & 9318,33 & 12339,63 & 0,25 & 0,05 \\
\hline & & & 22 & 4415,65 & 5757,90 & 0,23 & 0,04 \\
\hline & & & 23 & 4411,27 & 5829,10 & 0,24 & 0,05 \\
\hline & & & 24 & 4556,03 & 6064,17 & 0,25 & 0,05 \\
\hline & & & Média & 5516,55 & 7393,48 & 0,25 & 0,05 \\
\hline & & & Desvio & 1946,48 & 2607,11 & 0,02 & 0,00 \\
\hline & & & Relação & 35,28 & 35,26 & 7,47 & 3,16 \\
\hline & \multirow{18}{*}{ 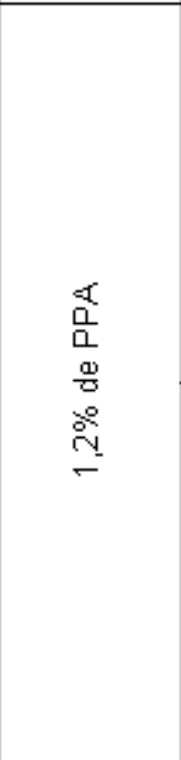 } & \multirow{9}{*}{4} & 25 & 10065,43 & 11943,30 & 0,16 & 0,04 \\
\hline & & & 26 & 4212,78 & 5151,03 & 0,18 & 0,04 \\
\hline & & & 27 & 8884,54 & 10868,81 & 0,18 & 0,04 \\
\hline & & & 28 & 8483,80 & 10648,83 & 0,20 & 0,04 \\
\hline & & & 29 & 9947,00 & 11943,33 & 0,17 & 0,05 \\
\hline & & & 30 & 8568,13 & 10742,80 & 0,20 & 0,04 \\
\hline & & & Média & 8360,28 & 10216,35 & 0,18 & 0,04 \\
\hline & & & Desvio & 2142,91 & 2549,99 & 0,02 & 0,00 \\
\hline & & & Relaçäo & 25,63 & 24,96 & 10,11 & 3,32 \\
\hline & & \multirow{9}{*}{7} & 31 & 9244,57 & 11577,10 & 0,20 & 0,04 \\
\hline & & & 32 & 5566,47 & 7192,93 & 0,23 & 0,04 \\
\hline & & & 33 & 10299,23 & 12025,60 & 0,14 & 0,04 \\
\hline & & & 34 & 8284,87 & 10103,87 & 0,18 & 0,05 \\
\hline & & & 35 & 7827,50 & 10216,53 & 0,23 & 0,04 \\
\hline & & & 36 & 4671,80 & 6126,03 & 0,24 & 0,04 \\
\hline & & & Média & 7649,07 & 9540,34 & 0,20 & 0,04 \\
\hline & & & Desvio & 2154,36 & 2377,71 & 0,04 & 0,00 \\
\hline & & & Relação & 28,17 & 24,92 & 17,97 & 2,29 \\
\hline
\end{tabular}

Continua... 
Continuação da Tabela IV.2

\begin{tabular}{|c|c|c|c|c|c|c|c|}
\hline Aditivo & Modificad & $V / 1 \%)$ & $C P n^{\circ}$ & $\begin{array}{l}\text { Mod. Res. Total - } \\
\text { MCHRP }\end{array}$ & $\begin{array}{l}\text { Mod. Res. Instant. } \\
\text { - MCHRP }\end{array}$ & $\begin{array}{l}((M R i-M R t) / M R i) \\
-M C H R P\end{array}$ & $\begin{array}{l}\text { Atraso } \\
\text { Médio }\end{array}$ \\
\hline \multirow{46}{*}{ 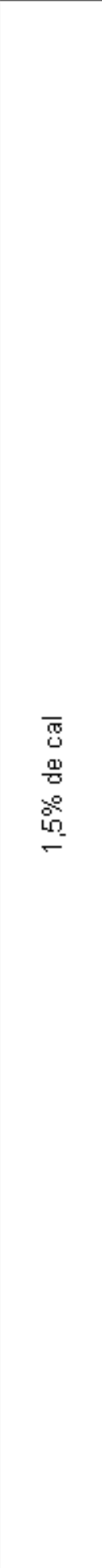 } & \multirow{15}{*}{$\begin{array}{l}\frac{x}{0} \\
\text { 뭄 } \\
\text { 몽 } \\
8\end{array}$} & \multirow{8}{*}{4} & 37 & 5024,67 & 6480,87 & 0,22 & 0,04 \\
\hline & & & 38 & 5638,20 & 7603,80 & 0,26 & 0,05 \\
\hline & & & 39 & 5191,33 & 6832,40 & 0,24 & 0,04 \\
\hline & & & 40 & 5215,83 & 6730,73 & 0,22 & 0,04 \\
\hline & & & 42 & 4846,33 & 6362,17 & 0,24 & 0,05 \\
\hline & & & Média & 5183,27 & 6801,99 & 0,24 & 0,04 \\
\hline & & & Desvio & 294,44 & 486,18 & 0,01 & 0,00 \\
\hline & & & Relação & 5,68 & 7,15 & 5,85 & 1,70 \\
\hline & & \multirow{7}{*}{7} & 44 & 4690,40 & 6465,43 & 0,27 & 0,05 \\
\hline & & & 45 & 4572,67 & 6060,90 & 0,25 & 0,05 \\
\hline & & & 47 & 4515,00 & 6045,70 & 0,25 & 0,05 \\
\hline & & & 48 & 4175,97 & 5655,13 & 0,26 & 0,05 \\
\hline & & & Média & 4488,51 & 6056,79 & 0,26 & 0,05 \\
\hline & & & Desvio & 220,78 & 330,89 & 0,01 & 0,00 \\
\hline & & & Relação & 4,92 & 5,46 & 4,80 & 1,51 \\
\hline & \multirow{16}{*}{ 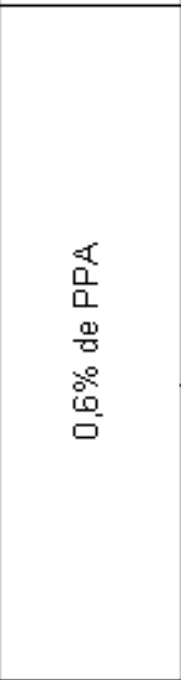 } & \multirow{9}{*}{4} & 49 & 5460,80 & 7189,87 & 0,24 & 0,04 \\
\hline & & & 50 & 6251,97 & 8260,17 & 0,24 & 0,05 \\
\hline & & & 51 & 5090,47 & 6696,37 & 0,24 & 0,04 \\
\hline & & & 52 & 8192,35 & 10539,03 & 0,22 & 0,04 \\
\hline & & & 53 & 5703,93 & 7601,40 & 0,25 & 0,05 \\
\hline & & & 54 & 5268,00 & 6967,48 & 0,24 & 0,04 \\
\hline & & & Média & 5994,58 & 7875,72 & 0,24 & 0,04 \\
\hline & & & Desvio & 1149,89 & 1414,38 & 0,01 & 0,00 \\
\hline & & & Relaçăo & 19,18 & 17,96 & 3,80 & 1,60 \\
\hline & & \multirow{7}{*}{7} & 55 & 4773,40 & 6385,07 & 0,25 & 0,05 \\
\hline & & & 56 & 4954,33 & 6558,80 & 0,24 & 0,05 \\
\hline & & & 58 & 4969,58 & 6433,65 & 0,23 & 0,04 \\
\hline & & & 59 & 5452,33 & 7231,63 & 0,25 & 0,05 \\
\hline & & & Média & 5037,41 & 6652,29 & 0,24 & 0,05 \\
\hline & & & Desvio & 290,61 & 393,10 & 0,01 & 0,00 \\
\hline & & & Relaçăo & 5,77 & 5,91 & 4,26 & 1,63 \\
\hline & \multirow{15}{*}{$\begin{array}{l}\frac{x}{0} \\
\text { 뭄 } \\
\text { 뭉 } \\
\stackrel{\circ}{\circ} \\
\stackrel{0}{2}\end{array}$} & \multirow{8}{*}{4} & 61 & 6472,47 & 8353,13 & 0,22 & 0,04 \\
\hline & & & 62 & 7040,40 & 9238,90 & 0,24 & 0,04 \\
\hline & & & 63 & 6176,70 & 8064,27 & 0,23 & 0,04 \\
\hline & & & 64 & 6225,70 & 7913,50 & 0,21 & 0,04 \\
\hline & & & 66 & 6734,58 & 8832,80 & 0,24 & 0,04 \\
\hline & & & Média & 6529,97 & 8480,52 & 0,23 & 0,04 \\
\hline & & & Desvio & 361,62 & 550,06 & 0,01 & 0,00 \\
\hline & & & Relação & 5,54 & 6,49 & 4,53 & 1,47 \\
\hline & & \multirow{7}{*}{7} & 67 & 6037,15 & 7732,60 & 0,22 & 0,04 \\
\hline & & & 69 & 6796,24 & 8487,34 & 0,20 & 0,04 \\
\hline & & & 71 & 5864,70 & 7476,57 & 0,22 & 0,04 \\
\hline & & & 72 & 5573,83 & 7440,80 & 0,25 & 0,05 \\
\hline & & & Média & 6067,98 & 7784,33 & 0,22 & 0,04 \\
\hline & & & Desvio & 521,80 & 486,36 & 0,02 & 0,00 \\
\hline & & & Relação & 8,60 & 6,25 & 9,78 & 3,86 \\
\hline
\end{tabular}

Continua... 
Continuação da Tabela IV.2

\begin{tabular}{|c|c|c|c|c|c|c|c|}
\hline Aditivo & Modificadc & $=V / V(\%)$ & $C P n^{\circ}$ & $\begin{array}{l}\text { Mod. Res. Total - } \\
\text { MCHRP }\end{array}$ & $\begin{array}{l}\text { Mod. Res. instant. } \\
\text { - MCHRP }\end{array}$ & $\begin{array}{l}((M R i-M R t) / M R i) \\
-M C H R P\end{array}$ & $\begin{array}{l}\text { Atraso } \\
\text { Médio }\end{array}$ \\
\hline \multirow{44}{*}{$\begin{array}{l}\overline{8} \\
\mathrm{D} \\
\mathrm{D} \\
\mathrm{D} \\
\stackrel{8}{\circ} \\
\mathrm{m}^{\circ}\end{array}$} & \multirow{14}{*}{$\begin{array}{l}\frac{x}{0} \\
\text { 무 } \\
\text { 몽 } \\
8 \\
8\end{array}$} & \multirow{7}{*}{4} & 73 & 5479,43 & 7426,73 & 0,26 & 0,05 \\
\hline & & & 74 & 5032,27 & 6824,50 & 0,26 & 0,05 \\
\hline & & & 75 & 5598,73 & 7418,10 & 0,25 & 0,05 \\
\hline & & & 78 & 6837,73 & 9157,07 & 0,25 & 0,05 \\
\hline & & & Média & 5737,04 & 7706,60 & 0,26 & 0,05 \\
\hline & & & Desvio & 773,24 & 1007,23 & 0,01 & 0,00 \\
\hline & & & Relação & 13,48 & 13,07 & 3,23 & 1,03 \\
\hline & & \multirow{7}{*}{7} & 79 & 3792,40 & 5210,93 & 0,27 & 0,05 \\
\hline & & & 80 & 3807,87 & 5169,20 & 0,26 & 0,05 \\
\hline & & & 82 & 4689,35 & 6345,95 & 0,26 & 0,05 \\
\hline & & & 83 & 4090,70 & 5597,70 & 0,27 & 0,05 \\
\hline & & & Média & 4095,08 & 5580,95 & 0,27 & 0,05 \\
\hline & & & $\begin{array}{l}\text { Desvio } \\
\end{array}$ & 419,24 & 545,27 & 0,01 & 0,00 \\
\hline & & & Relação & 10,24 & 9,77 & 1,93 & 1,63 \\
\hline & \multirow{16}{*}{ 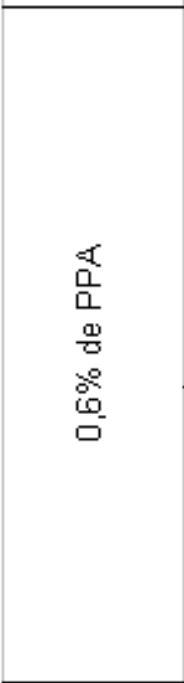 } & \multirow{9}{*}{4} & 85 & 5765,00 & 7454,93 & 0,23 & 0,05 \\
\hline & & & 86 & 5758,07 & 7612,53 & 0,24 & 0,05 \\
\hline & & & 87 & 5379,93 & 6971,33 & 0,23 & 0,04 \\
\hline & & & 88 & 5196,17 & 6815,63 & 0,24 & 0,04 \\
\hline & & & 89 & 5024,67 & 6463,13 & 0,22 & 0,04 \\
\hline & & & 90 & 5953,00 & 7707,10 & 0,23 & 0,04 \\
\hline & & & Média & 5512,81 & 7170,78 & 0,23 & 0,04 \\
\hline & & & Desvio & 367,08 & 496,02 & 0,01 & 0,00 \\
\hline & & & Relação & 6,66 & 6,92 & 3,34 & 1,31 \\
\hline & & \multirow{7}{*}{7} & 91 & 5329,45 & 6988,35 & 0,24 & 0,05 \\
\hline & & & 92 & 4259,53 & 5616,93 & 0,24 & 0,05 \\
\hline & & & 94 & 4388,33 & 5764,57 & 0,24 & 0,04 \\
\hline & & & 95 & 4308,60 & 5751,87 & 0,25 & 0,04 \\
\hline & & & Média & 4571,48 & 6030,43 & 0,24 & 0,04 \\
\hline & & & $\begin{array}{l}\text { Desvio } \\
\end{array}$ & 508,09 & 642,10 & 0,01 & 0,00 \\
\hline & & & Relação & 11,11 & 10,65 & 2,51 & 0,86 \\
\hline & \multirow{14}{*}{ 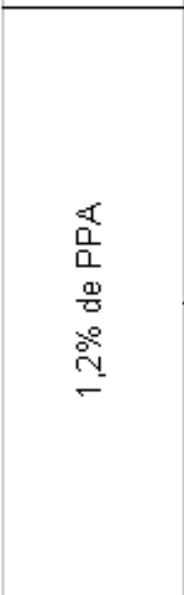 } & \multirow{7}{*}{4} & 99 & 5017,90 & 6346,67 & 0,21 & 0,04 \\
\hline & & & 100 & 4952,50 & 6209,25 & 0,20 & 0,04 \\
\hline & & & 101 & 7042,35 & 8551,40 & 0,18 & 0,04 \\
\hline & & & 102 & 5659,57 & 7316,30 & 0,23 & 0,04 \\
\hline & & & Média & 5668,08 & 7105,90 & 0,20 & 0,04 \\
\hline & & & \begin{tabular}{|l|} 
Desvio \\
\end{tabular} & 970,13 & 1082,31 & 0,02 & 0,00 \\
\hline & & & Relação & 17,12 & 15,23 & 10,22 & 1,78 \\
\hline & & \multirow{7}{*}{7} & 103 & 4857,83 & 6204,93 & 0,22 & 0,04 \\
\hline & & & 104 & 4597,87 & 6027,63 & 0,24 & 0,04 \\
\hline & & & 107 & 6344,23 & 8120,23 & 0,22 & 0,05 \\
\hline & & & 108 & 4374,93 & 5663,18 & 0,23 & 0,04 \\
\hline & & & Média & 5043,71 & 6503,99 & 0,22 & 0,04 \\
\hline & & & Desvio & 889,18 & 1100,84 & 0,01 & 0,00 \\
\hline & & & Relação & 17,63 & 16,93 & 4,19 & 1,61 \\
\hline
\end{tabular}


Tabela IV. 3.Módulo de Resiliência para todos os fatores a $10^{\circ} \mathrm{C}$, descartando ensaios fora de um desvio padrão em relação à média.

\begin{tabular}{|c|c|c|c|c|c|c|c|}
\hline Aditivo & Modificad & $V /(\%)$ & $C P n^{\circ}$ & $\begin{array}{l}\text { Mod. Res. Total - } \\
\text { MCHRP }\end{array}$ & $\begin{array}{l}\text { Mod. Res. Instant. } \\
\text { - MCHRP }\end{array}$ & $\begin{array}{l}\text { ((MRi - MRtt)/MRI) } \\
\text { - MCHRP }\end{array}$ & $\begin{array}{l}\text { Atraso } \\
\text { Médio }\end{array}$ \\
\hline \multirow{47}{*}{$\begin{array}{l}\overline{\mathrm{D}} \\
\mathrm{d} \\
\mathrm{D} \\
\stackrel{\circ}{\circ}\end{array}$} & \multirow{16}{*}{$\begin{array}{l}\frac{x}{0} \\
\frac{0}{1} \\
\frac{\Phi}{5} \\
8 \\
8\end{array}$} & \multirow{7}{*}{4} & 1 & 16274,53 & 18708,27 & 0,13 & 0,04 \\
\hline & & & 3 & 16496,33 & 19034,57 & 0,13 & 0,04 \\
\hline & & & 5 & 16088,70 & 18490,20 & 0,13 & 0,04 \\
\hline & & & 6 & 16125,83 & 18574,53 & 0,13 & 0,04 \\
\hline & & & Média & 16094,14 & 18503,47 & 0,13 & 0,04 \\
\hline & & & Desvio & 890,01 & 1064,28 & 0,00 & 0,00 \\
\hline & & & Relação & 5,53 & 5,75 & 2,07 & 2,06 \\
\hline & & \multirow{9}{*}{7} & 7 & 13170,67 & 15256,93 & 0,14 & 0,04 \\
\hline & & & 8 & 11481,70 & 13540,10 & 0,15 & 0,04 \\
\hline & & & 9 & 12187,53 & 14185,97 & 0,14 & 0,04 \\
\hline & & & 10 & 12993,23 & 15651,63 & 0,17 & 0,04 \\
\hline & & & 11 & 12012,20 & 14234,57 & 0,16 & 0,04 \\
\hline & & & 12 & 11831,83 & 14130,53 & 0,16 & 0,04 \\
\hline & & & Média & 12279,53 & 14499,96 & 0,15 & 0,04 \\
\hline & & & Desvio & 666,39 & 790,72 & 0,01 & 0,00 \\
\hline & & & Relação & 5,43 & 5,45 & 8,26 & 1,35 \\
\hline & \multirow{15}{*}{ 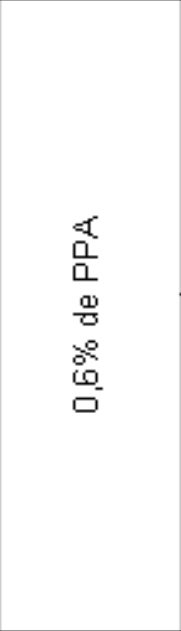 } & \multirow{7}{*}{4} & 15 & 17441,67 & 19819,20 & 0,12 & 0,04 \\
\hline & & & 16 & 17409,87 & 20044,03 & 0,13 & 0,04 \\
\hline & & & 17 & 16130,30 & 18359,57 & 0,12 & 0,04 \\
\hline & & & 18 & 15983,07 & 18530,00 & 0,14 & 0,04 \\
\hline & & & Média & 15071,89 & 17341,09 & 0,13 & 0,04 \\
\hline & & & Desvio & 2667,85 & 2956,62 & 0,01 & 0,00 \\
\hline & & & Relação & 17,70 & 17,05 & 7,41 & 0,97 \\
\hline & & \multirow{8}{*}{7} & 19 & 12699,87 & 14710,27 & 0,14 & 0,04 \\
\hline & & & 20 & 12547,63 & 14564,47 & 0,14 & 0,04 \\
\hline & & & 22 & 13799,57 & 15820,40 & 0,13 & 0,04 \\
\hline & & & 23 & 13325,33 & 15300,03 & 0,13 & 0,04 \\
\hline & & & 24 & 13256,70 & 15435,43 & 0,14 & 0,04 \\
\hline & & & Média & 13358,55 & 15393,01 & 0,13 & 0,04 \\
\hline & & & Desvio & 728,22 & 725,62 & 0,01 & 0,00 \\
\hline & & & Relação & 5,45 & 4,71 & 5,72 & 0,62 \\
\hline & \multirow{16}{*}{ 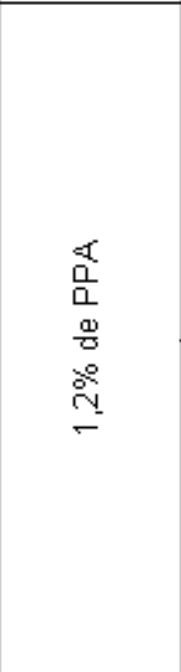 } & \multirow{8}{*}{4} & 26 & 17959,73 & 20086,20 & 0,11 & 0,04 \\
\hline & & & 27 & 17756,57 & 20566,20 & 0,14 & 0,04 \\
\hline & & & 28 & 15861,20 & 18073,97 & 0,12 & 0,04 \\
\hline & & & 29 & 16067,50 & 17961,00 & 0,11 & 0,04 \\
\hline & & & 30 & 16733,50 & 18863,77 & 0,11 & 0,04 \\
\hline & & & Média & 15954,58 & 18045,17 & 0,12 & 0,04 \\
\hline & & & Desvio & 2412,77 & 2812,75 & 0,01 & 0,00 \\
\hline & & & Relação & 15,12 & 15,59 & 10,66 & 2,79 \\
\hline & & \multirow{8}{*}{7} & 31 & 16290,47 & 18474,90 & 0,12 & 0,04 \\
\hline & & & 33 & 16433,83 & 18256,33 & 0,10 & 0,04 \\
\hline & & & 34 & 17524,20 & 19178,80 & 0,09 & 0,04 \\
\hline & & & 35 & 16423,83 & 18785,47 & 0,13 & 0,04 \\
\hline & & & 36 & 19917,93 & 22184,93 & 0,10 & 0,04 \\
\hline & & & Média & 16262,92 & 18262,02 & 0,11 & 0,04 \\
\hline & & & Desvio & 2927,07 & 3084,72 & 0,02 & 0,00 \\
\hline & & & Relação & 18,00 & 16,89 & 16,23 & 1,14 \\
\hline
\end{tabular}

Continua... 
Continuação da Tabela IV.3

\begin{tabular}{|c|c|c|c|c|c|c|c|}
\hline Aditivo & Modificadc & $c V /(\%)$ & $C P n^{\circ}$ & $\begin{array}{l}\text { Mod. Res. Total - } \\
\text { MCHRP }\end{array}$ & $\begin{array}{l}\text { Mod. Res. instant. } \\
\text { - NCHRP }\end{array}$ & $\begin{array}{l}((M R i-M R t) / M R i) \\
- \text { MCHRP }\end{array}$ & $\begin{array}{l}\text { Atraso } \\
\text { Médio }\end{array}$ \\
\hline \multirow{46}{*}{ 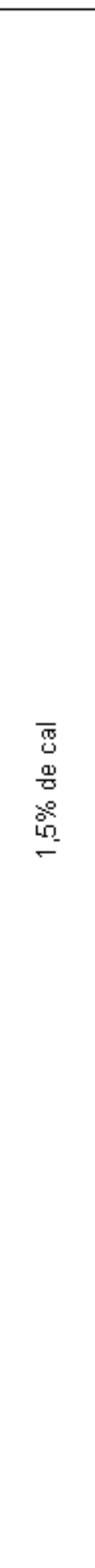 } & \multirow{15}{*}{ 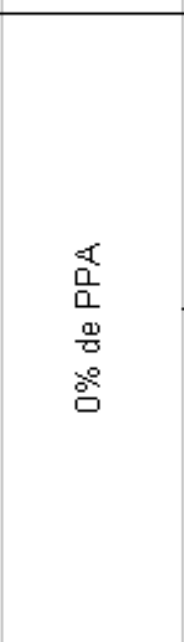 } & \multirow{7}{*}{4} & 37 & 16588,30 & 19392,03 & 0,14 & 0,04 \\
\hline & & & 39 & 15310,13 & 17733,10 & 0,14 & 0,04 \\
\hline & & & 40 & 14677,73 & 16948,03 & 0,13 & 0,04 \\
\hline & & & 42 & 16532,77 & 18818,33 & 0,12 & 0,04 \\
\hline & & & Média & 16055,63 & 18337,42 & 0,12 & 0,04 \\
\hline & & & Desvio & 2219,29 & 2370,87 & 0,02 & 0,00 \\
\hline & & & Relação & 13,82 & 12,93 & 13,31 & 1,33 \\
\hline & & \multirow{8}{*}{7} & 43 & 13653,83 & 15848,37 & 0,14 & 0,04 \\
\hline & & & 44 & 14503,23 & 16413,43 & 0,12 & 0,04 \\
\hline & & & 46 & 13752,47 & 15980,90 & 0,14 & 0,04 \\
\hline & & & 47 & 13894,73 & 16249,10 & 0,14 & 0,04 \\
\hline & & & 48 & 14799,10 & 16890,93 & 0,12 & 0,04 \\
\hline & & & Média & 14352,00 & 16623,44 & 0,14 & 0,04 \\
\hline & & & Desvio & 723,40 & 924,96 & 0,01 & 0,00 \\
\hline & & & Relação & 5,04 & 5,56 & 10,34 & 1,13 \\
\hline & \multirow{15}{*}{ 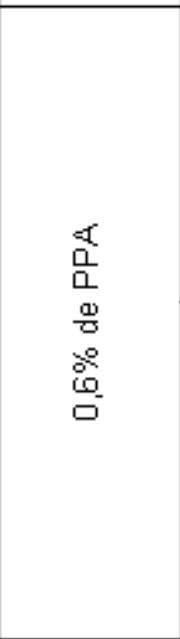 } & \multirow{7}{*}{4} & 50 & 15172,03 & 17231,07 & 0,12 & 0,04 \\
\hline & & & 51 & 13778,83 & 16151,50 & 0.15 & 0,04 \\
\hline & & & 53 & 16283,97 & 19047,27 & 0,14 & 0,04 \\
\hline & & & 54 & 15118,77 & 17761,27 & 0,15 & 0,04 \\
\hline & & & Média & 14980,04 & 17493,28 & 0,14 & 0,04 \\
\hline & & & Desvio & 2096,85 & 2678,00 & 0,02 & 0,00 \\
\hline & & & Relação & 14,00 & 15,31 & 11,55 & 2,28 \\
\hline & & \multirow{8}{*}{7} & 56 & 12855,93 & 15275,30 & 0,16 & 0,04 \\
\hline & & & 57 & 12533,60 & 14789,53 & 0,15 & 0,04 \\
\hline & & & 58 & 12819,93 & 14984,37 & 0,14 & 0,04 \\
\hline & & & 59 & 12394,73 & 14665,20 & 0,15 & 0,04 \\
\hline & & & 60 & 13709,97 & 16300,83 & 0,16 & 0,04 \\
\hline & & & Média & 13075,45 & 15435,93 & 0,15 & 0,04 \\
\hline & & & \begin{tabular}{|l|} 
Desvio \\
\end{tabular} & 693,28 & 817,99 & 0,01 & 0,00 \\
\hline & & & Relação & 5,30 & 5,30 & 3,77 & 1,69 \\
\hline & \multirow{16}{*}{ 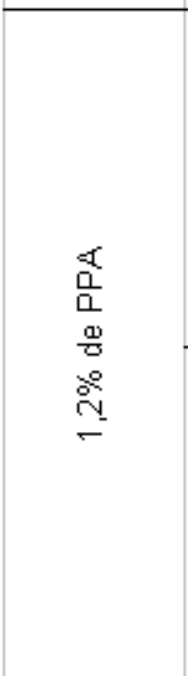 } & \multirow{8}{*}{4} & 62 & 15581,33 & 17885,80 & 0,13 & 0,04 \\
\hline & & & 63 & 16908,17 & 19274,77 & 0,12 & 0,04 \\
\hline & & & 64 & 16396,87 & 18618,47 & 0,12 & 0,04 \\
\hline & & & 65 & 16106,57 & 18599,07 & 0,13 & 0,04 \\
\hline & & & 66 & 14334,37 & 16405,37 & 0,13 & 0,04 \\
\hline & & & Média & 15153,48 & 17346,15 & 0,13 & 0,04 \\
\hline & & & \begin{tabular}{|l|} 
Desvio \\
\end{tabular} & 1952,45 & 2214,00 & 0,01 & 0,00 \\
\hline & & & Relação & 12,88 & 12,76 & 4,02 & 2,16 \\
\hline & & \multirow{8}{*}{7} & 67 & 15194,73 & 17884,70 & 0,15 & 0,04 \\
\hline & & & 68 & 12911,40 & 15026,43 & 0,14 & 0,04 \\
\hline & & & 69 & 15322,93 & 17455,83 & 0,12 & 0,04 \\
\hline & & & 70 & 14825,33 & 17053,43 & 0,13 & 0,04 \\
\hline & & & 72 & 13633,30 & 16070,27 & 0,15 & 0,04 \\
\hline & & & Média & 14022,07 & 16327,35 & 0,14 & 0,04 \\
\hline & & & Desvio & 1285,01 & 1372,70 & 0,01 & 0,00 \\
\hline & & & Relação & 9,16 & 8,41 & 9,11 & 3,39 \\
\hline
\end{tabular}

Continua... 
Continuação da Tabela IV.3

\begin{tabular}{|c|c|c|c|c|c|c|c|}
\hline Aditivo & Modificado & $=V / V(\%)$ & $C P n^{\circ}$ & $\begin{array}{l}\text { Mod. Res. Total - } \\
\text { MCHRP }\end{array}$ & $\begin{array}{l}\text { Mod. Res. instant. } \\
\text { - MCHRP }\end{array}$ & $\begin{array}{l}((M R i-M R t) / M R i) \\
-M C H R P\end{array}$ & $\begin{array}{l}\text { Atraso } \\
\text { Médio }\end{array}$ \\
\hline \multirow{49}{*}{ 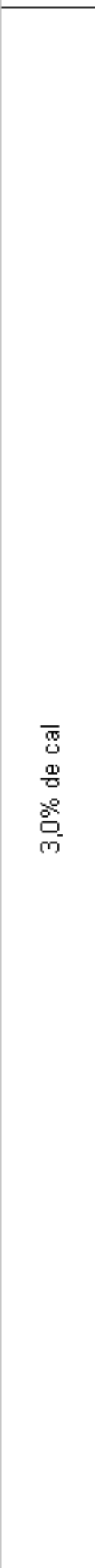 } & \multirow{16}{*}{$\begin{array}{l}\frac{x}{0} \\
\text { 뭄 } \\
\text { 몸 } \\
\text { 욤 }\end{array}$} & \multirow{8}{*}{4} & 73 & 13420,53 & 15750,47 & 0,15 & 0,04 \\
\hline & & & 74 & 16231,50 & 18691,43 & 0,13 & 0,04 \\
\hline & & & 75 & 13993,27 & 16176,63 & 0,13 & 0,04 \\
\hline & & & 76 & 13866,57 & 15664,73 & 0,11 & 0,04 \\
\hline & & & 77 & 13586,60 & 16015,07 & 0,15 & 0,04 \\
\hline & & & Média & 14614,25 & 16942,67 & 0,14 & 0,04 \\
\hline & & & Desvio & 1409,47 & 1636,60 & 0,01 & 0,00 \\
\hline & & & Relacão & 9.64 & 9.66 & 976 & 2,22 \\
\hline & & \multirow{8}{*}{7} & 80 & 11712,10 & 14068,97 & 0,17 & 0,04 \\
\hline & & & 81 & 13160,83 & 15392,70 & 0,15 & 0,04 \\
\hline & & & 82 & 12268,10 & 14485,77 & 0,15 & 0,04 \\
\hline & & & 83 & 12305,93 & 14636,17 & 0,16 & 0,04 \\
\hline & & & 84 & 10991,27 & 13157,47 & 0.16 & 0,04 \\
\hline & & & Média & 12779,01 & 15060,78 & 0,15 & 0,04 \\
\hline & & & Desvio & 1839,27 & 1893,20 & 0,01 & 0,00 \\
\hline & & & Relação & 14,39 & 12,57 & 9,55 & 1,58 \\
\hline & \multirow{16}{*}{ 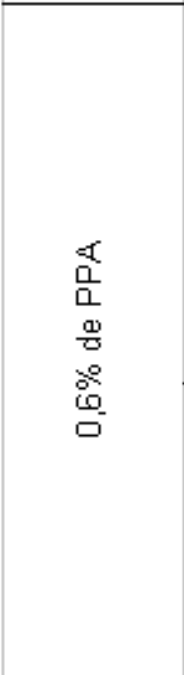 } & \multirow{9}{*}{4} & 85 & 14839,13 & 17353,63 & 0,14 & 0,04 \\
\hline & & & 86 & 14085,43 & 16071,03 & 0,12 & 0,04 \\
\hline & & & 87 & 13801,90 & 15806,63 & 0,13 & 0,04 \\
\hline & & & 88 & 13829,40 & 16338,70 & 0,15 & 0,04 \\
\hline & & & 89 & 13716,80 & 16055,10 & 0,15 & 0,04 \\
\hline & & & 90 & 14370,23 & 16609,33 & 0,13 & 0,04 \\
\hline & & & Média & 14107,15 & 16372,41 & 0,14 & 0,04 \\
\hline & & & Desvio & 430,85 & 553,48 & 0,01 & 0,00 \\
\hline & & & Relacão & 3,05 & 3,38 & 8,74 & 1,40 \\
\hline & & \multirow{7}{*}{7} & 91 & 14628,70 & 17241,73 & 0,15 & 0,04 \\
\hline & & & 94 & 13030,17 & 15487,50 & 0,16 & 0,04 \\
\hline & & & 95 & 13988,60 & 16668,27 & 0,16 & 0,04 \\
\hline & & & 96 & 13002,43 & 15390,50 & 0,16 & 0,04 \\
\hline & & & Média & 13730,12 & 16156,68 & 0,15 & 0,04 \\
\hline & & & Desvio & 1508,66 & 1562,96 & 0,01 & 0,00 \\
\hline & & & Relação & 10,99 & 9,67 & 9,48 & 2,97 \\
\hline & \multirow{17}{*}{ 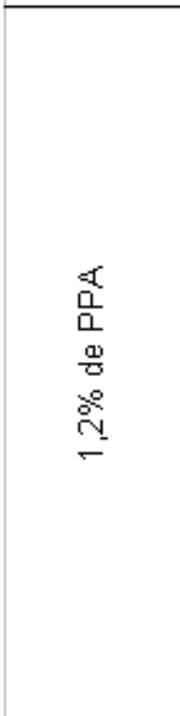 } & \multirow{8}{*}{4} & 98 & 15830,03 & 17613,43 & 0,10 & 0,04 \\
\hline & & & 99 & 16574,43 & 19071,83 & 0,13 & 0,04 \\
\hline & & & 100 & 19417,77 & 22746,57 & 0,15 & 0,04 \\
\hline & & & 101 & 20465,35 & 22808,10 & 0,10 & 0,04 \\
\hline & & & 102 & 18318,73 & 20799,13 & 0.12 & 0,04 \\
\hline & & & Média & 16935,55 & 19254,29 & 0,12 & 0,04 \\
\hline & & & Desvio & 3377,42 & 3892,01 & 0,02 & 0,00 \\
\hline & & & Relação & 19,94 & 20,21 & 14,23 & 1,06 \\
\hline & & \multirow{9}{*}{7} & 103 & 13708,10 & 15462,90 & 0,11 & 0,04 \\
\hline & & & 104 & 13482,90 & 15748,60 & 0,14 & 0,04 \\
\hline & & & 105 & 14712,43 & 17001,57 & 0,13 & 0,04 \\
\hline & & & 106 & 14353,20 & 16537,97 & 0,13 & 0,04 \\
\hline & & & 107 & 14982,20 & 17082,73 & 0,12 & 0,04 \\
\hline & & & 108 & 13532,60 & 15735,23 & 0,14 & 0,04 \\
\hline & & & Média & 14128,57 & 16261,50 & 0,13 & 0,04 \\
\hline & & & Desvio & 643,26 & 703,75 & 0,01 & 0,00 \\
\hline & & & Relação & 4,55 & 4,33 & 8,58 & 1,21 \\
\hline
\end{tabular}


ANEXO V - VALORES OBTIDOS PARA RESISTÊNCIA À TRAÇÃO. 
Tabela V. 1. Resultados para Resistência à Tração para todos os corpos-de-prova.

\begin{tabular}{|c|c|c|c|c|c|c|c|c|c|}
\hline Aditivo & Modificador & $V / V(\%)$ & Condicionamento & $C P$ & $G m b(e s t)$ & $G m b$ (corr) & Aitura $(\mathrm{mm})$ & $F(K g)$ & $R T$ (MPa) \\
\hline \multirow{36}{*}{ 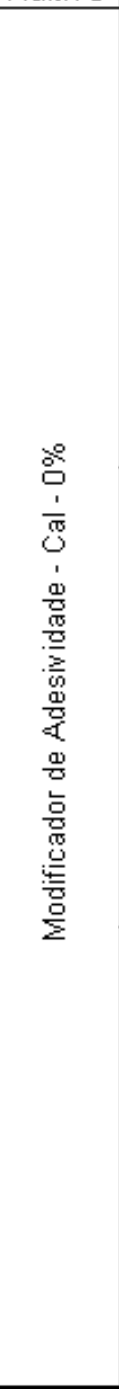 } & \multirow{12}{*}{ 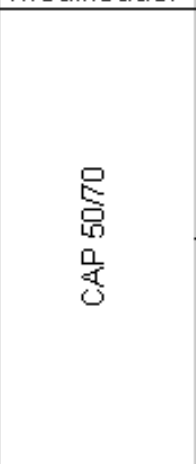 } & \multirow{6}{*}{$4 \%$} & \multirow{9}{*}{ Sem Cond. } & 1 & 2,328 & 2,371 & 65,87 & 1740 & 1,65 \\
\hline & & & & 2 & 2,329 & 2,372 & 65,84 & 1733 & 1,64 \\
\hline & & & & 3 & 2,330 & 2,376 & 65,79 & 1698 & 1,61 \\
\hline & & & & 4 & 2,329 & 2,377 & 65,73 & 1794 & 1,70 \\
\hline & & & & 5 & 2,325 & 2,377 & 65,96 & 1838 & 1,74 \\
\hline & & & & 6 & 2,324 & 2,367 & 65,8 & 1734 & 1,65 \\
\hline & & \multirow{6}{*}{$7 \%$} & & 7 & 2,231 & 2,301 & 68,68 & 1286 & 1,17 \\
\hline & & & & 8 & 2,223 & 2,286 & 68,96 & 1236 & 1,12 \\
\hline & & & & 9 & 2,224 & 2,306 & 68,7 & 1424 & 1,29 \\
\hline & & & \multirow{3}{*}{ Com Cond. } & 10 & 2,228 & 2,297 & 68,63 & 1297 & 1,18 \\
\hline & & & & 11 & 2,225 & 2,283 & 68,73 & 1166 & 1,06 \\
\hline & & & & 12 & 2,228 & 2,302 & 68,65 & 1191 & 1,08 \\
\hline & \multirow{12}{*}{ 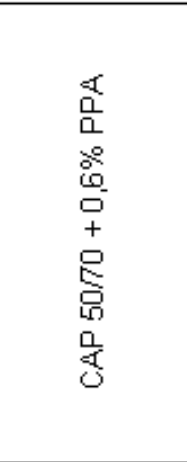 } & \multirow{6}{*}{$4 \%$} & \multirow{9}{*}{ Sem Cond. } & 13 & 2,325 & 2,378 & 65,78 & 1876 & 1,78 \\
\hline & & & & 14 & 2,328 & 2,377 & 65,63 & 1683 & 1,60 \\
\hline & & & & 15 & 2,320 & 2,371 & 65,87 & 1773 & 1,68 \\
\hline & & & & 16 & 2,330 & 2,381 & 65,73 & 1870 & 1,78 \\
\hline & & & & 17 & 2,321 & 2,372 & 65,83 & 1907 & 1,81 \\
\hline & & & & 18 & 2,320 & 2,371 & 65,87 & 1821 & 1,73 \\
\hline & & \multirow{6}{*}{$7 \%$} & & 19 & 2,216 & 2,285 & 68,96 & 1275 & 1,15 \\
\hline & & & & 20 & 2,216 & 2,279 & 68,94 & 1280 & 1,16 \\
\hline & & & & 21 & 2,217 & 2,289 & 68,93 & 1624 & 1,47 \\
\hline & & & \multirow{3}{*}{ Com Cond. } & 22 & 2,217 & 2,285 & 68,91 & 1525 & 1,38 \\
\hline & & & & 23 & 2,217 & 2,292 & 68,93 & 1428 & 1,29 \\
\hline & & & & 24 & 2,217 & 2,285 & 68,91 & 1279 & 1,16 \\
\hline & \multirow{12}{*}{ 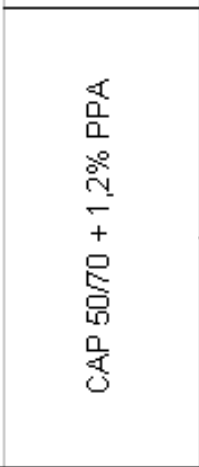 } & \multirow{6}{*}{$4 \%$} & \multirow{9}{*}{ Sem Cond. } & 25 & 2,337 & 2,385 & 65,43 & 2069 & 1,97 \\
\hline & & & & 26 & 2,329 & 2,376 & 65,66 & 1979 & 1,88 \\
\hline & & & & 27 & 2,328 & 2,373 & 65,79 & 2004 & 1,90 \\
\hline & & & & 28 & 2,320 & 2,375 & 66,02 & 1969 & 1,86 \\
\hline & & & & 29 & 2,330 & 2,377 & 65,69 & 2127 & 2,02 \\
\hline & & & & 30 & 2,324 & 2,380 & 65,74 & 2125 & 2,02 \\
\hline & & \multirow{6}{*}{$7 \%$} & & 31 & 2,260 & 2,321 & 67,62 & 1751 & 1,62 \\
\hline & & & & 32 & 2,226 & 2,289 & 68,65 & 1561 & 1,42 \\
\hline & & & & 33 & 2,228 & 2,307 & 68,69 & 1875 & 1,70 \\
\hline & & & \multirow{3}{*}{ Com Cond. } & 34 & 2,227 & 2,324 & 68,72 & 1779 & 1,62 \\
\hline & & & & 35 & 2,229 & 2,370 & 68,71 & 1779 & 1,62 \\
\hline & & & & 36 & 2,227 & 2,336 & 68,73 & 1494 & 1,36 \\
\hline
\end{tabular}

Continua... 


\section{Continuação da Tabela V.1}

\begin{tabular}{|c|c|c|c|c|c|c|c|c|c|}
\hline \multicolumn{4}{|c|}{ Aditivo Modificador Vv (\%) Condicionamento } & $C P$ & $G m b$ (est) & $G m b$ (corr) & Aitura $(\mathrm{mm})$ & $F(K g)$ & $R T(M P a)$ \\
\hline \multirow{36}{*}{$\frac{\stackrel{8}{\circ}}{\frac{1}{-}}$} & \multirow{12}{*}{$\begin{array}{l}p \\
8 \\
8 \\
0 \\
0\end{array}$} & \multirow{6}{*}{$4 \%$} & \multirow{9}{*}{ Sem Cond. } & 37 & 2,338 & 2,371 & 65,36 & 1559 & 1,49 \\
\hline & & & & 38 & 2,330 & 2,372 & 65,57 & 1515 & 1,44 \\
\hline & & & & 39 & 2,327 & 2,376 & 65,66 & 1501 & 1,43 \\
\hline & & & & 40 & 2,333 & 2,377 & 65,5 & 1480 & 1,41 \\
\hline & & & & 41 & 2,326 & 2,377 & 65,69 & 1578 & 1,50 \\
\hline & & & & 42 & 2,323 & 2,367 & 65,77 & 1569 & 1,49 \\
\hline & & \multirow{6}{*}{$7 \%$} & & 43 & 2,207 & 2,301 & 69,24 & 1166 & 1,05 \\
\hline & & & & 44 & 2,217 & 2,286 & 68,93 & 1225 & 1,11 \\
\hline & & & & 45 & 2,218 & 2,306 & 68,88 & 1346 & 1,22 \\
\hline & & & \multirow{3}{*}{ Com Cond. } & 46 & 2,216 & 2,297 & 68,94 & 1371 & 1,24 \\
\hline & & & & 47 & 2,217 & 2,283 & 68,93 & 1358 & 1,23 \\
\hline & & & & 48 & 2,218 & 2,302 & 68,9 & 1313 & 1,19 \\
\hline & \multirow{12}{*}{$\begin{array}{l}x \\
0 \\
0 \\
8 \\
0 \\
0 \\
0 \\
+ \\
0 \\
0 \\
0 \\
0 \\
0 \\
0 \\
0\end{array}$} & \multirow{6}{*}{$4 \%$} & \multirow{9}{*}{ Sem Cond. } & 49 & 2,331 & 2,371 & 65,55 & 1523 & 1,45 \\
\hline & & & & 50 & 2,314 & 2,372 & 66,04 & 1576 & 1,49 \\
\hline & & & & 51 & 2,322 & 2,376 & 65,79 & 1637 & 1,55 \\
\hline & & & & 52 & 2,316 & 2,377 & 65,97 & 1732 & 1,64 \\
\hline & & & & 53 & 2,305 & 2,377 & 66,28 & 1617 & 1,52 \\
\hline & & & & 54 & 2,315 & 2,367 & 65,99 & 1804 & 1,71 \\
\hline & & \multirow{6}{*}{$7 \%$} & & 55 & 2,207 & 2,301 & 69,22 & 1069 & 0,96 \\
\hline & & & & 56 & 2,209 & 2,286 & 69,17 & 1168 & 1,05 \\
\hline & & & & 57 & 2,209 & 2,306 & 69,17 & 1492 & 1,35 \\
\hline & & & \multirow{3}{*}{ Com Cond. } & 58 & 2,209 & 2,297 & 69,18 & 1505 & 1,36 \\
\hline & & & & 59 & 2,208 & 2,283 & 69,2 & 1328 & 1,20 \\
\hline & & & & 60 & 2,208 & 2,302 & 69,19 & 1141 & 1,03 \\
\hline & \multirow{12}{*}{ 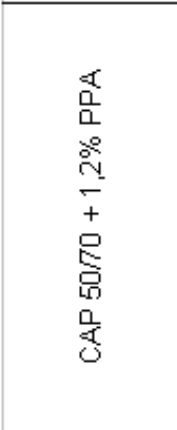 } & \multirow{6}{*}{$4 \%$} & \multirow{9}{*}{ Sem Cond. } & 61 & 2,314 & 2,368 & 66,03 & 1950 & 1,84 \\
\hline & & & & 62 & 2,305 & 2,365 & 66,29 & 1922 & 1,81 \\
\hline & & & & 63 & 2,298 & 2,362 & 66,49 & 1971 & 1,85 \\
\hline & & & & 64 & 2,309 & 2,367 & 66,18 & 1820 & 1,72 \\
\hline & & & & 65 & 2,322 & 2,371 & 65,8 & 2121 & 2,01 \\
\hline & & & & 66 & 2,308 & 2,363 & 66,21 & 2143 & 2,02 \\
\hline & & \multirow{6}{*}{$7 \%$} & & 67 & 2,218 & 2,301 & 68,89 & 1467 & 1,33 \\
\hline & & & & 68 & 2,216 & 2,286 & 68,95 & 1313 & 1,19 \\
\hline & & & & 69 & 2,215 & 2,294 & 68,97 & 1157 & 1,05 \\
\hline & & & \multirow{3}{*}{ Com Cond. } & 70 & 2,215 & 2,295 & 68,98 & 1664 & 1,51 \\
\hline & & & & 71 & 2,217 & 2,285 & 68,93 & 1592 & 1,44 \\
\hline & & & & 72 & 2,215 & 2,285 & 68,98 & 1664 & 1,51 \\
\hline
\end{tabular}

Continua... 


\section{Continuação da Tabela V.1}

\begin{tabular}{|c|c|c|c|c|c|c|c|c|c|}
\hline \multirow[t]{2}{*}{ Aditivo } & \multicolumn{3}{|c|}{ Modificador VV (\%) Condicionamento } & \multirow{2}{*}{$\begin{array}{c}C P \\
73\end{array}$} & \multirow{2}{*}{$\frac{G m b \text { (est) }}{2,321}$} & \multirow{2}{*}{$\frac{G m b \text { (corr) }}{2,370}$} & \multirow{2}{*}{$\begin{array}{c}\text { Aitura }(\mathrm{mm}) \\
65,82\end{array}$} & \multirow{2}{*}{$\frac{F(\mathrm{Kg})}{1496}$} & \multirow{2}{*}{$\begin{array}{c}R T(\mathrm{MPa}) \\
1,42\end{array}$} \\
\hline & \multirow{12}{*}{ 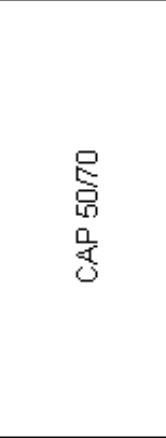 } & \multirow{6}{*}{$4 \%$} & \multirow{9}{*}{ Sem Cond. } & & & & & & \\
\hline \multirow{35}{*}{ 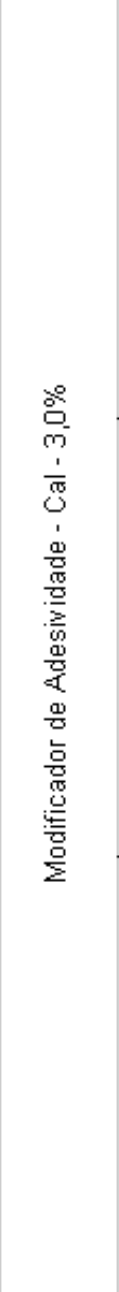 } & & & & 74 & 2,301 & 2,366 & 66,4 & 1430 & 1,34 \\
\hline & & & & 75 & 2,302 & 2,359 & 66,36 & 1564 & 1,47 \\
\hline & & & & 76 & 2,313 & 2,358 & 66,06 & 1573 & 1,49 \\
\hline & & & & 77 & 2,301 & 2,359 & 66,4 & 1543 & 1,45 \\
\hline & & & & 78 & 2,310 & 2,364 & 66,13 & 1394 & 1,32 \\
\hline & & \multirow{6}{*}{$7 \%$} & & 79 & 2,209 & 2,284 & 69,17 & 1271 & 1,15 \\
\hline & & & & 80 & 2,209 & 2,279 & 69,18 & 1132 & 1,02 \\
\hline & & & & 81 & 2,207 & 2,274 & 69,23 & 1245 & 1,12 \\
\hline & & & \multirow{3}{*}{ Com Cond. } & 82 & 2,208 & 2,293 & 69,2 & 1294 & 1,17 \\
\hline & & & & 83 & 2,209 & 2,277 & 69,17 & 1229 & 1,11 \\
\hline & & & & 84 & 2,207 & 2,293 & 69,22 & 1255 & 1,13 \\
\hline & \multirow{12}{*}{ 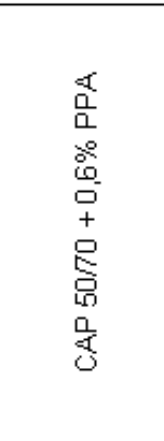 } & \multirow{6}{*}{$4 \%$} & \multirow{9}{*}{ Sem Cond. } & 85 & 2,311 & 2,357 & 66,1 & 1655 & 1,56 \\
\hline & & & & 86 & 2,312 & 2,361 & 66,08 & 1749 & 1,65 \\
\hline & & & & 87 & 2,303 & 2,358 & 66,33 & 1766 & 1,66 \\
\hline & & & & 88 & 2,302 & 2,354 & 66,37 & 1716 & 1,61 \\
\hline & & & & 89 & 2,309 & 2,358 & 66,18 & 1921 & 1,81 \\
\hline & & & & 90 & 2,308 & 2,360 & 66,21 & 1913 & 1,80 \\
\hline & & \multirow{6}{*}{$7 \%$} & & 91 & 2,208 & 2,291 & 69,19 & 1299 & 1,17 \\
\hline & & & & 92 & 2,206 & 2,299 & 69,25 & 1307 & 1,18 \\
\hline & & & & 93 & 2,209 & 2,278 & 69,17 & 1388 & 1,25 \\
\hline & & & \multirow{3}{*}{ Com Cond. } & 94 & 2,209 & 2,276 & 69,17 & 1420 & 1,28 \\
\hline & & & & 95 & 2,207 & 2,275 & 69,23 & 1309 & 1,18 \\
\hline & & & & 96 & 2,207 & 2,275 & 69,23 & 1313 & 1,18 \\
\hline & \multirow{12}{*}{ 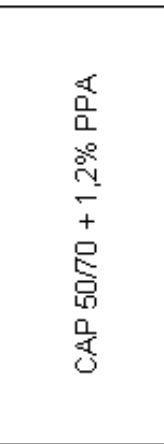 } & \multirow{6}{*}{$4 \%$} & \multirow{9}{*}{ Sem Cond. } & 97 & 2,305 & 2,354 & 66,28 & 1759 & 1,66 \\
\hline & & & & 98 & 2,308 & 2,357 & 66,21 & 1932 & 1,82 \\
\hline & & & & 99 & 2,287 & 2,349 & 66,82 & 1807 & 1,69 \\
\hline & & & & 100 & 2,301 & 2,351 & 66,41 & 1911 & 1,80 \\
\hline & & & & 101 & 2,300 & 2,353 & 66,43 & 1920 & 1,81 \\
\hline & & & & 102 & 2,290 & 2,350 & 66,73 & 1757 & 1,64 \\
\hline & & \multirow{6}{*}{$7 \%$} & & 103 & 2,210 & 2,258 & 69,13 & 1297 & 1,17 \\
\hline & & & & 104 & 2,207 & 2,276 & 69,23 & 1235 & 1,11 \\
\hline & & & & 105 & 2,208 & 2,294 & 69,2 & 1630 & 1,47 \\
\hline & & & \multirow{3}{*}{ Com Cond. } & 106 & 2,207 & 2,279 & 69,23 & 1504 & 1,36 \\
\hline & & & & 107 & 2,206 & 2,284 & 69,25 & 1356 & 1,22 \\
\hline & & & & 108 & 2,207 & 2,298 & 69,23 & 1342 & 1,21 \\
\hline
\end{tabular}


